\title{
DIATOM DATA FROM BRADLEY LAKE, OREGON: DOWNCORE ANALYSES
}

\author{
Eileen Hemphill-Haley \\ Adjunct Faculty / Research Associate \\ Department of Geology \\ Humboldt State University \\ Arcata, CA 95521 \\ ehh@H2Tunes.com \\ Roger C. Lewis \\ Faculty Research Assistant \\ Oregon State University \\ 104 Ocean Admin Building \\ Corvallis, OR 97331 \\ rlewis@coas.oregonstate.edu
}

U.S. Geological Survey Open-File Report 03-190 


\section{ABSTRACT}

Displaced marine diatoms provide biostratigraphic evidence for tsunami inundation at Bradley Lake, a small freshwater lake on the south-central Oregon coast. During the past 7,200 years, fine-grained lacustrine deposits in the deep axis of the lake were disturbed 17 times by the erosion and emplacement of coarse-grained gyttja and, in some cases, sand. By identifying diatoms in closely spaced core samples, we determined that 13 of the 17 events (termed "disturbance events") record prehistoric tsunamis in Bradley Lake. We consider the evidence strong for 11 events, based on numbers and diversity of marine taxa: De1, De2, De4, De5, De6, De7, De8, De11, De12, De13, and De17. The evidence is less compelling for an additional 2 events (De9 and De10), although tsunami inundation is likely. Finally, we identified 4 events (De3, De14, De15 and De16) in which there were no marine diatoms to support tsunami inundation, although stratigraphic data shows that the lake bottom was disturbed.

Freshwater diatoms dominate throughout the Bradley Lake record, showing that the lake has remained a freshwater habitat throughout its existence. However, anomalous occurrences of three species of brackish diatoms (Thalassiosira bramaputrae, Cyclotella meneghiniana, and Mastogloia smithii) may be evidence for short-lived periods of slightly elevated salinities in the lake following De16, De13, De12, De11, De9, De8, and De5. With the exception of De12, increased abundances of one or more of the brackish species is coincident with decreased numbers of freshwater diatoms. A temporary rise in salinity, as evidenced by short-lived increases in abundances of brackish species and decreases in abundances of freshwater species, is consistent with tsunami inundation into the lake.

\section{INTRODUCTION}

Diatoms are members of the yellow-brown algae of the phylum Bacillariphyta (Round et al. 1990). They produce a set of silt-sized shells, or frustules, made of biogenic silica, which encase the chlorophyl of the single-celled plants, and may accumulate in sediment after the plant has died ${ }^{1}$. It is the production of the fossilizable frustules that make diatoms useful in biostratigraphy, as their accumulation in sediment can provide a lasting record of the paleoecological conditions that existed at the time of deposition.

1 In this paper, the term "diatom" refers to the fossil remains of the organism (the frustules). References to autecology of various species is based primarily on results of other studies, with some observations of modern distributions in and around Bradley Lake. 
Owing to their small size, aquatic habitat, position at the base of the food chain, and propensity to be incorporated in fine-grained sedimentary deposits, diatoms are often displaced from their place of origin. There are numerous records of windblown diatoms being transported great distances from their place of origin. Fine dust coating surfaces in southern France was found to contain diatoms originating from northern African playas (Seyve and Fourtanier, 1989). Pleistocene diatoms in a core from the northeastern Pacific Ocean were likely transported with windblown loess from the Great Basin of the U.S. (Sancetta et al., 1992), and windblown diatoms, primarily from Africa, have been collected in aerosol samples on ships, or found in deep-sea cores, from the Atlantic (Folger, 1970; Melia, 1984; Pokras and Mix, 1985). The eminent Charles Darwin, while sailing off the southern coast of Africa, observed terrestrial diatoms in dust on the sails of the H.M.S. Beagle (Darwin, 1846). Animals, and birds in particular, play a significant role in dispersing diatoms, either by ingesting them or inadvertently transporting them on their feet or bodies (Proctor, 1959; Atkinson, 1972). Diatoms grow in fresh, brackish, and marine water, and therefore may be displaced by the flow of creeks and rivers, ocean currents, tidal currents, or by storm surges which may carry marine species unusually far inland.

Diatoms can also be transported by another mechanism: tsunamis. Estuarine tidal-flat diatoms in silt and sand capping buried lowland soils provide supporting evidence for prehistoric tsunamis, triggered by earthquakes in the Cascadia subduction zone in coastal Oregon and Washington (Darienzo and Peterson, 1990; Hemphill-Haley, 1995; 1996; Atwater and Hemphill-Haley, 1997; Kelsey et al., 1998; Witter et al., 2001). Deposits from historical tsunamis in Newfoundland, Canada (1929) and Flores Island, Indonesia (1992) left extensive deposits containing marine diatoms as well as freshwater species incorporated into the deposits as the tsunamis swept inland (Dawson et al, 1996). Diatom deposits in lakes and ponds have also provided evidence for past tsunamis, as in Lagoon Creek in northern California (Garrison-Laney, 1998), and Kanim and Deserted lakes on Vancouver Island (Hutchinson et al., 1997; 2000). The Storegga tsunami, triggered by a submarine landslide 7200 years ago, deposited an extensive sand sheet containing marine diatoms on the coast of Scotland (Dawson et al., 1988; Long et al, 1989), and washed marine species into small lakes as high as $11 \mathrm{~m}$ above sea level on the Norwegian coast (Bondevik et al., 1997a, 1997b). Landward surges by historical and paleotsunamis deposited marine diatoms in freshwater coastal lakes of Japan (Minoura and Nakata, 1994; Minoura et al., 1994).

The purpose of this study was to similarly use occurrences of anomalous marine diatoms in a freshwater lake - Bradley Lake on the south-central Oregon coast - to document past tsunamis from Cascadia subduction-zone earthquakes. The diatom analyses reported here are part of a collaborative 
effort with our colleagues Alan Nelson ${ }^{2}$, Harvey Kelsey ${ }^{3}$, and Rob Witter ${ }^{4}$ who began the study in 1993 with reconnaissance coring in several lakes on the south-central Oregon coast. The results of that preliminary study showed that Bradley Lake (fig.1) was the best candidate for recording prehistoric tsunamis because: 1) it is a small, protected basin with a thick ( $>6 \mathrm{~m}$ ) accumulation of fine-grained lacustrine mud; and 2) it is positioned too far inland $(0.5 \mathrm{~km})$ and too high above sea level $(5.5 \mathrm{~m})$ to have an open tidal exchange with the ocean or be inundated by relatively frequent, smaller events such as storms or El Niños. By examining a 14 piston and 13 vibracores from the lake floor, Nelson, Kelsey and Witter showed that fine-grained lacustrine deposits in the deep axis of the lake were disturbed 17 times during the past 7,200 years by the erosion and emplacement of coarse-grained gyttja and, in some cases, sand (Nelson et al., 1998; Kelsey et al., 1999). Using closely spaced samples primarily in core BR-94E, with additional samples from the other cores (fig. 1; appendix 2;), we determined that 13 of the 17 disturbance events included the emplacement of marine diatoms into an otherwise persistent freshwater environment. Considering the various mechanisms by which diatoms can be displaced, the anomalous marine species were likely washed into Bradley Lake by tsunamis.

We use the diatom data to show how it is consistent with tsunami inundation, and how we arrived at our conclusions that tsunamis inundated Bradley Lake. Microfossil data represent a powerful tool for differentiating prehistoric tsunami deposits from other kinds of sediment only when combined with detailed stratigraphic and sedimentological studies, high-precision radiocarbon dating, and regional correlations with other sites showing evidence for past earthquakes and tsunamis. Such analyses are currently being compiled for Bradley Lake, and will be reported elsewhere (Alan Nelson and Harvey Kelsey, pers. comm.).

Roger Lewis processed most of the diatom samples for this report, with additional help from Wendy Ebersole. A description of Lewis' technique for producing quantitative diatom slides, and a list of samples used, are found in Appendices 1 and 2. Eileen Hemphill-Haley identified and counted the diatoms; those data are in Appendices 3 and 4. Descriptive summaries for each of the 17 anomalous depositional events, termed "disturbance events," can be found below beginning on page 9.

2 Alan R. Nelson, U.S. Geological Survey, MS-966, POB 25046, Denver, CO 80225 / anelson@usgs.gov

3 Harvey M. Kelsey, Department of Geology, Humboldt State University, Arcata, CA 95521 / hmk1@humboldt.edu 


\section{DIATOM GROUPS IMPORTANT FOR THIS STUDY}

Diatoms are particularly useful for this study because they proliferate in Bradley Lake as well as the adjacent Pacific Ocean, but distinctly different populations are found in the two environments. To simplify analyses, diatoms were placed in three ecological categories and several subcategories. Individual taxa in these categories are listed in Appendix 4.

\section{$\underline{\text { Marine diatoms }}$}

Marine diatoms include taxa that are presently living in the adjacent coastal waters, or are derived from Tertiary diatomites that form coastal terraces in the area of Bradley Lake. The presence of the diatomites, and the continuous erosion of diatom frustules from them, necessitated separating fossil marine taxa that might arrive in the lake simply through erosion of local rocks from modern taxa that likely record inundation of marine water and sediment from the Pacific Ocean $0.5 \mathrm{~km}$ to the west. The diatomites form white, chalky bluffs on Bandon Beach, north of the outflow of Bradley Lake, similar in appearance to exposures of Monterey Formation along portions of the central California coast (e.g., Garrison and Douglas, 1981). According to Whiting and Schrader (1985) some of the best examples of Tertiary diatomites in Oregon are found at this locality. The diatomites added an unexpected complication of an additional source for displaced marine diatoms at Bradley Lake, but Whiting and Schrader's detailed taxa list helped us to determine which species in the lake record might have originated from the diatomites. Where the terrace extends eastward to form the northern shore of Bradley Lake, the buff-colored diatomite grades into a dark gray diatom-rich mudstone which is densely vegetated. Erosion from the north-shore terrace is likely much slower than for the exposed coastal bluffs, but is undoubtedly a major source for fossil marine diatoms in the lake.

Because of the presence of the local diatomite and diatom-rich mudstone, the marine diatoms are subdivided into three groups:

1) Hm group: modern marine diatoms from coastal Pacific Ocean.

These diatoms provide the best evidence for tsunami inundation into Bradley Lake. We observed live specimens in surficial sediment of the lower beach and surf zone $0.5 \mathrm{~km}$ west of Bradley Lake.

2) HTm group: extant marine diatoms found in the modern coastal ocean as well as in Tertiary diatomites.

4 Robert C. Witter, William Lettis and Associates, 1777 Botelho Drive, Walnut Creek, CA 94596 / witter@lettis.com 
Many of the specimens in this group probably originate from modern surficial deposits, but as the same taxa are also found as fossils in the diatomites, it's impossible to separate modern from fossil examples of these species.

3) Tm group: extinct marine diatoms from the Tertiary diatomites, not found in the modern coastal ocean.

Diatoms in this group are not living in the modern coastal ocean. However, their fossils are eroding from the terraces on the beach and north shore of Bradley Lake, and thus low numbers are found as a background signal throughout the Bradley Lake record. But since they are abundantly found in surface samples near the terraces - including in the bed of the outflow stream from the lake - large numbers could be expected to be transported and deposited into the lake by a tsunami.

\section{$\underline{\text { Brackish diatoms }}$}

Three prominent "brackish" species appear to proliferate following some disturbance events. These include the planktonic species Thalassiosira bramaputrae and Cyclotella meneghiniana, and the benthic species Mastogloia smithii. Although these species are common in brackish water, they also tolerate fresh water. Thus their presence may record more than just salinity in the lake. Consequently, the significance of these diatoms requires further study. All three species proliferate following some disturbance events but not others, and all do not necessarily respond simultaneously following any given event. Based on observations of detrital peat in core $94 \mathrm{E}$, it is possible that M. smithii is associated with expansion of marshes in the shallows of Bradley Lake, and subsequent peat accumulation (see "Significance of a clast of detrital peat in core 94E" on page 16). C. meneghiniana may be associated with the expansion of a different kind of habitat - the drowning of riparian vegetation along the shores of the lake (e.g. Parsons, 1998). C. meneghiniana is found in a wide range of environments from shallow freshwater ponds to large saline lakes, prefers eutrophic conditions, and also grows well in turbid water (Dr. Sherilyn Fritz, University of Nebraska, pers. comm.). Therefore, abrupt increases in $C$. meneghiniana could be a response to a number of different factors, including increased salinity, expansion of epiphytic habitat, increased turbidity of the lake water, and greater availability of nutrients. Higher nutrient levels would result from increased influx to the lake and/or reduced competition from other species whose numbers may have declined because of any of the aforementioned factors. Also of interest to this study is that both C. meneghiniana and T. bramaputrae may be halophilic, i.e. their growth is actually stimulated by increases in salt (Foged, 1981).

For the purposes of this report, C. meneghiniana, T. bramaputrae and M. smithii are reported as "brackish" species, with the recognition that their presence may also be recording the influence of other 
paleoecological factors. Salinity tolerances for these species are shown in Figure 2. The data are based on records from modern lakes in the western U.S. and Canada (Cumming and Smol, 1993, Fritz et al., 1993, Wilson et al. 1995), and estuaries in southern California (Carpelan, 1978) and Australia (John, 1983). It is clear from the data that a wide range of salinities are possible for these taxa, but salinity increases of 1-4 g/L might be a viable explanation for their episodic appearances in Bradley Lake. Closer scrutiny of all diatom assemblages in the Bradley Lake record may reveal other taxa that could provide further insight into paleoecological changes over time. For example, Cocconeis placentula var. euglypta, Rhopalodia gibberula, and Bacillaria paradoxa, which were not enumerated for this study, are present in some samples, and might also be indicative of "brackish" conditions.

T. bramaputrae, C. meneghiniana and M. smithii first appear in the record at De17. T. bramaputrae and C. meneghiniana are found throughout the Bradley Lake record; M. smithii was not observed in deposits younger than De2 (fig. 3). These species are found in low-level concentrations ("background" concentrations, $<10^{4}$ valves/cc) in many samples in and between disturbance events. This is in contrast to the possible "blooms" (large increases in numbers in response to ecological factors) that are observed in sediment above a number of events (Table 1, fig. 3), where abundances reach $>10^{4}$ or even $>10^{5}$ valves/cc (e.g., C. meneghiniana in finely laminated mud above De11 and De8).

\section{$\underline{\text { Freshwater diatoms }}$}

Freshwater diatoms are abundant and diverse in Bradley Lake. Planktonic diatoms mainly consist of small centric species of Cyclotella and Aulacoseira, but also pennate species of Asterionella and Tabellaria. Benthic populations are very diverse, including small and large species of Navicula, Stauroneis, Pinnularia, Cymbella, Eunotia, Fragilaria, Synedra, Rhopalodia, Gomphonema,

Gomphoneis, and others. We counted four subcategories of freshwater diatoms as a means of recording broad paleoecological changes in the lake record:

1) Aulacoseira italica valves and spores: blooms of this species may possibly record rapid overturning of the lake or some other opportunistic situation that allowed it to out-compete other diatom species for limited nutrients.

2) Planktonic diatoms: indicative of normal planktonic production. Includes a small $(<4 \mu \mathrm{m}$ diameter $)$ species of Aulacoseira, Cyclotella stelligera, Tabellaria spp., and Asterionella spp.

3) Small benthic diatoms: indicative of normal benthic productivity and gradual transport to lake bottom. Includes species of Eunotia, Fragilaria, Navicula, Cymbella, etc., that are $<40 \mu \mathrm{m}$ along the apical (longest) axis. 
4) Large benthic diatoms: indicative of rapid transport when concentrated in coarse-grained deposits. Includes species of Eunotia, Gophomeis, Navicula, Pinnularia, Cymbella, etc., that are $>40 \mu \mathrm{m}$ along the apical axis.

\section{METHODS: COUNTING TECHNIQUES}

The main objective of this study was to identify occurrences of anomalous marine diatoms in the lake deposits. In order to get an overview of changes in lake ecology over time, brackish-water diatoms and broad groups of freshwater diatoms were also enumerated. Diatoms were counted by scanning the slides at magnifications of $650 \mathrm{x}$ to $1250 \mathrm{x}$ with an Olympus BH-2 microscope, using transmitted light and Normarski interference contrast. Numbers of freshwater diatoms were estimated by counting all valves on three vertical traverses, with taxa subdivided into the four subcategories listed above. Marine (Hm, Htm and Tm groups) and brackish diatoms were counted along either 14 or 20 vertical traverses (Appendix 3). In order to compare results from sample to sample, the data were converted from actual number of valves counted ("raw counts", Appendix 4) to estimated numbers of valves per cubic centimeter ("valves/cc", Appendix 3). This was necessary because the number of valves observed will depend on the concentration of the sediment and diatoms on the slide, and provided a more accurate and useful way to view changes in diatom concentration over time. Our sample-preparation technique is based on previously tested techniques that show that counting any area of the slide should give a representative view of the entire sample (Battarbee, 1973; Laws, 1983; Roelofs and Pisias, 1986), and results were calculated by:

$$
\text { valves } / \mathrm{cc}=\mathrm{D} /(\mathrm{A} \cdot \mathrm{F})
$$

Where $\mathrm{D}=$ number of diatom valves counted; $\mathrm{A}=$ volume of aliquot $\mathrm{used}$, in cc; $\mathrm{F}=$ fraction of total sample observed ( $=$ (number of vertical traverses $\bullet$ area of one traverse) / total area of settling chamber).

When present, displaced marine $(\mathrm{Hm})$ diatoms were exceptionally rare relative to the prolific freshwater taxa, in some cases on the order of 1 marine valve per 10,000 valves of freshwater diatoms (e.g., De2, De6). This required slow progress to locate these rare, but significant taxa. Relative to Hm diatoms, the three brackish taxa, M. smithii, T. bramaputrae and C. meneghiniana, were significantly more prominent.

We identified diatoms with the aid of several widely used references for diatom taxonomy, including Hustedt (1930; 1927-1966), Patrick and Reimer (1966; 1975), Germain (1981), Krammer and Lange-Bertalot (1986; 1988; 1991a; 1991b), and the Baltic Marine Biologists Publication series 16a-e 
(1993; 1994; 1995; 1996; 1998). Other helpful references included Foged (1981), Hasle (1978), Mahood et al. (1986), Cumming et al. (1995) and Hakansson and Chepurnov (1999).

\section{RESULTS}

Based on occurrences of displaced Holocene marine diatoms, we conclude that 13 disturbance events may record past tsunamis in Bradley Lake (Table 1; fig. 3). We consider the evidence strong for 11 events, based on numbers and diversity of marine taxa: De1, De2, De4, De5, De6, De7, De8, De11, De12, De13, and De17. The evidence is less compelling for an additional 2 events (De9 and De10), although tsunami inundation remains a plausible explanation. Finally, we identified 4 events (De3, De14, De15 and De16) in which there were no marine diatoms to support tsunami inundation, although stratigraphic data shows that the lake bottom was disturbed.

\section{SUMMARY OF DISTURBANCE EVENTS}

In the following, we describe diatom analyses for each of the 17 disturbance events in the Bradley Lake record, and the evidence we used to conclude which of the events may have included deposition by tsunamis.

General terms for diatom concentrations are:

Very rare: $<10^{3}$ valves $/$ cc

Rare: $10^{3}-10^{4}$ valves/cc

Common: $10^{4}-10^{5}$ valves/cc

Abundant: $>10^{5}$ valves/cc

\section{\begin{tabular}{|l|l|l|l|}
\hline De1 & 250 yr BP & Core BR-94E & Strong diatom evidence for tsunami \\
\hline
\end{tabular}}

Disturbance event 1 (De1) is identified in core 94E by a 1-cm-thick bed of woody detritus at 60 cm overlain by massive gyttja and black muddy gyttja from $59 \mathrm{~cm}$ to $51 \mathrm{~cm}$ (figs. 4 and 5). Freshwater diatoms and sponge spicules are abundant in the detritus and overlying gyttja, which is consistent with redeposition of biogenic debris from the shallow margins of the lake. Freshwater diatom assemblages are diverse, but large, mostly broken benthic taxa are prominent.

Diatom evidence for a tsunami is shown by occurrences of rare marine diatoms $(\mathrm{Hm}$ and $\mathrm{HTm}$ groups), which are first observed in massive mud at 50 and $48 \mathrm{~cm}$. The marine taxa consist of species typical of estuaries and the coastal ocean, including Thalassiosira pacifica, Thalassionema 
nitzschioides, Actinopytchus senarius, and Delphineis karstenii. Their absence from deposits below 50 $\mathrm{cm}$ is the result of differential settling of the smaller marine diatoms relative to the coarser sediment and biogenic particles (including large benthic diatoms and sponge spicules) that comprise the detritus and gyttja.

"Black Soupy" is a deposit of brown and black organic clay at $30-35 \mathrm{~cm}$ in core E (fig. 4). Holocene marine diatoms are absent, but HTm diatoms are rare at $30 \mathrm{~cm}$. Brackish diatoms are present but rare in "Black Soupy", not exceeding "background" abundances of $>10^{4}$ valves/cc. The freshwater diatoms Aulacoseira spp. (particularly A. italica) are prominent, possibly recording a rapid overturning of the lake.

\section{\begin{tabular}{|l|l|l|l|}
\hline De2 & 995-920 yr BP & Core BR-94E, F & Strong diatom evidence for tsunami \\
\hline
\end{tabular}}

Disturbance event 2 (De2) is identified in core BR-94E as a 1.5-cm-thick bed of muddy sand from 113.5-112 cm (figs. 4 and 6) overlain by massive gyttja from 112 to $100 \mathrm{~cm}$. The stratigraphic evidence for a tsunami associated with De2 is one of the strongest for the entire Bradley Lake record, with an eastward-thinning sand sheet capped by massive gyttja, which, in many cores, is then overlain by finely laminated mud (Nelson et al., 1998.). Diatom evidence also strongly supports a tsunami for De2. All diatoms are rare in the muddy sand because of terrigenous dilution, but marine taxa are present (fig. 6). Marine diatoms are rare to common in the massive gyttja, and include exceptionally fragile specimens of Thalassiosira spp. and Skeletonema costatum in several samples. Occurrences of these delicate species show that they were deposited and buried quickly to enhance their preservation. An errant valve of an Hm diatom (T. pacifica) in massive mud at $80 \mathrm{~cm}$ (figs. 4 and 6) would have been deposited many years after De2, and is not associated with the event. Its occurrence is likely the result of gradual reworking over time of the large amount sediment and diatoms brought into the lake by the tsunami.

The post-De2 stratigraphy in most cores we examined in Bradley Lake includes finely laminated mud capping the massive gyttja, which is comparable to older disturbance events that exhibit strong diatom evidence for tsunamis (e.g. De8, De11, De12). However, unlike these older events, there are no brackish diatoms in the finely laminated mud overlying De2. We were not able to examine diatoms in finely laminated mud in core 94E because of sediment disturbance at the break between sections 2 and 3 of the core, but we examined diatoms in core 94F, about 40 m east of core 94E (fig.1). Occurrences of marine diatoms in core 94F are comparable to core 94E. However, no ecological change appears to be associated with the finely laminated unit. A small number of brackish diatoms are found in the 
massive gyttja of De2 (fig. 6), presumably displaced from epiphytic habitats along the margins of the lake, but there is no evidence for a post-event bloom of these species as they are absent in the finely laminated mud above the disturbance event. In situ freshwater populations are about half as abundant in finely laminated mud after De2 than in massive and laminated mud underlying De2. This explains the formation of the finely laminated mud, which differs from "normal" laminated lake mud by thinner dark laminae, i.e., which are organic-rich layers dominantly composed of biogenic particles, especially diatoms. The absence of abundant brackish diatoms may be the result of a number of factors, not the least of which might include less salt water reaching the lake and fewer "seed" species in the lake to originate a bloom.

\section{\begin{tabular}{|l|l|l|l|}
\hline De3 & 1130-980 yr BP & Core BR-94E & No diatom evidence for tsunami
\end{tabular}}

Disturbance event 3 (De3) is identified in core 94E as a massive gyttja layer from $120 \mathrm{~cm}$ to 124 $\mathrm{cm}$. There is no diatom evidence for a tsunami, as no marine taxa are observed either in or above the gyttja (fig. 7). Instead, the gyttja contains abundant biogenic debris, including large benthic freshwater diatoms and sponge spicules, which would have been displaced from the shallow margins of the lake or the delta of China Creek.

\begin{tabular}{|l|l|l|l|}
\hline De4 & 1510-1320 yr BP & Core BR-94E & Strong diatom evidence for tsunami \\
\hline
\end{tabular}

Disturbance event 4 (De4) is identified in core 94E by a massive gyttja bed between $160 \mathrm{~cm}$ and $154 \mathrm{~cm}$. It is overlain by finely laminated mud from $154 \mathrm{~cm}$ to $152 \mathrm{~cm}$ (fig. 8). Marine diatoms ( $\mathrm{Hm}$ group) are rare in massive gyttja between $158.5 \mathrm{~cm}$ and $155 \mathrm{~cm}$, as well as in finely laminated mud at $154 \mathrm{~cm}$ and laminated mud at $150 \mathrm{~cm}$ (figs. 7 and 8). $\mathrm{Hm}$ diatoms are absent at the base of De4 at 160 $\mathrm{cm}$, but both HTm and Tm diatoms are present. The brackish diatoms Thalassiosira bramaputrae and Mastogloia smithii are very rare in the finely laminated mud at $154 \mathrm{~cm}$; Cyclotella meneghiniana is absent. The concentrations of these taxa in the finely laminated mud are comparable to the underlying massive gyttja of De4, as well as in pre-De4 lake mud. This shows that the ecological impacts of the earthquake and tsunami were not great enough to cause a post-event bloom of these taxa. However, a post-De4 reduction in numbers of freshwater diatoms (154 cm in core 94E; fig. 8) shows that the tsunami did have at least a temporary ecological impact on in situ freshwater lake diatoms. 


\begin{tabular}{|l|l|l|l|}
\hline De5 & 1820-1600 yr BP & Core BR-94E & Strong diatom evidence for tsunami \\
\hline
\end{tabular}

Disturbance event 5 (De5) is superjacent to De6 in core 94E, with the emplacement of De5 having formed an erosional contact with massive gyttja of De6 (figs. 9 and 10). The basis for designating De5 and De6 as two distinct events in core 94E include an erosional contact at $200 \mathrm{~cm}$, and a correlation with the same events in core 94M, where De5 and De6 are clearly separated by fine laminated lake mud (Kelsey et al., 1999).

De5 is recognized in core 94E by two separate coarse-grained units (muddy sand from $200.5 \mathrm{~cm}$ to $199 \mathrm{~cm}$, and sandy mud from $200 \mathrm{~cm}$ to $194 \mathrm{~cm}$ ) capped by massive gyttja from $194 \mathrm{~cm}$ to $188 \mathrm{~cm}$ (fig. 10). Similar to other disturbance events, the rapidly deposited sand and massive gyttja of De5 is overlain by finely laminated mud $(188-183 \mathrm{~cm})$.

Evidence for a tsunami associated with the emplacement of De5 is shown by occurrences of marine diatoms (Hm and HTm groups) throughout the sand and massive gyttja between $200-180 \mathrm{~cm}$. They are particularly prominent between 194 and $188 \mathrm{~cm}$, as well as in finely laminated mud at $186 \mathrm{~cm}$. The brackish species Thalassiosira bramaputrae and Mastogloia smithii are found in all of the De5 and De6 samples between 210-180 cm but reach greatest abundances in the lower part of finely laminated mud at $186 \mathrm{~cm}$. Cyclotella meneghiniana is likewise abundant at $186 \mathrm{~cm}$, where it appears abruptly (i.e., unlike T. bramaputrae and M. smithii, it is absent in underlying deposits). Only a few valves are observed at $184 \mathrm{~cm}$, in contrast to an apparent bloom at $186 \mathrm{~cm}$, suggesting ecological conditions favoring the growth of this species had diminished by the time the upper part of the finely laminated mud was deposited. Higher abundances of brackish diatoms is coincident with lower abundances of freshwater diatoms in the finely laminated mud as compared with overlying mud. Relatively lower numbers of freshwater diatoms in the sand and gyttja of both De5 and De6 are probably the result of terrigenous dilution from rapidly deposited sediment rather than an environmental response from the diatom populations. However, the high number of the brackish diatoms do likely suggest a post-De5 rise in salinity for the lake possibly coupled with a change in diatom habitat (disruption of shore-edge benthic zone? submergence of riparian vegetation?).

\begin{tabular}{|l|l|l|l|}
\hline De6 & 1820-1600 yr BP & Core BR-94E & Strong diatom evidence for tsunami \\
\hline
\end{tabular}

Disturbance event 6 (De6) is identified in core 94E by medium-fine sand from $209 \mathrm{~cm}$ to 204.2 , overlain by massive gyttja from $204 \mathrm{~cm}$ to $201 \mathrm{~cm}$ (fig. 10). The emplacement of sand and gyttja 
during De5 eroded an unknown amount of sediment emplaced during De6, as well as any sediment that accumulated in the period of time between De6 and De5.

Diatom evidence for a tsunami associated with De6 is shown by rare or very rare occurrences of marine diatoms in the sand and overlying massive gyttja. The brackish diatoms M. smithii and T. bramaputrae are associated with De6 deposits, and T. bramaputrae is relatively prominent in massive gyttja at $202 \mathrm{~cm}$. However, the ecologic significance of their occurrences is equivocal as the sand and gyttja of De6 represent rapid deposition in the deep axis of the lake.

\section{\begin{tabular}{|l|l|l|l|}
\hline De7 & 2860-2750 yr BP & Core BR-94E & Strong diatom evidence for tsunami \\
\hline
\end{tabular}}

Disturbance event 7 (De7) is recognized in core BR-94E by a thin layer of muddy sand from 303-301.5 cm, overlain by massive gyttja from $301.5 \mathrm{~cm}$ to $297 \mathrm{~cm}$ (figs. 11 and 12). The gyttja and sand of De7 are capped by finely laminated mud from $297 \mathrm{~cm}$ to $295 \mathrm{~cm}$.

Evidence for a tsunami associated with De7 is shown by occurrences of $\mathrm{Hm}$ diatoms in the sand and massive gyttja. Marine diatoms, particularly Thalassiosira pacific, have highest concentrations at the top of the gyttja at $298 \mathrm{~cm}$.

The brackish diatoms Thalassiosira bramaputrae and Mastogloia smithii are rare in massive mud at $304 \mathrm{~cm}$, massive gyttja at $301 \mathrm{~cm}$, and laminated mud at $290 \mathrm{~cm}$ (fig. 12); Cyclotella meneghiniana is absent in these deposits as well as in mud underlying De7. Relative to assemblages in lake mud above and below De7, abundances of freshwater diatoms are an order of magnitude less abundant in finely laminated mud capping De7 at $296 \mathrm{~cm}$ (fig. 12). They are also one-half to one-fifth as abundant as the terrigenous-diluted assemblages in gyttja and sand of De7. The three species of brackish diatoms are basically absent from the finely laminated mud (only a few valves of $T$. bramaputrae observed) showing that the paleoecological conditions that favored growth of these particular species following other disturbance events (e.g., De5, De8) did not occur following De7.

\begin{tabular}{|l|l|l|l|}
\hline De8 & 3250-3060 yr BP & Core BR-94E & Strong diatom evidence for tsunami \\
\hline
\end{tabular}

Disturbance event 8 (De8) is recognized in core BR-94E by fine gray sand at $338 \mathrm{~cm}$ overlain by muddy sand from $337 \mathrm{~cm}$ to $335 \mathrm{~cm}$ and massive gyttja from $335 \mathrm{~cm}$ to $332 \mathrm{~cm}$ (figs. 11 and 13). The De8 deposits are capped by finely laminated mud from $332 \mathrm{~cm}$ to $327 \mathrm{~cm}$.

Evidence for a tsunami associated with De8 is shown by occurrences of marine diatoms ( $\mathrm{Hm}$ and HTm groups), which are rare but diverse in the muddy sand and massive gyttja, as well as in 
overlying finely laminated and laminated mud. There are prominent occurrences of taxa derived from adjacent Tertiary diatomites (Tm group) in the upper part of De8 and in post-De8 deposits (fig. 11).

A post-De8 change in lake ecology or freshwater habitat is shown by the abundance of Cyclotella meneghiniana in finely laminated mud at $330 \mathrm{~cm}$, coincident with a strong reduction in numbers of freshwater diatoms, as compared to assemblages in laminated mud above and below the event. The other brackish diatoms are common in the finely laminated mud, but C. meneghiniana is approximately an order of magnitude more abundant. Abundances of freshwater diatoms in the sand and massive gyttja of De8 are relatively low because of terrigenous dilution, and are dominated by large, broken pennate diatoms and siliceous phytoliths, consistent with redeposition of deposits from the shallow margins of the lake.

The freshwater species Aulacoseira italica is prominent in laminated and massive lake sediment between $320-305 \mathrm{~cm}$, with concentrations roughly equal to all other freshwater species combined.

\section{\begin{tabular}{|l|l|l|l|}
\hline De9 & 3400-3210 yr BP & Core BR-95BB & Weak diatom evidence for tsunami \\
\hline
\end{tabular}}

Disturbance event 9 (De9) is recognized in core 95BB by a 5-cm-thick bed of massive gyttja between $276.5 \mathrm{~cm}$ and $271.5 \mathrm{~cm}$ (figs. 14 and 15). Large benthic diatoms and sponge spicules are prominent in the gyttja, consistent with redeposition from the shallow margins of the lake. Marine diatoms (Hm and HTm groups) are very rare in the uppermost part of the gyttja, as well as in an overlying 1-cm-thick unit of finely laminated mud from $271.5 \mathrm{~cm}$ to $270.5 \mathrm{~cm}$. The brackish species Thalassiosira bramaputrae is rare in the finely laminated mud, indicative of a small, though possibly significant, ecological shift in lake ecology or diatom habitat following the disturbance event. $C$. meneghiniana does not exceed "background" levels in this unit; M. smithii was not observed in any samples directly below, within, or directly above De9. A conspicuous concentration of the freshwater diatom Aulacoseira italica in the upper part of the gyttja at $272 \mathrm{~cm}$ coincides with low numbers of small planktonic diatoms, which then increase by a factor of five in deposits above the gyttja. This may record ecological factors initially favoring a bloom of $A$. italica (destratification and rapid overturning of the lake?) which allowed it to out-compete tiny planktonic species for limited nutrients in the water column. A possible return to a strongly stratified lake, as suggested by deposition of finely laminated mud above De9, may have helped to re-establish populations of small planktonic species. This postDe9 bloom in planktonic diatoms is comparable to the diatom-productivity pattern immediately following De10, as discussed below. 


\section{\begin{tabular}{|l|l|l|l|}
\hline De10 & 3830-3630 yr BP & Core BR-95BB & Weak diatom evidence for tsunami \\
\hline
\end{tabular}}

Disturbance event 10 (De10) is identified in core 95BB by massive gyttja from $309 \mathrm{~cm}$ to 305 cm (figs. 14 and 16). Large pennate diatoms and sponge spicules are abundant in the gyttja, consistent with redeposition from the shallow margins of the lake. Marine diatoms (Hm and HTm groups) and brackish diatoms are present but very rare (fig. 16). Finely laminated mud between $305 \mathrm{~cm}$ and 301.5 cm overlies the gyttja of De10. This juxtaposition of finely laminated mud above coarse-grained deposits is similar to other disturbance events that show evidence for tsunamis, such as De5, De8, De11, De13 and De16. However, the finely laminated mud of De10 differs from some of these other disturbance events in that it does not contain high numbers of brackish diatoms. Also, the finely laminated mud contains an intercalated bed of massive mud (at $303 \mathrm{~cm}$ ) that was formed by the dense accumulation of tiny planktonic diatoms, particularly Cyclotella stelligera and a small $(<4-5 \mu \mathrm{m}$ diameter) species of Aulacoseira. We did not observe this kind of massive deposit associated with any other disturbance event. (These small planktonic diatoms are likewise abundant in the overlying sample in the upper section of finely-laminated mud at $302 \mathrm{~cm}$; fig. 16). It is unclear whether this is evidence for continued proliferation of these taxa or reworking of massive numbers of valves produced during an initial growth event. However, as possible evidence for disruption to the lake's shallow, nearshore benthic habitats following the disturbance event, numbers of benthic diatoms are reduced by about half in the finely laminated mud following Del (between $290 \mathrm{~cm}$ and $304 \mathrm{~cm}$ ) as compared with pre-De10 deposits (between $309 \mathrm{~cm}$ and $315 \mathrm{~cm}$ ).

\section{\begin{tabular}{l|l|l|l|} 
De11 & 4280-4000 yr BP & Core BR-94E & Strong diatom evidence for tsunami
\end{tabular}}

Disturbance event 11 (De11) is identified in core 94E by a 2-cm-thick plant detritus bed overlain by $4 \mathrm{~cm}$ of massive gyttja (figs. 17 and 18).

Evidence for a tsunami associated with De11 is shown by occurrences of marine diatoms $(\mathrm{Hm}$ and HTm groups) at the top of the gyttja bed and overlying finely laminated mud. The plant detritus bed at $438.5 \mathrm{~cm}$ contains abundant large freshwater diatoms and sponge spicules which were redeposited from the shallow margins of the lake. Marine diatoms are only found at the top of the gyttja unit because of differential settling relative to the larger, heavier benthic diatoms, sponge spicules and terrigenous detritus. Brackish diatoms are prominent in finely laminated mud at $433 \mathrm{~cm}$, with Cyclotella meneghiniana roughly an order of magnitude more abundant than M. elliptica and T. 
bramaputrae combined (fig. 18). This increase in numbers of brackish species is coincident with a sharp decrease in numbers of typical in situ freshwater taxa.

Paleoecological significance of a clast of muddy detrital peat in core 94E.

A clast of muddy detrital peat recovered from core 94E $(373-401 \mathrm{~cm})$ may provide some additional insight about post-De11 changes in diatom populations. Based on ${ }^{14} \mathrm{C}$ analyses and stratigraphic correlations (Nelson et al., 1998.), the peat accumulated in a marshy environment 41503920 cal yr BP (about the time of De11) but was redeposited at the site of core 94E much later, possibly more than a century after De10 (A. Nelson, pers. comm.). The peat clast can be divided into two subunits based on diatoms: 1$)$ the $F W$ subunit $(377-400 \mathrm{~cm})$ containing a large variety of freshwater benthic species; and 2) the $B D$ subunit $(373-377 \mathrm{~cm})$ containing abundant brackish diatoms (Table 2; fig. 19).

The concentration of brackish species in the peat clast records a period following De11 when brackish species flourished while numbers of other freshwater diatoms were reduced (fig. 18). Mastogloia smithii is prominent in the $B D$ subunit, and other benthic species that can tolerate brackish conditions such as Rhopalodia gibba, Campylosira echineis, Tryblionella apiculata, and Diploneis smithii var. rhombica are also prevalent. It is noteworthy that Thalassiosira bramaputrae and Cyclotella meneghinian, both planktonic species, are rare relative to M. elliptica and in the peat clast, since the shallow benthic environment represented by the muddy peat would not have been their optimum growth environment. Also, the fact that C. meneghiniana significantly outnumbers $M$. smithii in post-De11 deposits in core 94E shows that planktonic taxa were more readily transported to the deep axis of Bradley Lake, simply by filtering out of the water column, than benthic brackish taxa accumulating in marshy areas at the margins of the lake (e.g., in the vicinity of the delta of China Creek on the east side of the lake). This is an important observation for a number of disturbance events in which M. smithii tends to be less abundant than either of the planktonic species C. meneghiniana or $T$. bramaputrae (De9, De12, De13, De16 and De17).

Diatoms in the $F W$ subunit dominantly consist of large benthic and epiphytic species typical of freshwater wetlands, such as Eunotia formica, E. robusta var. tetradon, Pinnularia microstauron, Stauroneis phoenicenteron, Cymbella aspera, Diploneis smithii, D. finmarchia, Gomphonema augur, plus many others. Large species of Surirella and Neidium are also prominent, as are sponge spicules. In its present orientation, the clast contains the $B D$ subunit at the top, which would indicate a transition from a true freshwater-marsh assemblage to an assemblage dominated by species (e.g., $T$. bramaputrae, M. smithii) usually found in brackish water. However, we do not know if the peat is in 
the correct orientation; it may be upside-down. This is weakly supported by uncalibrated ${ }^{14} \mathrm{C}$ ages which are slightly older at the top of the clast $\left(3740 \pm 50{ }^{14} \mathrm{C}\right.$ yr BP at $\left.373 \mathrm{~cm}\right)$ than at the bottom $(3700$ $\pm 50{ }^{14} \mathrm{C}$ yr BP at $\left.401 \mathrm{~cm}\right)$. In the latter case, the clast would record the initial growth of a wetland favorable to brackish species following De11, followed by a return to more typical freshwater assemblages some years after De11.

\section{\begin{tabular}{|l|l|l|l|}
\hline De12 & 4410-4230 yr BP & Core BR-94E & Strong diatom evidence for tsunami \\
\hline
\end{tabular}}

Disturbance event 12 (De12) is identified in core 94E by a thin layer of sand and sandy mud at $470 \mathrm{~cm}$ to $465 \mathrm{~cm}$, overlain by massive gyttja from $465 \mathrm{~cm}$ to $462 \mathrm{~cm}$ (fig. 20). $H m$ diatoms are common in the sand and overlying gyttja (figs. 17 and 20), particularly Thalassiosira pacifica, a species prolific in coastal waters and prominent in modern surficial deposits of the lower beach proximal to Bradley Lake. Brackish diatoms are present in low numbers in the sand and gyttja of De12 (fig. 20). T. bramaputrae is common in overlying finely laminated mud at $460 \mathrm{~cm} ; M$. smithii is rare and $C$. meneghiniana is very rare in this unit. Brackish diatoms are also found in overlying faintly laminated lake mud, and T. bramaputrae and C. meneghiniana are particularly prominent at $454 \mathrm{~cm}$, where they reach between $10^{4}$ and $10^{5}$ valves/cc. The $454 \mathrm{~cm}$ depth horizon contains an abundance of brackish diatoms whereas abundances of freshwater diatoms are relatively reduced, with the exception of the planktonic species Aulacoseira italica. A. italica may have bloomed in response to greater availability of limited nutrients in the lake left by diminished benthic populations.

\begin{tabular}{|l|l|l|l|}
\hline De13 & 4650-4420 yr BP & Core BR-95X & Strong diatom evidence for tsunami \\
\hline
\end{tabular}

Disturbance event 13 (De13) is identified in core $95 \mathrm{X}$ by a thin, two-layered gyttja bed, with light grayish brown gyttja from $447.9 \mathrm{~cm}$ to $448.5 \mathrm{~cm}$ overlying dark grayish brown gyttja from 448.5 $\mathrm{cm}$ to $449.5 \mathrm{~cm}$ (figs. 21 and 22). The dark gyttja layer contains mostly terrigenous material and roughly half as many diatoms as the lighter gyttja layer. The light and dark layers are likely the result of differential settling during the same depositional event, with a denser, more terrigenous-rich dark layer settling to the lake floor in advance of a lighter-colored, diatom-rich layer. The massive gyttja is capped by finely laminated mud (448 $\mathrm{cm}$ to $443 \mathrm{~cm}$ ).

Diatom evidence for a tsunami is shown by common occurrences of $\mathrm{Hm}$ diatoms in the upper part of the gyttja bed and lower part of the overlying finely laminated mud (fig. 21). HTm and Tm diatoms are also prominent at these intervals. $H m$ diatoms are present but very rare in the lower, dark- 
brown gyttja layer. A possible change in lake salinity or diatom habitat following De13 is shown by a massive bloom of Cyclotella meneghiniana in finely laminated mud at $444 \mathrm{~cm}$. (In contrast, neither $T$. bramaputrae nor M. smithii exceed "background" levels for any samples in or above De13, from 449 $\mathrm{cm}$ to $437 \mathrm{~cm})$. The large increase in numbers of $C$. meneghiniana coincides with lower numbers of freshwater taxa, which, with the exception of Aulacoseira italica, remain low throughout massive and laminated mud for more than $10 \mathrm{~cm}$ above De13, from $437 \mathrm{~cm}$ to $444 \mathrm{~cm}$.

\section{\begin{tabular}{|l|l|l|l|}
\hline De14 & 4780-4540 yr BP & Core BR-95X & No diatom evidence for tsunami \\
\hline
\end{tabular}}

Disturbance event 14 (De14) is characterized in core 95X by a two-layered gyttja deposit, with dark grayish-brown gyttja from $455.5 \mathrm{~cm}$ to $458 \mathrm{~cm}$ overlying light grayish brown massive gyttja from $458 \mathrm{~cm}$ to $459.5 \mathrm{~cm}$ (fig. 23).

$H m$ diatoms are absent in the gyttja and overlying mud (fig. 23). Freshwater diatoms are rare in the gyttja, and consist mainly of large pennate species and sponge spicules. This is consistent with redeposition of coarse biogenic debris from shallow areas of the lake. There is no obvious difference in concentrations of freshwater diatoms between the light and dark gyttja layers. Fewer benthic freshwater diatoms are found in laminated mud above De14 are lower than in massive lake mud predating De14, possibly indicating a disruption of shallow benthic environments as a result of the disturbance event. Numbers of small planktonic freshwater diatoms also diminish after, as compared to before, De14. An exception to this is the planktonic freshwater species Aulacoseira italica, which is abundant at $455 \mathrm{~cm}$. This may record an oportunistic bloom of this species, possibly caused by a rapid overturning of the stratified lake following the emplacement of De14.

\section{\begin{tabular}{|l|l|l|l|}
\hline De15 & 5600-5320 yr BP & Core BR-94E & No diatom evidence for tsunami \\
\hline
\end{tabular}}

Disturbance event 15 (De15) is identified in core 94E as a debris layer at $540 \mathrm{~cm}$, overlain by massive gyttja from $538 \mathrm{~cm}$ to $536 \mathrm{~cm}$. $H m$ and brackish diatoms are absent in the detritus bed and gyttja (fig. 24). Instead, the diatom assemblage consists of large, mostly broken freshwater diatoms and sponge spicules, with rare occurrences of HTm and Tm species. The presence of these species, and absence of brackish diatoms in sediment above De15, is consistent with redeposition of sediment and diatoms from the shallow margins of the lake without an influx of marine water or coincident change in diatom habitat or lake ecology. 


\section{\begin{tabular}{|l|l|l|l|}
\hline De16 & 6510-6310 yr BP & Core BR-94E & No diatom evidence for tsunami
\end{tabular}}

Disturbance event 16 (De16) is identified in core 94E as a woody detritus bed at $609 \mathrm{~cm}$, capped by massive gyttja from $607 \mathrm{~cm}$ to $605.5 \mathrm{~cm}$ (fig. 25). $\mathrm{Hm}$ diatoms are absent in the woody detritus bed and massive gyttja, but freshwater diatoms are abundant. This is consistent with redeposition of shallow-water detritus from the margins of the lake.

Compared to other disturbance events, De16 is lithologically and biostratigraphically enigmatic. In all other cases where finely laminated mud is associated with a disturbance event (Table 3), the unit lies directly above the sandy or massive gyttja deposits of the event. However, for De16 a unit of finely laminated mud $(594.5-601 \mathrm{~cm})$ is separated from a unit of massive gyttja $(607-605.5 \mathrm{~cm})$ by approximately $5 \mathrm{~cm}$ of intermittently laminated lake mud (605.5-601 cm; fig. 25). The intermittently laminated mud contains abundant freshwater diatoms, and is lithologically indicative of "normal" lake sedimentation (Kelsey et al., 1999). Compared to assemblages in the "normal" lake mud, freshwater diatoms are two orders of magnitude less abundant in finely laminated mud at $595 \mathrm{~cm}$ and $600 \mathrm{~cm}$. Brackish planktonic diatoms (Cyclotella meneghiniana and Thalassiosira bramaputra)e are prominent in the upper part of the finely laminated mud at $595 \mathrm{~cm}$, as well as in overlying massive mud at $590 \mathrm{~cm}$ (fig. 25). The increased abundances of brackish diatoms and decreased abundances of freshwater diatoms in the finely laminated mud is evidence for a period of reduced productivity for in situ freshwater populations. In addition to elevated salinity, other mechanisms for this may have included physical disruption of shallow benthic habitats from landslides or an abrupt increase in lake level caused by blockage of the lake outlet.

In addition to abundant freshwater diatoms in the "normal" laminated mud at $602.5 \mathrm{~cm}$, brackish planktonic diatoms (T. bramaputrae and C. meneghiniana) are also abundant (fig. 25). The benthic species $M$. smithii does not exceed "background" abundances in any samples within or above De16. Although an abundance of freshwater diatoms is consistent with the presence of "normal" laminated mud, concurrent abundances of brackish diatoms appears contradictory. It may be possible that a small increase in salt stimulated the growth of the brackish species, but that the change in salinity was not great enough to immediately disrupt in situ freshwater populations. Although anomalous occurrences of brackish diatoms suggests a increase in salinity associated with De16, Hm diatoms were not observed. Therefore, we have no evidence, in the form of displaced marine diatoms, for a tsunami having inundated the lake.

The freshwater planktonic diatom Aulacoseira italica is prominent in massive mud at $590 \mathrm{~cm}$, but it does not dominate the assemblage as in other events in which massive numbers may show that the 
species successfully out-competed other taxa for limited nutrients in the lake (e.g., De8, De9, De12). Abundances of freshwater diatoms in the massive gyttja and detritus of De16 are artifacts of redeposition of benthic assemblages in the deep axis of the lake.

\begin{tabular}{|l|l|l|l|}
\hline De17 & 7390-7220 yr BP & Core BR-94E & Strong diatom evidence for tsunami \\
\hline
\end{tabular}

Disturbance event 17 (De17) is identified in core 94E by $2 \mathrm{~cm}$ of sand and muddy sand at 635 cm to $633 \mathrm{~cm}$.

The absence of planktonic diatoms in peaty mud below $640 \mathrm{~cm}$, but abundance of freshwater benthic diatoms, shows that the site was a freshwater marsh prior to deposition of De17. First occurrences of freshwater planktonic diatoms above De17 at $630 \mathrm{~cm}$, and presence of poorly preserved finely laminated mud from $628 \mathrm{~cm}$ to $632 \mathrm{~cm}$, attest to a transition from freshwater marsh to pond or lake (fig. 26). The depth of this incipient lake is not known, but based on comparisons with other lakes, this probably represents a deepening to at least $5 \mathrm{~m}$ (Larsen and MacDonald, 1993).

With the exception of a single valve of T. bramaputrae at $636 \mathrm{~cm}$ (Appendix 3), no brackish or marine diatoms are observed in core 94E prior to De17 (figs. 24). Hm and HTm diatoms are first observed in sand at $634 \mathrm{~cm}$, and include species that are likewise associated with succeeding disturbance events, such as Thalassiosira pacifica, Delphineis karstenii, and Cocconeis scutellum. Hm and HTm diatoms are more frequent in finely laminated mud at $632 \mathrm{~cm}$ than in the underlying sand, a pattern also repeated for succeeding disturbance events. Tm diatoms are also first observed at $634 \mathrm{~cm}$, which shows that prior to the post-De17 transition from marsh to lake, there was no mechanism to transport diatoms from the nearby diatomite to the site of core 94E. T. bramaputrae is common in faint, finely laminated mud between 624-630 cm; C. meneghiniana is present but rare above De17 at $630 \mathrm{~cm}$ (Fig. 27). This may reflect a small increase in salinity (or change in diatom habitat?) following De17.

\section{CONCLUSIONS}

1) Based on occurrences of displaced Holocene marine diatoms, we conclude that 13 disturbance events record past tsunamis in Bradley Lake. We consider the evidence strong for 11 events, based on numbers and diversity of marine taxa: De1, De2, De4, De5, De6, De7, De8, De11, De12, De13, and De17. The evidence is less compelling for an additional 2 events (De9 and De10), although tsunami inundation is likely. Finally, we identified 4 events (De3, De14, De15 and De16) in which there were no marine diatoms to support tsunami inundation, although stratigraphic data shows that the lake bottom was disturbed. 
2) Anomalous increases in numbers of three species of brackish diatoms (Thalassiosira bramaputrae, Cyclotella meneghiniana, and Mastogloia smithii) following De16, De13, De12, De11, De9, De8, and De5 may be evidence for short-lived periods of slightly elevated salinities in the lake. With the exception of De12, increased abundances of one or more of the brackish species is coincident with decreased numbers of freshwater diatoms. This is further evidence for a shift in ecological conditions following some events which favored species like T. bramaputrae and C. meneghiniana, whose growth may be stimulated by small amounts of salt, and M. smithii, a benthic species commonly found on muddy estuarine banks and marshes, over in situ freshwater diatoms. High numbers of T. bramaputrae and $C$. meneghiniana, both planktonic halophilic species, might also be the result of the ability of these taxa to out-compete struggling freshwater benthic populations for limited nutrients in the lake.

3) The fact that freshwater populations, though temporarily diminished following some events, manage to recover and persist throughout the Bradley Lake record is evidence that any salinity increases must have been small ( $1 \mathrm{~g} / \mathrm{L}$ ? $2 \mathrm{~g} / \mathrm{L}$ ?), and did not persist long enough to permanently destroy in situ populations.

4) Large numbers of the brackish taxa listed above are not found in deposits younger than De5, to include De2, which includes common marine diatoms and strong stratigraphic evidence for tsunami incursion. The reason for this is equivocal, but may simply be the result of fewer "seed" species being present in the lake to facilitate a bloom. It is possible that a more detailed accounting of freshwater and euryhaline diatoms throughout the lake record might provide greater insight into small-scale changes in salinity in the lake over time. 


\section{REFERENCES}

Atwater, B.F., and Hemphill-Haley, E.,1997, Recurrence Intervals for Great Earthquakes of the Past 3500 Years at Northeastern Willapa Bay, Washington: USGS Professional Paper 1576, 108 p.

Atkinson, K.M., 1972, Birds as transporters of algae. British Phycological Journal, No. 7, p.319-321.

Baltic Marine Biologists Publication 16a (1993), Intercalibraton and distribution of diatom species in the Baltic Sea, Volume 1. Snoeijs, P. (ed.)., 129 pp.

Baltic Marine Biologists Publication 16b (1994), Intercalibraton and distribution of diatom species in the Baltic Sea, Volume 2. Snoeijs, P. and Vilbaste, S. (eds.), 125 pp.

Baltic Marine Biologists Publication 16c (1995), Intercalibraton and distribution of diatom species in the Baltic Sea, Volume 3. Snoeijs, P. and Potapova, M. (eds.)., 126 pp.

Baltic Marine Biologists Publication 16d (1996), Intercalibraton and distribution of diatom species in the Baltic Sea, Volume 4. Snoeijs, P. and Kasperoviciene, J. (eds.)., 126 pp.

Baltic Marine Biologists Publication 16e (1998), Intercalibraton and distribution of diatom species in the Baltic Sea, Volume 5. Snoeijs, P. and Balashova, N. (eds.)., 144 pp.

Battarbee, R.W., 1973, A new method for the estimation of absolute microfossil numbers, with reference especially to diatoms. Limnology and Oceanography, vol. 18, no. 4, p. 647-652.

Bondevik, S., Svendsen, J.I., and Mangerud, J., 1997, Tsunami sedimentary facies deposited by the Storegga tsunami in shallow marine basins and coastal lakes, western Norway. Sedimentology, v. 44, p. 1115-1131.

Bondevik, S., Svendsen, J.I., and Mangerud, J., and Kaland, P.E., 1997, The Storegga tsunami along the Norwegian coast, its age and runup. Boreas, v. 26, p. 29-53.

Carpelan, L.H., 1978, Revision of Kolbe's System der Halobien based n diatoms of California lagoons. Oikos, vol. 31, p. 112-122.

Cumming, B.F., and Smol, J.P., 1993, Development of diatom-based salinity models for paleoclimatic research from lakes in British Columbia (Canada). Hydrobiologia, vol. 269/270, p. 179-196.

Cumming, B.F., Wilson, S.E., Hall, R.I., and Smol, J.P., 1995, Diatoms from British Columbia (Canada) Lakes and Their Relationship to Salinity, Nutrients, and Other Limnological Variables. Koeltz Scientific Publishers, Stuttgart, Germany, 207 p.

Darienzo, M.E., and Peterson, C.D., 1990, Episodic tectonic subsidence of late Holocene salt marshes, northern Oregon central Cascadia margin. Tectonics, v. 9, no. 1, p. 1022.

Darwin, C.E., 1846, An account of the fine dust which falls on vessels in the Atlantic Ocean. Quarterly Journal of the Geological Society of London, v. 2, p. 26. 
Dawson, A.G., Long, D., and Smith, D.E., 1988, The Storegga slides: Evidence from eastern Scotland for a possible tsunami. Marine Geology, v. 82, p. 271-276.

Dawson, S., Smith, D.E., Ruffman, A., and Shi, S., 1996, The diatom biostratigraphy of tsunami sediments: Examples from recent and Middle Holocene events. Phys. Chem. Earth, v. 21, no. 12, p. $87-92$.

Foged, N., 1981, Diatoms in Alaska: Bibliotheca Phycologia, v. 53, 316 p.

Folger, D.W., 1970, Wind transport of land-derived mineral, biogenic and industrial matter over the North Atlantic. Deep-Sea Research, vo., 17, p. 337-352.

Fritz, S.C., Juggins, S., and Battarbee, R.W., 1993, Diatom assemblages and ionic characterization of lakes of the northern Great Plains, North America: A tool for reconstructing past salinity and climate fluctuations. Canadian Journal of Fisheries and Aquatic Science, vol. 50, p. 1844-1856.

Garrison, R.E., and Douglas, R.G., 1981, The Monterey Formation and Related Siliceous Rocks of California. Society of Economic Paleontologists and Mineralogists, Special Publication Volume 15 Garrison-Laney, C. 1998, Diatom Evidence for Tsunami Inundation from Lagoon Creek, a Coastal Freshwater Pond, Del Norte County, California. Unpublished Master's Thesis, Humboldt State University, $200 \mathrm{pp}$.

Germain, H., 1981, Flore des diatomées diatomophycées eaux douces et saumatres du Massif Armoricain et des contrées voisines d'Eruope occidentale: Paris, Sociéte Nouvelle des Éditions Boubée, 444 p.

Håkansson, H., and Chepurnov, V., 1999, A study of variation in valve morphology of the diatom Cyclotella meneghiniana in monoclonal cultures: effect of auxospore formation and different salinity conditions. Diatom Research, vol. 14, no. 2, p. 251-272.

Hasle, G.R., 1978, Some freshwater and brackish water species of the diatom genus Thalassiosira Cleve. Phycologia, vol. 17, no. 3, p. 263-292.

Hemphill-Haley, E., 1995, Diatom evidence for earthquake-induced subsidence and tsunami 300 years ago in southern coastal Washington: Geological Society of America Bulletin, v. 107, no. 3, p. 367378.

Hemphill-Haley, E., 1996, Diatoms as an aid in identifying late Holocene tsunami deposits.: The Holocene, v. 6, no. 4, p. 439-448.

Hustedt, F. 1930, Bacillariophyta (Diatomaceae), in Pascher, A. , ed., Die Süsswasser-flora Mitteleuropas, Heft 10: Jena, Gustav Fishcer Verlag, 466 p. 
Hustedt, F., 1927-1966, Die Kieselalgen Deutschlands, Österreichs und der Schweiz mit

Berücksichtigung der übrigen Länder Europas sowie der angrenzenden Meeresgebiete, Part I, II, III:

Dr. L. Rabenhorst's Kryptogamen-Flora v. 7, Part I, p. 1-920; Part II, p. 1-845; Part III, p. 1-816.

Hutchinson, I., Clague, J.J., and Mathewes, R.W., 1997, Reconstructing the tsunami record on an emerging coast: a case study of Kanim Lake, Vancouver Island, British Columbia, Canada. Journal of Coastal Research, v. 13, no. 2, p. 545-553.

Hutchinson, I., Guibault, J.-P., Clague, J.J., and Bobrowsky, P.T., 2000, Tsunamis and tectonic deformation at the northern Cascadia margin: a 3000-year record from Deserted Lake, Vancouver Island, British Columbia, Canada. The Holocene, v. 10, no. 4, p. 429-439.

John, J., 1983, Observations on Thalassiosira lacustris (Grunow) Hasle populations from western Australia. Nova Hedwigia, vol. 38, p. 323-337.

Kelsey, H.M., Witter, R.C. and Hemphill-Haley, E., 1998, Response of a small estuary in Oregon to the subductin earthquake deformation cycle: Geology, v. 23, no. 3, p. 231-234.

Kelsey, H.M., Nelson, A.R., Hemphill-Haley, E., and Witter, R.C., 1999, A 7,000 year record of tsunamis generated by the Cascadia subduction zone, evidence from a coastal lake in Oregon [abstract]; Geological Society of America Abstracts with Programs, v. 31. No. 6, p. A-68.

Krammer, K., and Lange-Bertalot, H., 1986, Sußwasserflora von Mitteleuropa. Bacillariophyceae 1. Teil: Naviculaceae: Stuttgart, Gustav Fischer Verlag, 876 p.

Krammer, K., and Lange-Bertalot, H., 1988, Sußwasserflora von Mitteleuropa. Bacillariophyceae 2. Teil: Bacillariaceae, Epithemiaceae, Surirellaceae: Stuttgart, Gustav Fischer Verlag, 596 p.

Krammer, K., and Lange-Bertalot, H., 1991a, Sußwasserflora von Mitteleuropa. Bacillariophyceae 3. Teil: Centrales, Fragilariaceae, Eunotiaceae: Stuttgart, Gustav Fischer Verlag, 576 p.

Krammer, K., and Lange-Bertalot, H., 1991b, Sußwasserflora von Mitteleuropa. Bacillariophyceae 4. Teil: Achnanthaceae, Kritische Ergänzungen zu Navicula (Lineolatae) un Gomphonema: Stuttgart, Gustav Fischer Verlag, 437 p.

Larsen, C.P.S., and MacDonald, G.M., 1993, Lake morphometry, sediment mixing and the selection of sites for fine resolution palaeoecologic studies. Quaternary Science Reviews, v. 12, p. 781-792.

Laws, R.A., 1983, Preparing strewn slides for quantitative microscopical analyses: A test using calibrated microspheres. Micropaleontology, vol. 29, no. 1, p. 60-65.

Long, D., Smith, D.E., and Dawson, A.G., 1989, A Holocene tsunami deposit in eastern Scotland. Journal of Quaternary Science, v. 4, p. 61-66.

Mahood, A.D., Fryxell, G.A., and McMillan, M., 1986, The diatom genus Thalassiosira: species from the San Francisco Bay area: Proc. Calif. Acad. Sci., v. 44, p. 127-156. 
Melia, M.B., 1984, The distribution and relationship between palynomorphs in aerosols and deep-sea sediments off the coast of West Africa. Marine Geology, v. 58, p. 345-371.

Minoura, K., and Nakata, T., 1994, Discovery of an ancient tsunami deposit in coastal sequences of southwest Japan: Verification of a large historic tsunami. The Island Arc, v.3, p. 66-72.

Minoura, K., Nakaya, S., and Uchida, M., 1994, Tsunami deposits in a lacustrine sequence of the Sanriku coast, northeast Japan. Sedimentary Geology, v. 89, p. 25-31.

Moore, T.C., 1973, Method of randomly distributing grains for microscopic examination. Journal of Sedimentary Petrology, vol. 43, no. 3, p. 904-906.

Nelson, A.R., Kelsey, H.M., Hemphill-Haley, E., and Witter, R.C., 1998, AMS ${ }^{14}$ C dating of a 7300 year earthquake history from an Oregon coastal lake [abstract]; Geological Society of America Abstracts with Programs, v. 30. No. 7, p. A-162.

Nelson, A.R., Kelsey, H.M., Hemphill-Haley, E., and Witter, R.C., 2000, Oxcal analyses and varvebased sedimentation rates constrain the times of ${ }^{14} \mathrm{C}$-dated tsunamis in southern Oregon. Penrose Conference on Cascadia Tricentennial, Seaside, Oregon, June 2000.

Parsons, M.L., 1998, Salt marsh sedimentary record of the landfall of Hurricane Andrew on the Louisiana coast: Diatoms and other paleoindicators: Journal of Coastal Research, v. 14, no. 3, p. 939-950.

Patrick, R. and C.W. Reimer, 1966, The Diatoms of the United States Exclusive of Alaska and Hawaii. I. Monographs of Acad. Nat. Sci. Philad., v. 13, 688 p.

Patrick, R. and C.W. Reimer, 1975, The Diatoms of the United States Exclusive of Alaska and Hawaii. II (1). Monographs of Acad. Nat. Sci. Philad., v. 13, 213 p.

Pokras, E.M., and Mix, A.C., 1985, Eolian evidence for spacial variability of late Quaternary climates in tropical Africa. Quaternary Research, v. 24, p. 137-149.

Proctor, V.W., 1959, Dispersal of fresh water algae by migratory water birds. Science, v. 130, p. 623624.

Roelofs, A.K., and Pisias, N.G., 1986, Revised technique for preparing quantitative radiolarian slides from deep-sea sediments. Micropaleontology, vol. 32, no. 2, p. 182-185.

Round, F.E., Crawford, R.M., and Mann, D.G., 1990, The Diatoms. Biology and Morphology of the Genera. Cambridge, Cambridge University Press, 747 p.

Sancetta, C., Lyle, M., Heusser, L., Zahn, R., and Bradbury, J.P., 1992, Late Glacial to Holocene changes in winds, upwelling and seasonal production of the northern California Current system. Quaternary Research, v. 38, p. 359-370. 
Seyve, C., and Fourtanier, E., 1989, Contenu microfloristique d'un sediment eolien actuel. Bulletin Centre pour Recherche et Exploration Production d'Elf-Aquitaine, v. 9, p. 137-154.

Stuiver, M., and Pearson, G.W., 1986, High-precision calibration of the radiocarbon time scale AD 1950-6000 BC. Radiocarbon, v. 28, p. 805-838.

Whiting, M.C., and Schrader, H., 1985, Late Miocene to Early Pliocene marine diatom and silicoflagellate floras from the Oregon coast and continental shelf. Micropaleontology 31, no.3 (1985) p. 249-270.

Wilson, S.E., Cumming, B.F., and Smol, J.P., 1995, Assessing the reliability of salinity inference models from diatom assemblages: an examination of a 219-lake data set from western North America. Canadian Journal of Fisheries and Aquatic Science, vol. 53, p. 1580-1594.

Witter, R.C., Kelsey, H.M., and Hemphill-Haley, 2001, Pacific storms, El Niño and tsunamis: Competing mechanisms for sand deposition in a coastal marsh, Euchre Creek, Oregon. Journal of Coastal Research, v. 17 , no. 3, p. 563-583. 


\section{FIGURE CAPTIONS}

Figure 1. Location of Bradley Lake, Oregon relative to the Cascadia subduction zone (A) and the Oregon coast (B). The boot-shaped lake (C) formed when coastal dunes blocked the channel of China Creek. Numbers on contour lines are depth in meters; letters show core locations.

Figure 2. Salinity ranges for brackish-water diatoms from Bradley Lake, based on modern occurrences in lakes and estuaries. CYCMEN: Cyclotella meneghiniana. THABRA: Thalassiosira bramaputrae. MASSMI, MASLAC: Mastogloia smithii + M. smithii var. lacustris. R1: Cumming and Smol, 1993. R2: Wilson et al., 1995. R3: Fritz et al., 993. R4: John, 1983. R5: Carpelan, 1978.

Figure 3. Concentrations of marine, brackish and freshwater diatoms for De1 through De17. Hm: marine diatoms from Holocene surficial deposits. Vertical dashed lines for brackish diatoms show an estimated delineation between "background" occurrences and large increases in growth of these taxa. Data are from core BR-94E, BR-94F (90-100 cm), BR-95BB (360-412 cm), and BR-95X $(473-498 \mathrm{~cm})$.

Figure 4. Concentrations of marine and brackish diatoms for De1, De2, and an enigmatic post-De1 event ("Black soupy"). Hm: marine diatoms from Holocene surficial deposits. HTm: marine diatoms from Holocene surficial deposits or Tertiary diatomites. Tm: Extinct marine diatoms from Tertiary diatomites. Data are from core BR-94E, except 90-100 cm, which are from 94F.

Figure 5. Stratigraphy and diatoms for De1, and "Black soupy," an enigmatic deposit of black organic ooze. Hm: marine diatoms from Holocene surficial deposits. $F W$ : benthic and planktonic freshwater diatoms. Data are from core BR-94E.

Figure 6. Stratigraphy and diatoms for De2. Hm: marine diatoms from Holocene surficial deposits. Data are from core BR-94E except for 90-100 cm which are from BR-94F.

Figure 7. Concentrations of marine and brackish diatoms for De3 and De4. Hm: marine diatoms from Holocene surficial deposits. HTm: marine diatoms from Holocene surficial deposits or Tertiary diatomites. Tm: Extinct marine diatoms from Tertiary diatomites. Data are from core BR-94E. 
Figure 8. Stratigraphy and diatoms for De4. Hm: marine diatoms from Holocene surficial deposits. Data are from core BR-94E.

Figure 9. Concentrations of marine and brackish diatoms for De5 and De6. Hm: marine diatoms from Holocene surficial deposits. HTm: marine diatoms from Holocene surficial deposits or Tertiary diatomites. Tm: Extinct marine diatoms from Tertiary diatomites. The dashed line marks an erosional contact between De5 and De6. Data are from core BR-94E.

Figure 10. Stratigraphy and diatoms for De5 and De6. Hm: marine diatoms from Holocene surficial deposits. Note the logarithmic scale for "Freshwater diatoms." The dashed line marks an erosional contact between De5 and De6. Data are from core BR-94E.

Figure 11. Concentrations of marine and brackish/high-conductivity diatoms for De7 and De8. Hm: marine diatoms from Holocene surficial deposits. HTm: marine diatoms from Holocene surficial deposits or Tertiary diatomites. Tm: Extinct marine diatoms from Tertiary diatomites. Note the logarithmic scale for "Brackish diatoms." Data are from core BR-94E.

Figure 12. Stratigraphy and diatoms for De7. Hm: marine diatoms from Holocene surficial deposits. $F W$ : benthic and planktonic freshwater diatoms. Data are from core BR-94E.

Figure 13. Stratigraphy and diatoms for De8. Hm: marine diatoms from Holocene surficial deposits. Vertical dashed lines for brackish diatoms show an estimated delineation between "background" occurrences and large increases in growth of these taxa. Data are from core BR-94E.

Figure 14. Concentrations of marine and brackish diatoms for De9 and De10. Hm: marine diatoms from Holocene surficial deposits. HTm: marine diatoms from Holocene surficial deposits or Tertiary diatomites. Tm: Extinct marine diatoms from Tertiary diatomites. Data are from core BR95BB. Numbers in parentheses represent comparable depths for core BR-94E.

Figure 15. Stratigraphy and diatoms for De9. Hm: marine diatoms from Holocene surficial deposits. $F W$ : benthic and planktonic freshwater diatoms. Data are from core BR-95BB. Numbers in parentheses represent comparable depths for core BR-94E. 
Figure 16. Stratigraphy and diatoms for De10. Hm: marine diatoms from Holocene surficial deposits. $F W$ : benthic and planktonic freshwater diatoms. Data are from core BR-95BB. Numbers in parentheses represent comparable depths for core BR-94E.

Figure 17. Concentrations of marine and brackish diatoms for De1 land De12. Hm: marine diatoms from Holocene surficial deposits. HTm: marine diatoms from Holocene surficial deposits or Tertiary diatomites. Tm: Extinct marine diatoms from Tertiary diatomites. Data are from core BR94E.

Figure 18. Stratigraphy and diatoms for De11. Hm: marine diatoms from Holocene surficial deposits. Note the logarithmic scales for "Brackish diatoms" and "Freshwater diatoms." Data are from core BR-94E.

Figure 19. Stratigraphy and diatoms for a clast of detrital peat recovered from core 94E. Horizontal dashed line shows the contact between peat containing brackish diatoms ("BD subunit") and freshwater diatoms ("FW subunit"). Note the logarithmic scales for "Brackish diatoms." Uncalibrated radiocarbon ages are reported in conventional radiocarbon years before AD 1950. This equates to an average calibrated age for the entire peat clast of 4150-3920 cal yr B.P.

Figure 20. Stratigraphy and diatoms for De12. Hm: marine diatoms from Holocene surficial deposits. $F W$ : benthic and planktonic freshwater diatoms. Data are from core BR-94E.

Figure 21. Concentrations of marine and brackish diatoms for De13 and De14. Hm: marine diatoms from Holocene surficial deposits. HTm: marine diatoms from Holocene surficial deposits or Tertiary diatomites. Tm: Extinct marine diatoms from Tertiary diatomites. Data are from core BR95X. Numbers in parentheses represent comparable depths for core BR-94E.

Figure 22. Stratigraphy and diatoms for De13. Hm: marine diatoms from Holocene surficial deposits. $F W$ : benthic and planktonic freshwater diatoms. Note the logarithmic scales for the brackish and freshwater diatom data. Vertical dashed lines for brackish diatoms show boundary between "background" levels and possible blooms of these taxa. Data are from core BR-95X. Numbers in parentheses represent comparable depths for core BR-94E. 
Figure 23. Stratigraphy and freshwater diatoms for De14. Data are from core BR-95X. Numbers in parentheses represent comparable depths for core BR-94E.

Figure 24. Concentrations of marine and brackish diatoms for De15, De16, and De17. Hm: marine diatoms from Holocene surficial deposits. HTm: marine diatoms from Holocene surficial deposits or Tertiary diatomites. Tm: Extinct marine diatoms from Tertiary diatomites. Data are from core BR-94E.

Figure 25. Stratigraphy and diatoms for De16. $F W$ : benthic and planktonic freshwater diatoms. Vertical dashed lines for benthic diatoms show boundary between "background" levels and possible blooms of these taxa. Data are from core BR-94E.

Figure 26. Concentrations of freshwater diatoms and calibrated ages (Nelson et al., 1998) for De15, De16, and De17. The appearance of planktonic diatoms ca. 7200 years ago records a transition from marshy wetland to lake. Data are from core BR-94E.

Figure 26. Concentrations of freshwater and brackish diatoms for De15, De16, and De17. Data are from core BR-94E. 
TABLE 1

\begin{tabular}{|c|c|c|c|c|c|}
\hline Event & $\begin{array}{c}\text { Age } \\
\text { (calibrated } \\
\text { years BP) }\end{array}$ & Hm & $\begin{array}{c}\text { CYCME } \\
\mathbf{N}\end{array}$ & THABRA & $\begin{array}{c}\text { MASEL } \\
\text { L }\end{array}$ \\
\hline "Black soupy" & & & - & - & \\
\hline De1 & 250 & $\square$ & & & \\
\hline De2 & $995-920$ & Q & & - & - \\
\hline De3 & $1130-980$ & & & & \\
\hline De4 & $1510-1320$ & Q & & • & • \\
\hline De5 & $1820-1600$ & ए & B & B & B \\
\hline De6 & $1820-1600$ & Q & & B & - \\
\hline De7 & $2860-2750$ & T & & - & \\
\hline De8 & $3250-3060$ & Q & B & B & \\
\hline De9 & $3400-3210$ & (口) & $\bullet$ & B & \\
\hline De10 & $3830-3630$ & (口) & $\cdot$ & $\cdot$ & $\cdot$ \\
\hline De11 & $4280-4000$ & Q & B & • & B \\
\hline De12 & $4410-4230$ & Q & B & B & • \\
\hline De13 & $4650-4420$ & T & $\mathrm{B}$ & $\cdot$ & $\cdot$ \\
\hline De14 & $4780-4540$ & & & • & • \\
\hline De15 & $5600-5320$ & & & & $\cdot$ \\
\hline De16 & $6510-6310$ & & B & B & • \\
\hline De17 & $7390-7220$ & Q & • & B & - \\
\hline
\end{tabular}

Table 1. Summary of post-disturbance-event occurrences for modern marine and brackish diatoms. Ages are from Nelson et al., 2000. Hm: modern marine diatoms; parentheses indicate very rare occurrences ( $>10^{3}$ valves/cc). Brackish diatoms: Cyclotella meneghiniana (CYCMEN), Thalassiosira bramaputrae (THABRA), and Mastogloia smithii (MASSMI). "B" = substantial increases or blooms following events. "•" = numbers not exceeding "background" levels, $<10^{4}$ valves/cc. 
TABLE 2

\begin{tabular}{|c|c|c|c|}
\hline & $\begin{array}{c}\text { Sample } \\
\text { (BR-94E) }\end{array}$ & Lithology & Diatoms \\
\hline & $363 \mathrm{~cm}$ & $\begin{array}{l}\text { Intermittently } \\
\text { laminated mud }\end{array}$ & $\begin{array}{l}\text { Diverse freshwater diatoms; rare brackish } \\
\text { diatoms }\end{array}$ \\
\hline & $365 \mathrm{~cm}$ & Massive mud & $\begin{array}{l}\text { Abundant benthic and planktonic } \\
\text { freshwater diatoms; rare brackish } \\
\text { diatoms }\end{array}$ \\
\hline & $370 \mathrm{~cm}$ & $\begin{array}{l}\text { Transition from muddy } \\
\text { detrital peat to massive } \\
\text { mud }\end{array}$ & $\begin{array}{l}\text { Abundant benthic and planktonic } \\
\text { freshwater diatoms; rare brackish } \\
\text { diatoms }\end{array}$ \\
\hline Peat clast & $375 \mathrm{~cm}$ & $\begin{array}{l}\text { Muddy detrital peat } \\
\text { (BD subunit) }\end{array}$ & $\begin{array}{l}\text { Abundant } M \text {. smithii plus other benthic } \\
\text { brackish species; } T \text {. bramaputrae and } \\
\text { C. meneghiniana present but rare); } \\
\text { rare freshwater diatoms. }\end{array}$ \\
\hline Peat clast & $380 \mathrm{~cm}$ & $\begin{array}{l}\text { Muddy detrital peat } \\
\text { ( } F W \text { subunit) }\end{array}$ & $\begin{array}{l}\text { Abundant large freshwater marsh diatoms; } \\
\text { common sponge spicules; preservation } \\
\text { moderate to poor. }\end{array}$ \\
\hline Peat clast & $385 \mathrm{~cm}$ & $\begin{array}{l}\text { Muddy detrital peat } \\
\text { (FW subunit) }\end{array}$ & $\begin{array}{l}\text { Abundant large freshwater marsh diatoms; } \\
\text { common sponge spicules; preservation } \\
\text { poor (severe valve fragmentation). }\end{array}$ \\
\hline Peat clast & $390 \mathrm{~cm}$ & $\begin{array}{l}\text { Muddy detrital peat } \\
\text { (FW subunit) }\end{array}$ & $\begin{array}{l}\text { Abundant large freshwater marsh diatoms; } \\
\text { common sponge spicules; preservation } \\
\text { poor (severe valve fragmentation). }\end{array}$ \\
\hline Peat clast & $395 \mathrm{~cm}$ & $\begin{array}{l}\text { Muddy detrital peat } \\
\text { (FW subunit) }\end{array}$ & $\begin{array}{l}\text { Abundant large freshwater marsh diatoms; } \\
\text { common sponge spicules; preservation } \\
\text { poor (severe valve fragmentation). }\end{array}$ \\
\hline \multirow[t]{3}{*}{ Peat clast } & $400 \mathrm{~cm}$ & $\begin{array}{l}\text { Muddy detrital peat } \\
\text { (FW subunit) }\end{array}$ & $\begin{array}{l}\text { Diverse freshwater diatoms and sponge } \\
\text { spicules; preservation good. }\end{array}$ \\
\hline & $402 \mathrm{~cm}$ & $\begin{array}{l}\text { Intermittently } \\
\text { laminated mud }\end{array}$ & $\begin{array}{l}\text { Diatoms rare relative to mud, mostly small } \\
\text { freshwater planktonic species; } \\
\text { preservation moderate to poor. }\end{array}$ \\
\hline & $404 \mathrm{~cm}$ & $\begin{array}{l}\text { Intermittently } \\
\text { laminated mud }\end{array}$ & $\begin{array}{l}\text { Diatoms rare relative to mud, mostly small } \\
\text { freshwater planktonic species; } \\
\text { preservation moderate to poor. }\end{array}$ \\
\hline
\end{tabular}

Table 2. Sample descriptions and summary of diatom analyses for a clast of muddy detrital peat recovered from $373 \mathrm{~cm}$ to $401 \mathrm{~cm}$ in core BR-94E. BD: Brackish diatoms. $F W$ : Freshwater diatoms. 
TABLE 3

\begin{tabular}{|c|c|c|c|c|}
\hline $\begin{array}{c}\text { Disturbance } \\
\text { Event }\end{array}$ & $\begin{array}{c}\text { Finely } \\
\text { laminated mud } \\
\text { superjacent to } \\
\text { De? }\end{array}$ & $\begin{array}{c}\text { Hm diatoms } \\
\text { present (i.e., } \\
\text { diatom evidence } \\
\text { for tsunami?) }\end{array}$ & $\begin{array}{c}\text { Brackish } \\
\text { diatoms } \\
\text { common in } \\
\text { finely } \\
\text { laminated } \\
\text { mud? }\end{array}$ & $\begin{array}{c}\text { Freshwater } \\
\text { diatoms } \\
\text { decrease in } \\
\text { finely laminated } \\
\text { mud? }\end{array}$ \\
\hline De2 & $\mathrm{Y}$ & $\mathrm{Y}$ & $\mathrm{N}$ & $\mathrm{Y}$ \\
\hline De4 & $\mathrm{Y}$ & $\mathrm{Y}$ & $\mathrm{Y}$ & $\mathrm{Y}$ \\
\hline De5 & $\mathrm{Y}$ & $\mathrm{Y}$ & $\mathrm{N}$ & $\mathrm{Y}$ \\
\hline De7 & $\mathrm{Y}$ & $\mathrm{Y}$ & $\mathrm{Y}$ & $\mathrm{Y}$ \\
\hline De8 & $\mathrm{Y}$ & $\mathrm{Y}$ & $\mathrm{N}$ & $\mathrm{Y}$ \\
\hline De9 & $\mathrm{Y}$ & $\mathrm{Y}$ & $\mathrm{Y}$ & $\mathrm{Y}$ \\
\hline De10 & $\mathrm{Y}$ & $\mathrm{Y}$ & $\mathrm{Y}$ & $\mathrm{Y}$ \\
\hline De11 & $\mathrm{Y}$ & $\mathrm{Y}$ & $\mathrm{Y}$ & (negligible) \\
\hline De12 & $\mathrm{Y}$ & $\mathrm{Y}$ & $\mathrm{N}$ & $\mathrm{Y}$ \\
\hline De13 & $\mathrm{Y}$ & $\mathrm{N}$ & $\mathrm{Y}$ & $\mathrm{Y}$ \\
\hline De16 & $\mathrm{Y}$ & $\mathrm{Y}$ & $\mathrm{Y}$ & $\mathrm{Y}$ \\
\hline
\end{tabular}

Table 3. Comparison of disturbance events that have overlying units of finely laminated mud. 

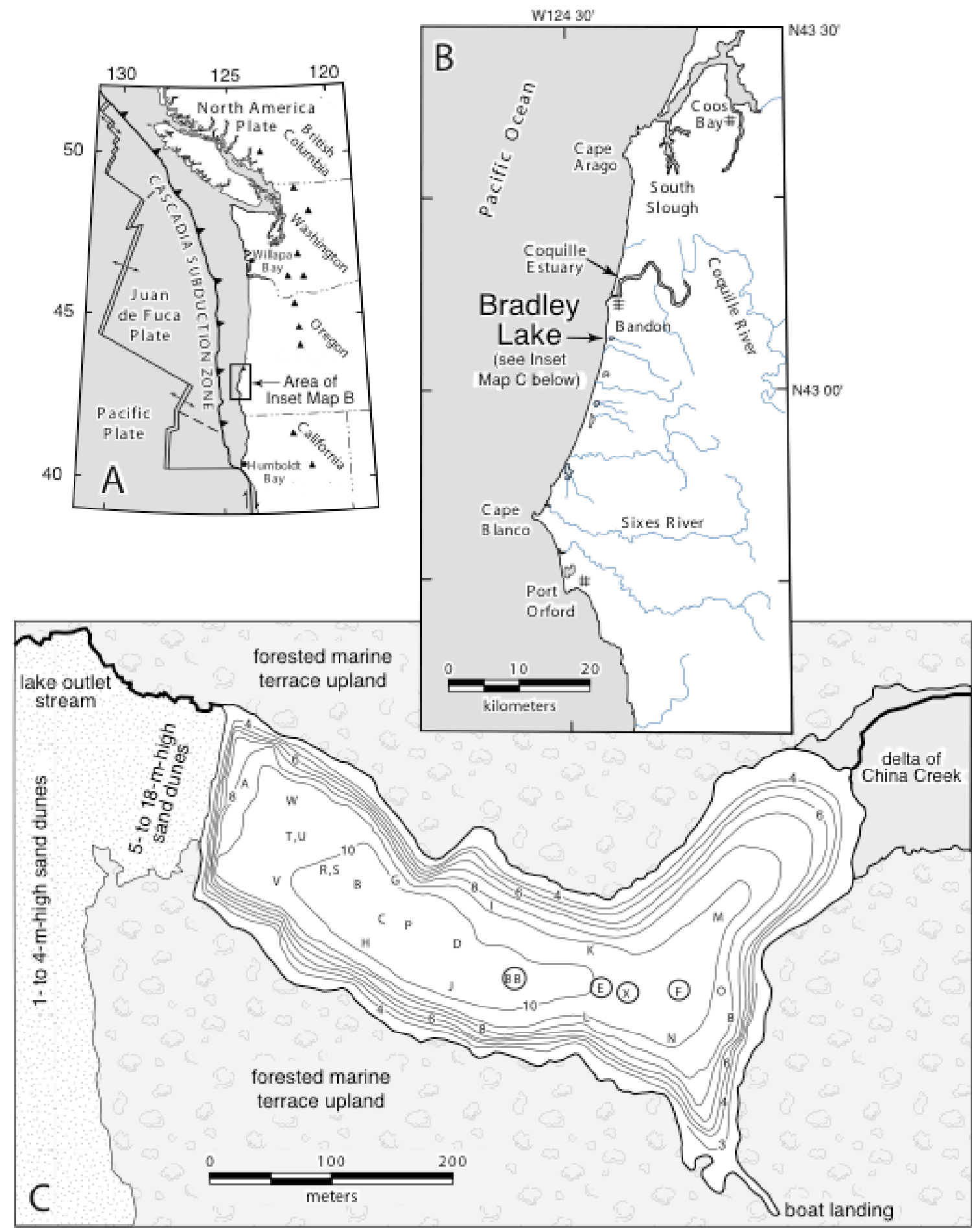

Figure1. Location of Bradley Lake, Oregon, relative to the Cascadia subduction zone (A) and the Oregon coast (B). The boot-shaped lake (C) formed when coastal dunes blocked the channel of China Creek. Numbers on contour lines are depth in meters; letters show core locations. Cores used in this report are circled. 


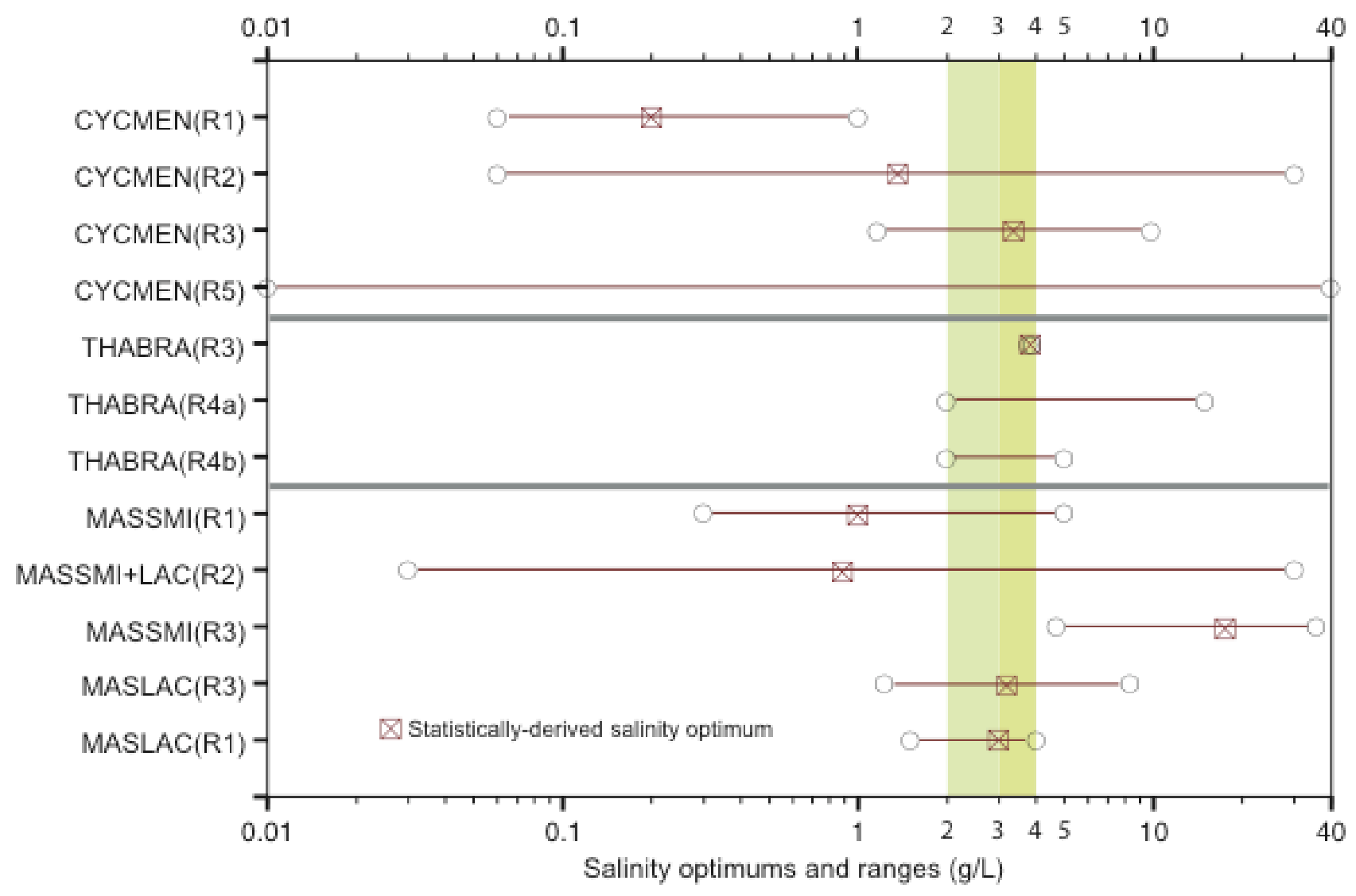

Figure 2. Salinity ranges for brackish-water diatoms from Bradley Lake, based on modern occurrences in lakes and estuaries. CYCMEN: Cyclotella meneghiniana. THABRA: Thalassiosira bramaputrae. MASSMI, MASLAC: Mastogloia smithii $+M$. smithii var. lacustris. References: Cumming and Smol, 1993 (R1); Wilson et al., 1995 (R2); Fritz et al., 1993 (R3); John, 1983 (R4); Carpelan, 1978 (R5). 


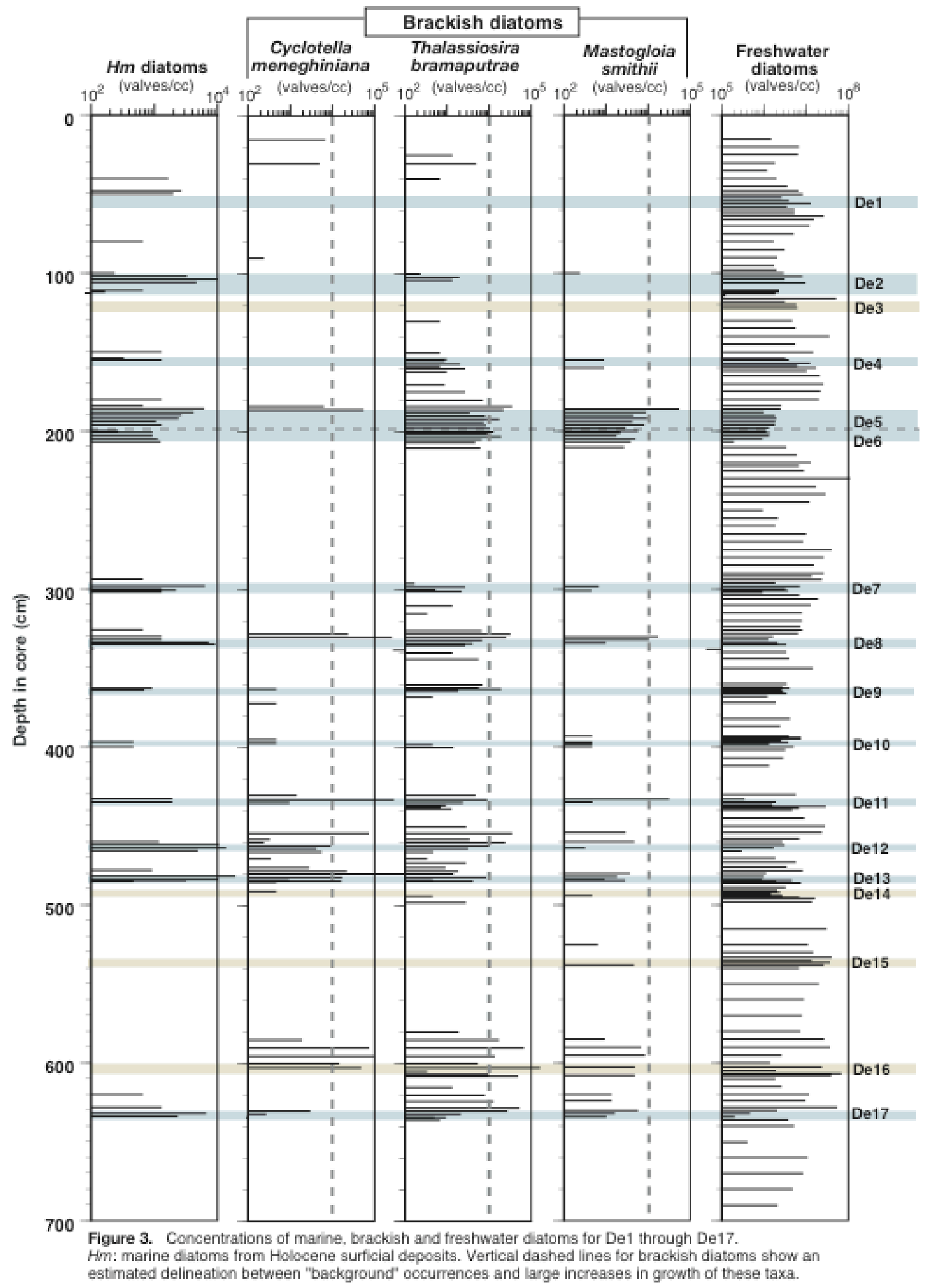




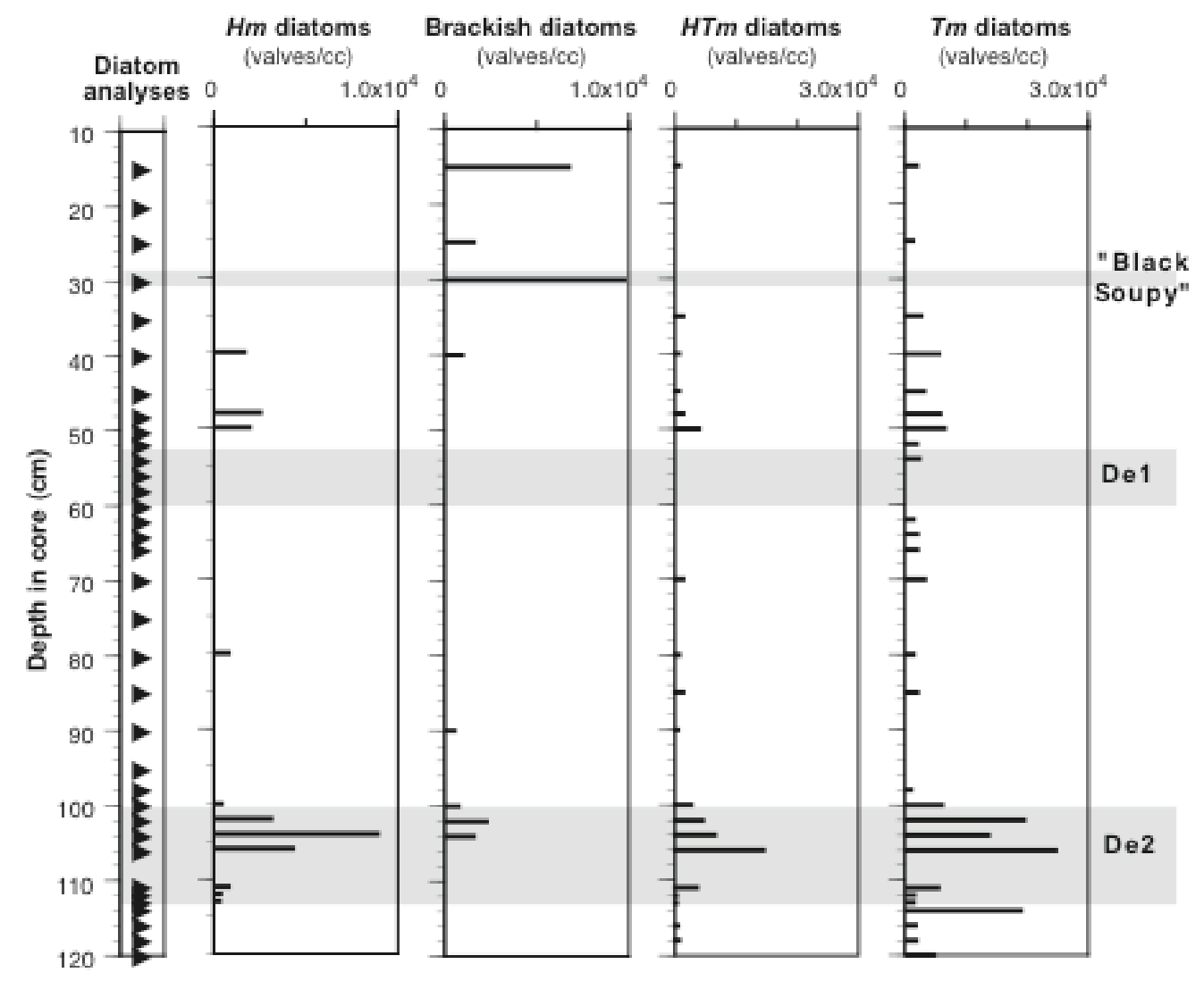

Figure 4. Concentrations of marine and brackish diatoms for De1, De2, and an enigmatic post-De1 event ("Black Soupy"). Hm: marine diatoms from Holocene surficial deposits. HTm: extant marine diatoms from Holocene surficial deposits or Tertiary diatomites. Tm: extinct marine diatoms from Tertiary diatomites. Data are from core BR-94E, except $90-100 \mathrm{~cm}$, which are from $94 \mathrm{~F}$. 


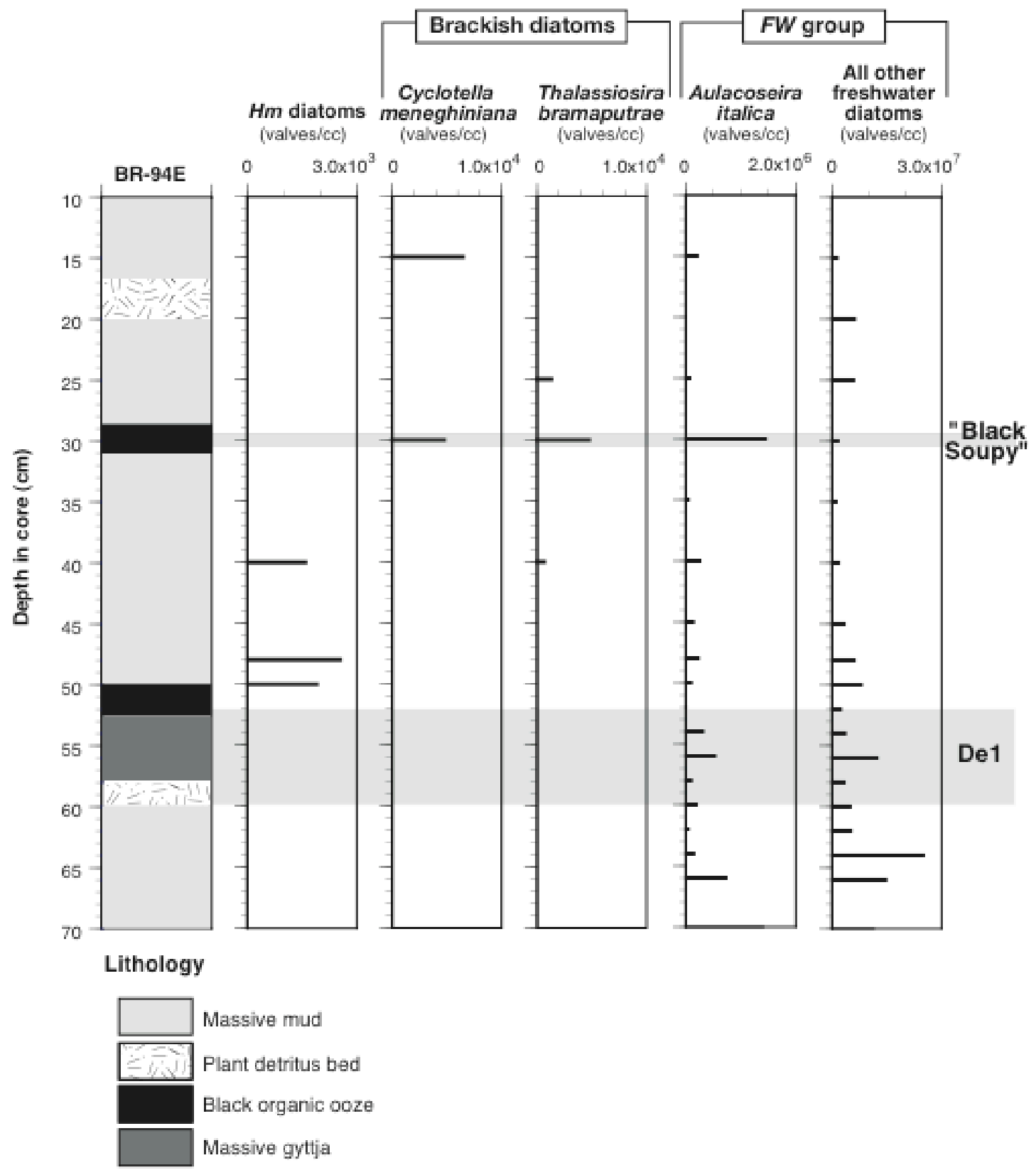

Figure 5. Stratigraphy and diatoms for De1, and "Black Soupy," an enigmatic deposit of black organic ooze. Hm: marine diatoms from Holocene surficial deposits.

FW: benthic and planktonic freshwater diatoms. Data are from core BR-94E. 

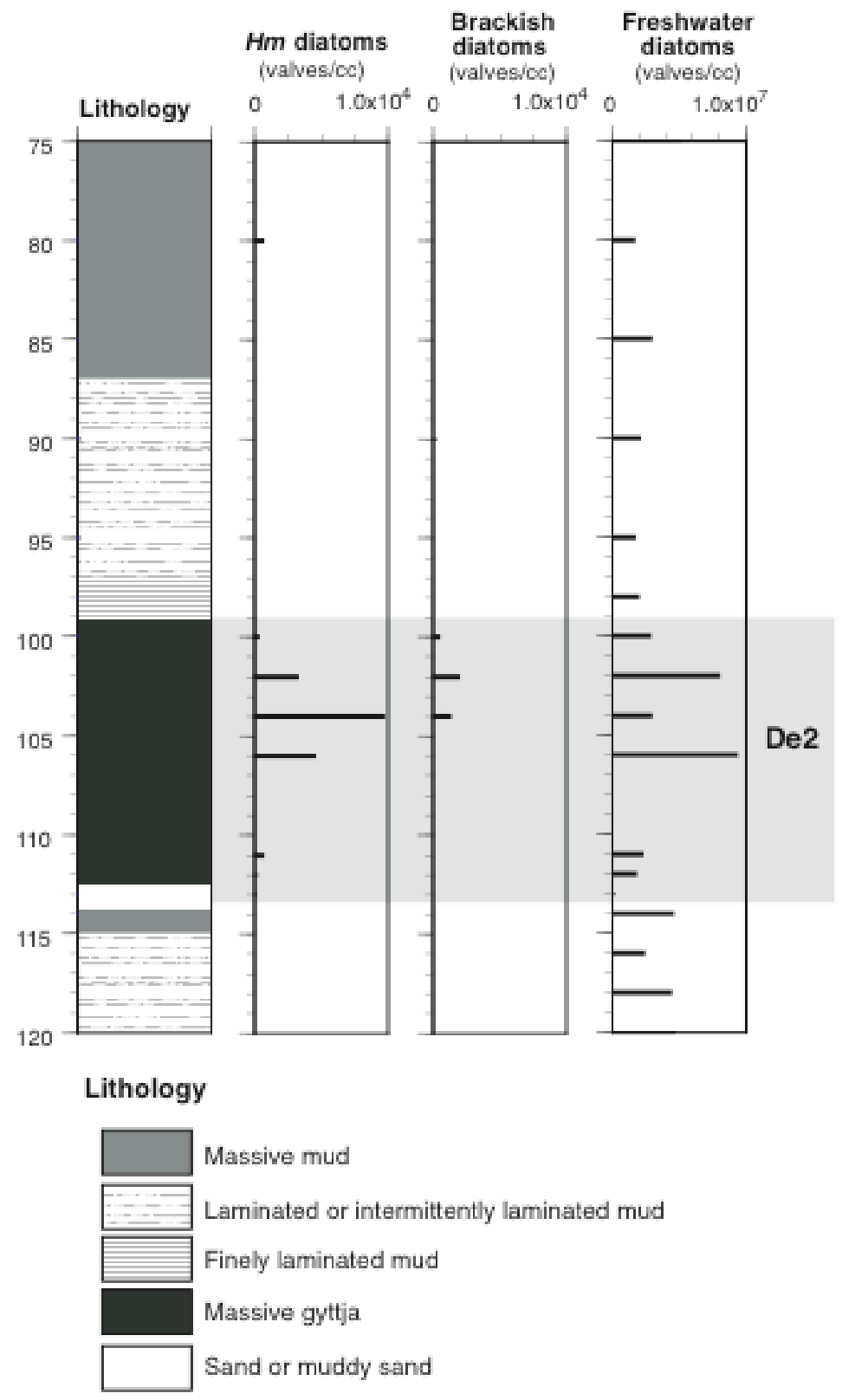

Figure 6. Stratigraphy and diatoms for De2. Hm: marine diatoms from Holocene surficial deposits. Data are from core BR-94E, except for $90-100 \mathrm{~cm}$, which are from BR-94F. 


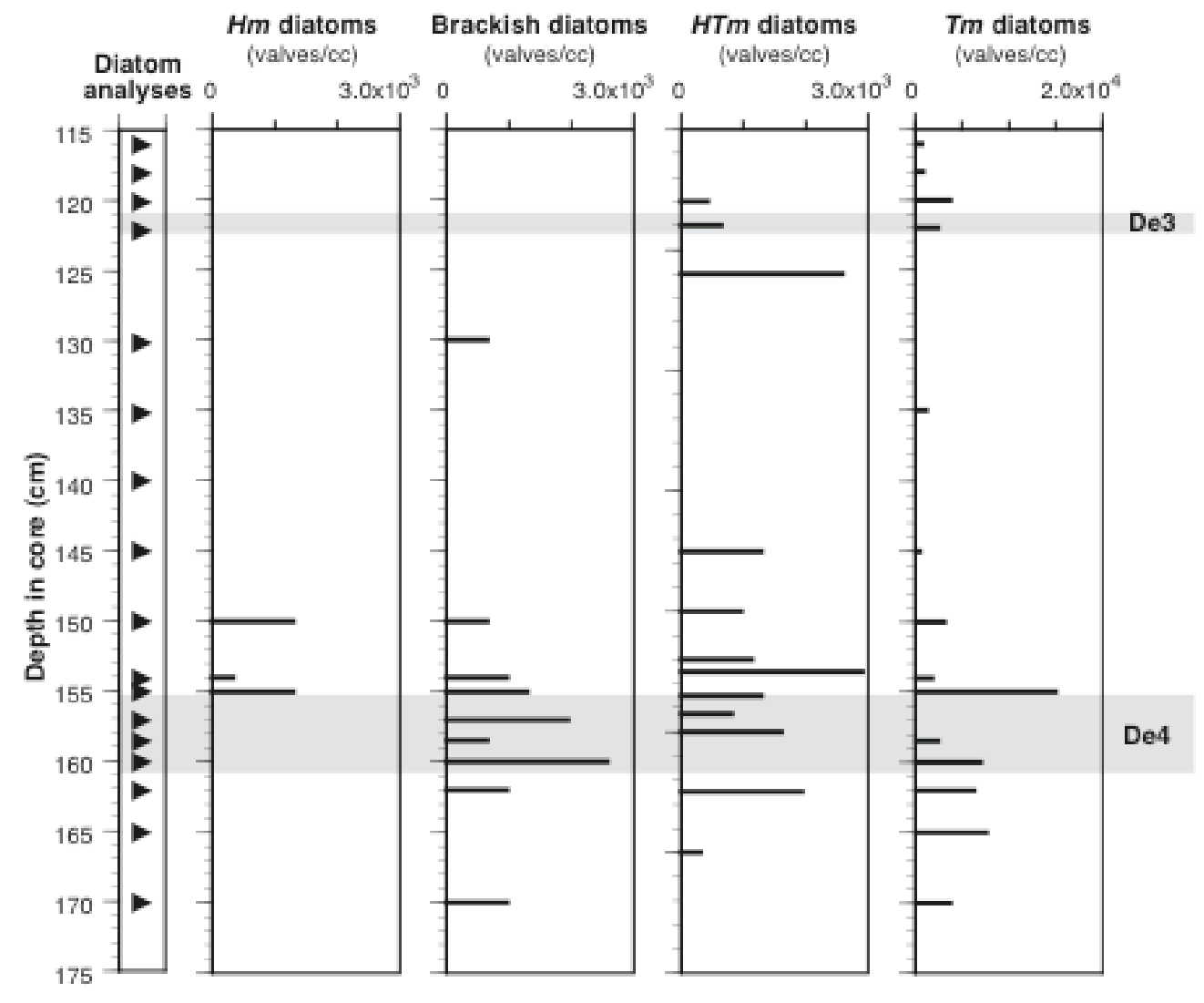

Figure 7. Concentrations of marine and brackish diatoms for De3 and De4. Hm: marine diatoms from Holocene surficial deposits. HTm: extant marine diatoms from Holocene surficial deposits or

Tertiary diatomites. Tm: extinct marine diatoms from Tertiary diatomites. Data are from core BR-94E. 


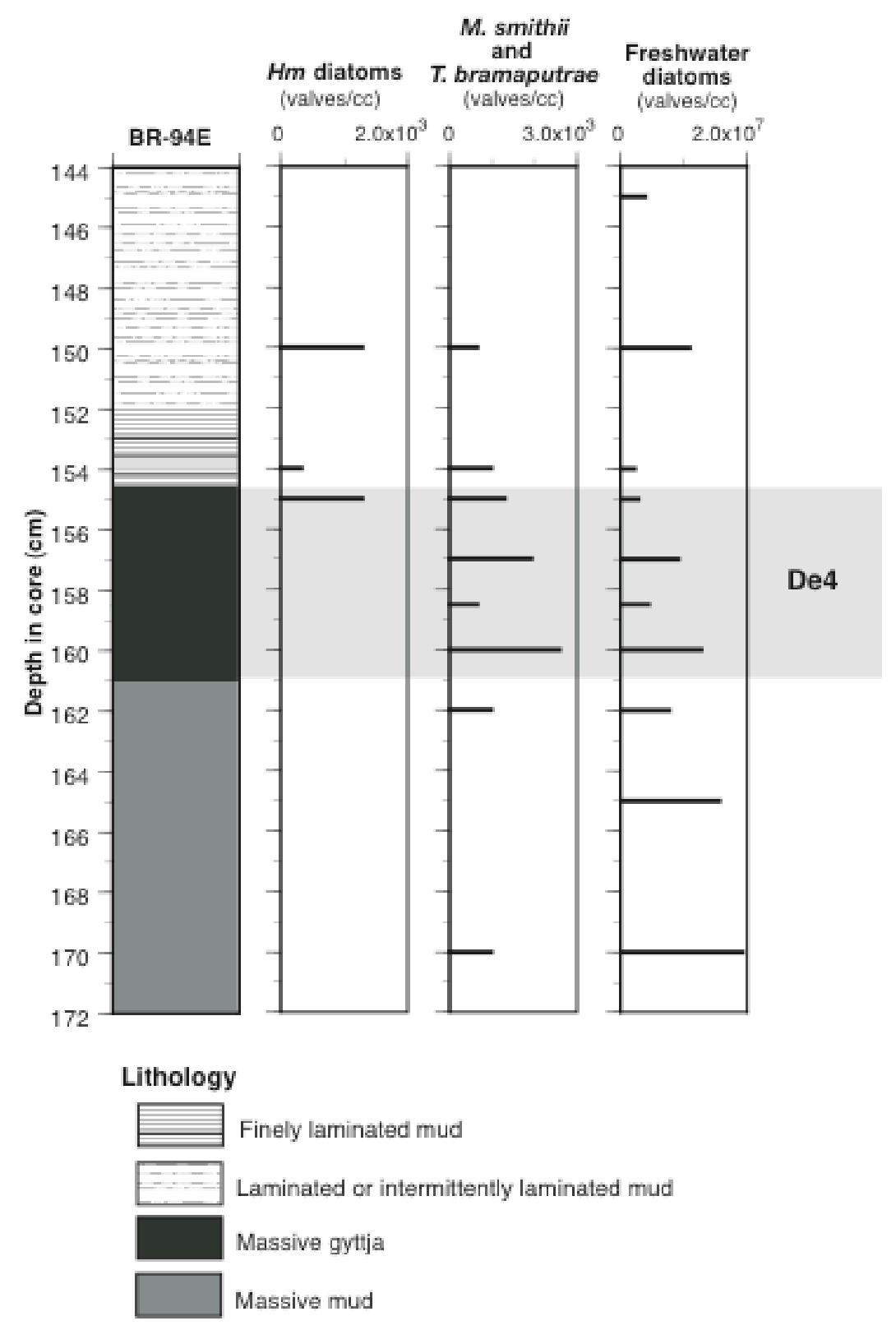

Figure 8. Stratigraphy and diatoms for De4. Him: marine diatoms from Holocene surficial deposits. Data are from core BR-94E. 


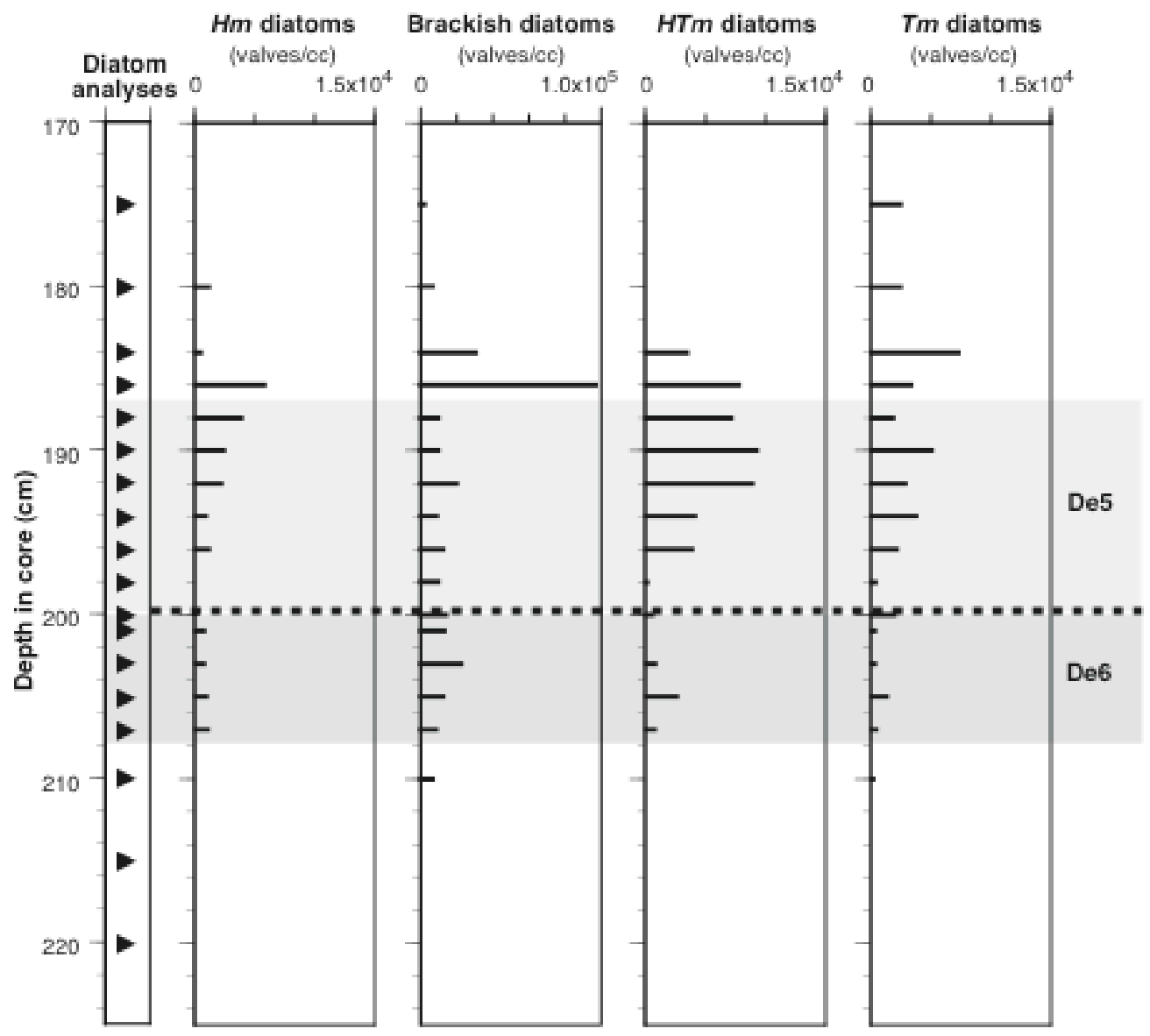

Figure 9. Concentrations of marine and brackish diatoms for De5 and De6.

Hm: marine diatoms from Holocene surficial deposits. HTm: extant marine diatoms from Holocene surficial deposits or Tertiary diatomites. Tm: extinct marine diatoms from Tertiary diatomites. The dashed line marks an erosional contact between De5 and De6. Data are from core BR-94E. 


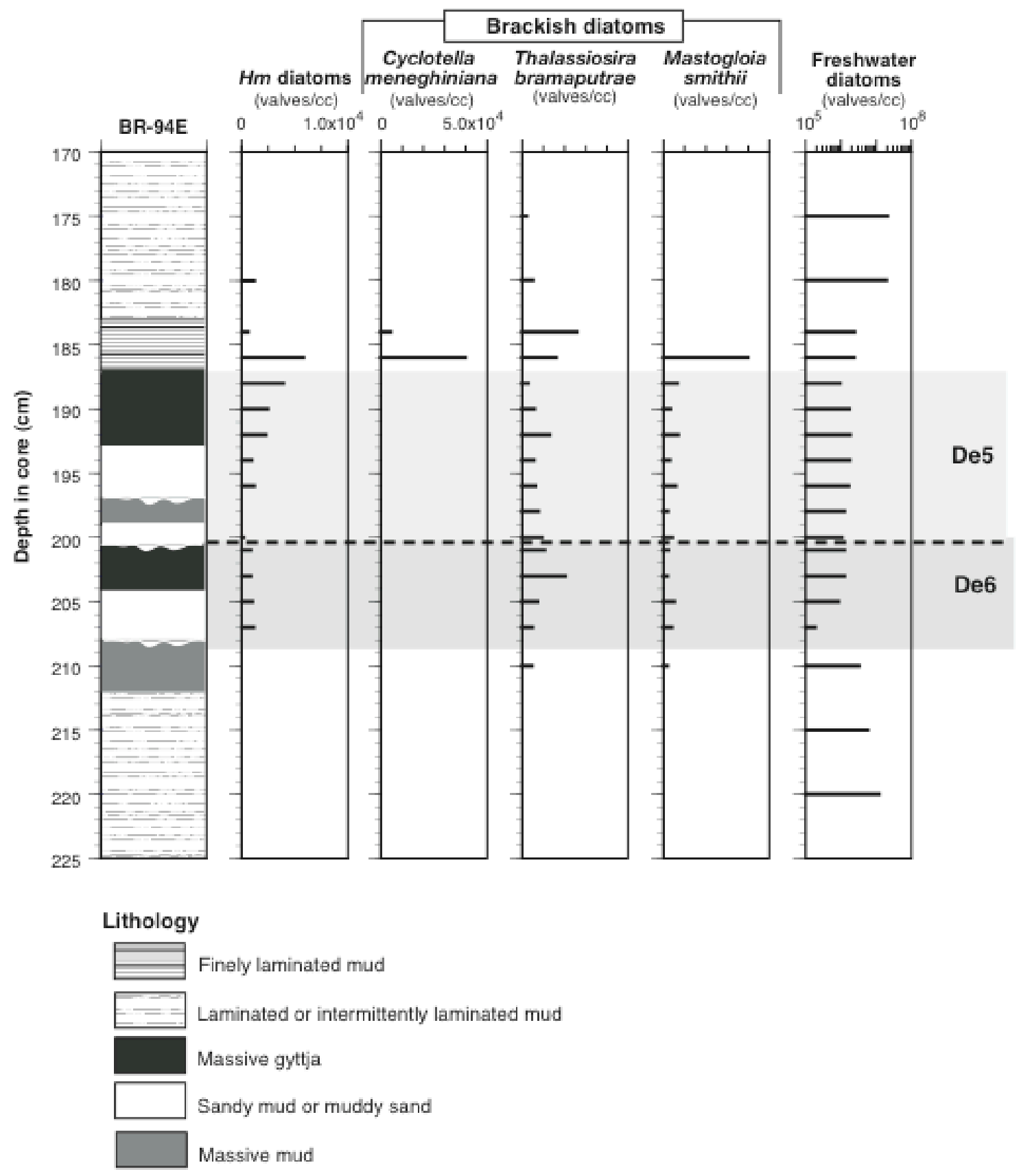

Figure 10. Stratigraphy and diatoms for De5 and De6. Him: marine diatoms from Holocene surficial deposits. Note the logarithmic scale for "Freshwater diatoms." The dashed line marks an erosional contact between De5 and De6. Data are from core BR-94E. 


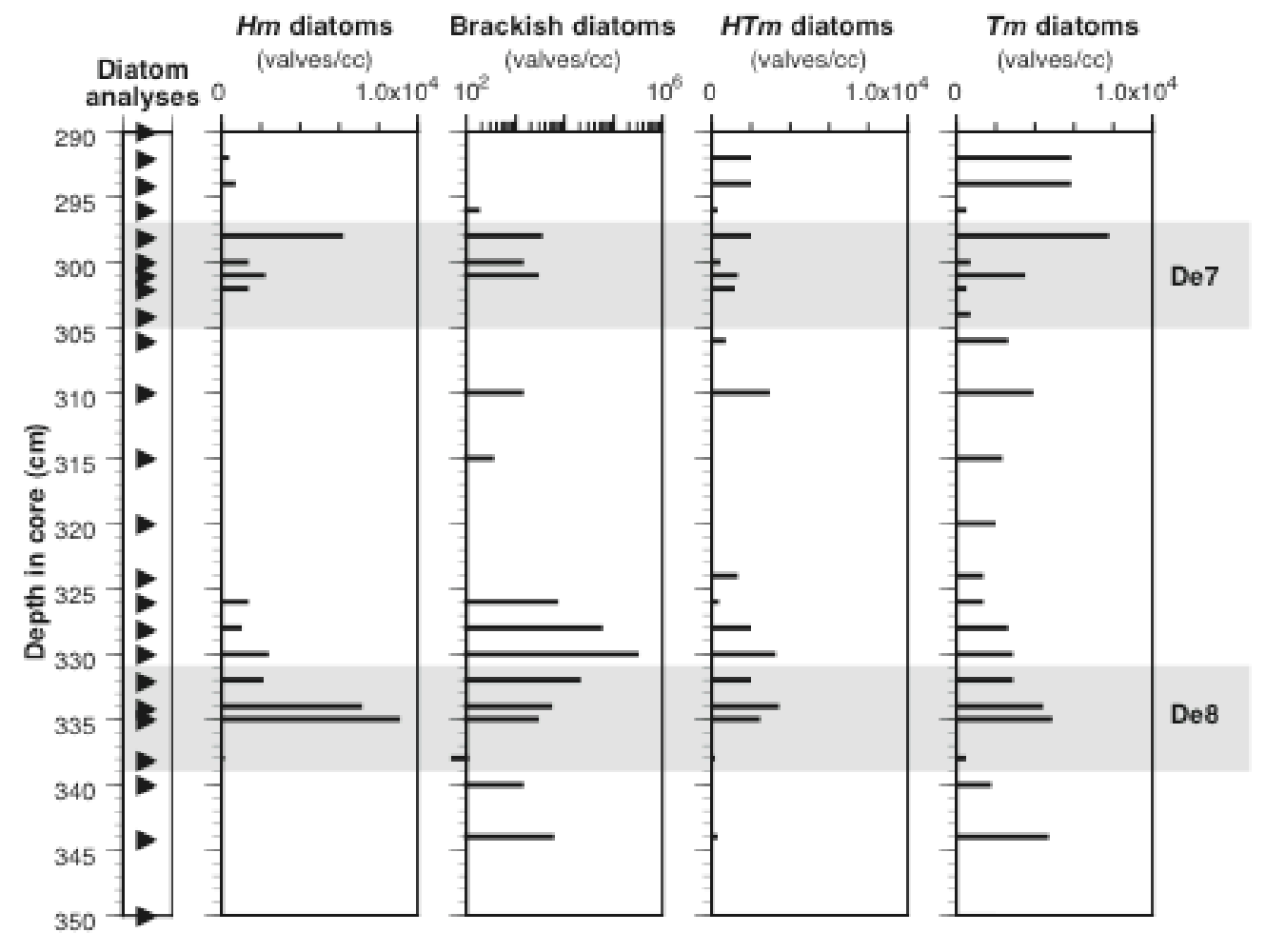

Figure 11. Concentrations of marine and brackish diatoms for De7 and De8.

$\mathrm{Hm}$ : marine diatoms from Holocene surficial deposits. HTm: extant marine diatoms from

Holocene surficial deposits or Tertiary diatomites. Tm: extinct marine diatoms from Tertiary diatomites. Note the logarithmic scale for "Brackish diatoms". Data are from core BR-94E. 


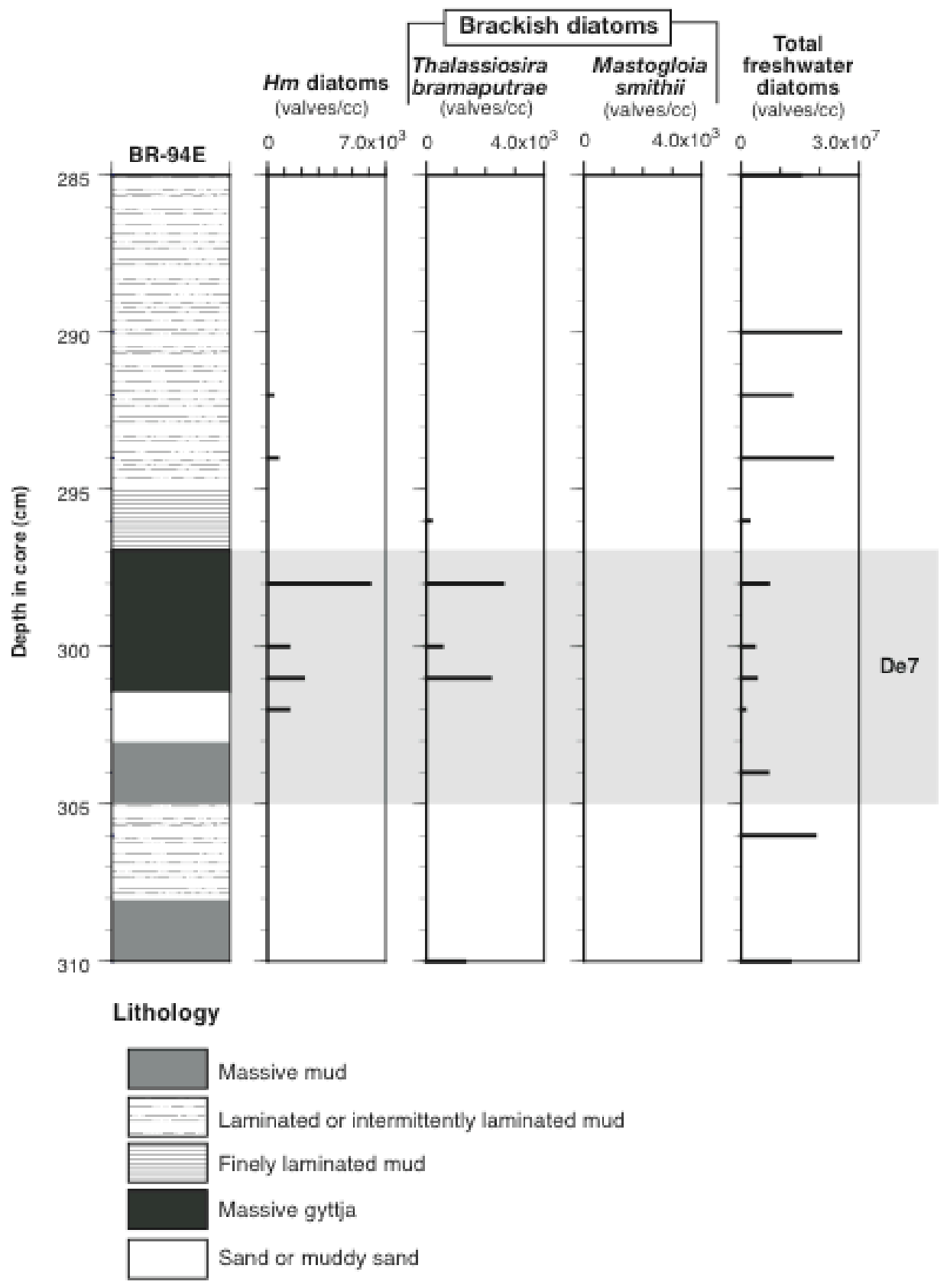

Figure 12. Stratigraphy and diatoms for De7. Hm: marine diatoms from Holocene surficial deposits. FW: benthic and planktonic freshwater diatoms. Data are from core BR-94E. 


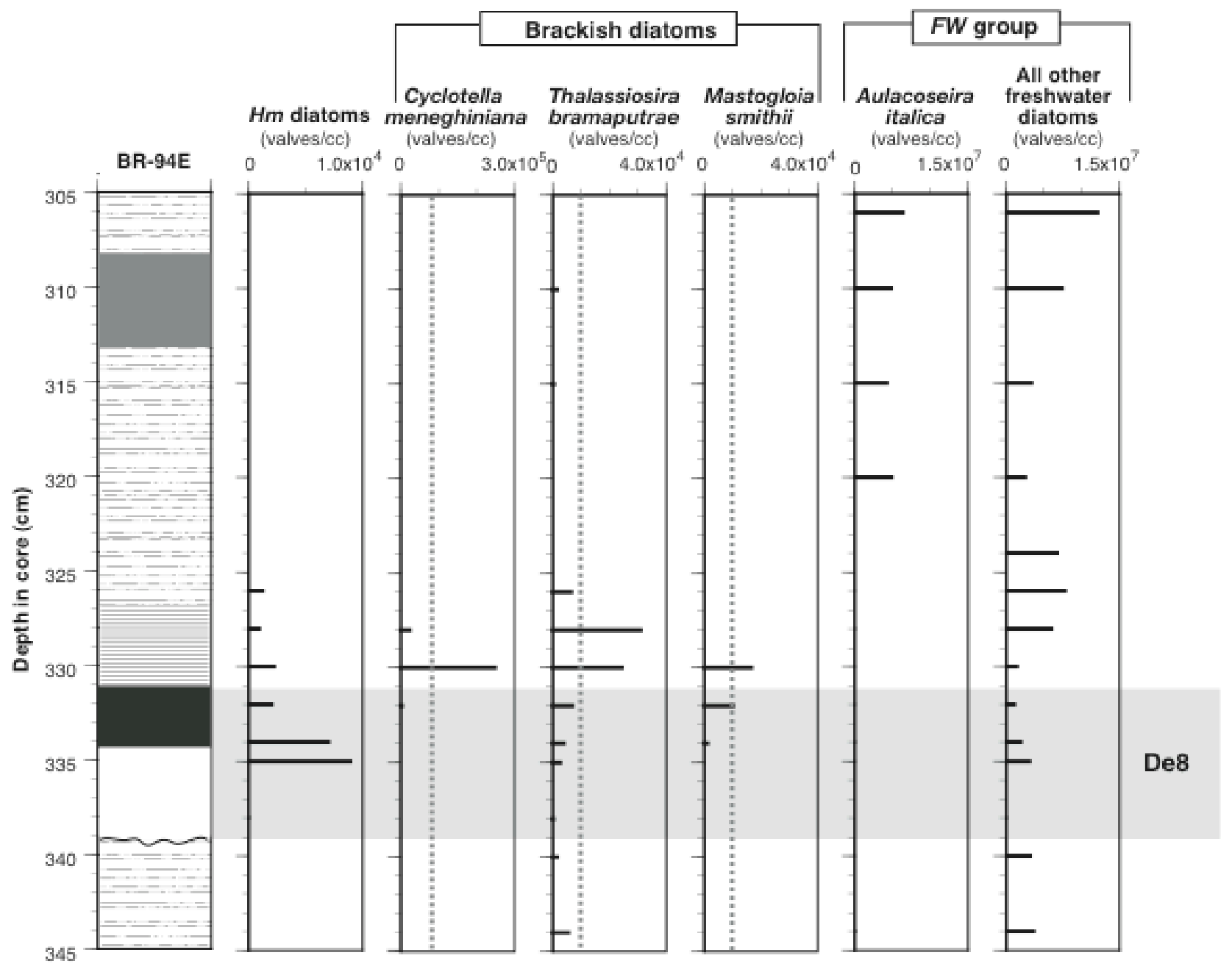

\section{Lithology}

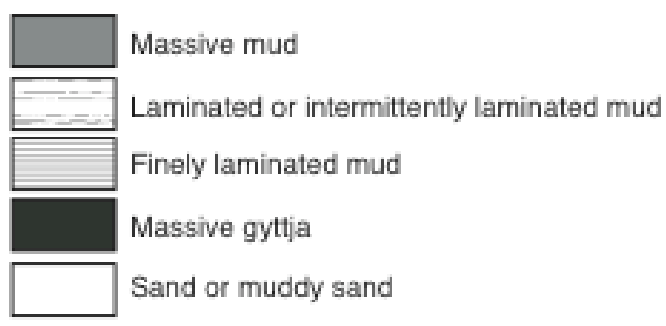

Figure 13. Stratigraphy and diatoms for De8. Hm: marine diatoms from Holocene surficial deposits. $F W$ : benthic and planktonic freshwater diatoms. Vertical dashed lines for brackish diatoms show an estimated delineation between "background" occurrences and large increases in growth of these taxa. Data are from core BR-94E. 


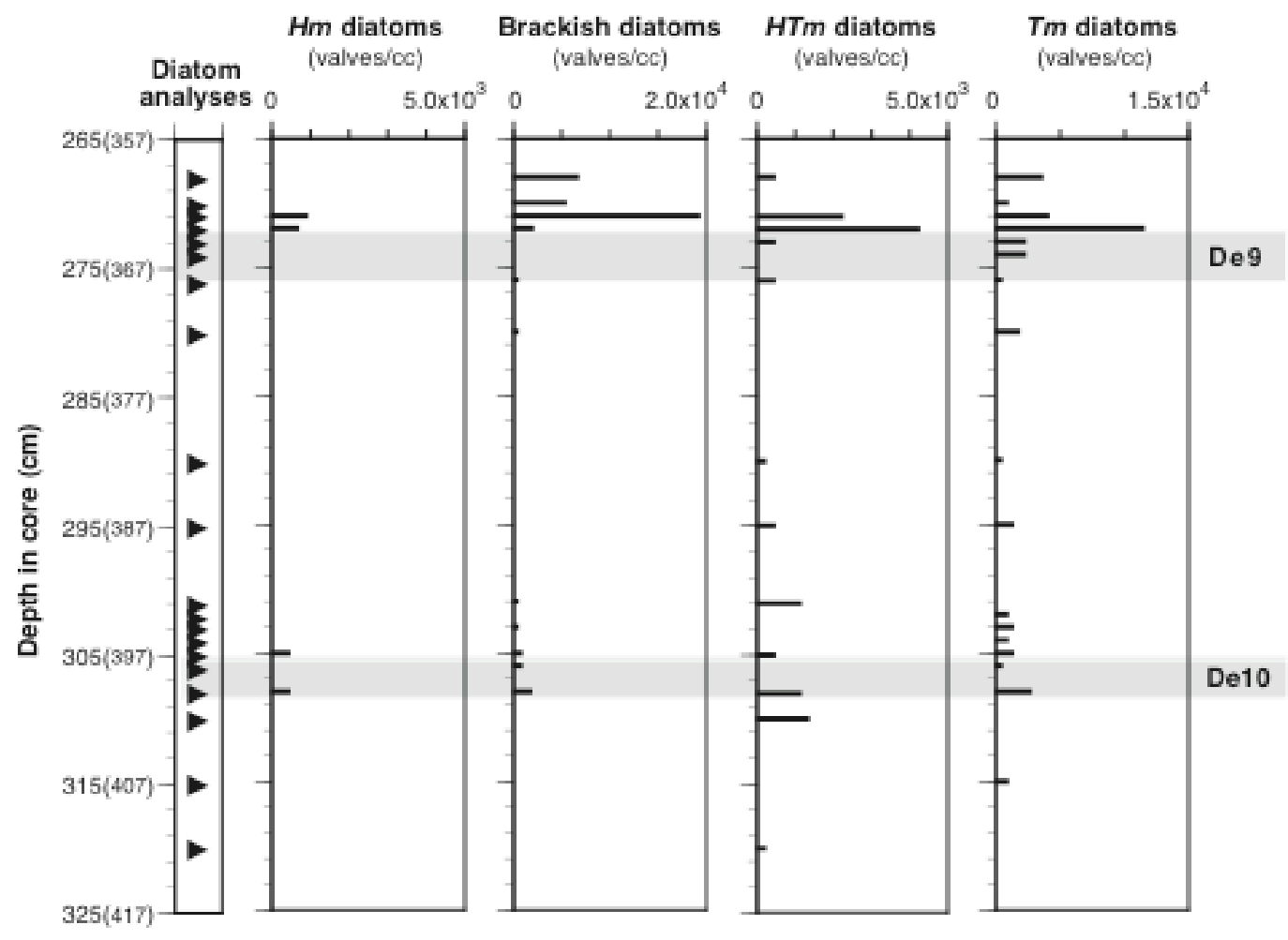

Figure 14. Concentrations of marine and brackish diatoms for De9 and De10.

$\mathrm{Hm}$ : marine diatoms from Holocene surficial deposits. HTm: extant marine diatoms from Holocene surficial deposits or Tertiary diatomites. Tm: extinct marine diatoms from Tertiary diatomites. Data are from core BR-95BB. Numbers in parentheses represent comparable depths for core BR-94E. 


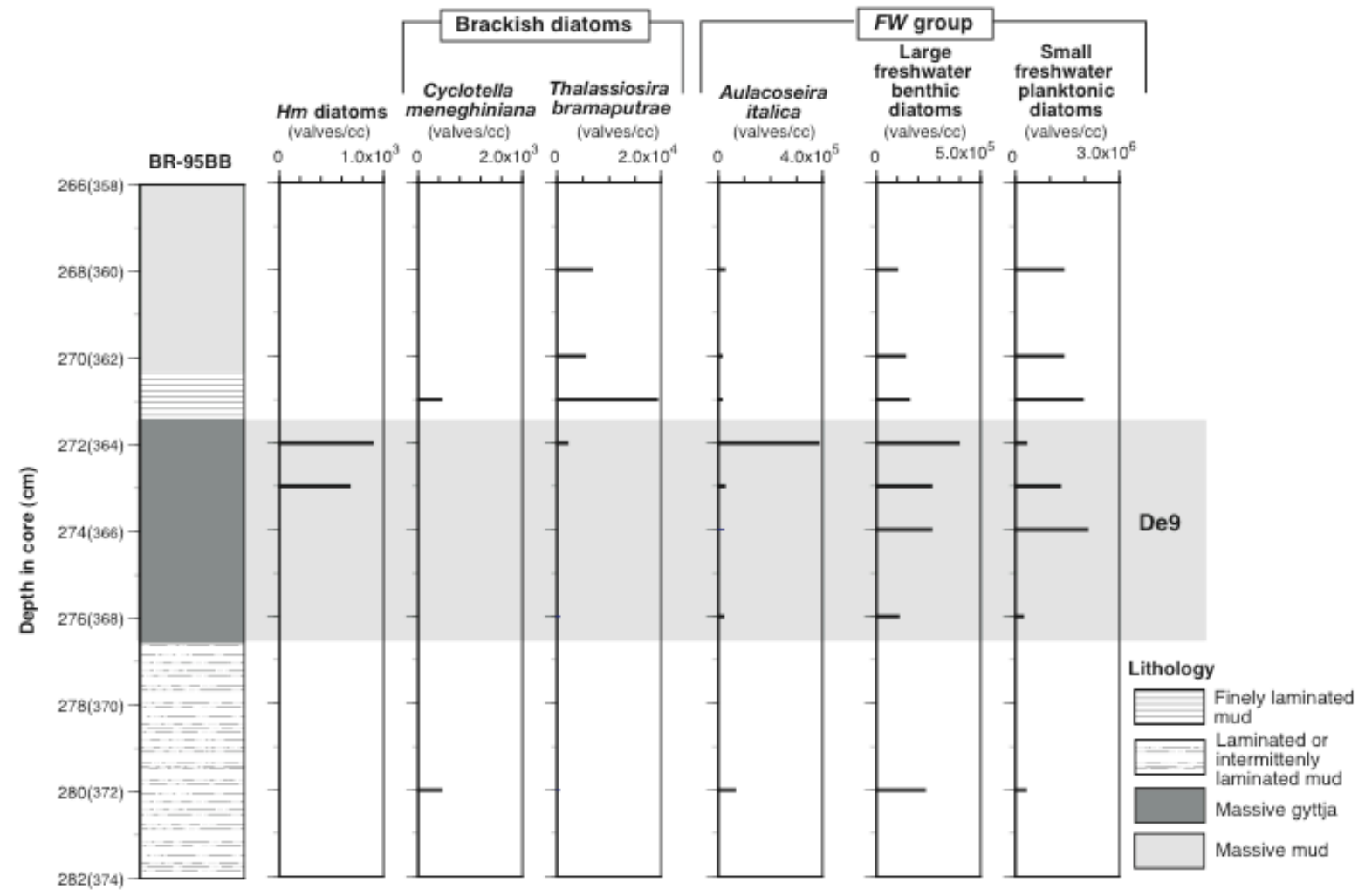

Figure 15. Stratigraphy and diatoms for De9. Hm: marine diatoms from Holocene surficial deposits. FW: benthic and planktonic freshwater diatoms. Data are from core BR-95BB. Numbers in parentheses represent comparable depths for core BR-94E. 


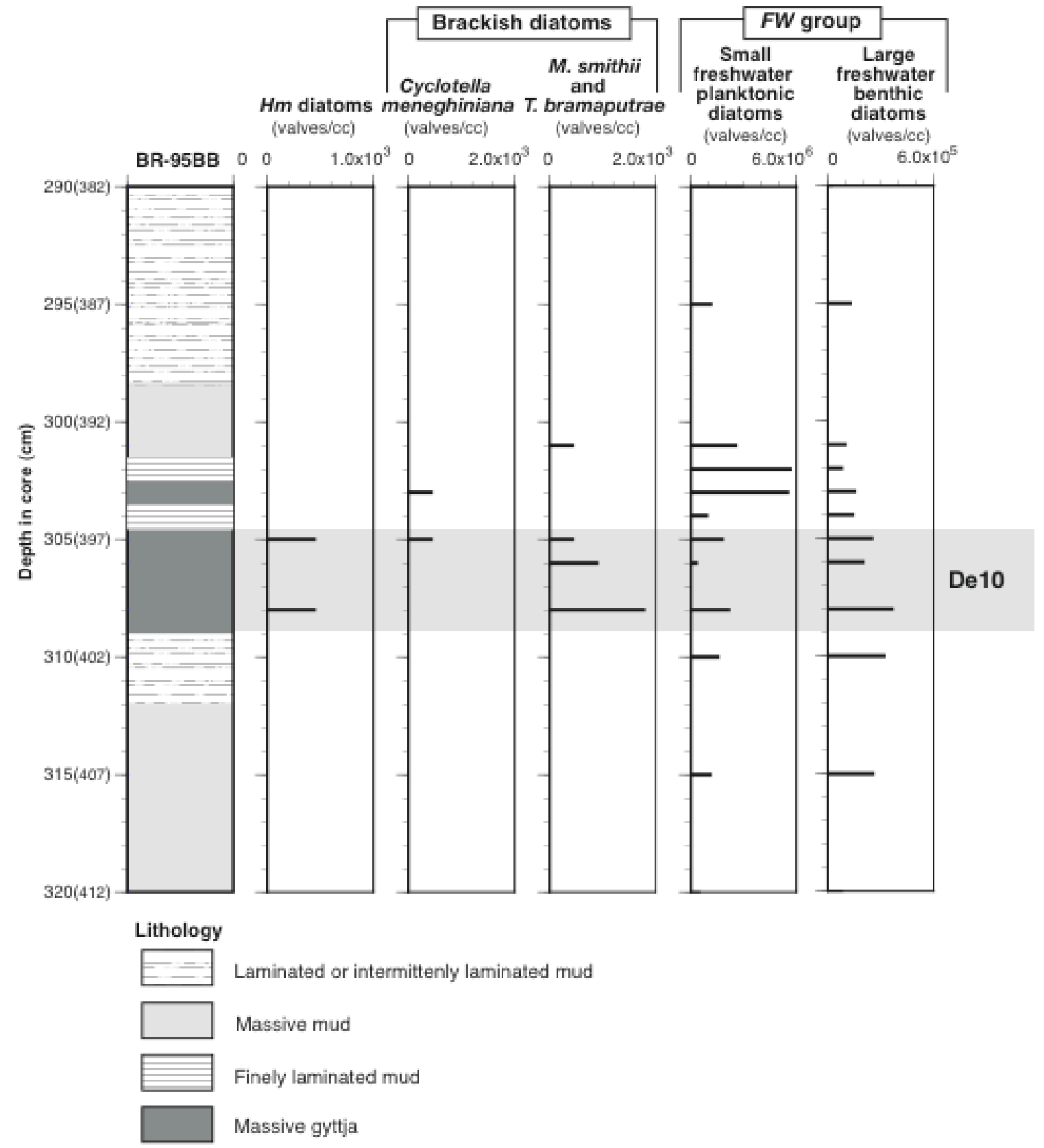

Figure 16. Stratigraphy and diatoms for De10. Hm: marine diatoms from Holocene surficial deposits. FW: benthic and planktonic freshwater diatoms. Data are from core BR-95BB. Numbers in parentheses represent comparable depths for core BR-94E. 


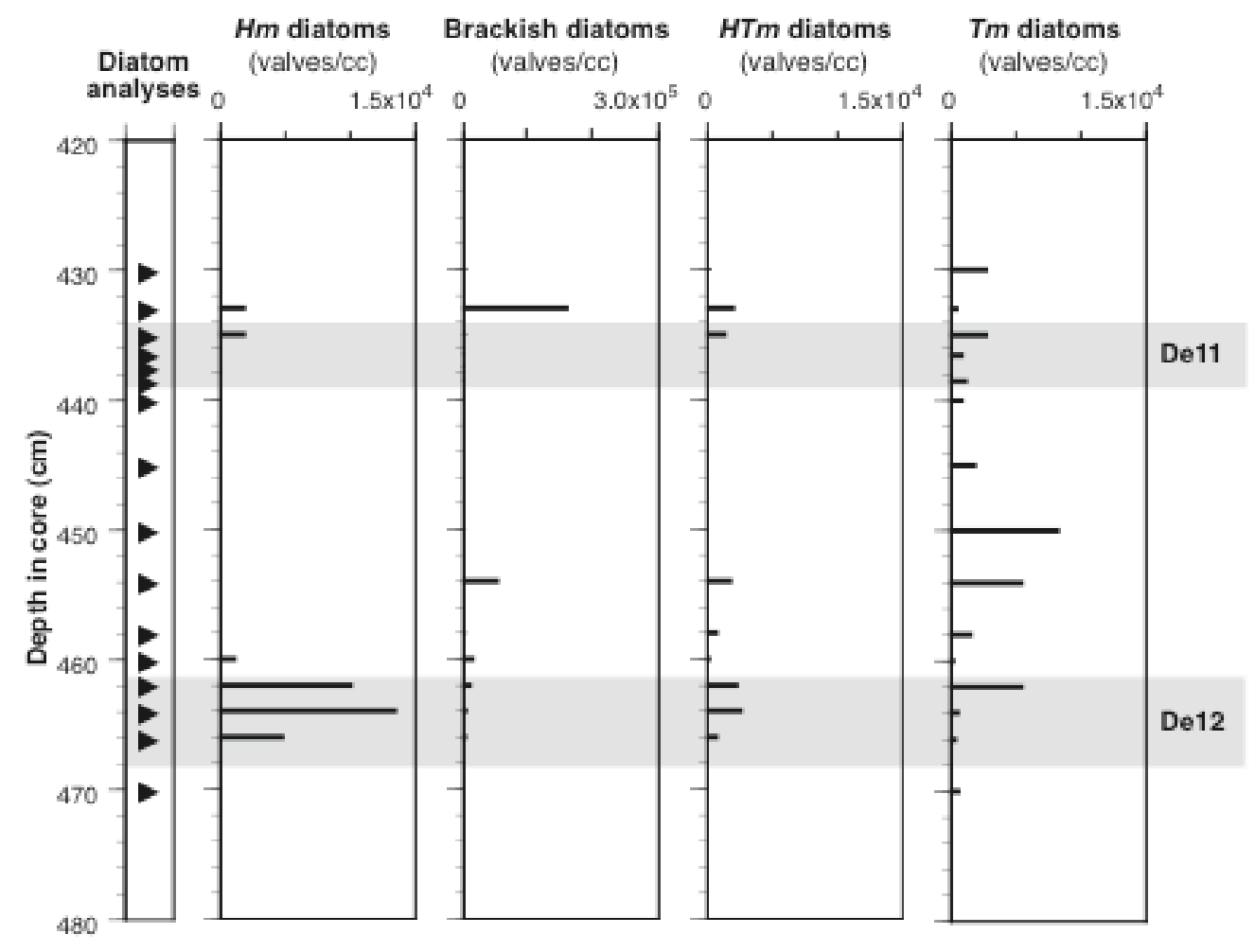

Figure 17. Concentrations of marine and brackish diatoms for De11and De12. Hm: marine diatoms from Holocene surficial deposits. HTm: extant marine diatoms from Holocene surficial deposits or Tertiary diatomites. Tm: extinct marine diatoms from Tertiary diatomites. Data are from core BR-94E. 


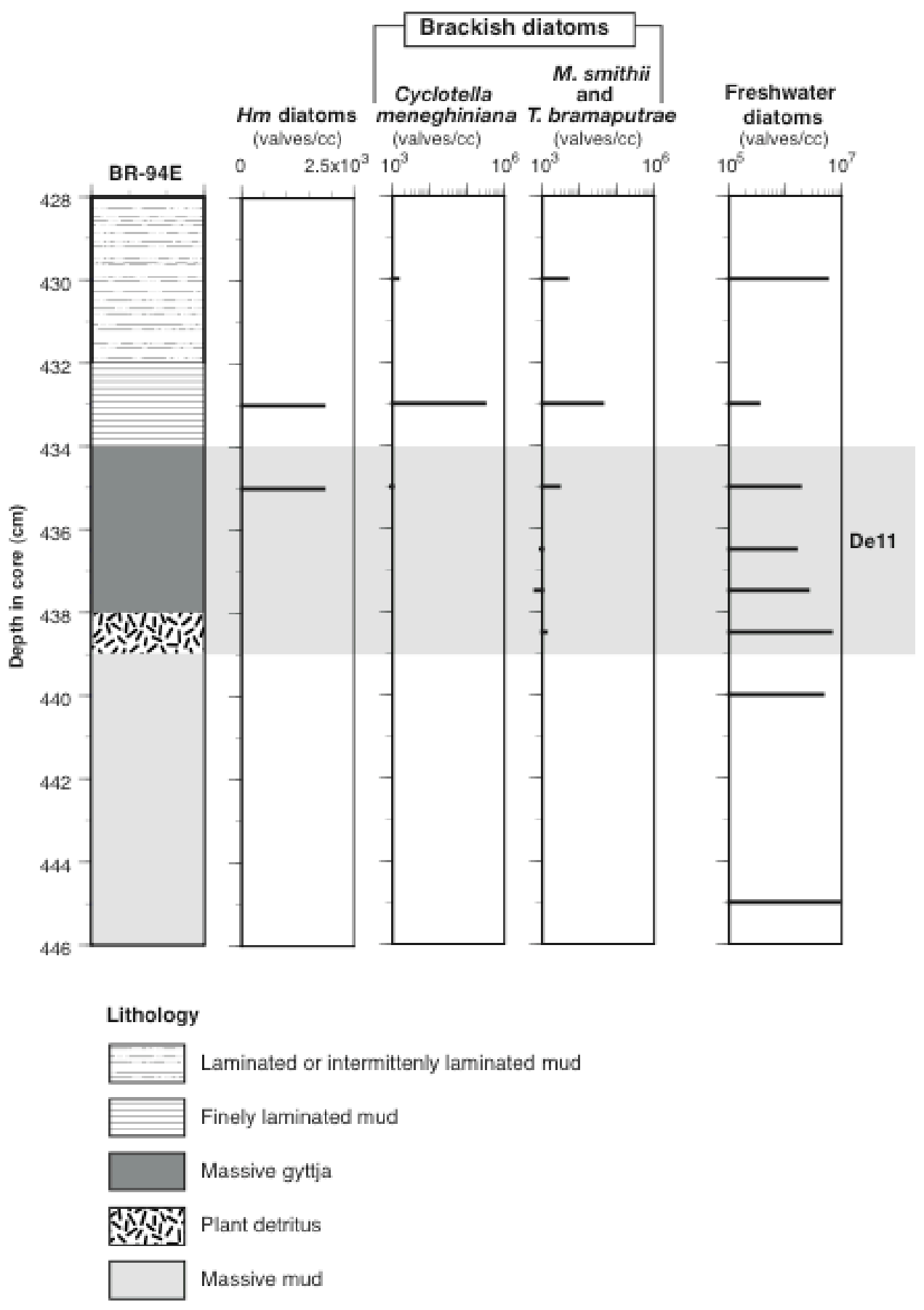

Figure 18. Stratigraphy and diatoms for De11. Hm: marine diatoms from Holocene surficial deposits. Note the logarithmic scales for "Brackish diatoms" and "Freshwater diatoms." Data are from core BR-94E. 


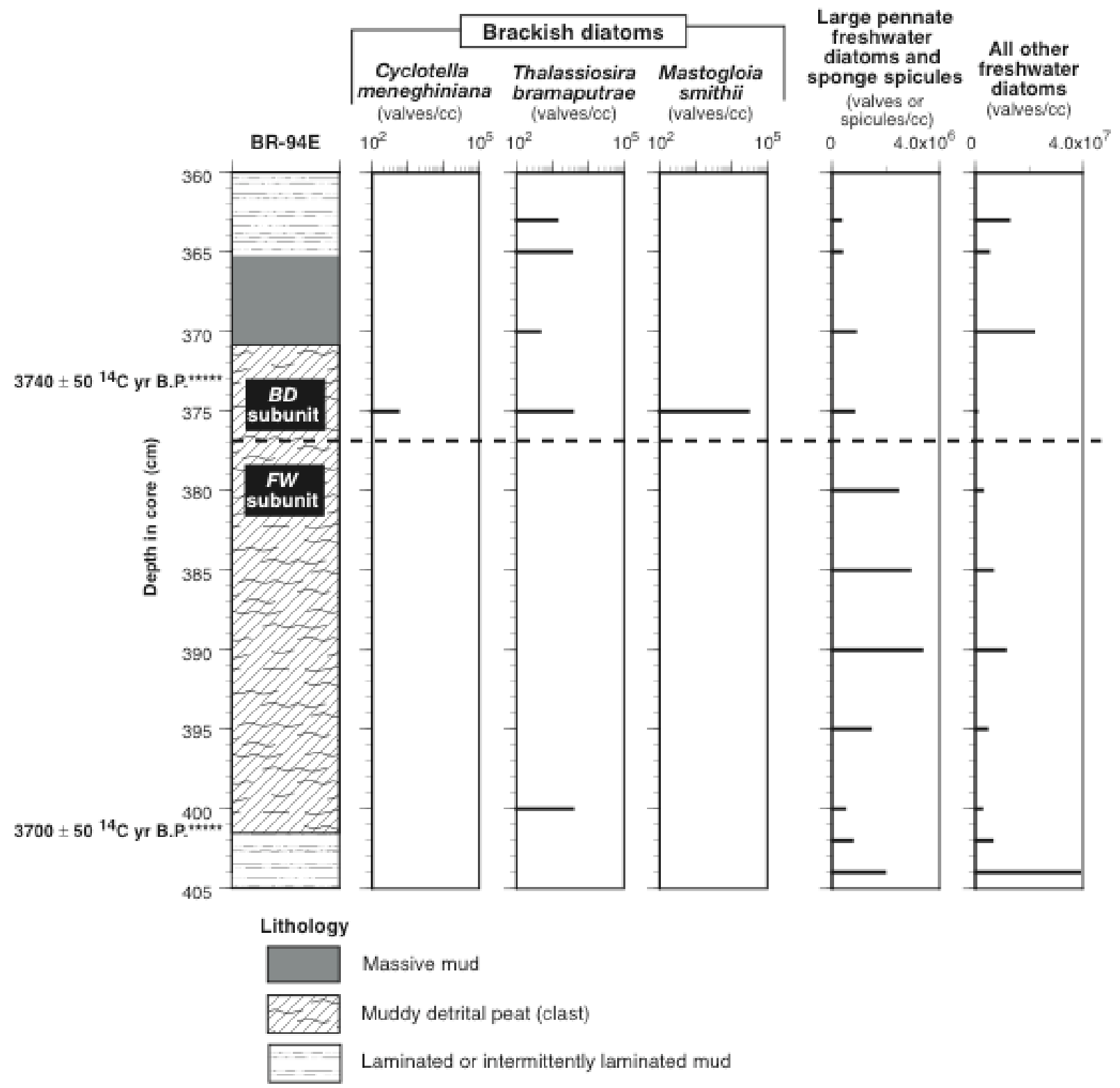

Figure 19. Stratigraphy and diatoms for a clast of detrital peat recovered from core $94 \mathrm{E}$. Horizontal dashed line shows the contact between peat containing brackish diatoms ("BD subunit") and freshwater diatoms ("FW subunit"). Note the logarithmic scales for "Brackish diatoms." Uncalibrated radiocarbon ages are reported in conventional radiocarbon years before AD 1950. This equates to an average calibrated age for the entire peat clast of $4150-3920 \mathrm{cal}$ yr B.P. 


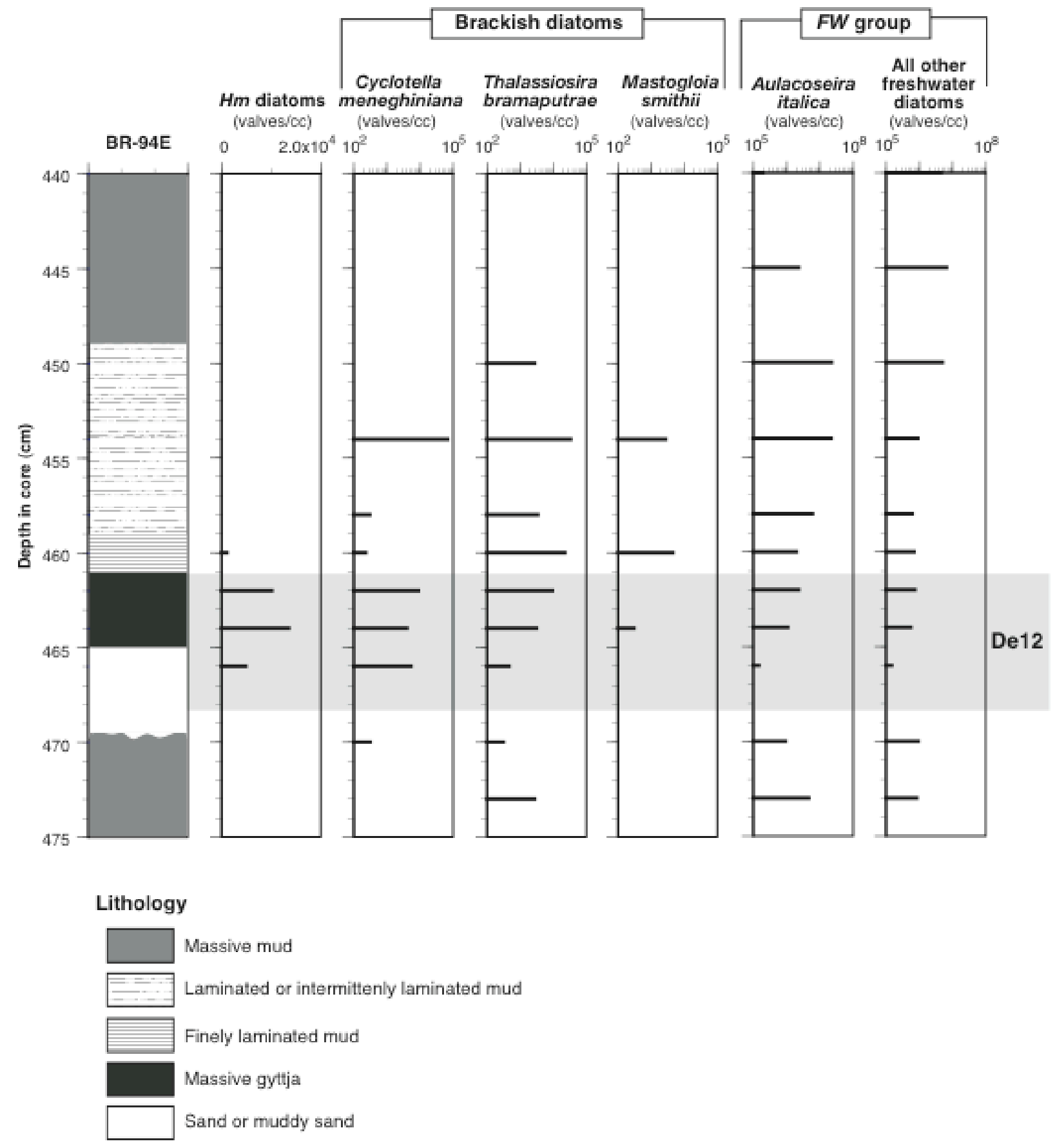

Figure 20. Stratigraphy and diatoms for De12. Hm: marine diatoms from Holocene surficial deposits. FW: benthic and planktonic freshwater diatoms. Data are from core BR-94E. 


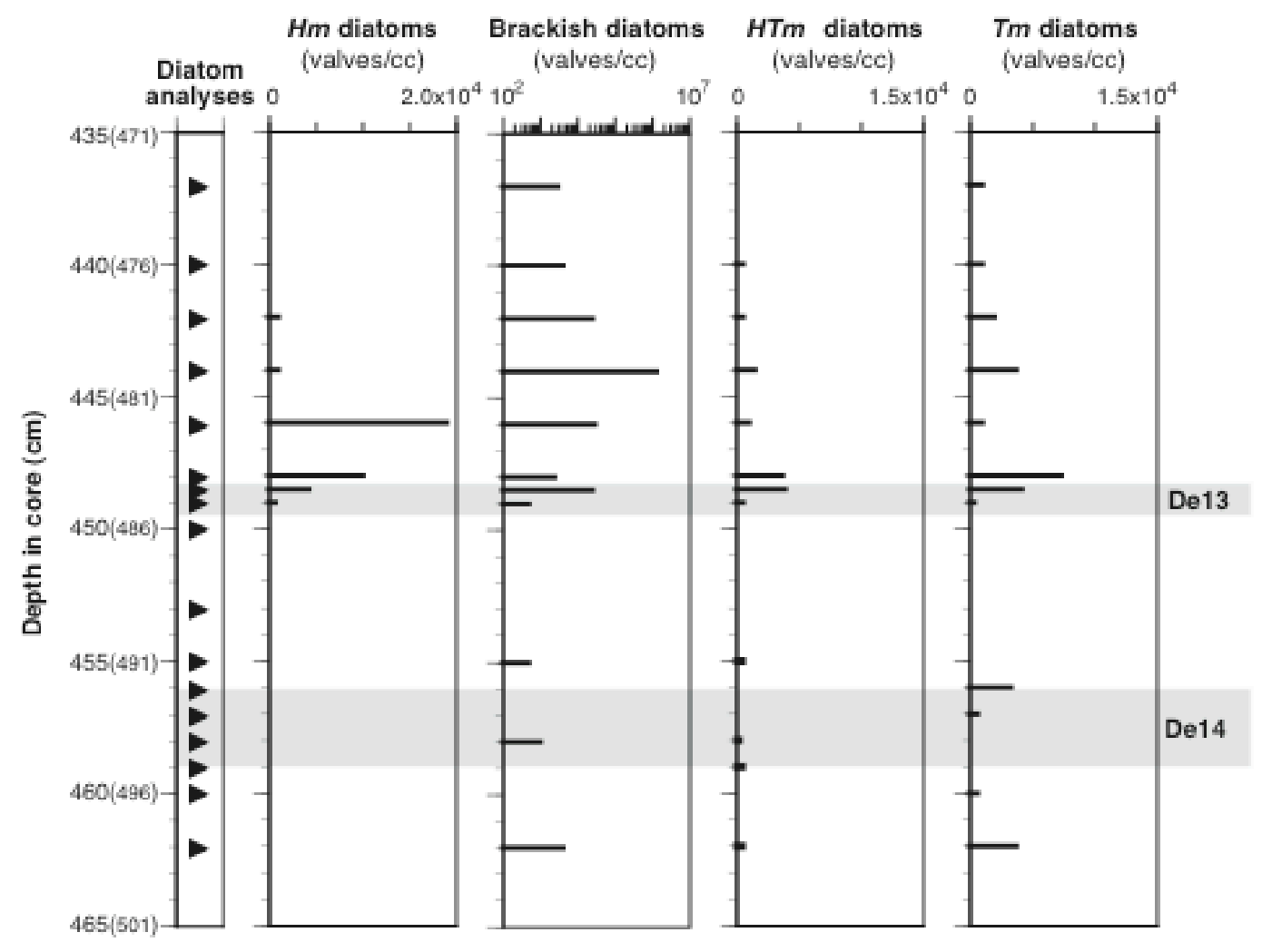

Figure 21. Concentrations of marine and brackish diatoms for De13 and De14. Hm: marine diatoms from Holocene surficial deposits. HTm: extant marine diatoms from Holocene surficial deposits or Tertiary diatomites. Tm: extinct marine diatoms from Tertiary diatomites. Note logarithmic scale for "Brackish diatoms." Data are from core BR-95X. Numbers in parentheses represent comparable depths for core $94 \mathrm{E}$. 


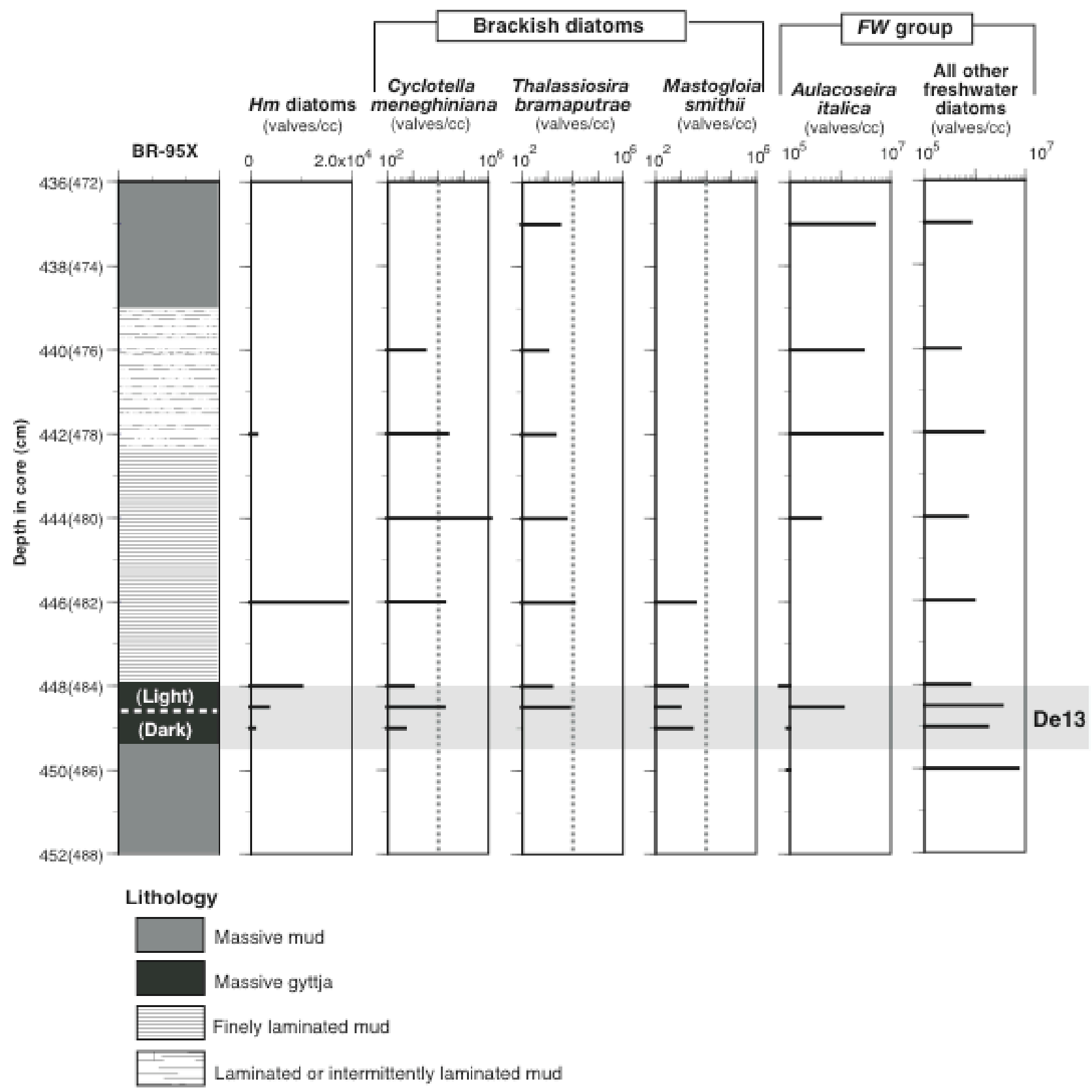

Figure 22. Stratigraphy and diatoms for De13. Hm: marine diatoms from Holocene surficial deposits. FW: benthic and planktonic freshwater diatoms. Note the logarithmic scales for the brackish and freshwater diatom data. Vertical dashed lines for brackish diatoms show boundary between "background" levels and possible blooms of these taxa. Data are from core BR-95X. Numbers in parentheses represent comparable depths for core 94E. 


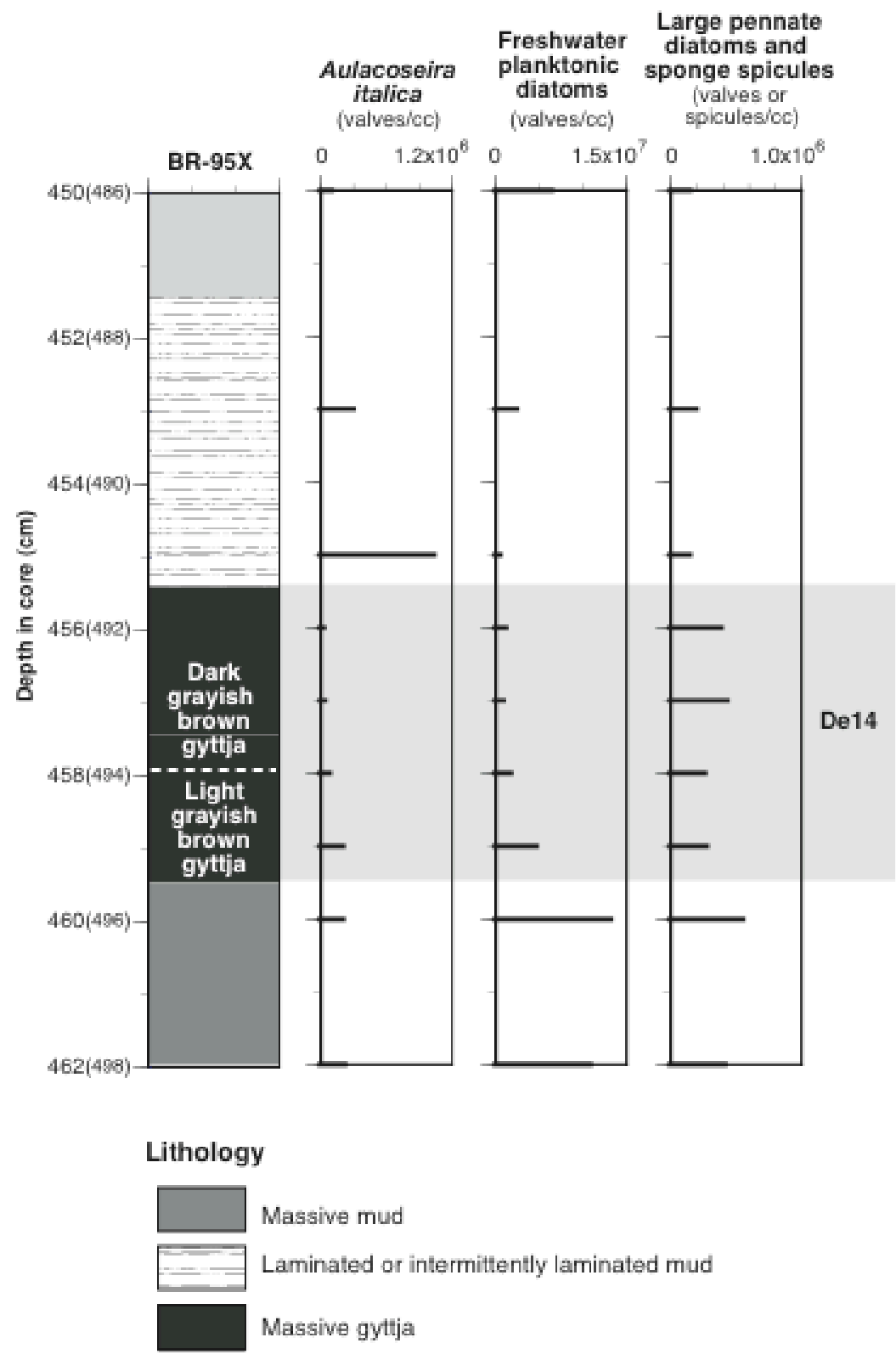

Figure 23. Stratigraphy and freshwater diatoms for De14. Data are from core BR-95X. Numbers in parentheses represent comparable depths for core 94E. 


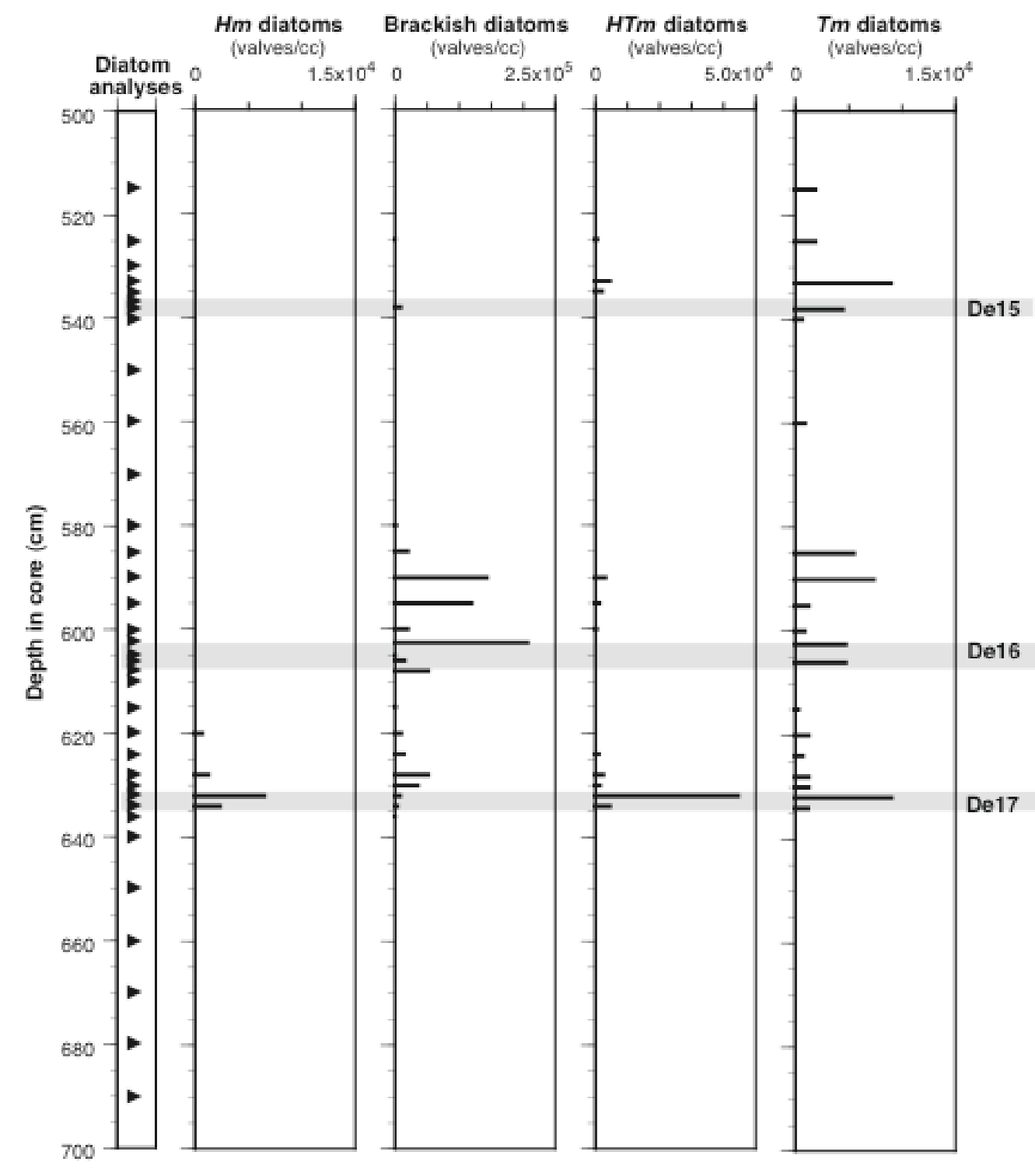

Figure 24. Concentrations of marine and brackish diatoms for De15, De16 and De17. Hm: marine diatoms from Holocene surficial deposits. HTm: extant marine diatoms from Holocene surficial deposits or Tertiary diatomites. Tm: extinct marine diatoms from Tertiary diatomites. Data are from core BR-94E. 


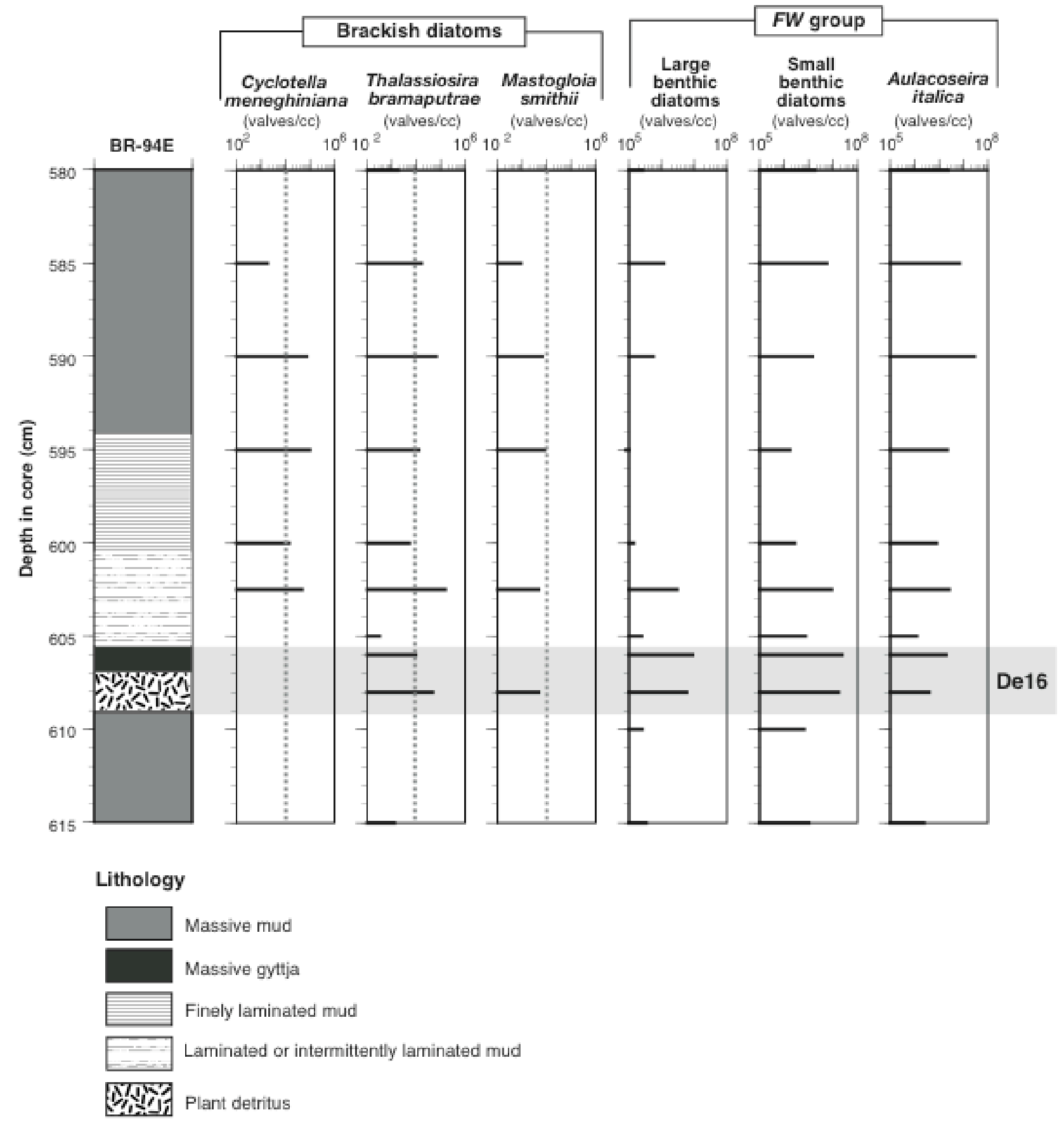

Figure 25. Stratigraphy and diatoms for De16. FW: benthic and planktonic freshwater diatoms. Vertical dashed lines show boundary between "background" levels and possible blooms of these taxa. Data are from core BR-94E. 


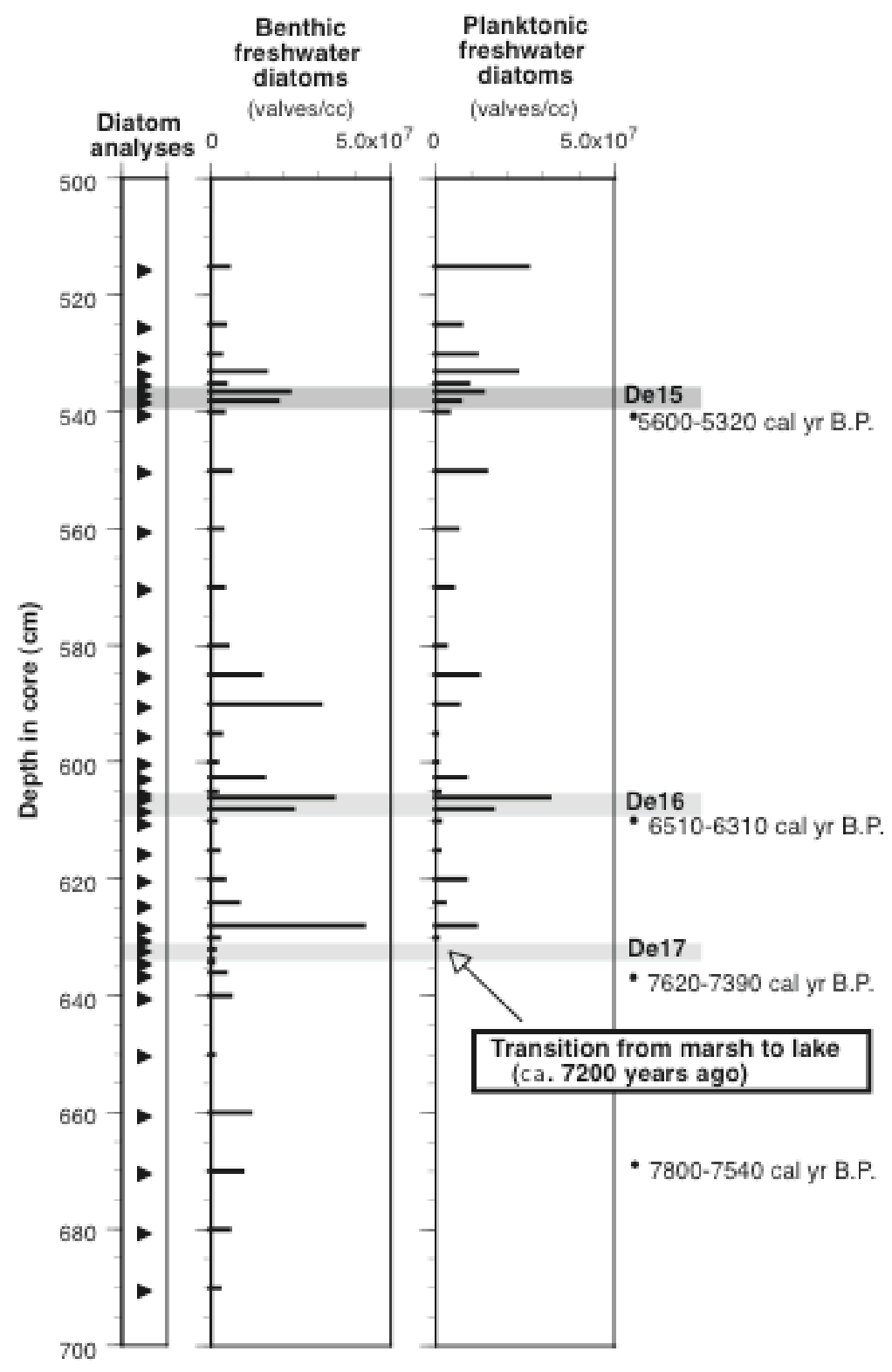

Figure 26. Concentrations of freshwater diatoms and ages (Nelson et al., 1998) for De15, De16 and De17. The appearance of planktonic diatoms ca. 7200 years ago records a transition from marshy wetland to lake. Data are from core BR-94E. 


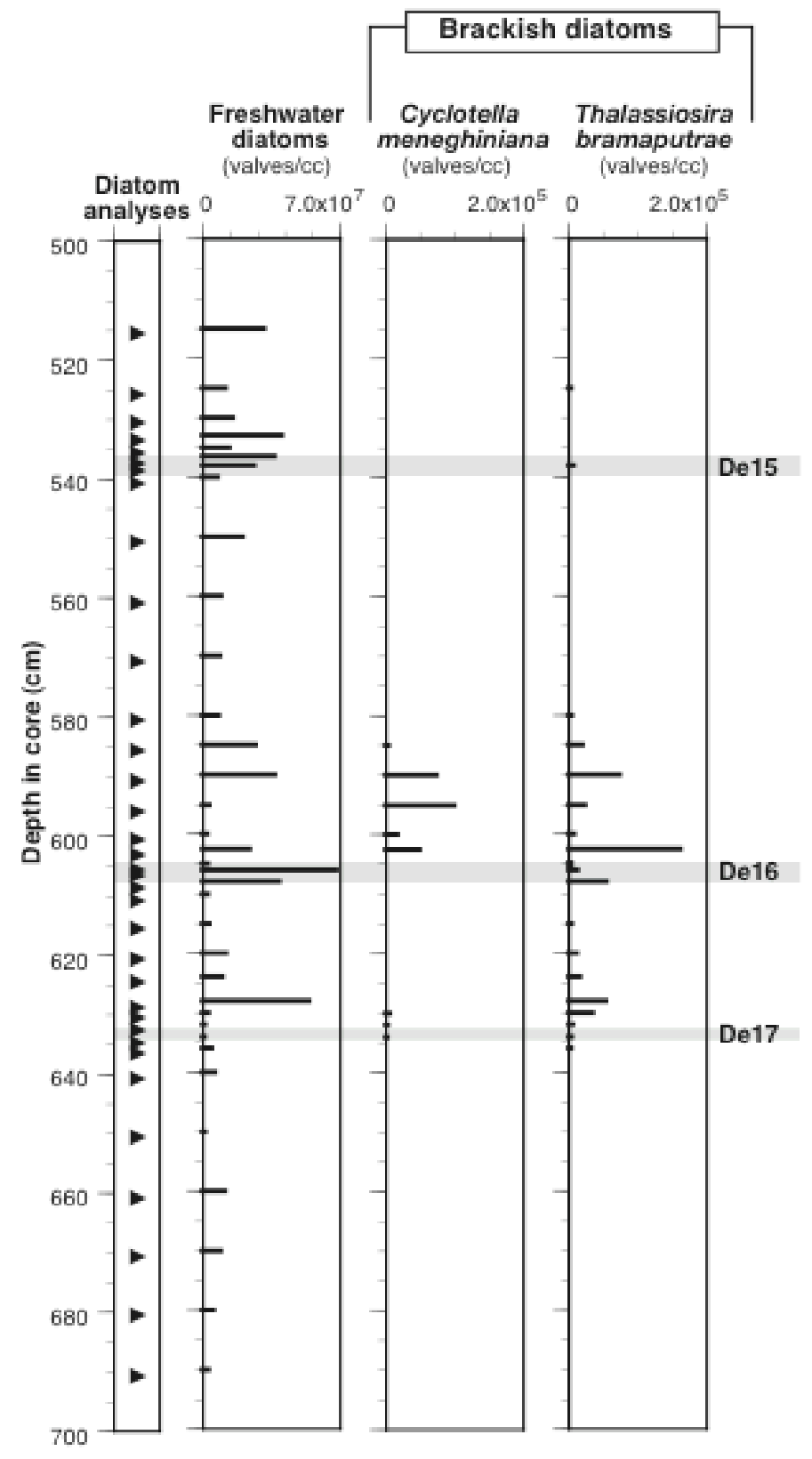

Figure 27. Concentrations of freshwater and brackish diatoms for De15, De16, and De17. Data are from core BR-94E. 


\section{APPENDIX 1: METHOD FOR PREPARING QUANTITATIVE DIATOM SLIDES}

\section{Overview}

Quantitative diatom analyses are required for documenting both spatial and temporal, absolute changes in diatom assemblages. Unlike qualitative microfossil-counting methods which unavoidably include inherent internal biases (i.e, "relative abundances"), quantitative analyses allow direct comparison of changes in species composition from sample to sample, since occurrences are measured relative to a standard, e.g., sediment volume.

Here we describe the diatom sample-processing technique we used at the USGS Western Coastal and Marine Geology Micropaleontology Laboratory. Our method is based on the methods described by Battarbee (1973) for diatoms and Moore (1973) and Roelofs and Pisias (1986) for radiolarians. The goal of the technique is to achieve a random distribution of a known volume of sediment by settling the material through a well-mixed fluid column onto glass cover slips in a settling chamber. The common practice of preparing strewn slides by transferring an aliquot of sediment and water directly onto a glass cover slip is known to distribute diatoms non-randomly (Battarbee, 1973), because the surface tension of the drying water may concentrate particles in the center of the cover glass. The result of this uneven distribution is that absolute numbers of diatoms cannot be determined unless the entire sample is scanned. However, when a sample is randomly and evenly distributed, a portion of the sample can be used to represent the entire sample (Roelofs and Pisias, 1986).

The diatom slide preparation consists of three parts: 1) chemical treatment; 2) sediment dispersal; and 3) cover-glass mounting. During chemical treatment, the sample is gently disaggregated and cleaned of organic matter. The sediment is then evenly dispersed on cover slips in a settling chamber. Finally, the cover slips are permanently fixed to glass slides for viewing with a light microscope.

\section{Procedure}

\section{A. Chemical treatment}

Materials needed:

1. Distilled water

2. 1-3 cc of sample

3. $100 \mathrm{ml}$ Pyrex beaker

4. $50 \mathrm{ml}$ graduated centrifuge tube 
5. $10 \mathrm{ml}$ of $30 \%$ Hydrogen Peroxide per sample

6. $5-10 \mathrm{ml}$ of $30 \%$ Hydrochloric Acid per sample

7. $\mathrm{pH}$ test paper

Step A1. Place about $2 \mathrm{cc}$ of sample into a $100 \mathrm{ml}$ beaker with $10 \mathrm{ml}$ of distilled water. Allow the sample to disaggregate a few minutes. Make sure that the beakers are spaced at least $5 \mathrm{~cm}$ apart and add $10 \mathrm{ml}$ of hydrogen peroxide to the samples. The samples may react rapidly in the first 10 minutes, but can be squirted with deionized water to prevent splattering or boiling over. Allow the reactions to proceed for at least two hours.

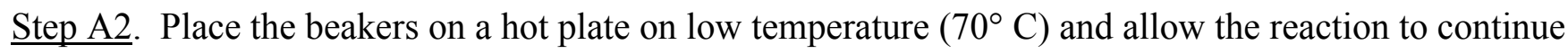
for an additional hour. If the samples are organic-rich, the sample may begin reacting strongly with the addition of heat, so it is important to watch the samples carefully during approximately the first 20 minutes of this step. If the samples begin to react violently or boil over, add more distilled water, and reduce the temperature of the hot plate.

$\underline{\text { Step A3 }}$. Once the reaction has ceased and all organic matter has been oxidized, add three drops of $30 \%$ hydrochloric acid $(\mathrm{HCl})$ to rid the sample of any calcium carbonate. How vigorous the sample reacts to the acid will depend on how much carbonate is present in the sample. Watch the reaction for several minutes, and as it slows, add more acid at a rate of about two drops per minute until the initial, violent reaction has ceased. When the reaction has slowed to the point at which there is no danger of boiling over, add an additional $2 \mathrm{ml}$ of $\mathrm{HCl}$ and allow the reaction to continue for about 20 minutes.

Step A4. Remove the beakers from the hot plate and allow to cool. Using a water bottle filled with distilled water, rinse the sample into a $50 \mathrm{ml}$ graduated centrifuge tube, and add enough water to fill the tube to $45 \mathrm{ml}$. Centrifuge at 800 RPM for 10 minutes.

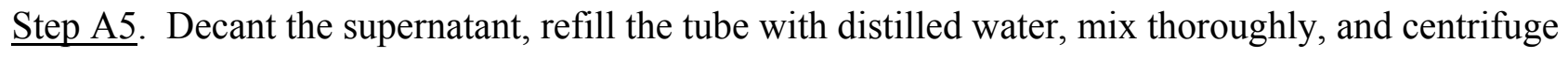
again. Rinse until the supernatant is neutral, as determined with $\mathrm{pH}$ test paper.

\section{B. Sediment dispersal}

Materials needed:

1. $22 \times 30 \mathrm{~mm}$ cover glass (two per sample)

2. $250 \mathrm{ml}$ beakers (one per sample)

3. $5 \mathrm{~cm}$ diameter glass disk

4. rubber cement 
5. Knots gelatin powder (optional) (1 g powder dissolved in $20 \mathrm{cc}$ distilled water)

6. small spatula

7. mechanical pipette and disposable tips

8. capillary tubes, thin plastic tubing and vacuum system

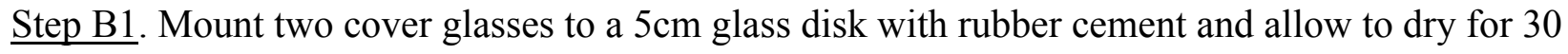
minutes.

$\underline{\text { Step B2. }}$ (Optional) ${ }^{5}$ Prepare a gelatin solution by dissolving $1 \mathrm{~g}$ of Knot's gelatin powder in $20 \mathrm{cc}$ distilled water. Place one drop of gelatin solution on the cover glass and distribute it evenly across the cover with a small spatula, keeping the coating as thin as possible. The gelatin will obscure optics if applied too thickly. If any small bumps form as the gelatin is drying, smooth them out with a small spatula. Place a small dot in the corner of one of the cover glasses with a permanent-ink marking pen to identify the gelatin-coated slide from the plain slide (our standard procedure is to mark the gelatin-coated slide).

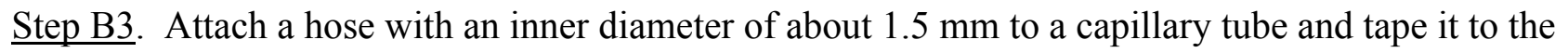
inside wall of the $250 \mathrm{ml}$ beaker. The tip of the capillary tube should be one centimeter from the bottom of the beaker. Pour $50 \mathrm{ml}$ distilled water into the beaker and submerge the glass disk with the cover glasses facing up.

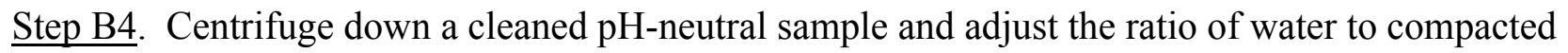
sediment to 10:1. Place the centrifuge tube in a stand and suspend the sample by stirring.

$\underline{\text { Step B5. }}$. With a mechanical pipette, draw a 40-60 $\mu 1$ aliquot while continuing to stir the mixture. The volume of the aliquot will depend on the material being used ${ }^{6}$, but our experience shows that $40 \mu 1$ is usually adequate. Transfer the aliquot to the $250 \mathrm{ml}$ beaker.

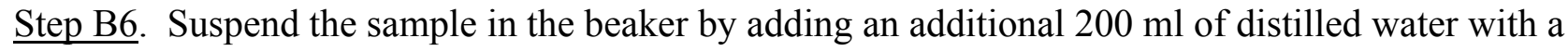
spray nozzle or squirt bottle. Allow the sediment to settle undisturbed eight to twelve hours.

${ }^{5}$ This gelatin-coating step is optional, but we have found that it is useful for preventing sediment from clumping on the cover slips, particularly in clay-rich material. The gelatin does, however, obscure the optics of the slide somewhat, which is a problem for photomicroscopy.

${ }^{6}$ The amount of sediment on the cover slips will be the same from sample to sample as long as one uses the same sediment-to-water ratio, aliquot volume, beaker diameter, and cover slip size. For example, our samples from Bradley Lake contain abundant diatoms (usually $>10^{5}$ diatoms/cc), and we have had excellent results dispersing a $40 \mu \mathrm{l}$ aliquot in a $250 \mathrm{ml}$ beaker (settling chamber). Using a $40 \mu \mathrm{l}$ aliquot, each slide (using a $22 \mathrm{~mm}$ x $30 \mathrm{~mm}$ cover slip) will contain $8 \times 10^{-4}$ of cleaned sediment. 


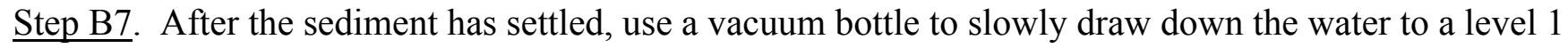
$\mathrm{cm}$ above the cover glass. Be careful not to disturb the sample, and allow the remaining water to evaporate. We recommend allowing the samples to air dry in a fume hood as this reduces the likelihood that the sediment particles will clump together on the cover glass. If heat lamps are used to speed up the evaporation process, keep them at least $20 \mathrm{~cm}$ above the beakers so that convection currents do not form to disturb the samples.

\section{Cover-slip mounting}

Materials needed:

1. 3" x 1" plain glass microscope slide

2. Mounting medium like Hyrax or Naphrax with refractive index of 1.74 .

3. $200 \mathrm{ml}$ Hydrogen Peroxide (30\%)

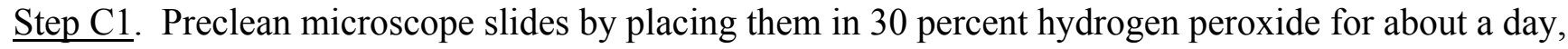
rinse thoroughly in deionized water and allow to dry. We find that this preliminary step improves the optics for the slides, even for those that are chemically pretreated at the factory.

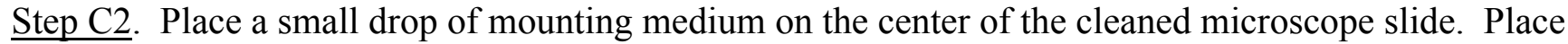
the cover glass, sediment side down, on the drop of mounting medium. Place the slide on a cool hotplate, and slowly increase the temperature to about $65-75^{\circ} \mathrm{C}$. The mounting medium will lose viscosity, and then bubbles will form as solvents are released. The process is complete when bubbles no longer form (about two minutes), and upon cooling the mounting medium will harden to permanently affix the cover slip to the slide.

Note: It is not advisable to heat the slide too rapidly or at too high of a temperature, as the mounting medium will discolor and become brittle. As an easy test, the temperature is too high if water sizzles on the hotplate. If done properly, the mounting medium should be a light straw color when dried, should not be brittle or crack easily, and should provide an archive-quality slide that could be stored for many years.

$\underline{\text { Step C3. }}$. The slides can be labeled either with printed adhesive paper labels or with a permanentmarker pen. 
Appendix 2. Core samples analyzed for diatoms.

\begin{tabular}{|c|c|c|c|}
\hline Sample ID & $\begin{array}{l}\text { Depth in } \\
\text { composite } \\
\text { core }(\mathrm{cm})\end{array}$ & Lithology & $\begin{array}{c}\text { Disturbance } \\
\text { event } \\
\text { (De) }\end{array}$ \\
\hline BR94E-15 & 15 & Massive mud & \\
\hline BR94E-20 & 20 & Plant detritus bed & \\
\hline BR94E-25 & 25 & Massive mud & \\
\hline BR94E-30 & 30 & Black organic ooze & "Black soupy" \\
\hline BR94E-35 & 35 & Massive mud & \\
\hline BR94E-40 & 40 & Massive mud & \\
\hline BR94E-45 & 45 & Massive mud & \\
\hline BR94E-48 & 48 & Massive mud & \\
\hline BR94E-50 & 50 & Massive mud & \\
\hline BR94E-52 & 52 & Black organic ooze & De1 \\
\hline BR94E-54 & 54 & Massive gyttja & De1 \\
\hline BR94E-56 & 56 & Massive gyttja & De1 \\
\hline BR94E-58 & 58 & Massive gyttja & De1 \\
\hline BR94E-60 & 60 & Plant detritus bed & De1 \\
\hline BR94E-62 & 62 & Massive mud & \\
\hline BR94E-64 & 64 & Massive mud & \\
\hline BR94E-66 & 66 & Massive mud & \\
\hline BR94E-70 & 70 & Massive mud & \\
\hline BR94E-75 & 75 & Massive mud & \\
\hline BR94E-80 & 80 & Massive mud & \\
\hline BR94E-85 & 85 & Massive mud & \\
\hline BR94F-90 & 90 & Intermittently laminated mud & \\
\hline BR94F-95 & 95 & Intermittently laminated mud & \\
\hline BR94F-98 & 98 & Finely laminated mud & \\
\hline BR94F-100 & 100 & Massive gyttja & De2 \\
\hline BR94E-102 & 102 & Massive gyttja & De2 \\
\hline BR94E-104 & 104 & Massive gyttja & De2 \\
\hline BR94E-106 & 106 & Massive gyttja & De2 \\
\hline BR94E-111 & 111 & Massive gyttja & De2 \\
\hline BR94E-112 & 112 & Massive gyttja & De2 \\
\hline BR94E-113 & 113 & Sand or sandy mud & De2 \\
\hline BR94E-114 & 114 & Massive mud & \\
\hline BR94E-116 & 116 & Laminated mud & \\
\hline BR94E-118 & 118 & Laminated mud & \\
\hline BR94E-120 & 119.5 & Laminated mud & \\
\hline BR94E-122 & 122 & Massive gyttja & De3 \\
\hline BR94E-130 & 130 & Laminated mud & \\
\hline BR94E-135 & 135 & Laminated mud & \\
\hline BR94E-140 & 140 & Laminated mud & \\
\hline BR94E-145 & 145 & Laminated mud & \\
\hline
\end{tabular}


Appendix 2. Core samples analyzed for diatoms.

\begin{tabular}{|c|c|c|c|}
\hline Sample ID & $\begin{array}{l}\text { Depth in } \\
\text { composite } \\
\text { core }(\mathrm{cm})\end{array}$ & Lithology & $\begin{array}{c}\text { Disturbance } \\
\text { event } \\
\text { (De) }\end{array}$ \\
\hline BR94E-150 & 150 & Laminated mud & \\
\hline BR94E-154 & 154 & Finely laminated mud & \\
\hline BR94E-155 & 155 & Massive gyttja & De4 \\
\hline BR94E-157 & 157 & Massive gyttja & De4 \\
\hline BR94E-159 & 158.5 & Massive gyttja & De4 \\
\hline BR94E-160 & 160 & Massive gyttja & De4 \\
\hline BR94E-162 & 162 & Massive mud & \\
\hline BR94E-165 & 165 & Massive mud & \\
\hline BR94E-170 & 170 & Massive mud & \\
\hline BR94E-175 & 175 & Intermittently laminated mud & \\
\hline BR94E-180 & 180 & Intermittently laminated mud & \\
\hline BR94E-184 & 184 & Finely laminated mud & \\
\hline BR94E-186 & 186 & Finely laminated mud & \\
\hline BR94E-188 & 188 & Massive gyttja & De5 \\
\hline BR94E-190 & 190 & Massive gyttja & De5 \\
\hline BR94E-192 & 192 & Massive gyttja & De5 \\
\hline BR94E-194 & 194 & Sandy mud & De5 \\
\hline BR94E-196 & 196 & Sandy mud & De5 \\
\hline BR94E-198 & 198 & Massive mud & De5 \\
\hline BR94E-200 & 200 & Muddy sand & De5 \\
\hline BR94E-201 & 201 & Massive gyttja & De6 \\
\hline BR94E-203 & 203 & Massive gyttja & De6 \\
\hline BR94E-205 & 205 & Medium-fine sand & De6 \\
\hline BR94E-207 & 207 & Medium-fine sand & De6 \\
\hline BR94E-210 & 210 & Massive mud & \\
\hline BR94E-215 & 215 & Laminated mud & \\
\hline BR94E-220 & 220 & Laminated mud & \\
\hline BR94E-222 & 222 & Laminated mud & \\
\hline BR94E-225 & 225 & Laminated mud & \\
\hline BR94E-230 & 230 & Massive mud & \\
\hline BR94E-235 & 235 & Laminated mud & \\
\hline BR94E-240 & 240 & Laminated mud & \\
\hline BR94E-245 & 245 & Laminated mud & \\
\hline BR94E-250 & 250 & Laminated mud & \\
\hline BR94E-255 & 255 & Laminated mud & \\
\hline BR94E-260 & 260 & Laminated mud & \\
\hline BR94E-265 & 265 & Laminated mud & \\
\hline BR94E-270 & 270 & Laminated mud & \\
\hline BR94E-275 & 275 & Laminated mud & \\
\hline BR94E-280 & 280 & Laminated mud & \\
\hline
\end{tabular}


Appendix 2. Core samples analyzed for diatoms.

\begin{tabular}{|c|c|c|c|}
\hline Sample ID & $\begin{array}{l}\text { Depth in } \\
\text { composite } \\
\text { core }(\mathrm{cm})\end{array}$ & Lithology & $\begin{array}{c}\text { Disturbance } \\
\text { event } \\
\text { (De) }\end{array}$ \\
\hline BR94E-285 & 285 & Laminated mud & \\
\hline BR94E-290 & 290 & Laminated mud & \\
\hline BR94E-292 & 292 & Laminated mud & \\
\hline BR94E-294 & 294 & Laminated mud & \\
\hline BR94E-296 & 296 & Finely laminated mud & \\
\hline BR94E-298 & 298 & Massive gyttja & De7 \\
\hline BR94E-300 & 300 & Massive gyttja & De7 \\
\hline BR94E-301 & 301 & Massive gyttja & De7 \\
\hline BR94E-302 & 302 & Sand or sandy mud & De7 \\
\hline BR94E-304 & 304 & Massive mud & \\
\hline BR94E-306 & 306 & Laminated mud & \\
\hline BR94E-310 & 310 & Massive mud & \\
\hline BR94E-315 & 315 & Laminated mud & \\
\hline BR94E-320 & 320 & Intermittently laminated mud & \\
\hline BR94E-324 & 324 & Intermittently laminated mud & \\
\hline BR94E-326 & 326 & Laminated mud & \\
\hline BR94E-328 & 328 & Finely laminated mud & \\
\hline BR94E-330 & 330 & Finely laminated mud & \\
\hline BR94E-332 & 332 & Massive gyttja & De8 \\
\hline BR94E-334 & 334 & Massive gyttja & De8 \\
\hline BR94E-335 & 335 & Sand or sandy mud & De8 \\
\hline BR94E-338 & 338 & Sand or sandy mud & De8 \\
\hline BR94E-340 & 340 & Intermittently laminated mud & \\
\hline BR94E-344 & 344 & Intermittently laminated mud & \\
\hline BR94E-350 & 350 & Laminated mud & \\
\hline BR95BB-268 & 360 & Massive mud & \\
\hline BR95BB-270 & 362 & Massive mud & \\
\hline BR95BB-271 & 363 & Finely laminated mud & \\
\hline BR95BB-272 & 364 & Massive gyttja & De9 \\
\hline BR95BB-273 & 365 & Massive gyttja & De9 \\
\hline BR95BB-274 & 366 & Massive gyttja & De9 \\
\hline BR95BB-276 & 368 & Massive gyttja & De9 \\
\hline BR95BB-280 & 372 & Laminated mud & \\
\hline BR95BB-290 & 382 & Laminated mud & \\
\hline BR95BB-295 & 387 & Laminated mud & \\
\hline BR95BB-301 & 393 & Massive mud & \\
\hline BR95BB-302 & 394 & Finely laminated mud & \\
\hline BR95BB-303 & 395 & Massive gyttja & \\
\hline BR95BB-304 & 396 & Finely laminated mud & \\
\hline BR95BB-305 & 397 & Massive gyttja & De10 \\
\hline
\end{tabular}


Appendix 2. Core samples analyzed for diatoms.

\begin{tabular}{|c|c|c|c|}
\hline Sample ID & $\begin{array}{l}\text { Depth in } \\
\text { composite } \\
\text { core }(\mathrm{cm})\end{array}$ & Lithology & $\begin{array}{c}\text { Disturbance } \\
\text { event } \\
\text { (De) }\end{array}$ \\
\hline BR95BB-306 & 398 & Massive gyttja & De10 \\
\hline BR95BB-308 & 400 & Massive gyttja & De10 \\
\hline BR95BB-310 & 402 & Intermittently laminated mud & \\
\hline BR95BB-315 & 407 & Massive mud & \\
\hline BR95BB-320 & 412 & Massive mud & \\
\hline BR94E-430 & 430 & Intermittently laminated mud & \\
\hline BR94E-433 & 433 & Finely laminated mud & \\
\hline BR94E-435 & 435 & Massive gyttja & De11 \\
\hline BR94E-437 & 436.5 & Massive gyttja & De11 \\
\hline BR94E-438 & 437.5 & Massive gyttja & De11 \\
\hline BR94E-439 & 438.5 & Plant detritus bed & De11 \\
\hline BR94E-440 & 440 & Massive mud & \\
\hline BR94E-445 & 445 & Massive mud & \\
\hline BR94E-450 & 450 & Laminated mud & \\
\hline BR94E-454 & 454 & Intermittently laminated mud & \\
\hline BR94E-458 & 458 & Laminated mud & \\
\hline BR94E-460 & 460 & Finely laminated mud & \\
\hline BR94E-462 & 462 & Massive gyttja & De12 \\
\hline BR94E-464 & 464 & Massive gyttja & De12 \\
\hline BR94E-466 & 466 & Sand or sandy mud & De12 \\
\hline BR94E-470 & 470 & Massive mud & \\
\hline BR95X-437 & 473 & Massive mud & \\
\hline BR95X-440 & 476 & Laminated mud & \\
\hline BR95X-442 & 478 & Laminated mud & \\
\hline BR95X-444 & 480 & Finely laminated mud & \\
\hline BR95X-446 & 482 & Finely laminated mud & \\
\hline BR95X-448 & 484 & Finely laminated mud & \\
\hline BR95X-449 & 484.5 & Massive gyttja & De13 \\
\hline BR95X-449 & 485 & Massive gyttja & De13 \\
\hline BR95X-450 & 486 & Massive mud & \\
\hline BR95X-453 & 489 & Intermittently laminated mud & \\
\hline BR95X-455 & 491 & Intermittently laminated mud & \\
\hline BR95X-456 & 492 & Massive gyttja & De14 \\
\hline BR95X-457 & 493 & Massive gyttja & De14 \\
\hline BR95X-458 & 494 & Massive gyttja & De14 \\
\hline BR95X-459 & 495 & Massive gyttja & De14 \\
\hline BR95X-460 & 496 & Massive mud & \\
\hline BR95X-462 & 498 & Massive mud & \\
\hline BR94E-515 & 515 & Massive mud & \\
\hline BR94E-525 & 525 & Laminated mud & \\
\hline
\end{tabular}


Appendix 2. Core samples analyzed for diatoms.

\begin{tabular}{|c|c|c|c|}
\hline Sample ID & $\begin{array}{l}\text { Depth in } \\
\text { composite } \\
\text { core }(\mathrm{cm})\end{array}$ & Lithology & $\begin{array}{c}\text { Disturbance } \\
\text { event } \\
\text { (De) }\end{array}$ \\
\hline BR94E-530 & 530 & Laminated mud & \\
\hline BR94E-533 & 533 & Laminated mud & \\
\hline BR94E-535 & 535 & Laminated mud & \\
\hline BR94E-537 & 536.5 & Massive gyttja & De15 \\
\hline BR94E-538 & 538 & Massive gyttja & De15 \\
\hline BR94E-540 & 540 & Plant detritus bed & De15 \\
\hline BR94E-550 & 550 & Laminated mud & \\
\hline BR94E-560 & 560 & Intermittently laminated mud & \\
\hline BR94E-570 & 570 & Intermittently laminated mud & \\
\hline BR94E-580 & 580 & Intermittently laminated mud & \\
\hline BR94E-585 & 585 & Massive mud & \\
\hline BR94E-590 & 590 & Massive mud & \\
\hline BR94E-595 & 595 & Finely laminated mud & \\
\hline BR94E-600 & 600 & Finely laminated mud & \\
\hline BR94E-603 & 602.5 & Intermittently laminated mud & \\
\hline BR94E-605 & 605 & Intermittently laminated mud & \\
\hline BR94E-607 & 607 & Massive gyttja & De16 \\
\hline BR94E-608 & 608 & Plant detritus bed & De16 \\
\hline BR94E-610 & 610 & Massive mud & \\
\hline BR94E-615 & 615 & Massive mud & \\
\hline BR94E-620 & 620 & Massive mud & \\
\hline BR94E-624 & 624 & Massive mud & \\
\hline BR94E-628 & 628 & Finely laminated mud (very faint) & \\
\hline BR94E-630 & 630 & Finely laminated mud (very faint) & \\
\hline BR94E-632 & 632 & Finely laminated mud (very faint) & \\
\hline BR94E-634 & 634 & Sand or sandy mud & De17 \\
\hline BR94E-636 & 636 & Massive mud & \\
\hline BR94E-640 & 640 & Muddy peat & \\
\hline BR94E-650 & 650 & Muddy peat & \\
\hline BR94E-660 & 660 & Muddy peat & \\
\hline BR94E-670 & 670 & Muddy peat & \\
\hline BR94E-680 & 680 & Muddy peat & \\
\hline BR94E-690 & 690 & Muddy peat & \\
\hline
\end{tabular}


Appendix 3. Downcore diatom data from Bradley Lake (diatom concentration in valves per ce of sediment).

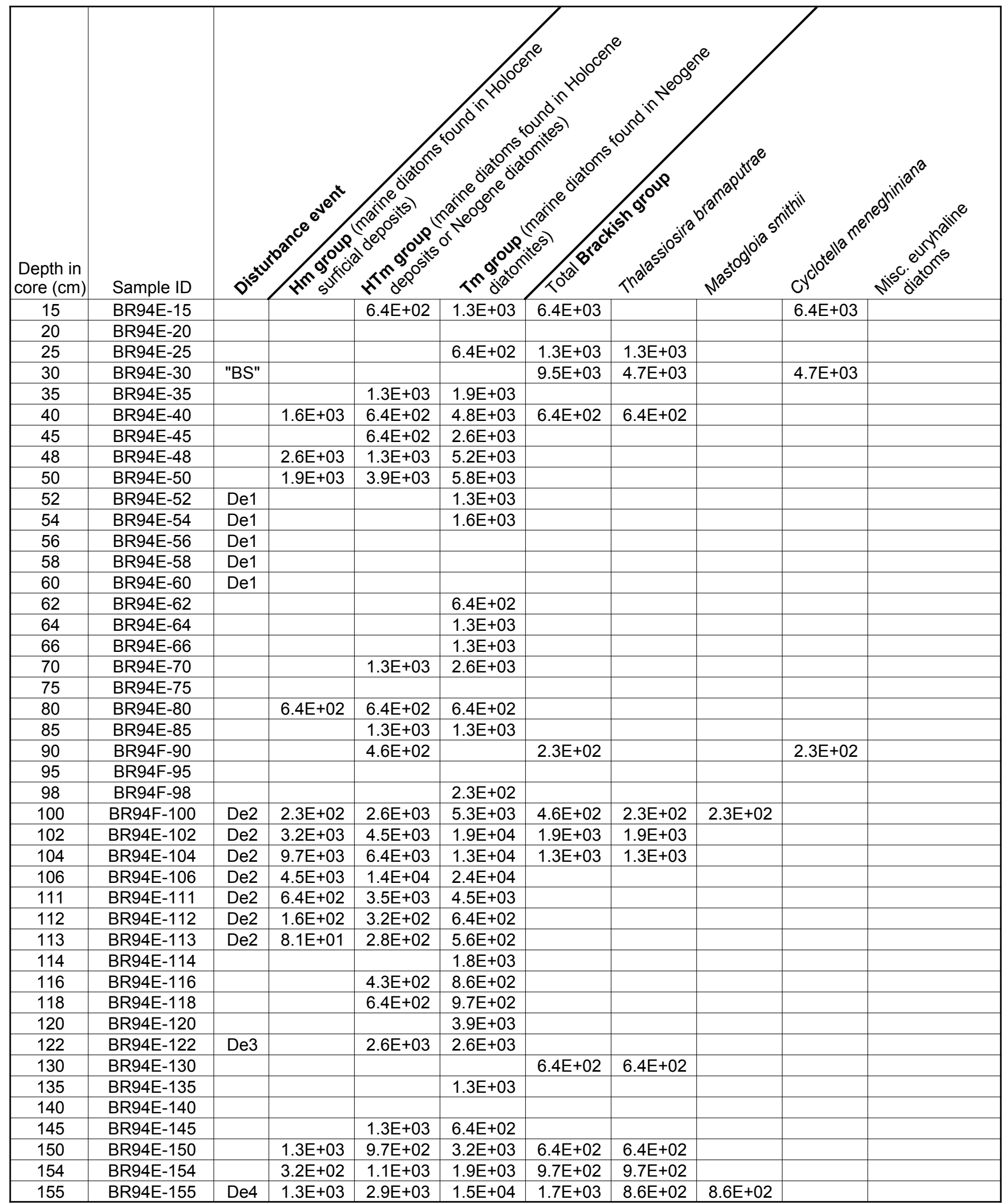




\section{Appendix 3. Downcore diatom data from Bradley Lake (diatom concentration in valves per ce of sediment).}

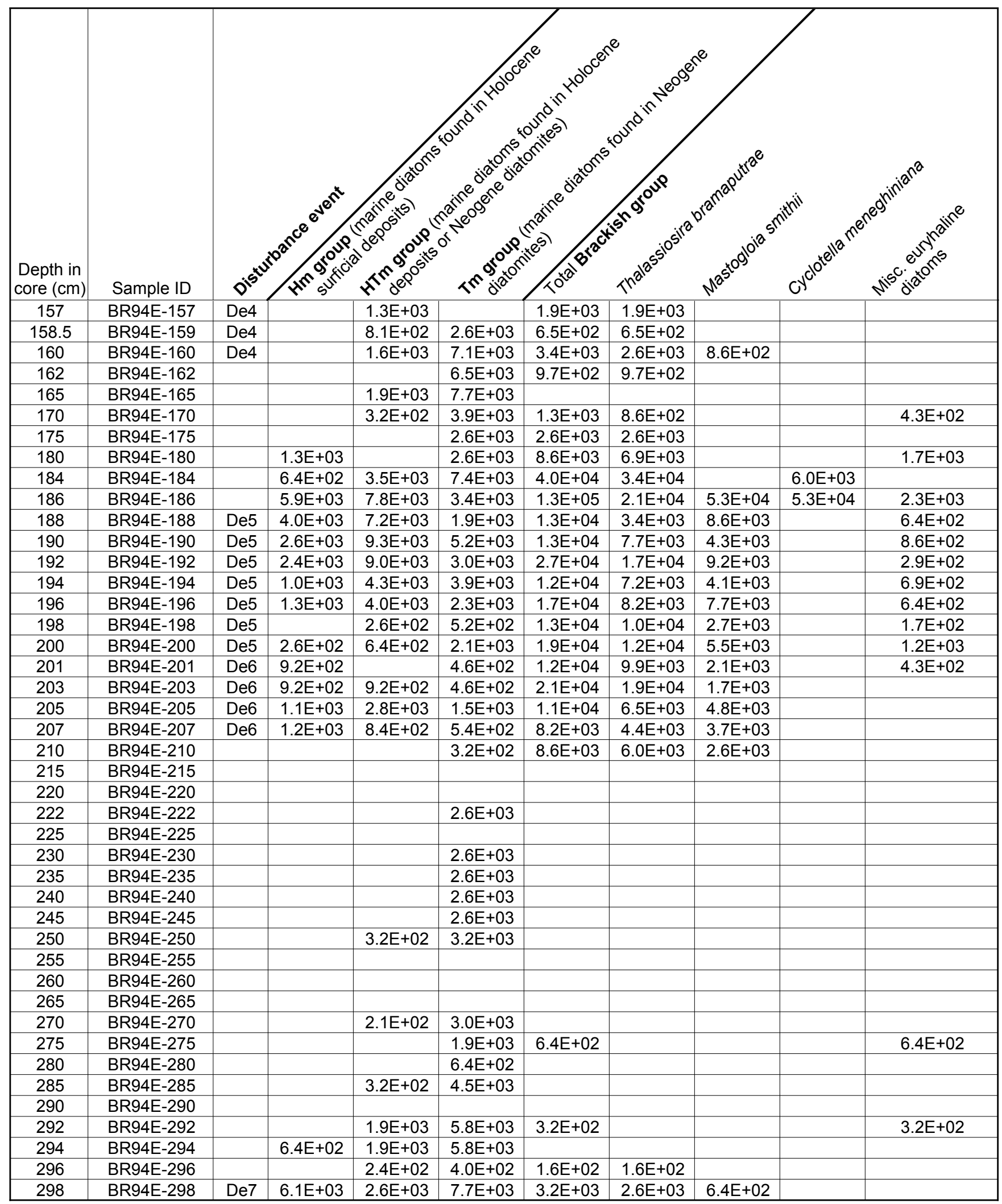




\section{Appendix 3. Downcore diatom data from Bradley Lake (diatom concentration in valves per ce of sediment).}






\section{Appendix 3. Downcore diatom data from Bradley Lake (diatom concentration in valves per ce of sediment).}

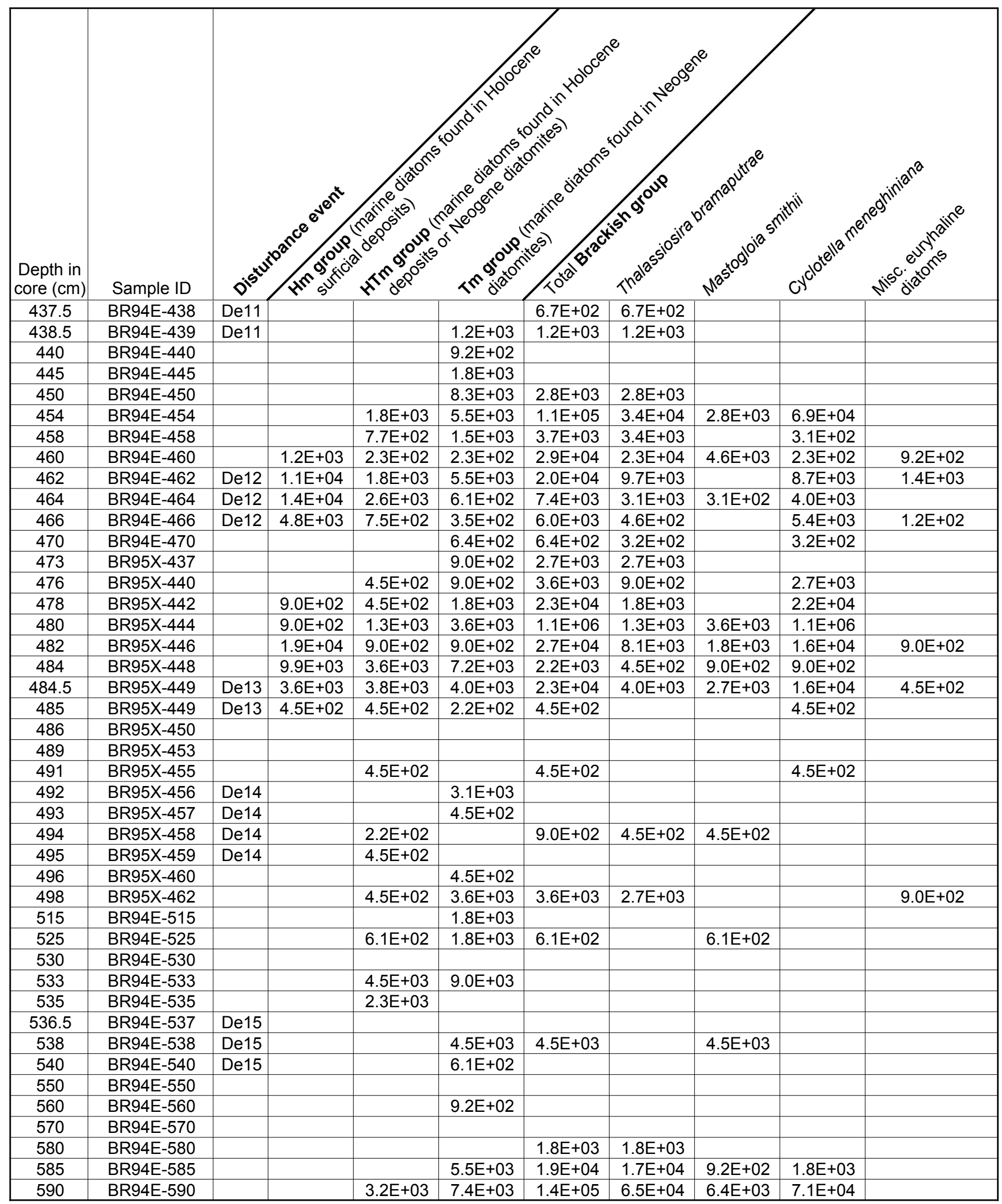


Appendix 3. Downcore diatom data from Bradley Lake (diatom concentration in valves per ce of sediment).

\begin{tabular}{|c|c|c|c|c|c|c|c|c|c|c|}
\hline $\begin{array}{c}\text { Depth in } \\
\text { core }(\mathrm{cm})\end{array}$ & Sample ID & $0^{15}$ & & & & & $\partial$ & $N^{2^{5}}$ & $\mathrm{Cr}^{\mathrm{CO}}$ & $4_{10} j_{0}$ \\
\hline 595 & BR94E-595 & & & $1.4 \mathrm{E}+03$ & $1.3 \mathrm{E}+03$ & $1.2 \mathrm{E}+05$ & $1.3 \mathrm{E}+04$ & $8.2 \mathrm{E}+03$ & $9.6 \mathrm{E}+04$ & \\
\hline 600 & BR94E-600 & & & $4.3 \mathrm{E}+02$ & $8.6 \mathrm{E}+02$ & $1.9 \mathrm{E}+04$ & $5.2 \mathrm{E}+03$ & & $1.4 \mathrm{E}+04$ & \\
\hline 602.5 & BR94E-603 & & & & $4.7 \mathrm{E}+03$ & $2.1 \mathrm{E}+05$ & $1.6 \mathrm{E}+05$ & $4.7 \mathrm{E}+03$ & $4.7 \mathrm{E}+04$ & \\
\hline 605 & BR94E-605 & & & & & $3.2 \mathrm{E}+02$ & $3.2 \mathrm{E}+02$ & & & \\
\hline 606 & BR94E-607 & De16 & & & $4.7 \mathrm{E}+03$ & $9.4 \mathrm{E}+03$ & $9.4 \mathrm{E}+03$ & & & \\
\hline 608 & BR94E-608 & De16 & & & & $5.2 \mathrm{E}+04$ & $4.7 \mathrm{E}+04$ & $4.7 \mathrm{E}+03$ & & \\
\hline 610 & BR94E-610 & & & & & & & & & \\
\hline 615 & BR94E-615 & & & & $2.6 \mathrm{E}+02$ & $1.3 \mathrm{E}+03$ & $1.3 \mathrm{E}+03$ & & & \\
\hline 620 & BR94E-620 & & $6.4 \mathrm{E}+02$ & & $1.3 \mathrm{E}+03$ & $9.0 \mathrm{E}+03$ & $7.7 \mathrm{E}+03$ & $1.3 \mathrm{E}+03$ & & \\
\hline 624 & BR94E-624 & & & $1.3 \mathrm{E}+03$ & $6.4 \mathrm{E}+02$ & $1.4 \mathrm{E}+04$ & $1.2 \mathrm{E}+04$ & $1.3 \mathrm{E}+03$ & & \\
\hline 628 & BR94E-628 & & $1.3 \mathrm{E}+03$ & $2.6 \mathrm{E}+03$ & $1.3 \mathrm{E}+03$ & $5.2 \mathrm{E}+04$ & $5.2 \mathrm{E}+04$ & & & \\
\hline 630 & BR94E-630 & & & $1.6 \mathrm{E}+03$ & $1.3 \mathrm{E}+03$ & $3.5 \mathrm{E}+04$ & $2.6 \mathrm{E}+04$ & $5.5 \mathrm{E}+03$ & $2.9 \mathrm{E}+03$ & $4.8 \mathrm{E}+02$ \\
\hline 632 & BR94E-632 & & $6.4 \mathrm{E}+03$ & $4.5 \mathrm{E}+04$ & $9.0 \mathrm{E}+03$ & $3.9 \mathrm{E}+03$ & $2.1 \mathrm{E}+03$ & $1.5 \mathrm{E}+03$ & $2.6 \mathrm{E}+02$ & $4.1 \mathrm{E}+03$ \\
\hline 634 & BR94E-634 & De17 & $2.3 \mathrm{E}+03$ & $4.6 \mathrm{E}+03$ & $1.2 \mathrm{E}+03$ & $2.0 \mathrm{E}+03$ & $9.2 \mathrm{E}+02$ & $1.0 \mathrm{E}+03$ & $9.2 \mathrm{E}+01$ & $1.6 \mathrm{E}+03$ \\
\hline 636 & BR94E-636 & & & & & $6.4 \mathrm{E}+02$ & $6.4 \mathrm{E}+02$ & & & \\
\hline 640 & BR94E-640 & & & & & & & & & \\
\hline 650 & BR94E-650 & & & & & & & & & \\
\hline 660 & BR94E-660 & & & & & & & & & \\
\hline 670 & BR94E-670 & & & & & & & & & \\
\hline 680 & BR94E-680 & & & & & & & & & \\
\hline 690 & BR94E-690 & & & & & & & & & \\
\hline
\end{tabular}




\section{Appendix 3. Downcore diatom data from Bradley Lake (diatom concentration in valves per ce of sediment).}

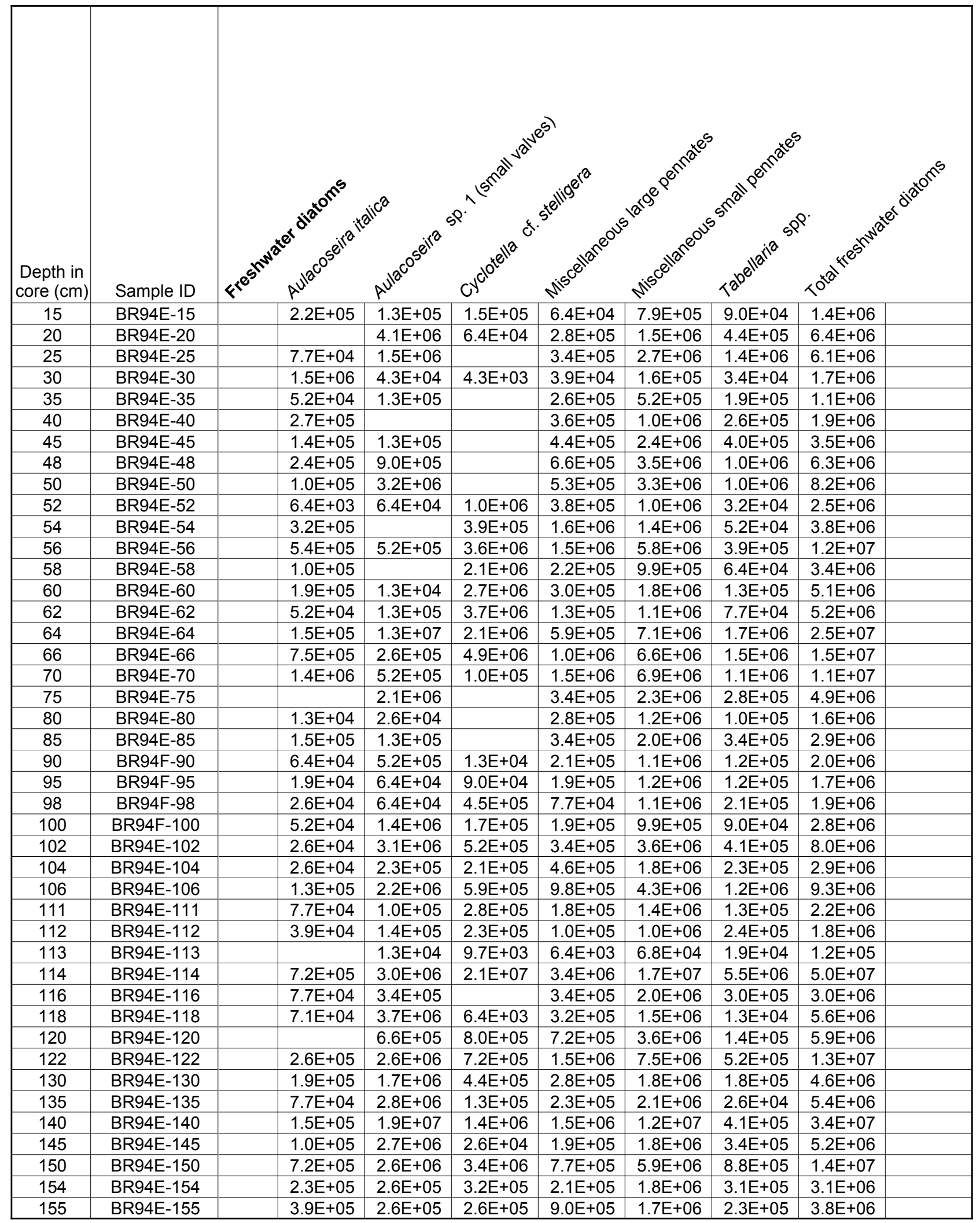




\section{Appendix 3. Downcore diatom data from Bradley Lake (diatom concentration in valves per ce of sediment).}

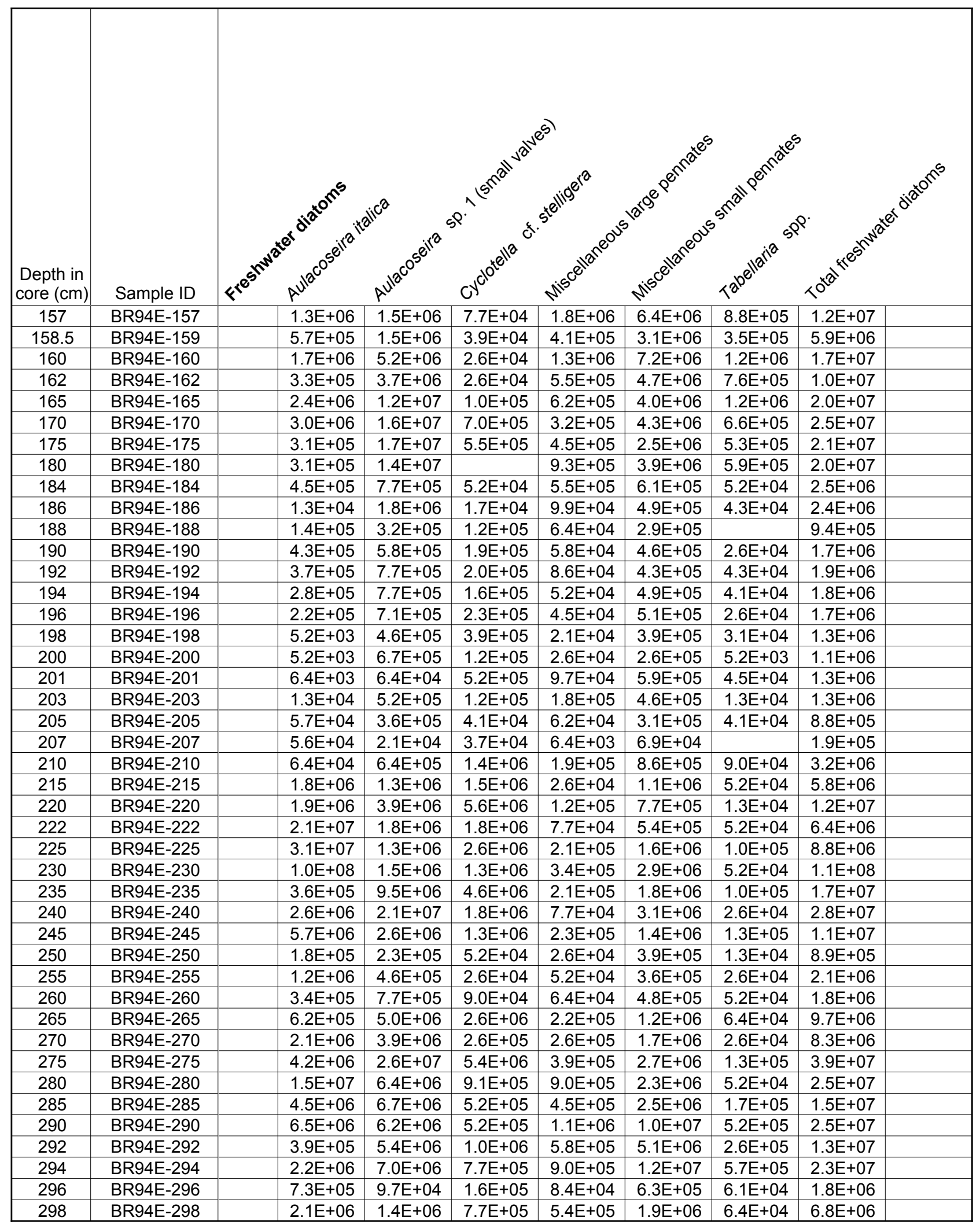




\section{Appendix 3. Downcore diatom data from Bradley Lake (diatom concentration in valves per ce of sediment).}

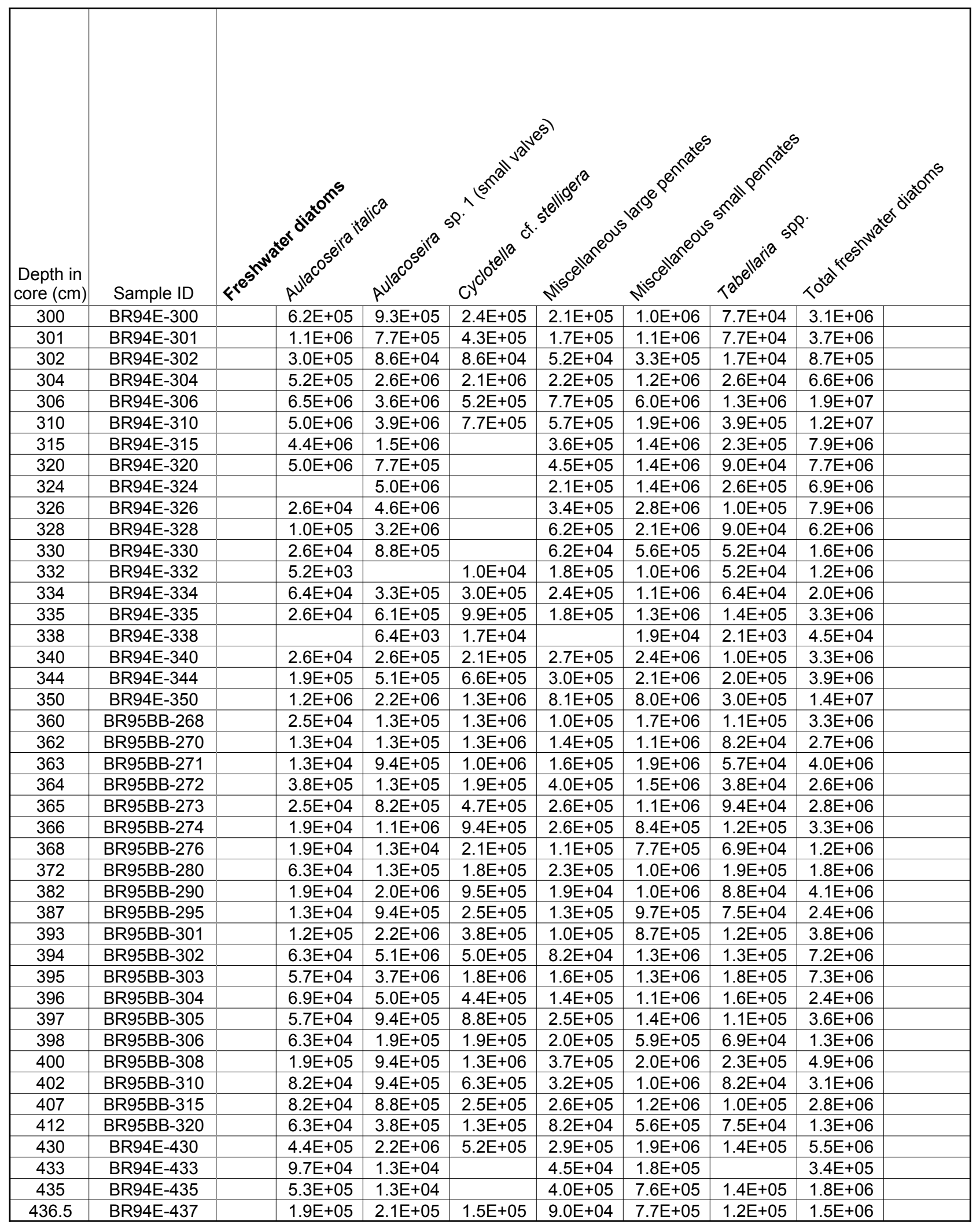




\section{Appendix 3. Downcore diatom data from Bradley Lake (diatom concentration in valves per ce of sediment).}

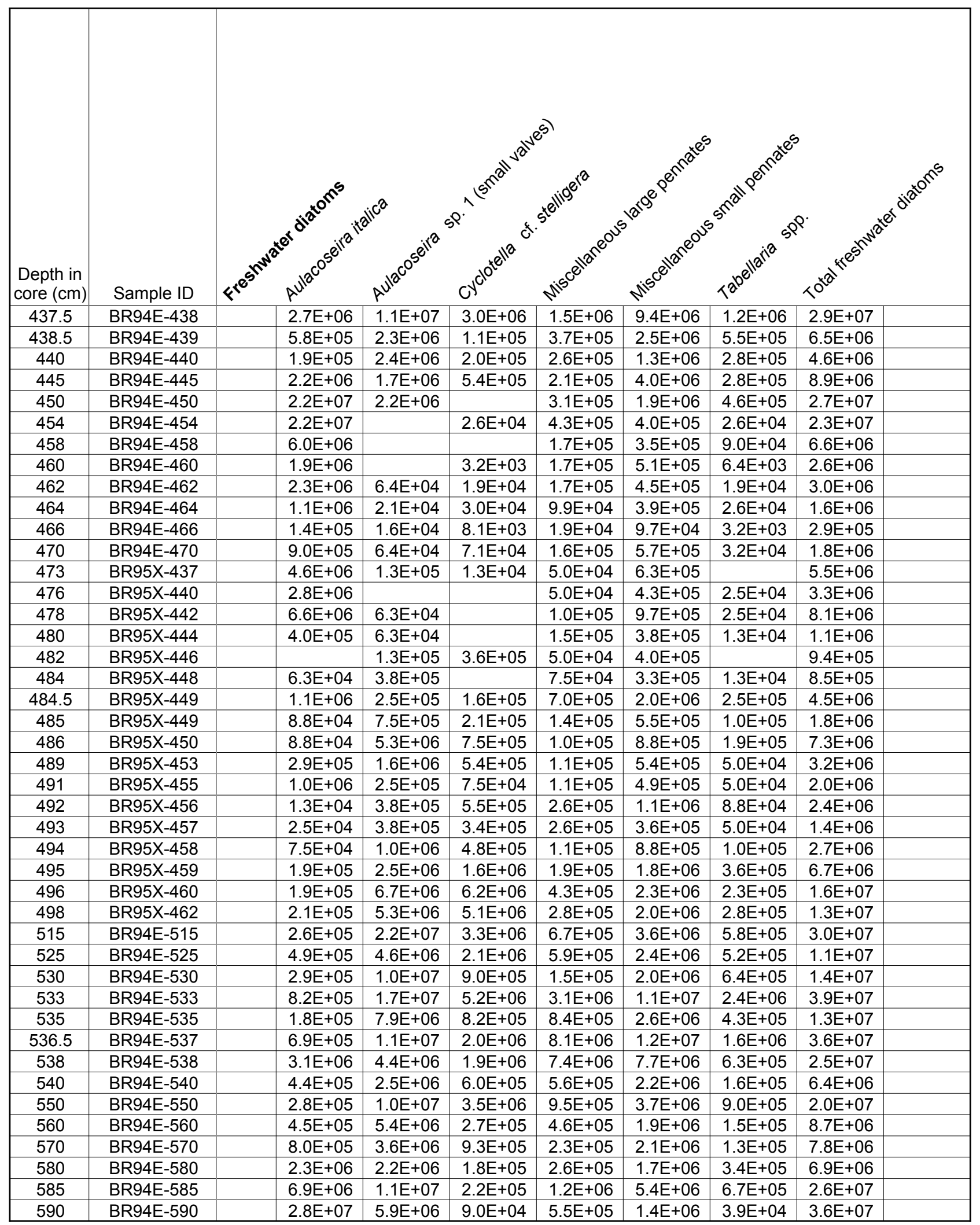


Appendix 3. Downcore diatom data from Bradley Lake (diatom concentration in valves per ce of sediment).

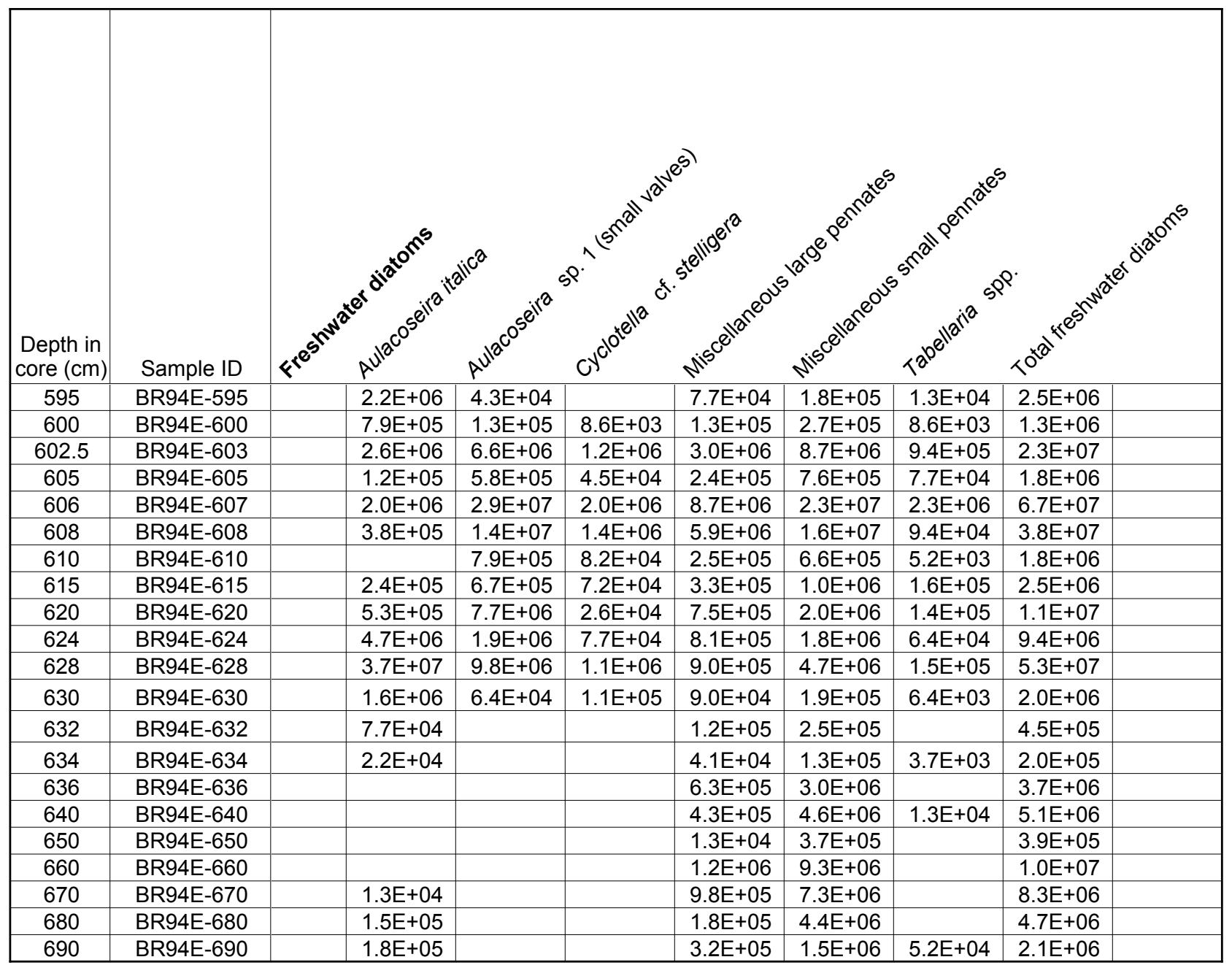


Appendix 3. Downcore diatom data from Bradley Lake (diatom concentration in valves per ce of sediment).

\begin{tabular}{|c|c|c|c|c|c|c|}
\hline $\begin{array}{l}\text { Depth in } \\
\text { core }(\mathrm{cm})\end{array}$ & Sample ID & $\begin{array}{c}\text { Number of } \\
\text { traverses } \\
\left(22 \mathrm{~mm}^{*}\right. \\
0.4 \mathrm{~mm}) \\
\text { counted }\end{array}$ & $\begin{array}{c}\text { Area of slide } \\
\text { observed } \\
\left(\mathrm{mm}^{\wedge} 2\right)\end{array}$ & $\begin{array}{l}\text { Area of } \\
\text { settling } \\
\text { chamber } \\
\left(\mathrm{mm}^{\wedge} 2\right)\end{array}$ & $\begin{array}{c}\text { Aliquot } \\
\text { volume }(\mu \mathrm{l}) \\
+ \\
\text { 10x dilution }\end{array}$ & $\begin{array}{l}\text { Percentage of } \\
\text { sample } \\
\text { scanned for } \\
\text { marine diatoms }\end{array}$ \\
\hline 15 & BR94E-15 & 20 & 176 & 1134 & 0.01 & $16 \%$ \\
\hline 20 & BR94E-20 & 20 & 176 & 1134 & 0.01 & $16 \%$ \\
\hline 25 & BR94E-25 & 20 & 176 & 1134 & 0.01 & $16 \%$ \\
\hline 30 & BR94E-30 & 20 & 176 & 1134 & 0.03 & $16 \%$ \\
\hline 35 & BR94E-35 & 20 & 176 & 1134 & 0.01 & $16 \%$ \\
\hline 40 & BR94E-40 & 20 & 176 & 1134 & 0.01 & $16 \%$ \\
\hline 45 & BR94E-45 & 20 & 176 & 1134 & 0.01 & $16 \%$ \\
\hline 48 & BR94E-48 & 20 & 176 & 1134 & 0.01 & $16 \%$ \\
\hline 50 & BR94E-50 & 20 & 176 & 1134 & 0.01 & $16 \%$ \\
\hline 52 & BR94E-52 & 20 & 176 & 1134 & 0.02 & $16 \%$ \\
\hline 54 & BR94E-54 & 20 & 176 & 1134 & 0.01 & $16 \%$ \\
\hline 56 & BR94E-56 & 20 & 176 & 1134 & 0.005 & $16 \%$ \\
\hline 58 & BR94E-58 & 20 & 176 & 1134 & 0.01 & $16 \%$ \\
\hline 60 & BR94E-60 & 20 & 176 & 1134 & 0.01 & $16 \%$ \\
\hline 62 & BR94E-62 & 20 & 176 & 1134 & 0.01 & $16 \%$ \\
\hline 64 & BR94E-64 & 20 & 176 & 1134 & 0.005 & $16 \%$ \\
\hline 66 & BR94E-66 & 20 & 176 & 1134 & 0.005 & $16 \%$ \\
\hline 70 & BR94E-70 & 20 & 176 & 1134 & 0.005 & $16 \%$ \\
\hline 75 & BR94E-75 & 20 & 176 & 1134 & 0.005 & $16 \%$ \\
\hline 80 & BR94E-80 & 20 & 176 & 1134 & 0.01 & $16 \%$ \\
\hline 85 & BR94E-85 & 20 & 176 & 1134 & 0.01 & $16 \%$ \\
\hline 90 & BR94F-90 & 20 & 176 & 1134 & 0.01 & $16 \%$ \\
\hline 95 & BR94F-95 & 20 & 176 & 1134 & 0.01 & $16 \%$ \\
\hline 98 & BR94F-98 & 20 & 176 & 1134 & 0.01 & $16 \%$ \\
\hline 100 & BR94F-100 & 20 & 176 & 1134 & 0.01 & $16 \%$ \\
\hline 102 & BR94E-102 & 20 & 176 & 1134 & 0.01 & $16 \%$ \\
\hline 104 & BR94E-104 & 20 & 176 & 1134 & 0.01 & $16 \%$ \\
\hline 106 & BR94E-106 & 20 & 176 & 1134 & 0.01 & $16 \%$ \\
\hline 111 & BR94E-111 & 20 & 176 & 1134 & 0.01 & $16 \%$ \\
\hline 112 & BR94E-112 & 20 & 176 & 1134 & 0.02 & $16 \%$ \\
\hline 113 & BR94E-113 & 20 & 176 & 1134 & 0.08 & $16 \%$ \\
\hline 114 & BR94E-114 & 20 & 176 & 1134 & 0.0025 & $16 \%$ \\
\hline 116 & BR94E-116 & 20 & 176 & 1134 & 0.015 & $16 \%$ \\
\hline 118 & BR94E-118 & 20 & 176 & 1134 & 0.02 & $16 \%$ \\
\hline 120 & BR94E-120 & 20 & 176 & 1134 & 0.01 & $16 \%$ \\
\hline 122 & BR94E-122 & 20 & 176 & 1134 & 0.0025 & $16 \%$ \\
\hline 130 & BR94E-130 & 20 & 176 & 1134 & 0.01 & $16 \%$ \\
\hline 135 & BR94E-135 & 20 & 176 & 1134 & 0.005 & $16 \%$ \\
\hline 140 & BR94E-140 & 20 & 176 & 1134 & 0.0025 & $16 \%$ \\
\hline 145 & BR94E-145 & 20 & 176 & 1134 & 0.01 & $16 \%$ \\
\hline 150 & BR94E-150 & 20 & 176 & 1134 & 0.01 & $16 \%$ \\
\hline 154 & BR94E-154 & 20 & 176 & 1134 & 0.02 & $16 \%$ \\
\hline 155 & BR94E-155 & 20 & 176 & 1134 & 0.01 & $16 \%$ \\
\hline
\end{tabular}




\section{Appendix 3. Downcore diatom data from Bradley Lake (diatom concentration in valves per ce of}

sediment).

\begin{tabular}{|c|c|c|c|c|c|c|}
\hline $\begin{array}{c}\text { Depth in } \\
\text { core }(\mathrm{cm})\end{array}$ & Sample ID & $\begin{array}{c}\text { Number of } \\
\text { traverses } \\
\left(22 \mathrm{~mm}^{*}\right. \\
0.4 \mathrm{~mm}) \\
\text { counted }\end{array}$ & $\begin{array}{c}\text { Area of slide } \\
\text { observed } \\
\left(\mathrm{mm}^{\wedge} 2\right)\end{array}$ & $\begin{array}{l}\text { Area of } \\
\text { settling } \\
\text { chamber } \\
\left(\mathrm{mm}^{\wedge} 2\right)\end{array}$ & $\begin{array}{c}\text { Aliquot } \\
\text { volume }(\mu \mathrm{l}) \\
+ \\
\text { 10x dilution }\end{array}$ & $\begin{array}{l}\text { Percentage of } \\
\text { sample } \\
\text { scanned for } \\
\text { marine diatoms }\end{array}$ \\
\hline 157 & BR94E-157 & 20 & 176 & 1134 & 0.01 & $16 \%$ \\
\hline 158.5 & BR94E-159 & 20 & 176 & 1134 & 0.02 & $16 \%$ \\
\hline 160 & BR94E-160 & 10 & 176 & 1134 & 0.01 & $16 \%$ \\
\hline 162 & BR94E-162 & 20 & 176 & 1134 & 0.02 & $16 \%$ \\
\hline 165 & BR94E-165 & 20 & 176 & 1134 & 0.005 & $16 \%$ \\
\hline 170 & BR94E-170 & 20 & 176 & 1134 & 0.01 & $16 \%$ \\
\hline 175 & BR94E-175 & 20 & 176 & 1134 & 0.01 & $16 \%$ \\
\hline 180 & BR94E-180 & 20 & 176 & 1134 & 0.005 & $16 \%$ \\
\hline 184 & BR94E-184 & 20 & 176 & 1134 & 0.01 & $16 \%$ \\
\hline 186 & BR94E-186 & 20 & 176 & 1134 & 0.03 & $16 \%$ \\
\hline 188 & BR94E-188 & 20 & 176 & 1134 & 0.02 & $16 \%$ \\
\hline 190 & BR94E-190 & 20 & 176 & 1134 & 0.02 & $16 \%$ \\
\hline 192 & BR94E-192 & 20 & 176 & 1134 & 0.015 & $16 \%$ \\
\hline 194 & BR94E-194 & 20 & 176 & 1134 & 0.025 & $16 \%$ \\
\hline 196 & BR94E-196 & 20 & 176 & 1134 & 0.02 & $16 \%$ \\
\hline 198 & BR94E-198 & 20 & 176 & 1134 & 0.025 & $16 \%$ \\
\hline 200 & BR94E-200 & 20 & 176 & 1134 & 0.025 & $16 \%$ \\
\hline 201 & BR94E-201 & 14 & 123.2 & 1134 & 0.02 & $12 \%$ \\
\hline 203 & BR94E-203 & 14 & 123.2 & 1134 & 0.01 & $12 \%$ \\
\hline 205 & BR94E-205 & 14 & 123.2 & 1134 & 0.025 & $12 \%$ \\
\hline 207 & BR94E-207 & 14 & 123.2 & 1134 & 0.06 & $12 \%$ \\
\hline 210 & BR94E-210 & 20 & 176 & 1134 & 0.02 & $16 \%$ \\
\hline 215 & BR94E-215 & 20 & 176 & 1134 & 0.005 & $16 \%$ \\
\hline 220 & BR94E-220 & 20 & 176 & 1134 & 0.01 & $16 \%$ \\
\hline 222 & BR94E-222 & 20 & 176 & 1134 & 0.005 & $16 \%$ \\
\hline 225 & BR94E-225 & 20 & 176 & 1134 & 0.005 & $16 \%$ \\
\hline 230 & BR94E-230 & 20 & 176 & 1134 & 0.005 & $16 \%$ \\
\hline 235 & BR94E-235 & 20 & 176 & 1134 & 0.005 & $16 \%$ \\
\hline 240 & BR94E-240 & 20 & 176 & 1134 & 0.005 & $16 \%$ \\
\hline 245 & BR94E-245 & 20 & 176 & 1134 & 0.005 & $16 \%$ \\
\hline 250 & BR94E-250 & 20 & 176 & 1134 & 0.01 & $16 \%$ \\
\hline 255 & BR94E-255 & 20 & 176 & 1134 & 0.005 & $16 \%$ \\
\hline 260 & BR94E-260 & 20 & 176 & 1134 & 0.01 & $16 \%$ \\
\hline 265 & BR94E-265 & 20 & 176 & 1134 & 0.01 & $16 \%$ \\
\hline 270 & BR94E-270 & 20 & 176 & 1134 & 0.015 & $16 \%$ \\
\hline 275 & BR94E-275 & 20 & 176 & 1134 & 0.01 & $16 \%$ \\
\hline 280 & BR94E-280 & 20 & 176 & 1134 & 0.01 & $16 \%$ \\
\hline 285 & BR94E-285 & 20 & 176 & 1134 & 0.01 & $16 \%$ \\
\hline 290 & BR94E-290 & 20 & 176 & 1134 & 0.005 & $16 \%$ \\
\hline 292 & BR94E-292 & 20 & 176 & 1134 & 0.01 & $16 \%$ \\
\hline 294 & BR94E-294 & 20 & 176 & 1134 & 0.005 & $16 \%$ \\
\hline 296 & BR94E-296 & 20 & 176 & 1134 & 0.04 & $16 \%$ \\
\hline 298 & BR94E-298 & 20 & 176 & 1134 & 0.01 & $16 \%$ \\
\hline
\end{tabular}


Appendix 3. Downcore diatom data from Bradley Lake (diatom concentration in valves per ce of sediment).

\begin{tabular}{|c|c|c|c|c|c|c|}
\hline $\begin{array}{l}\text { Depth in } \\
\text { core }(\mathrm{cm})\end{array}$ & Sample ID & $\begin{array}{c}\text { Number of } \\
\text { traverses } \\
\left(22 \mathrm{~mm}^{*}\right. \\
0.4 \mathrm{~mm}) \\
\text { counted }\end{array}$ & $\begin{array}{c}\text { Area of slide } \\
\text { observed } \\
\left(\mathrm{mm}^{\wedge} 2\right)\end{array}$ & $\begin{array}{l}\text { Area of } \\
\text { settling } \\
\text { chamber } \\
\left(\mathrm{mm}^{\wedge} 2\right)\end{array}$ & $\begin{array}{c}\text { Aliquot } \\
\text { volume }(\mu \mathrm{l}) \\
+ \\
\text { 10x dilution }\end{array}$ & $\begin{array}{l}\text { Percentage of } \\
\text { sample } \\
\text { scanned for } \\
\text { marine diatoms }\end{array}$ \\
\hline 300 & BR94E-300 & 20 & 176 & 1134 & 0.025 & $16 \%$ \\
\hline 301 & BR94E-301 & 20 & 176 & 1134 & 0.015 & $16 \%$ \\
\hline 302 & BR94E-302 & 20 & 176 & 1134 & 0.015 & $16 \%$ \\
\hline 304 & BR94E-304 & 20 & 176 & 1134 & 0.01 & $16 \%$ \\
\hline 306 & BR94E-306 & 20 & 176 & 1134 & 0.01 & $16 \%$ \\
\hline 310 & BR94E-310 & 20 & 176 & 1134 & 0.01 & $16 \%$ \\
\hline 315 & BR94E-315 & 20 & 176 & 1134 & 0.02 & $16 \%$ \\
\hline 320 & BR94E-320 & 20 & 176 & 1134 & 0.01 & $16 \%$ \\
\hline 324 & BR94E-324 & 20 & 176 & 1134 & 0.005 & $16 \%$ \\
\hline 326 & BR94E-326 & 20 & 176 & 1134 & 0.01 & $16 \%$ \\
\hline 328 & BR94E-328 & 20 & 176 & 1134 & 0.01 & $16 \%$ \\
\hline 330 & BR94E-330 & 20 & 176 & 1134 & 0.025 & $16 \%$ \\
\hline 332 & BR94E-332 & 20 & 176 & 1134 & 0.025 & $16 \%$ \\
\hline 334 & BR94E-334 & 20 & 176 & 1134 & 0.02 & $16 \%$ \\
\hline 335 & BR94E-335 & 20 & 176 & 1134 & 0.02 & $16 \%$ \\
\hline 338 & BR94E-338 & 20 & 176 & 1134 & 0.12 & $16 \%$ \\
\hline 340 & BR94E-340 & 20 & 176 & 1134 & 0.015 & $16 \%$ \\
\hline 344 & BR94E-344 & 20 & 176 & 1134 & 0.025 & $16 \%$ \\
\hline 350 & BR94E-350 & 20 & 176 & 1134 & 0.01 & $16 \%$ \\
\hline 360 & BR95BB-268 & 14 & 123.2 & 3316 & 0.06 & $4 \%$ \\
\hline 362 & BR95BB-270 & 14 & 123.2 & 3316 & 0.06 & $4 \%$ \\
\hline 363 & BR95BB-271 & 14 & 123.2 & 3316 & 0.06 & $4 \%$ \\
\hline 364 & BR95BB-272 & 14 & 123.2 & 3316 & 0.06 & $4 \%$ \\
\hline 365 & BR95BB-273 & 14 & 123.2 & 3316 & 0.06 & $4 \%$ \\
\hline 366 & BR95BB-274 & 14 & 123.2 & 3316 & 0.06 & $4 \%$ \\
\hline 368 & BR95BB-276 & 14 & 123.2 & 3316 & 0.06 & $4 \%$ \\
\hline 372 & BR95BB-280 & 15 & 123.2 & 3316 & 0.06 & $4 \%$ \\
\hline 382 & BR95BB-290 & 14 & 123.2 & 3316 & 0.06 & $4 \%$ \\
\hline 387 & BR95BB-295 & 14 & 123.2 & 3316 & 0.06 & $4 \%$ \\
\hline 393 & BR95BB-301 & 14 & 123.2 & 3316 & 0.06 & $4 \%$ \\
\hline 394 & BR95BB-302 & 14 & 123.2 & 3316 & 0.06 & $4 \%$ \\
\hline 395 & BR95BB-303 & 14 & 123.2 & 3316 & 0.06 & $4 \%$ \\
\hline 396 & BR95BB-304 & 14 & 123.2 & 3316 & 0.06 & $4 \%$ \\
\hline 397 & BR95BB-305 & 14 & 123.2 & 3316 & 0.06 & $4 \%$ \\
\hline 398 & BR95BB-306 & 14 & 123.2 & 3316 & 0.06 & $4 \%$ \\
\hline 400 & BR95BB-308 & 14 & 123.2 & 3316 & 0.06 & $4 \%$ \\
\hline 402 & BR95BB-310 & 14 & 123.2 & 3316 & 0.06 & $4 \%$ \\
\hline 407 & BR95BB-315 & 14 & 123.2 & 3316 & 0.06 & $4 \%$ \\
\hline 412 & BR95BB-320 & 14 & 123.2 & 3316 & 0.06 & $4 \%$ \\
\hline 430 & BR94E-430 & 14 & 123.2 & 1134 & 0.02 & $11 \%$ \\
\hline 433 & BR94E-433 & 14 & 123.2 & 1134 & 0.02 & $11 \%$ \\
\hline 435 & BR94E-435 & 14 & 123.2 & 1134 & 0.02 & $11 \%$ \\
\hline 436.5 & BR94E-437 & 14 & 123.2 & 1134 & 0.01 & $11 \%$ \\
\hline
\end{tabular}


Appendix 3. Downcore diatom data from Bradley Lake (diatom concentration in valves per ce of sediment).

\begin{tabular}{|c|c|c|c|c|c|c|}
\hline $\begin{array}{c}\text { Depth in } \\
\text { core }(\mathrm{cm})\end{array}$ & Sample ID & $\begin{array}{c}\text { Number of } \\
\text { traverses } \\
\left(22 \mathrm{~mm}^{*}\right. \\
0.4 \mathrm{~mm}) \\
\text { counted }\end{array}$ & $\begin{array}{c}\text { Area of slide } \\
\text { observed } \\
\left(\mathrm{mm}^{\wedge} 2\right)\end{array}$ & $\begin{array}{l}\text { Area of } \\
\text { settling } \\
\text { chamber } \\
\left(\mathrm{mm}^{\wedge} 2\right)\end{array}$ & $\begin{array}{c}\text { Aliquot } \\
\text { volume }(\mu \mathrm{l}) \\
+ \\
\text { 10x dilution }\end{array}$ & $\begin{array}{l}\text { Percentage of } \\
\text { sample } \\
\text { scanned for } \\
\text { marine diatoms }\end{array}$ \\
\hline 437.5 & BR94E-438 & 14 & 123.2 & 3316 & 0.006 & $4 \%$ \\
\hline 438.5 & BR94E-439 & 14 & 123.2 & 1134 & 0.015 & $11 \%$ \\
\hline 440 & BR94E-440 & 14 & 123.2 & 1134 & 0.03 & $11 \%$ \\
\hline 445 & BR94E-445 & 14 & 123.2 & 1134 & 0.01 & $11 \%$ \\
\hline 450 & BR94E-450 & 14 & 123.2 & 1134 & 0.01 & $11 \%$ \\
\hline 454 & BR94E-454 & 14 & 123.2 & 1134 & 0.01 & $11 \%$ \\
\hline 458 & BR94E-458 & 14 & 123.2 & 1134 & 0.03 & $11 \%$ \\
\hline 460 & BR94E-460 & 14 & 123.2 & 1134 & 0.04 & $11 \%$ \\
\hline 462 & BR94E-462 & 14 & 123.2 & 1134 & 0.02 & $11 \%$ \\
\hline 464 & BR94E-464 & 14 & 123.2 & 1134 & 0.03 & $11 \%$ \\
\hline 466 & BR94E-466 & 14 & 123.2 & 1134 & 0.08 & $11 \%$ \\
\hline 470 & BR94E-470 & 14 & 123.2 & 1134 & 0.03 & $16 \%$ \\
\hline 473 & BR95X-437 & 14 & 123.2 & 3316 & 0.06 & $4 \%$ \\
\hline 476 & BR95X-440 & 14 & 123.2 & 3316 & 0.06 & $4 \%$ \\
\hline 478 & BR95X-442 & 14 & 123.2 & 3316 & 0.06 & $4 \%$ \\
\hline 480 & BR95X-444 & 14 & 123.2 & 3316 & 0.06 & $4 \%$ \\
\hline 482 & BR95X-446 & 14 & 123.2 & 3316 & 0.06 & $4 \%$ \\
\hline 484 & BR95X-448 & 14 & 123.2 & 3316 & 0.06 & $4 \%$ \\
\hline 484.5 & BR95X-449 & 14 & 123.2 & 3316 & 0.06 & $4 \%$ \\
\hline 485 & BR95X-449 & 14 & 123.2 & 3316 & 0.06 & $4 \%$ \\
\hline 486 & BR95X-450 & 14 & 123.2 & 3316 & 0.06 & $4 \%$ \\
\hline 489 & BR95X-453 & 14 & 123.2 & 3316 & 0.06 & $4 \%$ \\
\hline 491 & BR95X-455 & 14 & 123.2 & 3316 & 0.06 & $4 \%$ \\
\hline 492 & BR95X-456 & 14 & 123.2 & 3316 & 0.06 & $4 \%$ \\
\hline 493 & BR95X-457 & 14 & 123.2 & 3316 & 0.06 & $4 \%$ \\
\hline 494 & BR95X-458 & 14 & 123.2 & 3316 & 0.06 & $4 \%$ \\
\hline 495 & BR95X-459 & 14 & 123.2 & 3316 & 0.06 & $4 \%$ \\
\hline 496 & BR95X-460 & 14 & 123.2 & 3316 & 0.06 & $4 \%$ \\
\hline 498 & BR95X-462 & 14 & 123.2 & 3316 & 0.06 & $4 \%$ \\
\hline 515 & BR94E-515 & 14 & 123.2 & 1134 & 0.01 & $11 \%$ \\
\hline 525 & BR94E-525 & 14 & 123.2 & 1134 & 0.015 & $11 \%$ \\
\hline 530 & BR94E-530 & 14 & 123.2 & 1134 & 0.015 & $11 \%$ \\
\hline 533 & BR94E-533 & 14 & 123.2 & 3316 & 0.006 & $4 \%$ \\
\hline 535 & BR94E-535 & 14 & 123.2 & 1134 & 0.01 & $11 \%$ \\
\hline 536.5 & BR94E-537 & 14 & 123.2 & 3316 & 0.006 & $4 \%$ \\
\hline 538 & BR94E-538 & 14 & 123.2 & 3316 & 0.006 & $4 \%$ \\
\hline 540 & BR94E-540 & 14 & 123.2 & 1134 & 0.015 & $11 \%$ \\
\hline 550 & BR94E-550 & 14 & 123.2 & 1134 & 0.01 & $11 \%$ \\
\hline 560 & BR94E-560 & 14 & 123.2 & 1134 & 0.01 & $11 \%$ \\
\hline 570 & BR94E-570 & 14 & 123.2 & 1134 & 0.005 & $11 \%$ \\
\hline 580 & BR94E-580 & 14 & 123.2 & 1134 & 0.01 & $11 \%$ \\
\hline 585 & BR94E-585 & 14 & 123.2 & 1134 & 0.01 & $11 \%$ \\
\hline 590 & BR94E-590 & 14 & 123.2 & 1134 & 0.01 & $11 \%$ \\
\hline
\end{tabular}


Appendix 3. Downcore diatom data from Bradley Lake (diatom concentration in valves per cc of sediment).

\begin{tabular}{|c|c|c|c|c|c|c|}
\hline $\begin{array}{c}\text { Depth in } \\
\text { core }(\mathrm{cm})\end{array}$ & Sample ID & $\begin{array}{c}\text { Number of } \\
\text { traverses } \\
(22 \mathrm{~mm} \text { * } \\
0.4 \mathrm{~mm}) \\
\text { counted }\end{array}$ & $\begin{array}{c}\text { Area of slide } \\
\text { observed } \\
\left(\mathrm{mm}^{\wedge} 2\right)\end{array}$ & $\begin{array}{l}\text { Area of } \\
\text { settling } \\
\text { chamber } \\
\left(\mathrm{mm}^{\wedge} 2\right)\end{array}$ & $\begin{array}{c}\text { Aliquot } \\
\text { volume }(\mu \mathrm{l}) \\
+ \\
\text { 10x dilution }\end{array}$ & $\begin{array}{l}\text { Percentage of } \\
\text { sample } \\
\text { scanned for } \\
\text { marine diatoms }\end{array}$ \\
\hline 595 & BR94E-595 & 20 & 176 & 1134 & 0.03 & $16 \%$ \\
\hline 600 & BR94E-600 & 20 & 176 & 1134 & 0.03 & $16 \%$ \\
\hline 602.5 & BR94E-603 & 20 & 176 & 3316 & 0.004 & $5 \%$ \\
\hline 605 & BR94E-605 & 20 & 176 & 1134 & 0.02 & $16 \%$ \\
\hline 606 & BR94E-607 & 20 & 176 & 3316 & 0.004 & $5 \%$ \\
\hline 608 & BR94E-608 & 20 & 176 & 3316 & 0.004 & $5 \%$ \\
\hline 610 & BR94E-610 & 20 & 176 & 1134 & 0.025 & $16 \%$ \\
\hline 615 & BR94E-615 & 20 & 176 & 1134 & 0.025 & $16 \%$ \\
\hline 620 & BR94E-620 & 20 & 176 & 1134 & 0.01 & $16 \%$ \\
\hline 624 & BR94E-624 & 20 & 176 & 1134 & 0.01 & $16 \%$ \\
\hline 628 & BR94E-628 & 20 & 176 & 1134 & 0.005 & $16 \%$ \\
\hline 630 & BR94E-630 & 20 & 176 & 1134 & 0.02 & $16 \%$ \\
\hline 632 & BR94E-632 & 20 & 176 & 1134 & 0.025 & $16 \%$ \\
\hline 634 & BR94E-634 & 20 & 176 & 1134 & 0.07 & $16 \%$ \\
\hline 636 & BR94E-636 & 20 & 176 & 1134 & 0.01 & $16 \%$ \\
\hline 640 & BR94E-640 & 20 & 176 & 1134 & 0.01 & $16 \%$ \\
\hline 650 & BR94E-650 & 20 & 176 & 1134 & 0.01 & $16 \%$ \\
\hline 660 & BR94E-660 & 20 & 176 & 1134 & 0.005 & $16 \%$ \\
\hline 670 & BR94E-670 & 20 & 176 & 1134 & 0.01 & $16 \%$ \\
\hline 680 & BR94E-680 & 20 & 176 & 1134 & 0.01 & $16 \%$ \\
\hline 690 & BR94E-690 & 20 & 176 & 1134 & 0.01 & $16 \%$ \\
\hline
\end{tabular}


Appendix 4. Downcore diatom data from Bradley Lake (raw counts).

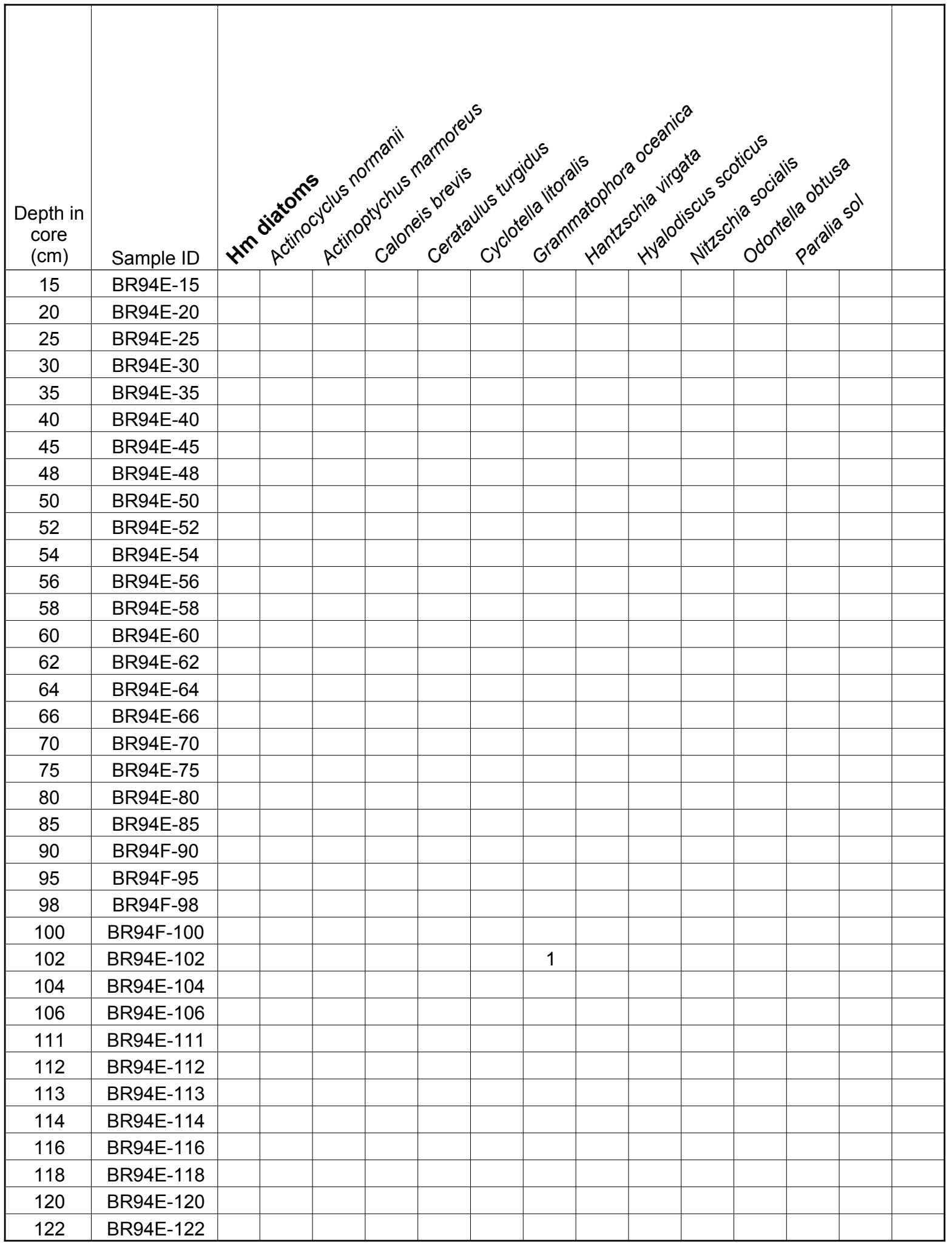


Appendix 4. Downcore diatom data from Bradley Lake (raw counts).

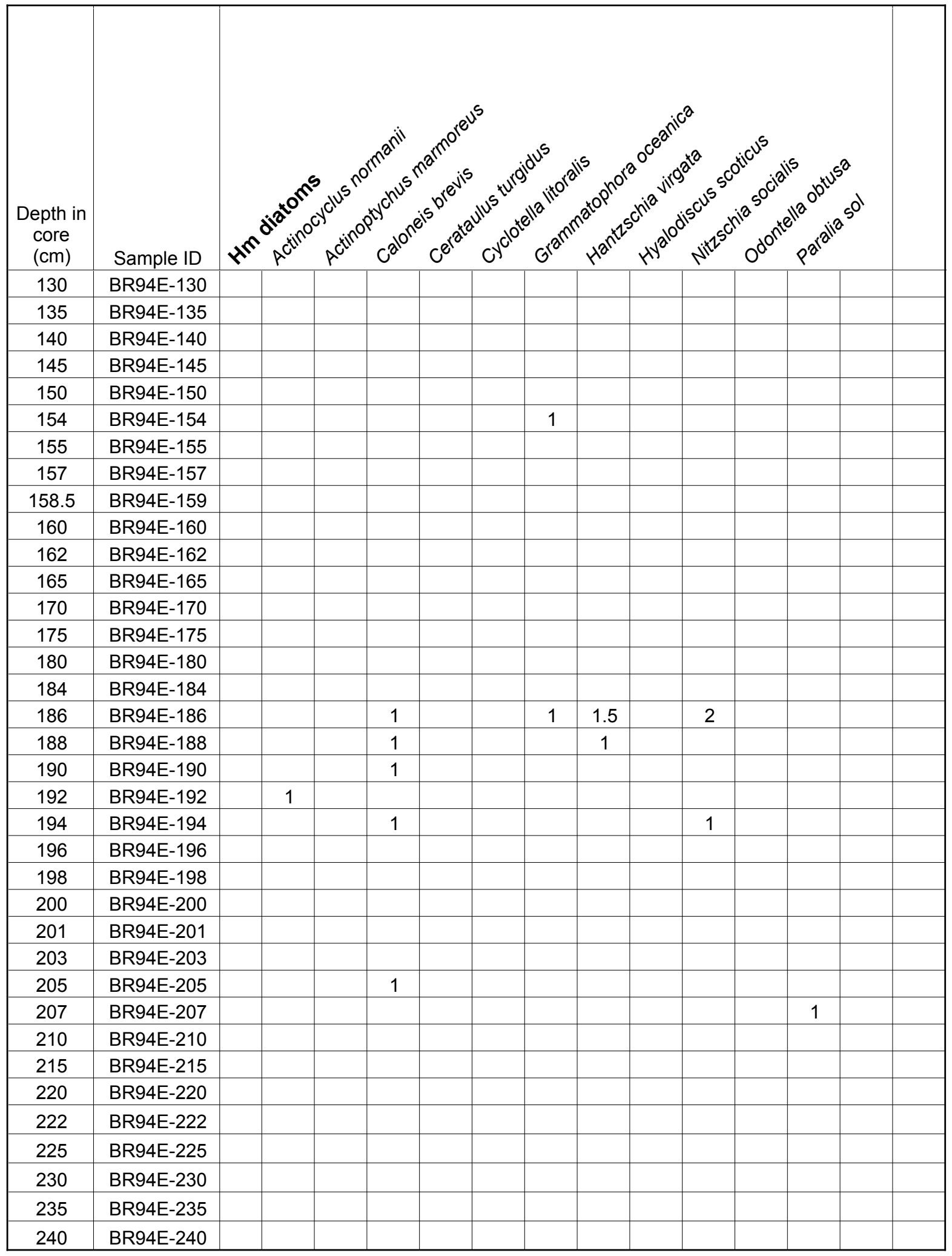


Appendix 4. Downcore diatom data from Bradley Lake (raw counts).

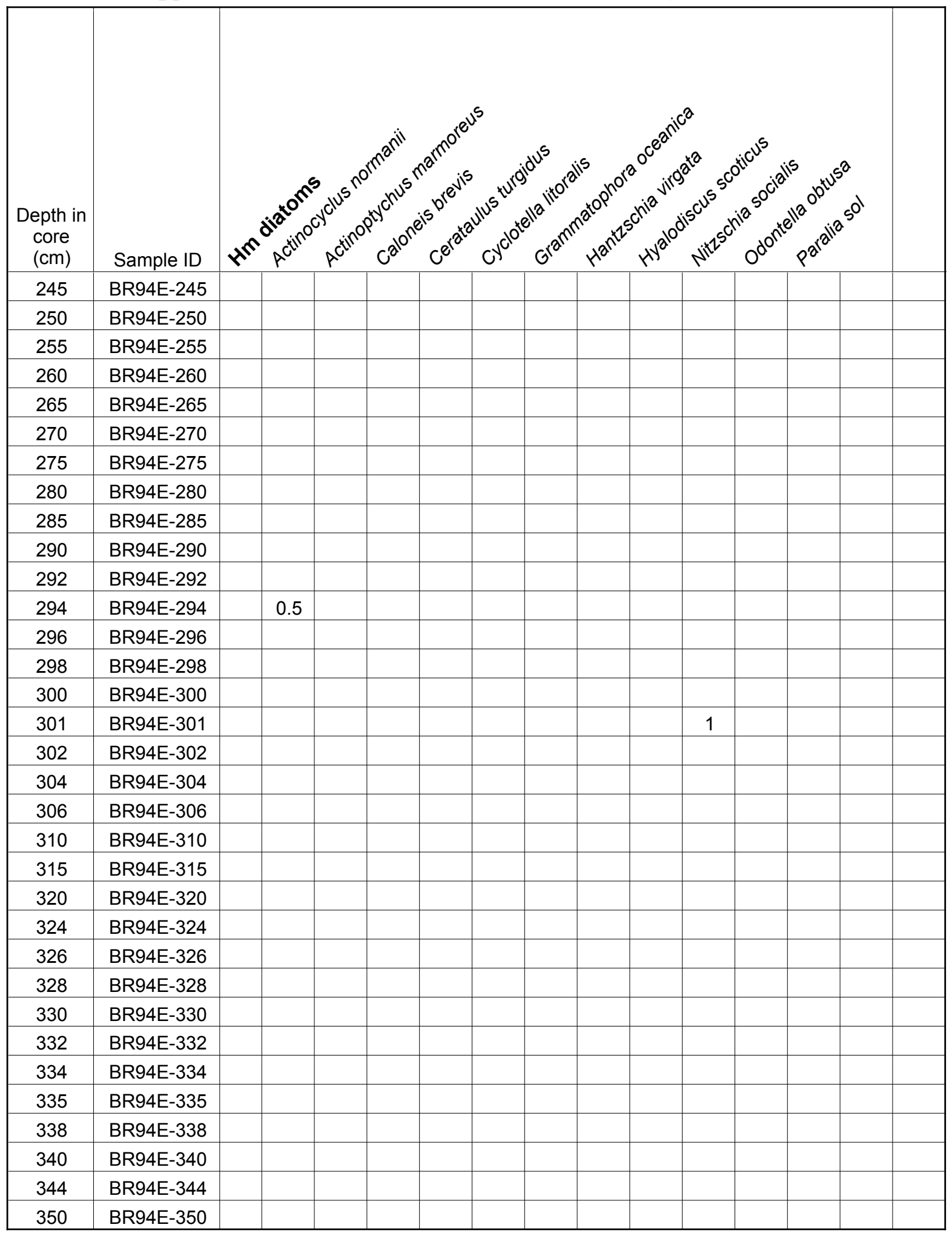


Appendix 4. Downcore diatom data from Bradley Lake (raw counts).

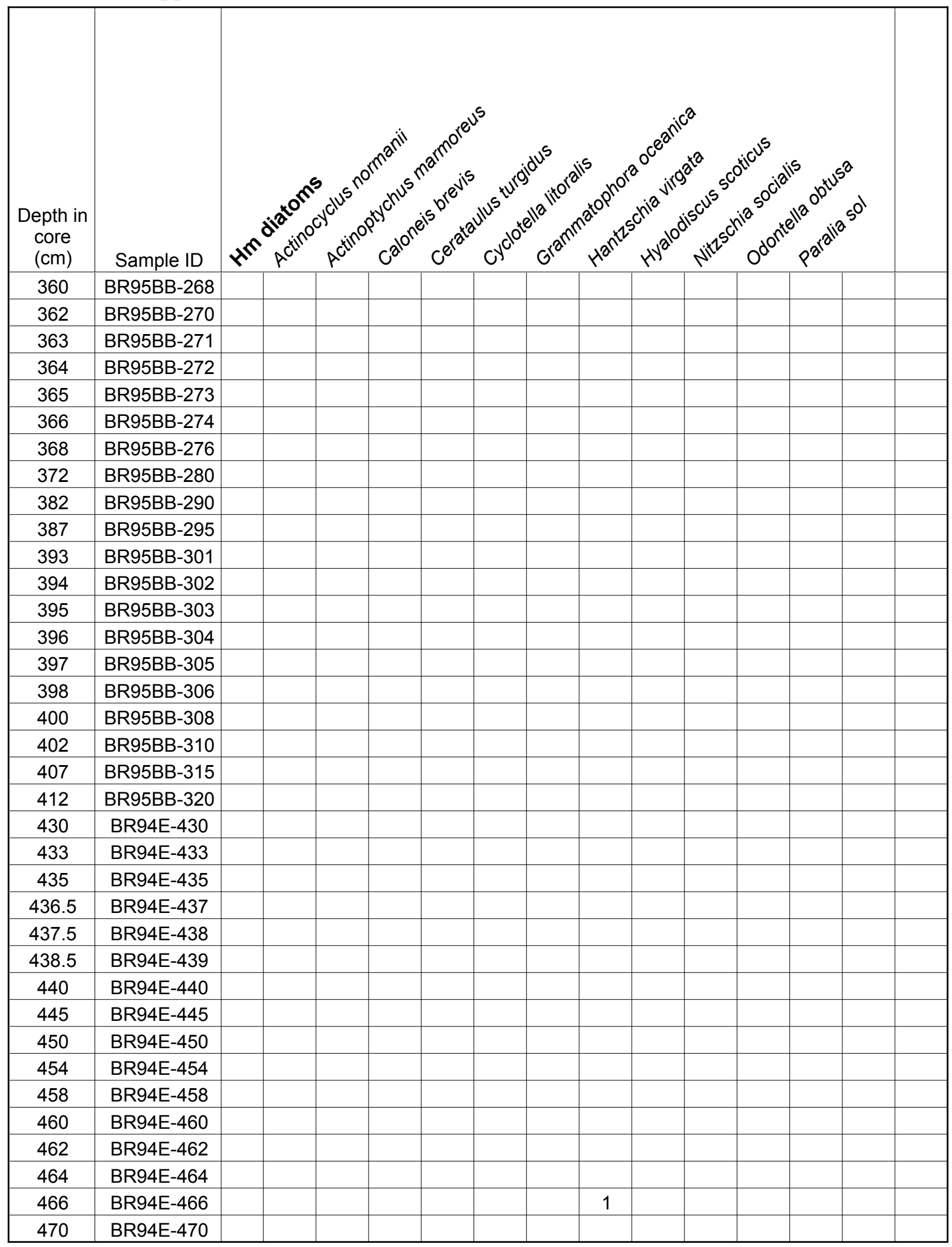


Appendix 4. Downcore diatom data from Bradley Lake (raw counts).

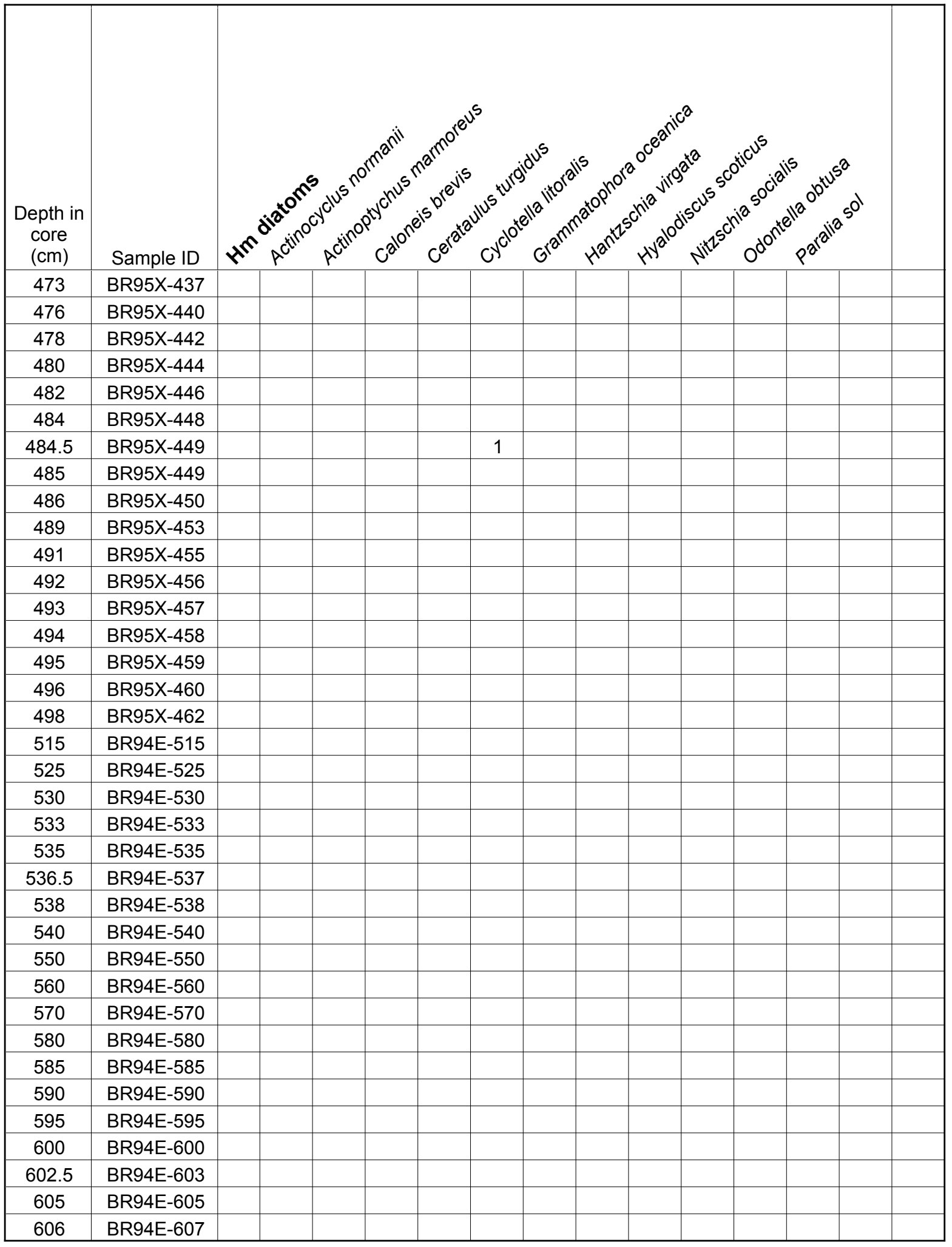


Appendix 4. Downcore diatom data from Bradley Lake (raw counts).

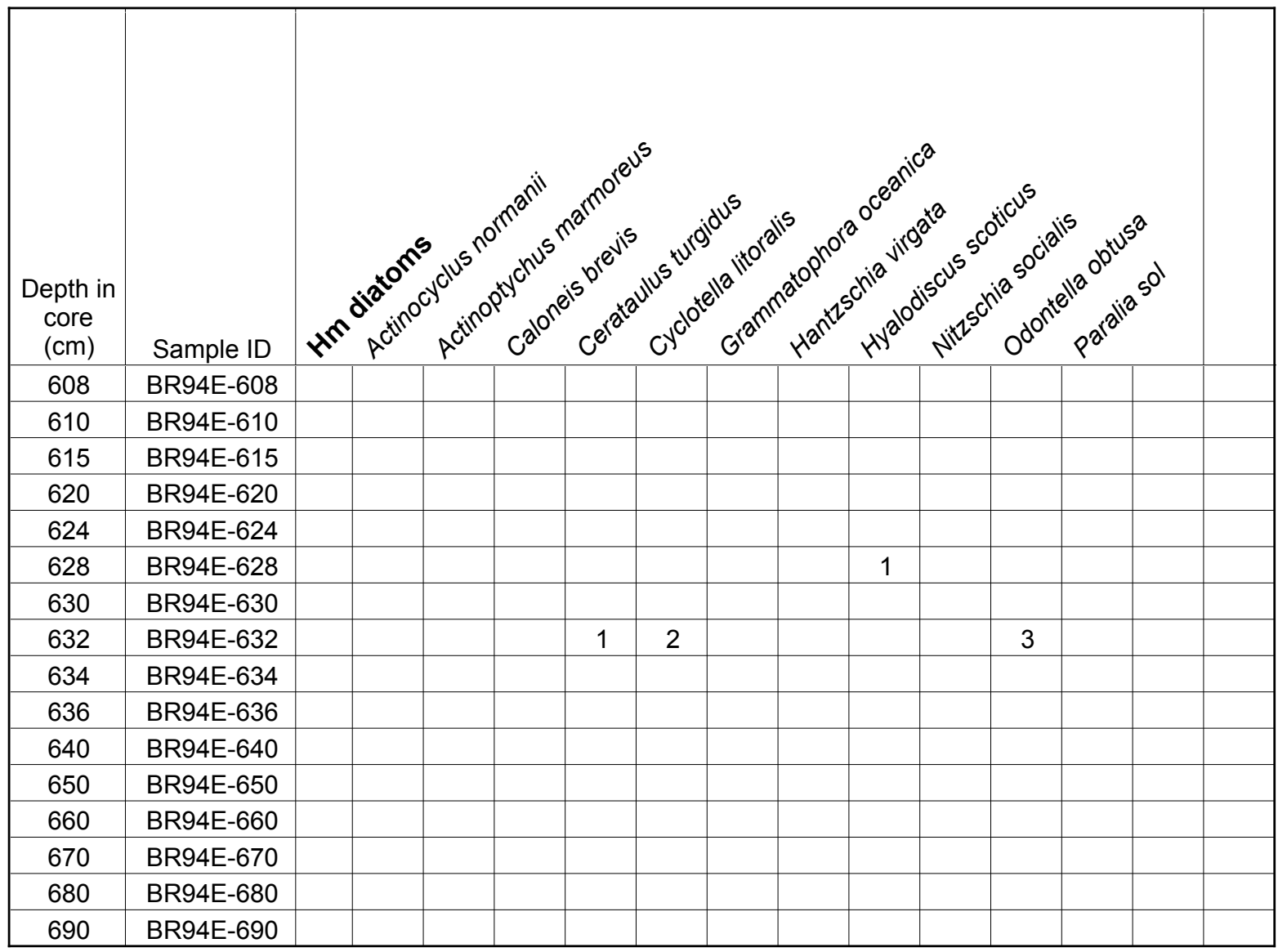


Appendix 4. Downcore diatom data from Bradley Lake (raw counts).

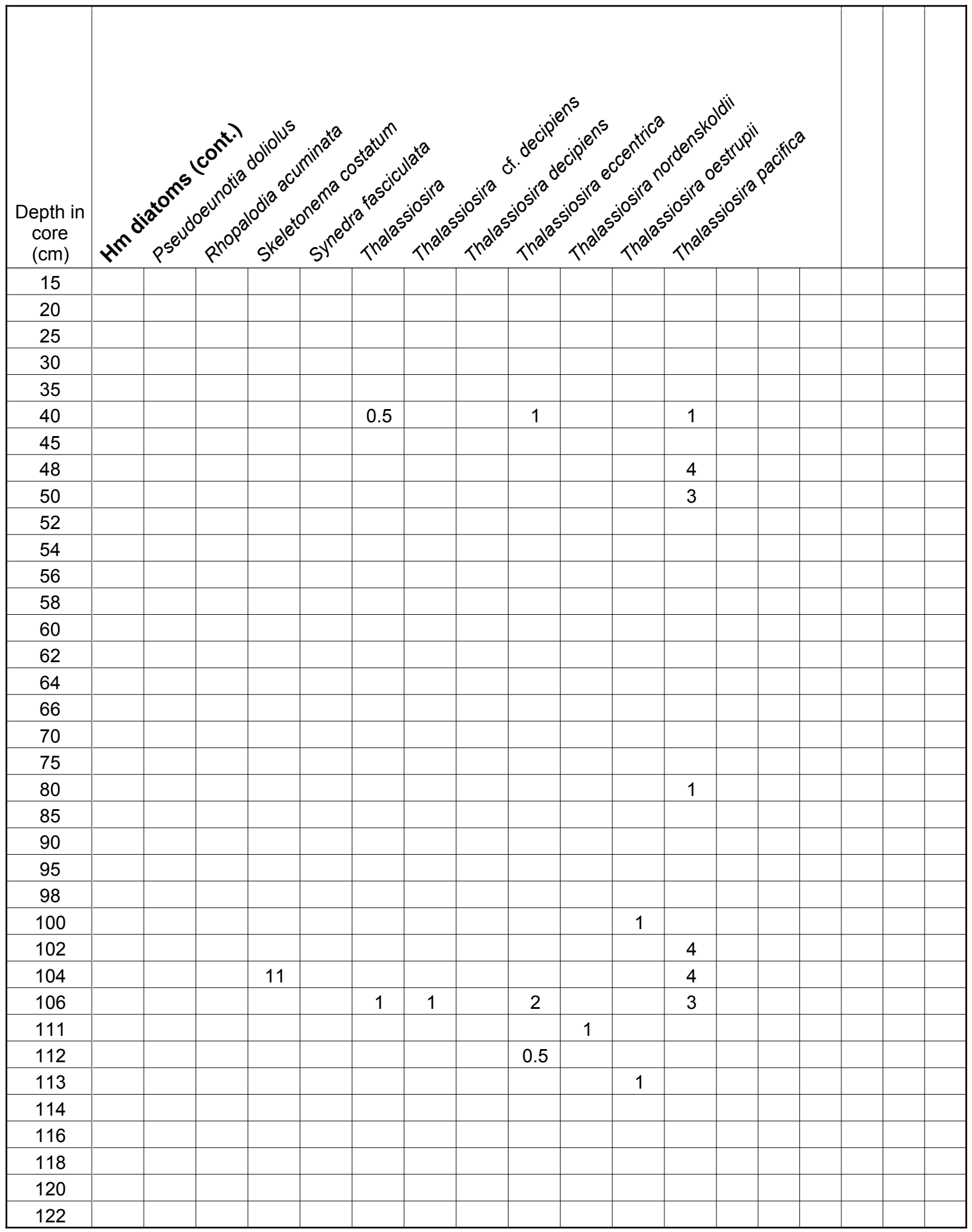


Appendix 4. Downcore diatom data from Bradley Lake (raw counts).

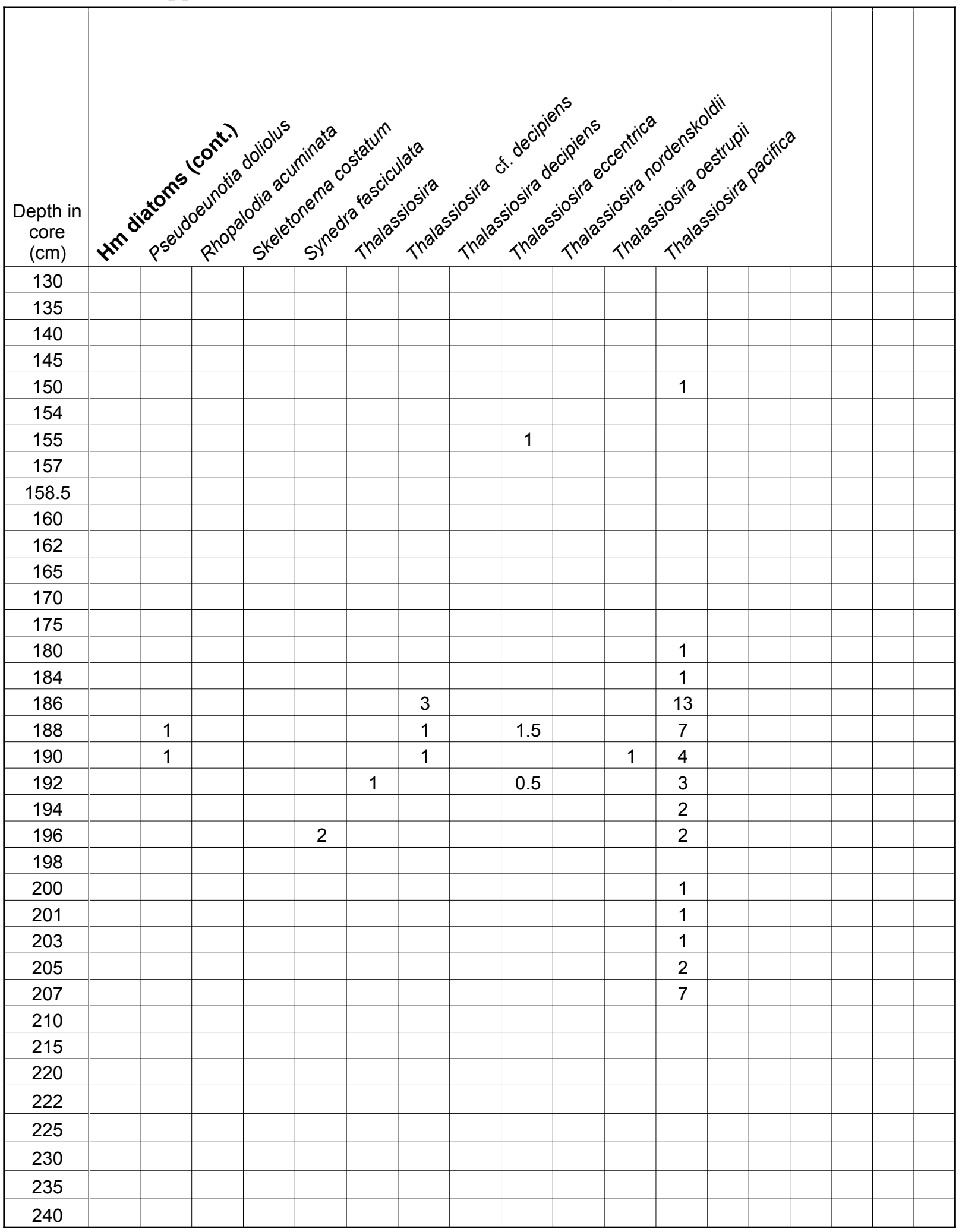


Appendix 4. Downcore diatom data from Bradley Lake (raw counts).

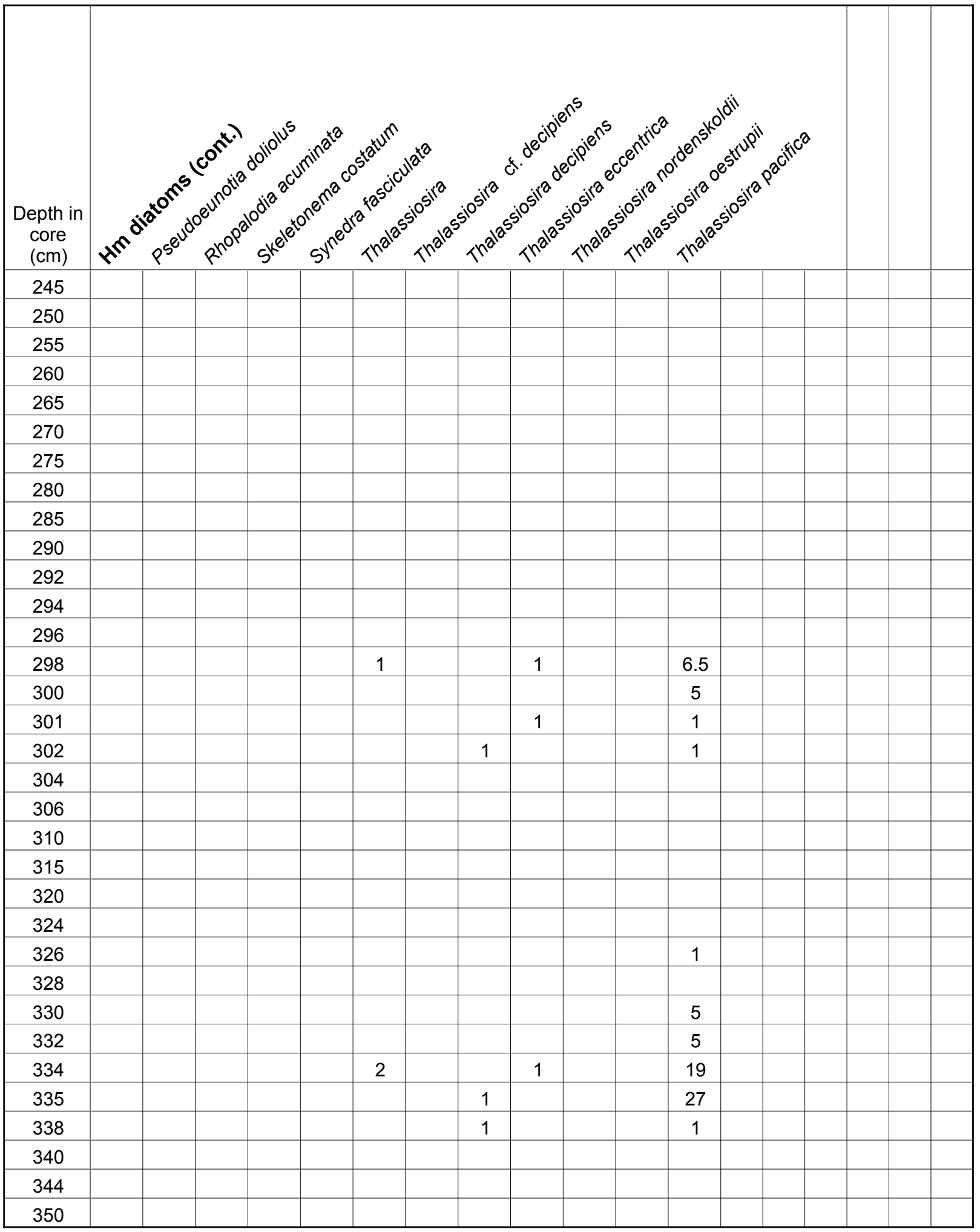


Appendix 4. Downcore diatom data from Bradley Lake (raw counts).

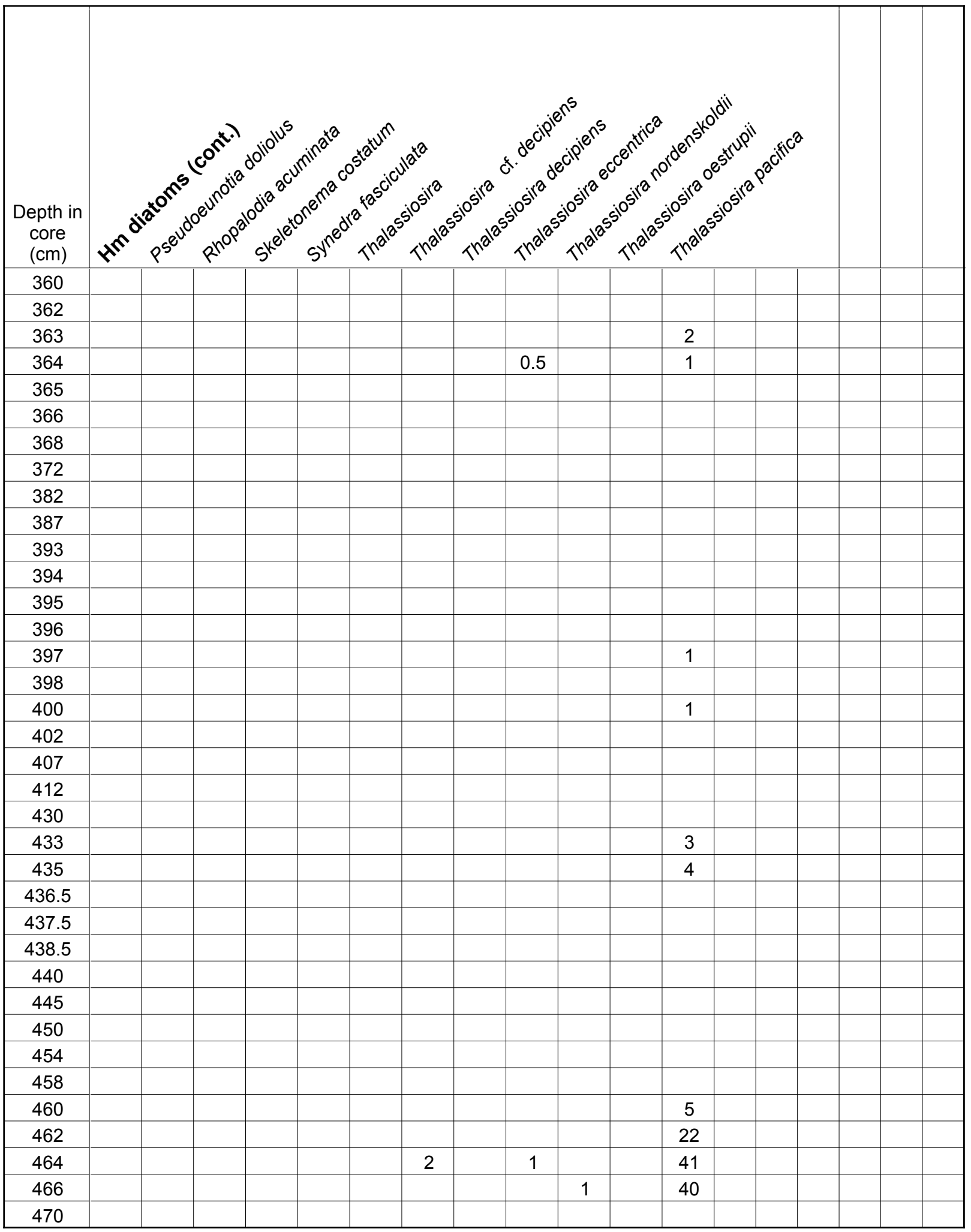


Appendix 4. Downcore diatom data from Bradley Lake (raw counts).

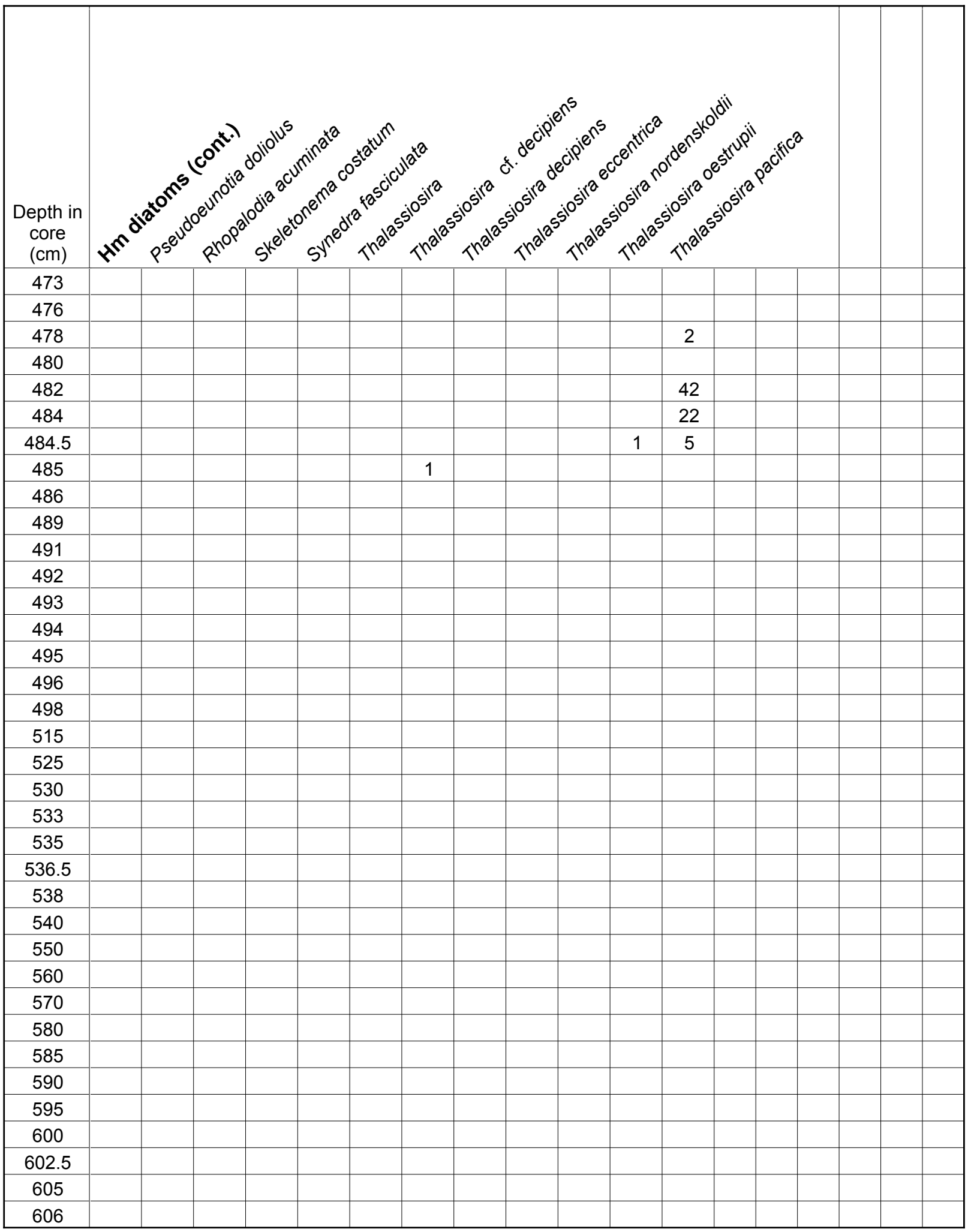


Appendix 4. Downcore diatom data from Bradley Lake (raw counts).

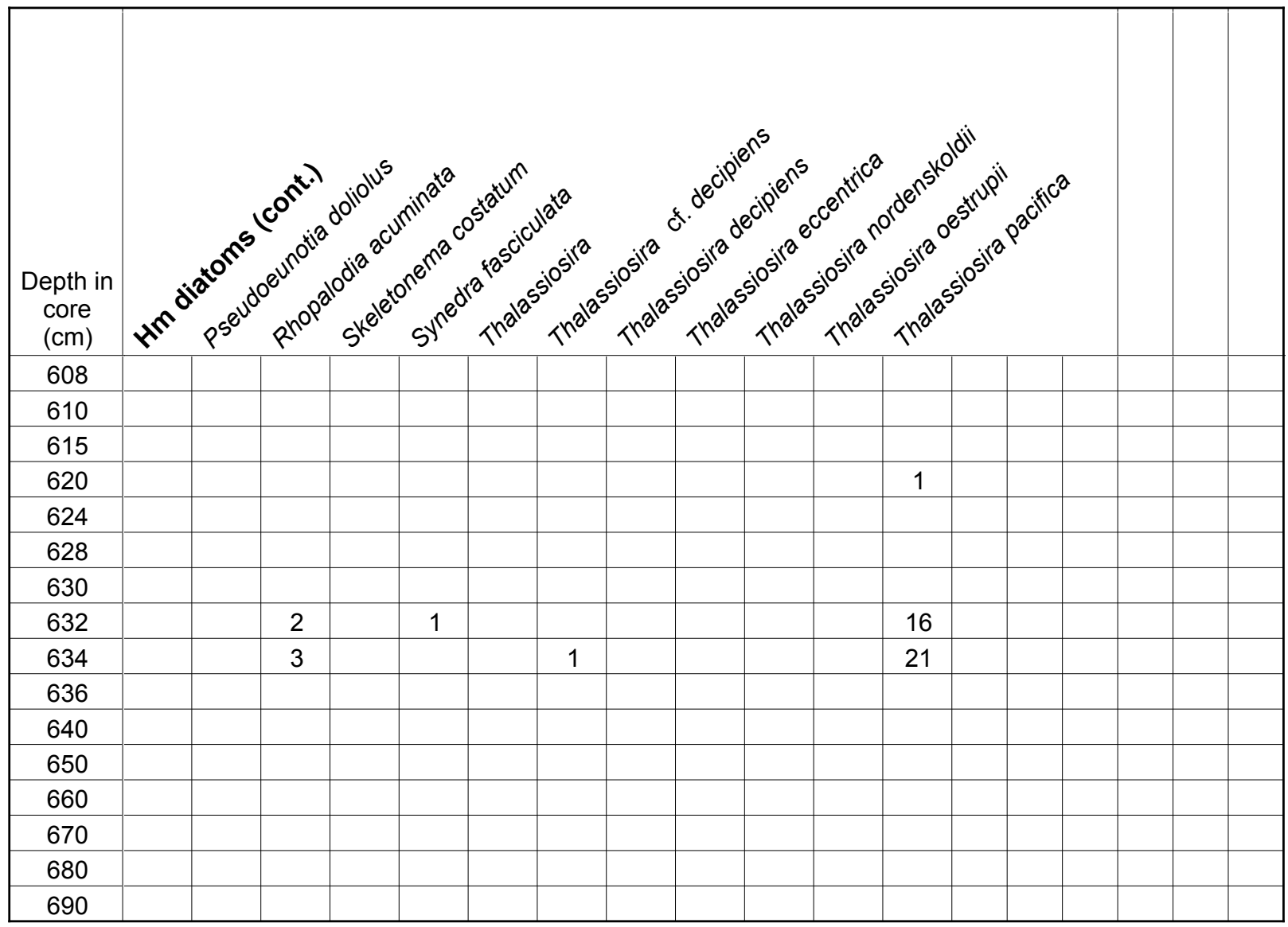


Appendix 4. Downcore diatom data from Bradley Lake (raw counts).

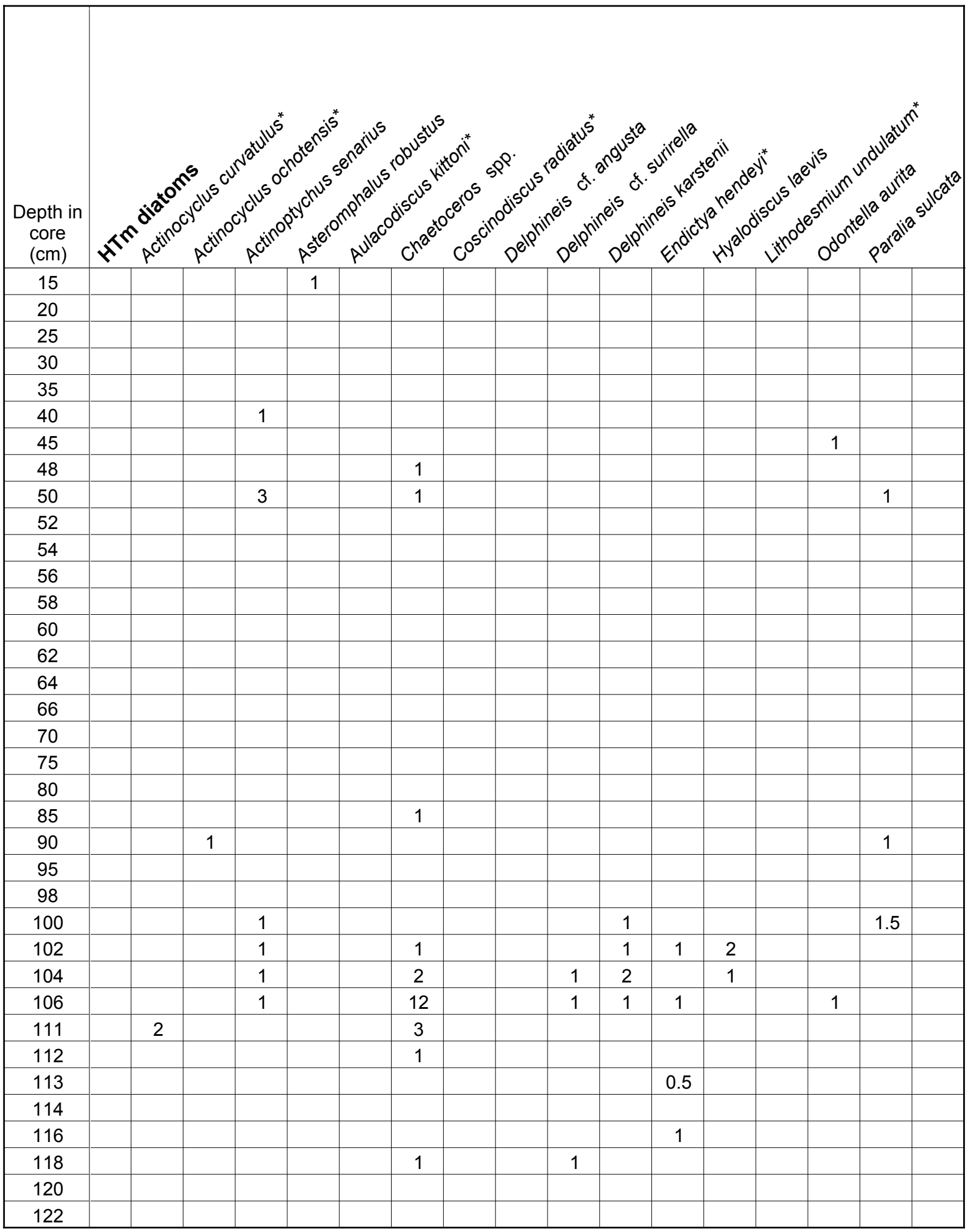


Appendix 4. Downcore diatom data from Bradley Lake (raw counts).

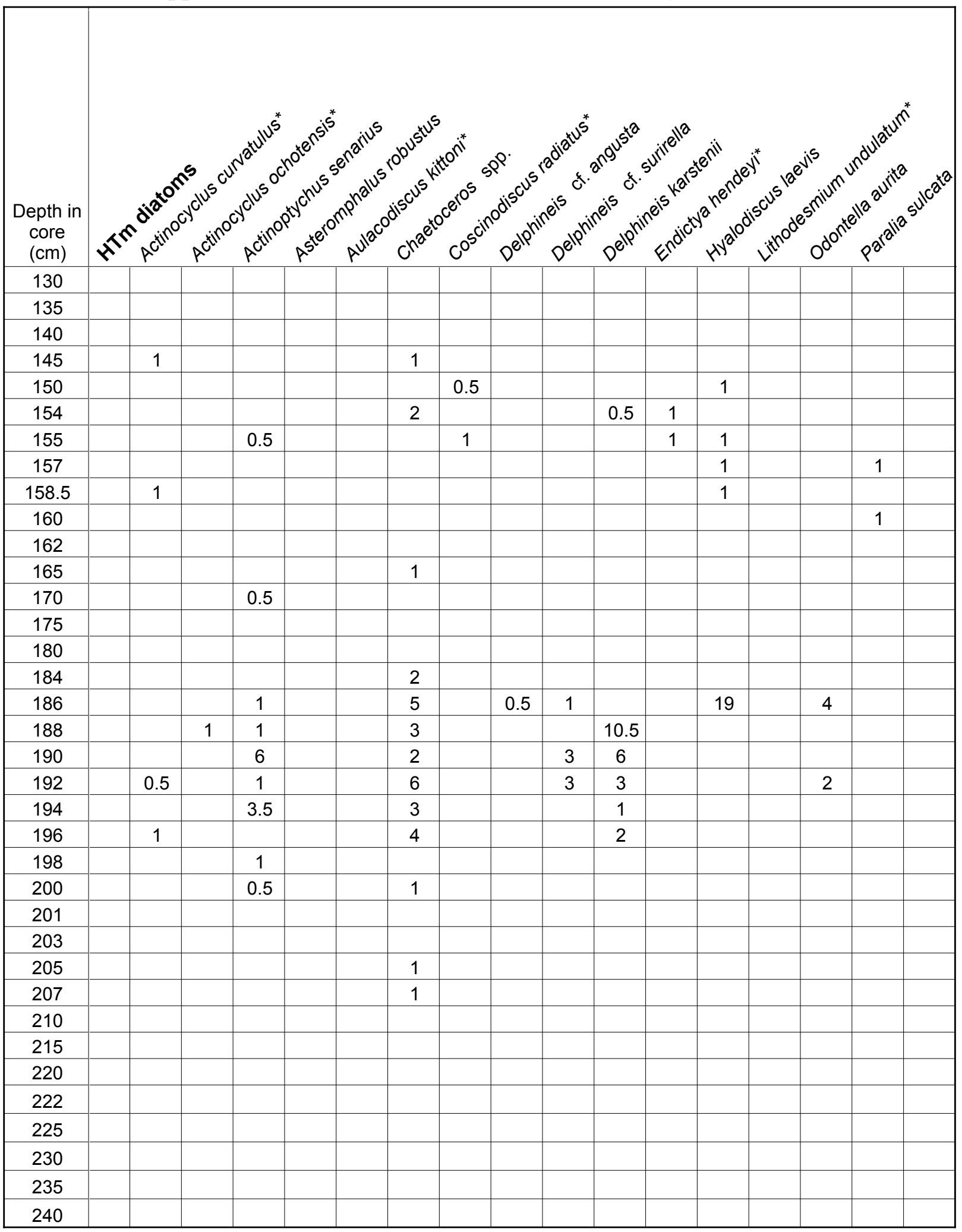


Appendix 4. Downcore diatom data from Bradley Lake (raw counts).

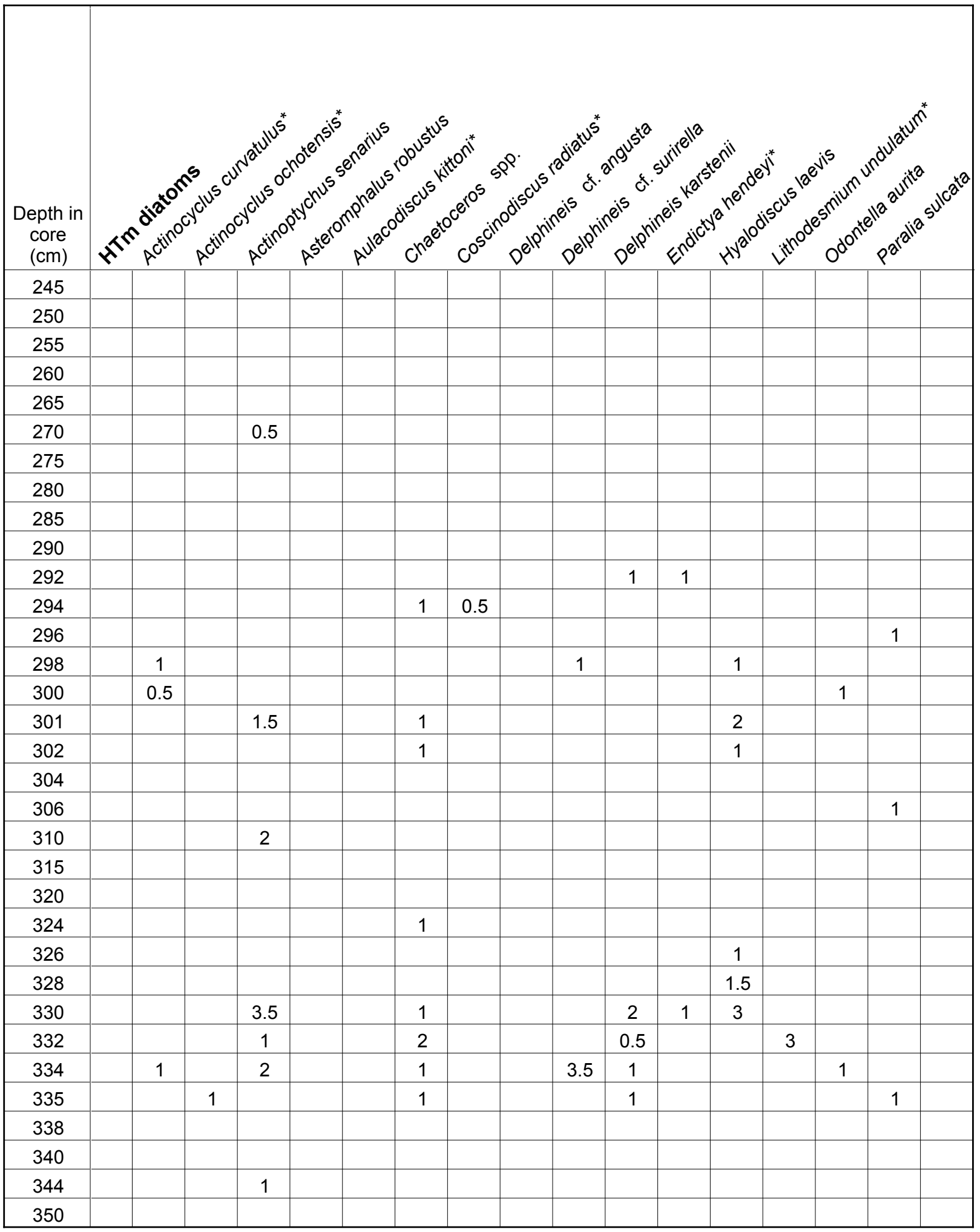


Appendix 4. Downcore diatom data from Bradley Lake (raw counts).

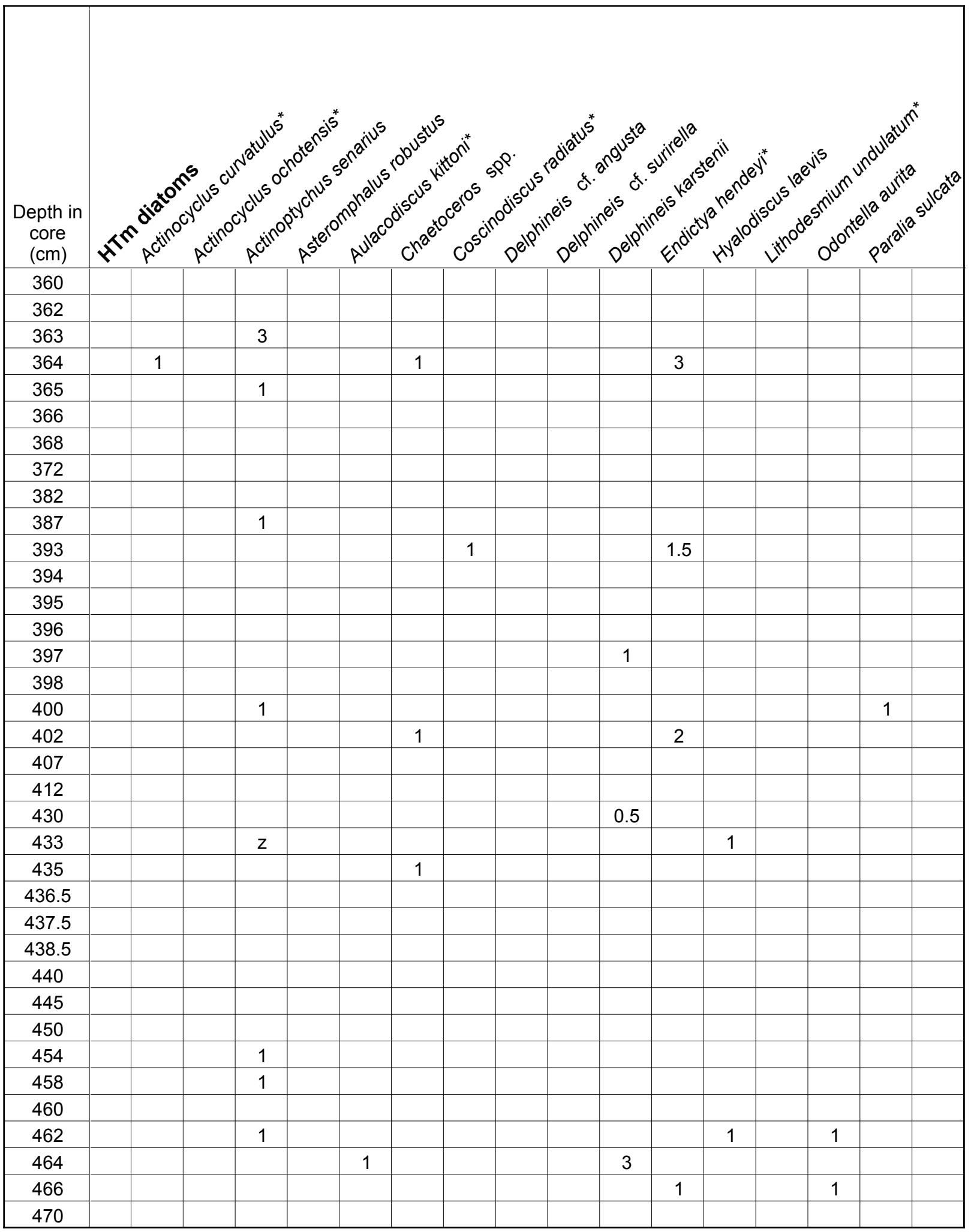


Appendix 4. Downcore diatom data from Bradley Lake (raw counts).

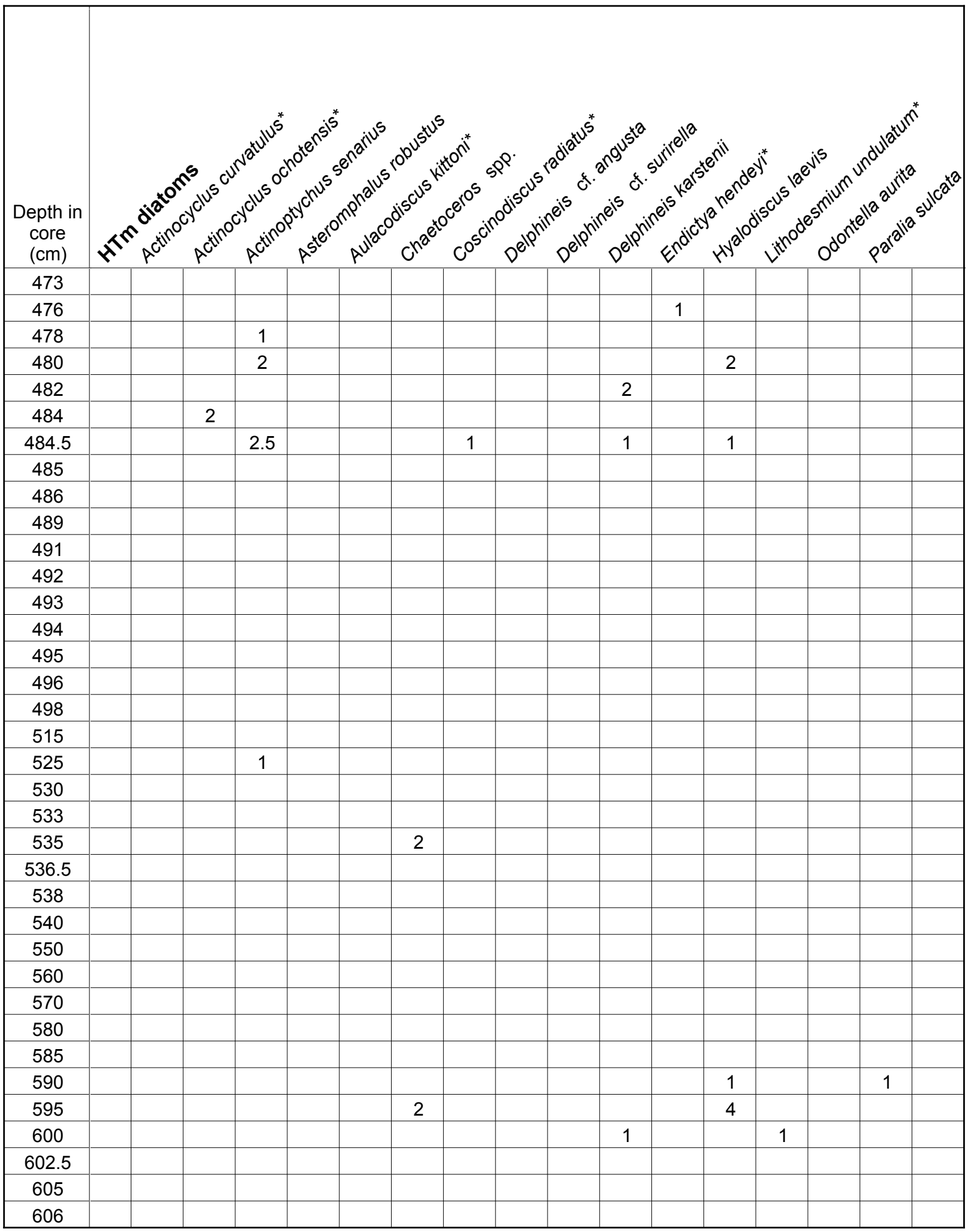


Appendix 4. Downcore diatom data from Bradley Lake (raw counts).

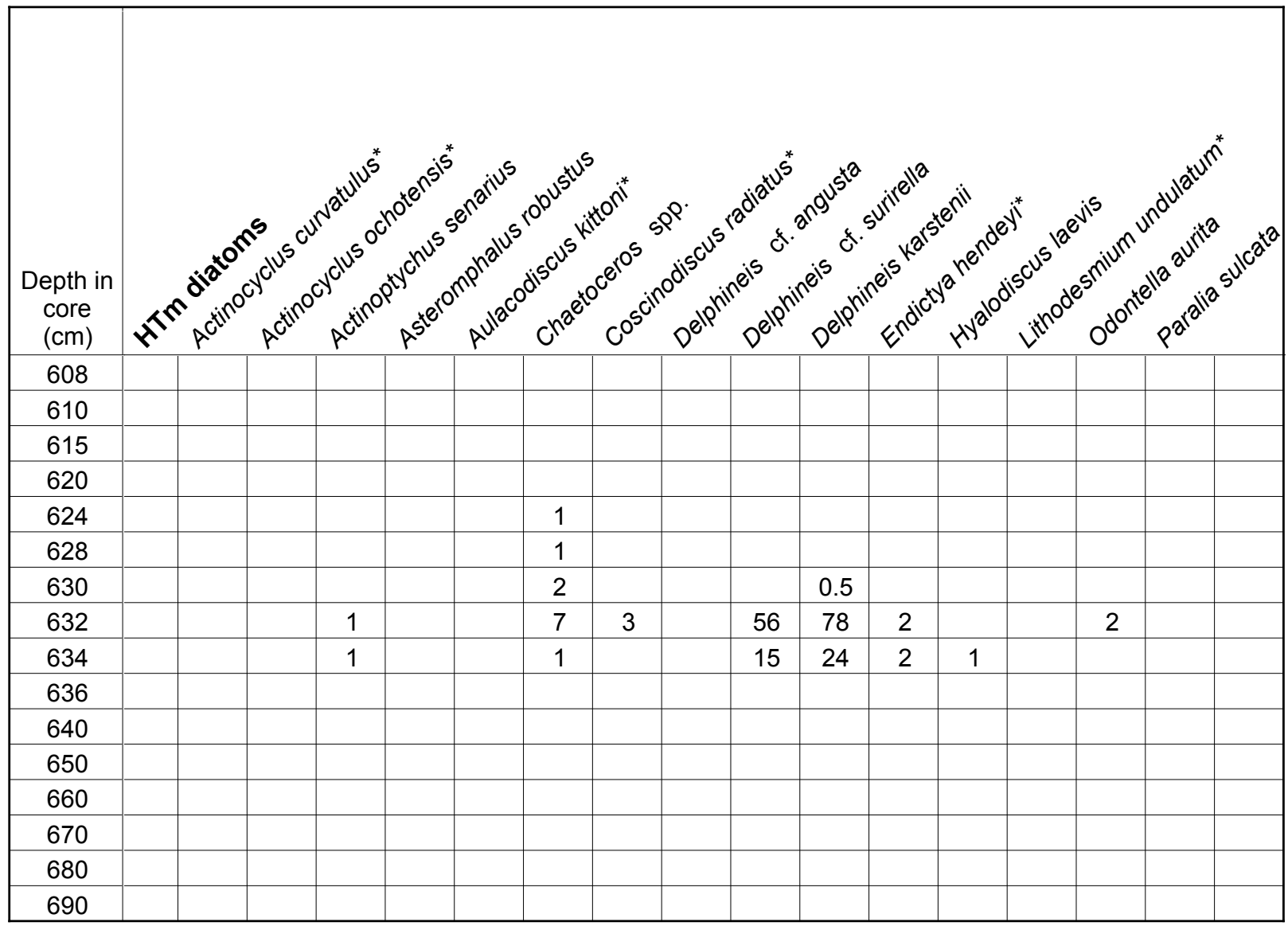


Appendix 4. Downcore diatom data from Bradley Lake (raw counts).

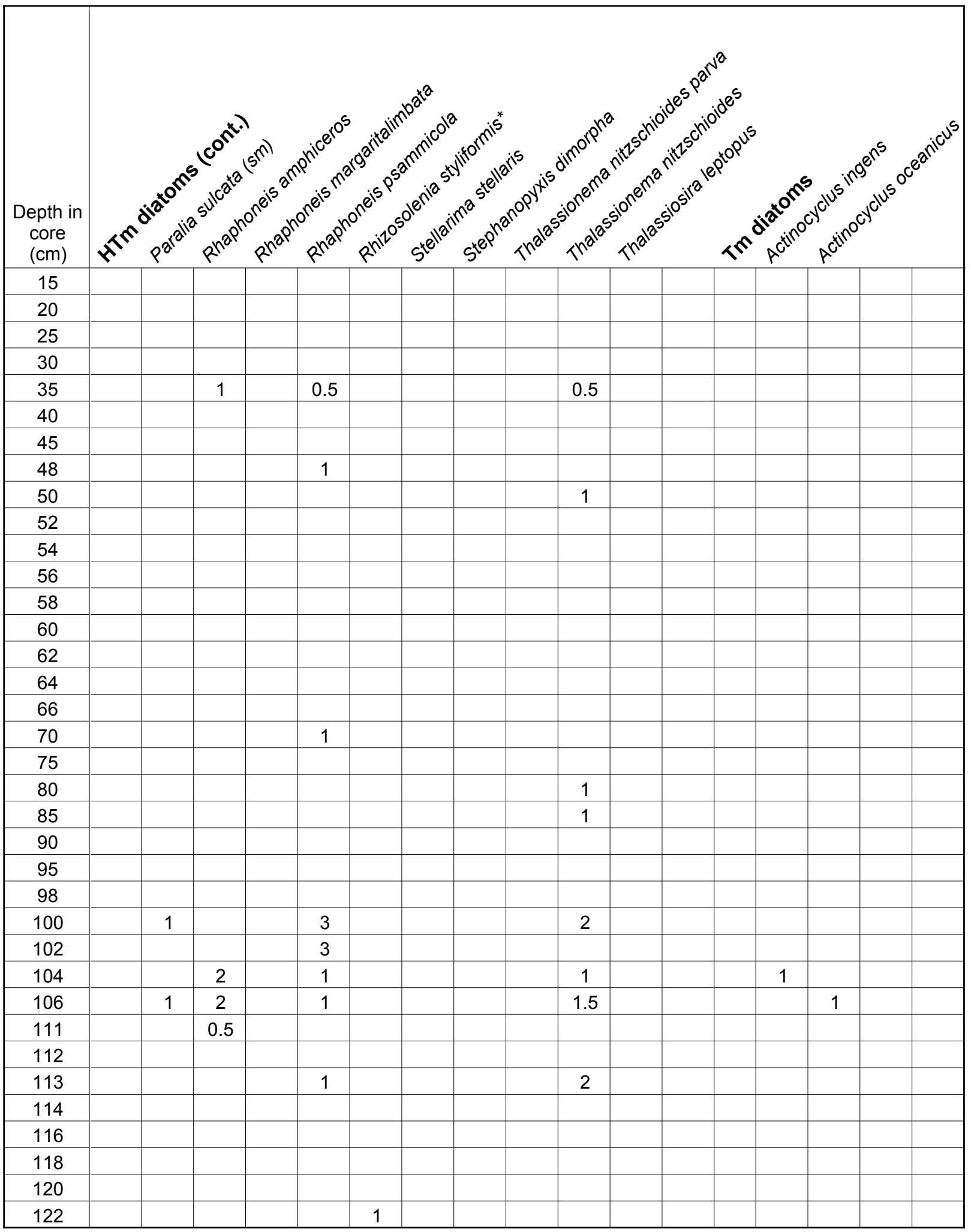


Appendix 4. Downcore diatom data from Bradley Lake (raw counts).

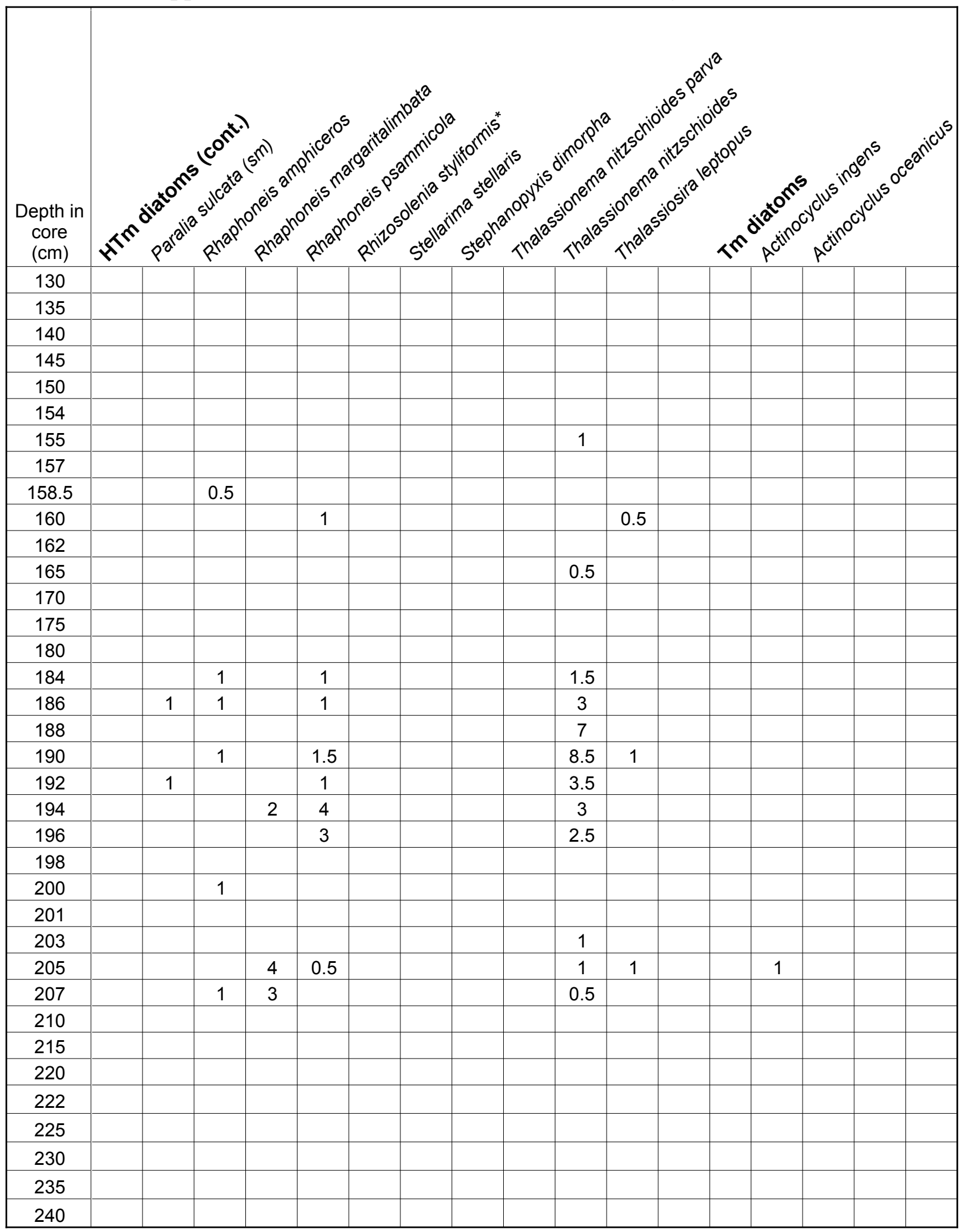


Appendix 4. Downcore diatom data from Bradley Lake (raw counts).

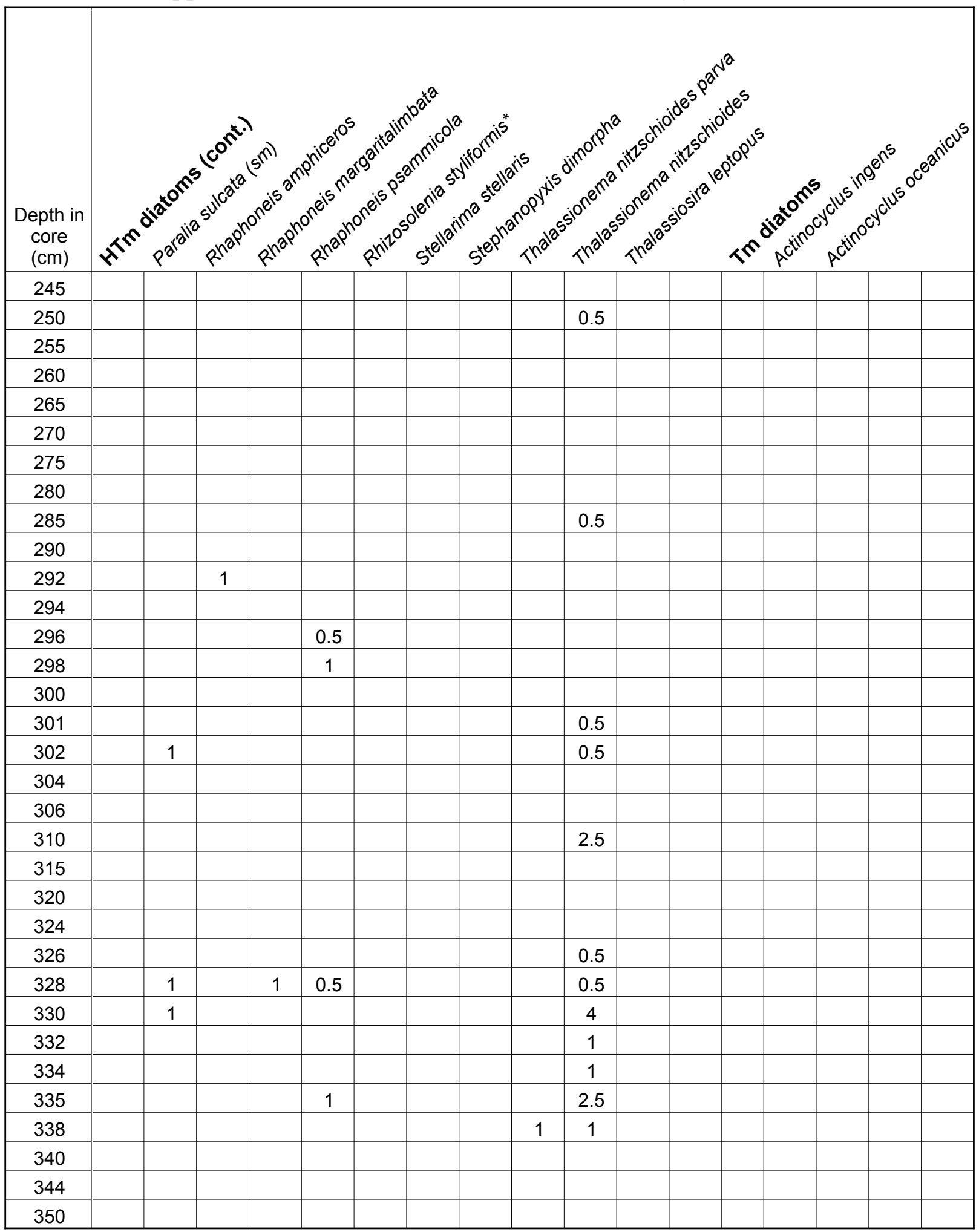


Appendix 4. Downcore diatom data from Bradley Lake (raw counts).

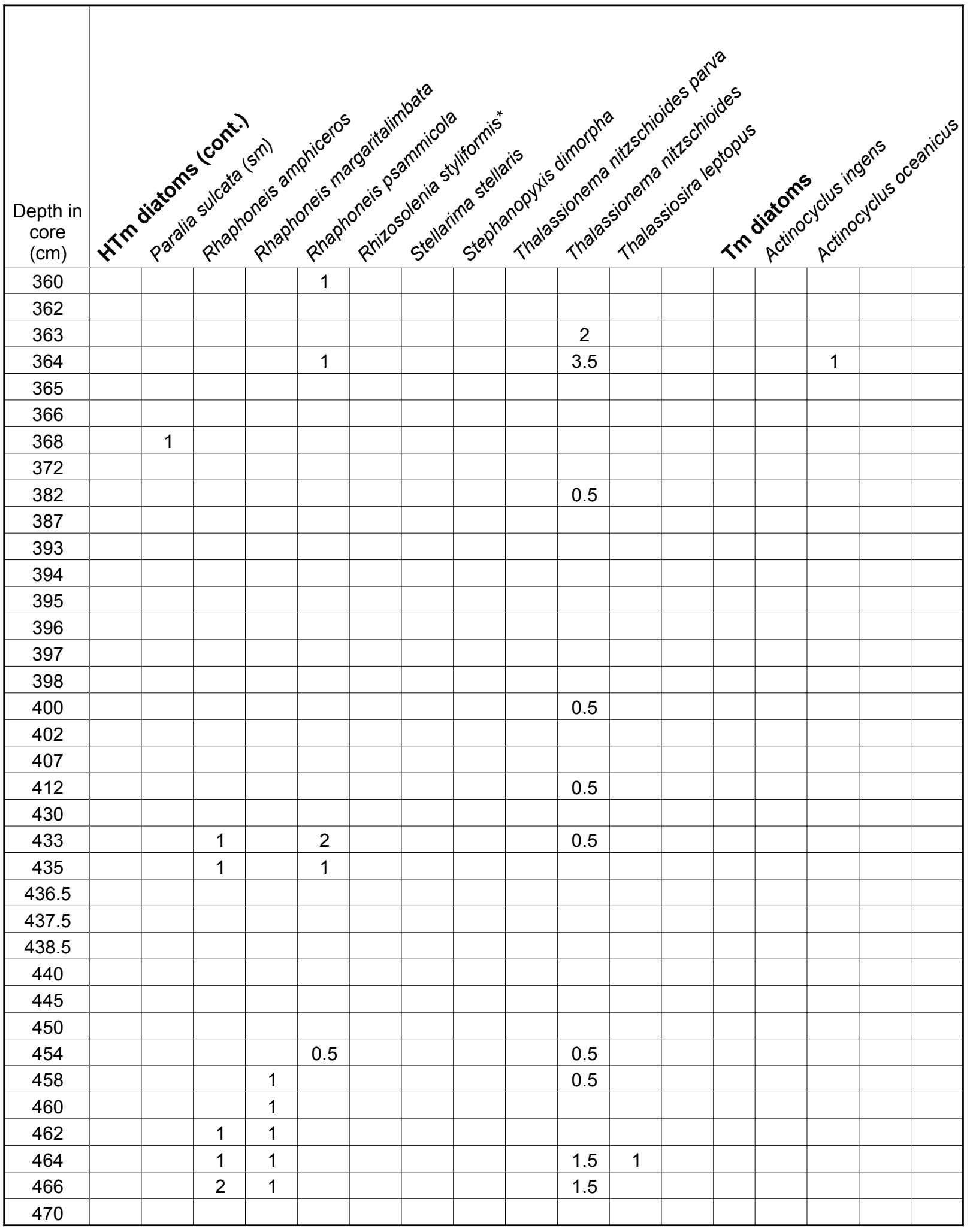


Appendix 4. Downcore diatom data from Bradley Lake (raw counts).

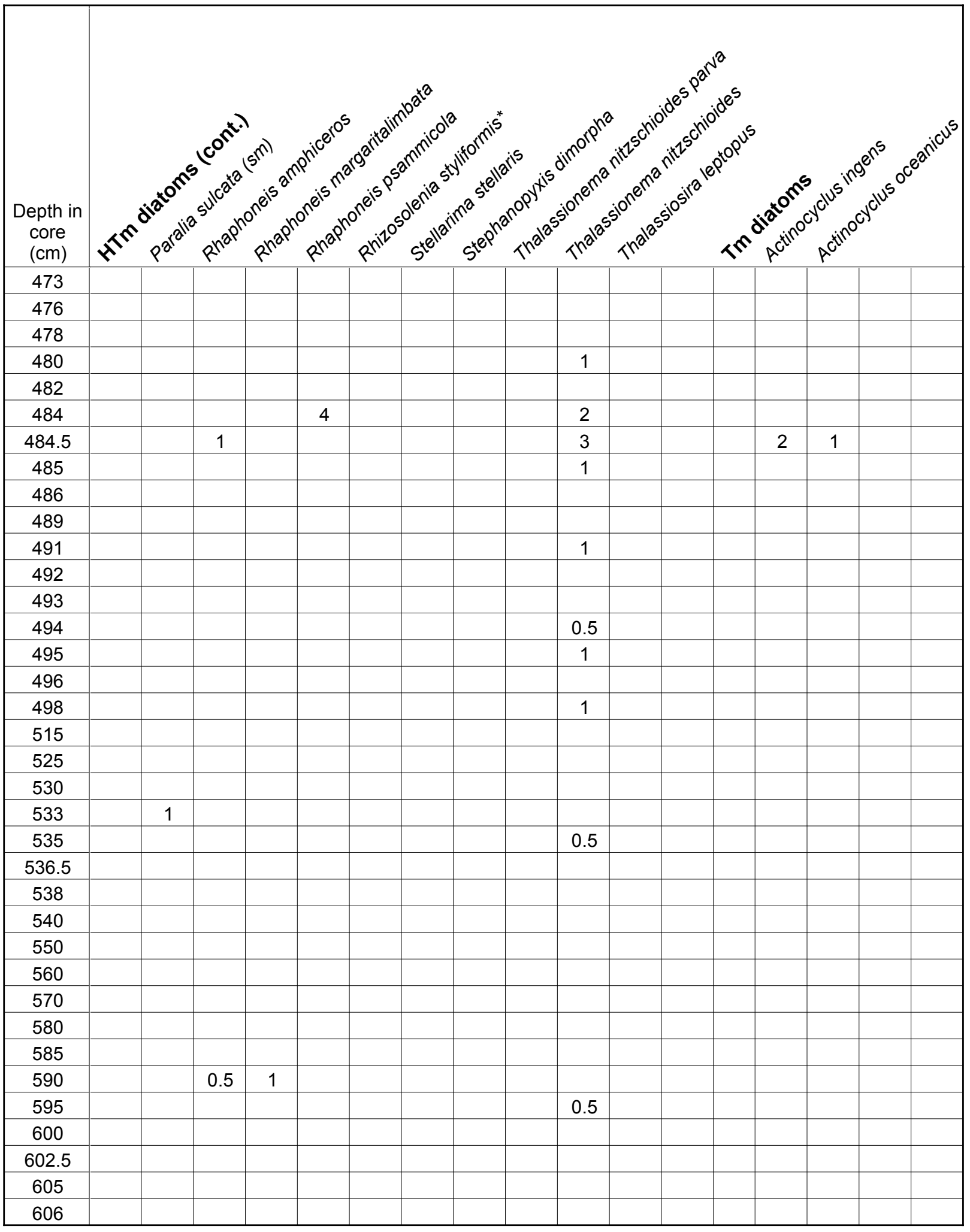


Appendix 4. Downcore diatom data from Bradley Lake (raw counts).

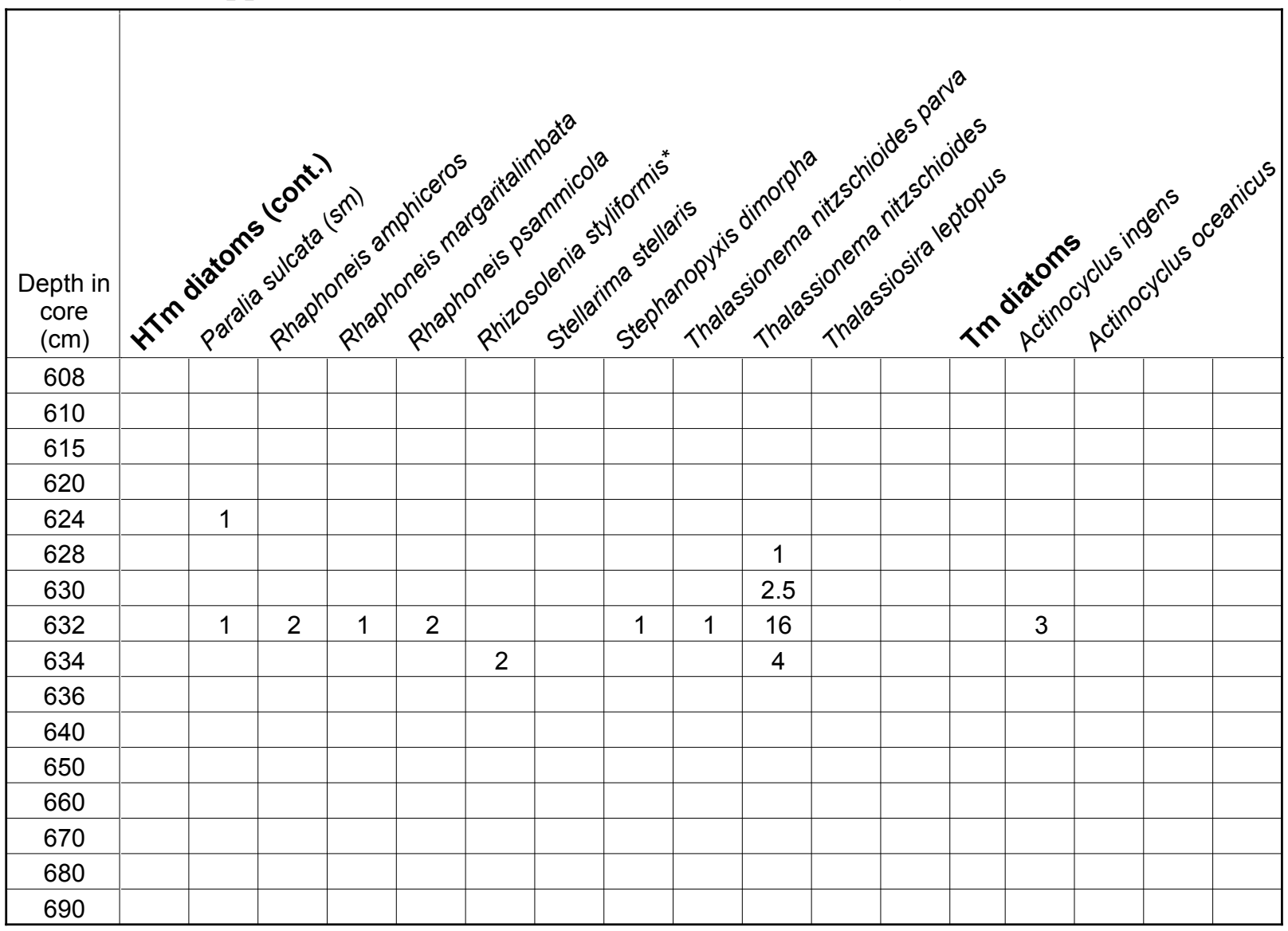


Appendix 4. Downcore diatom data from Bradley Lake (raw counts).

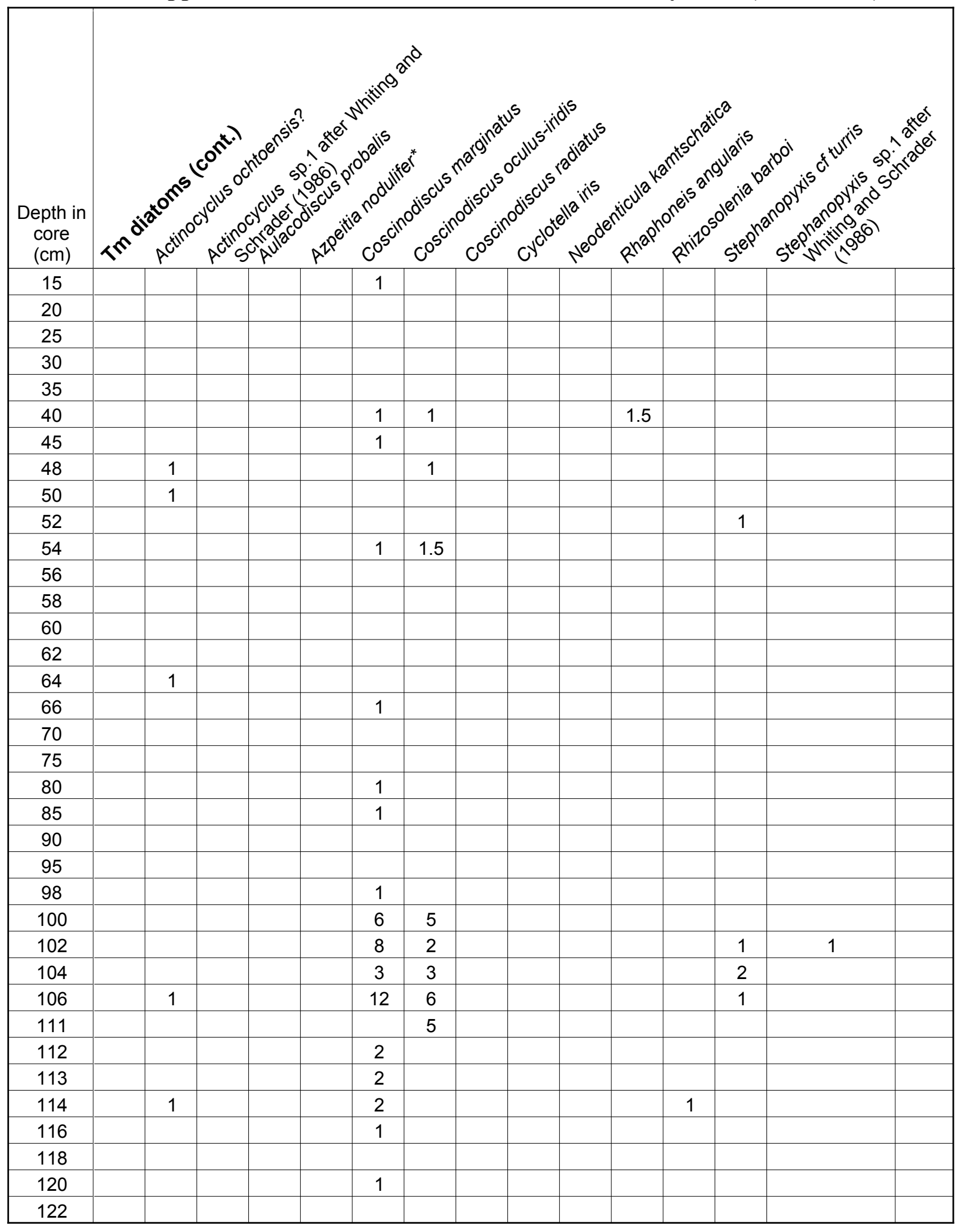


Appendix 4. Downcore diatom data from Bradley Lake (raw counts).

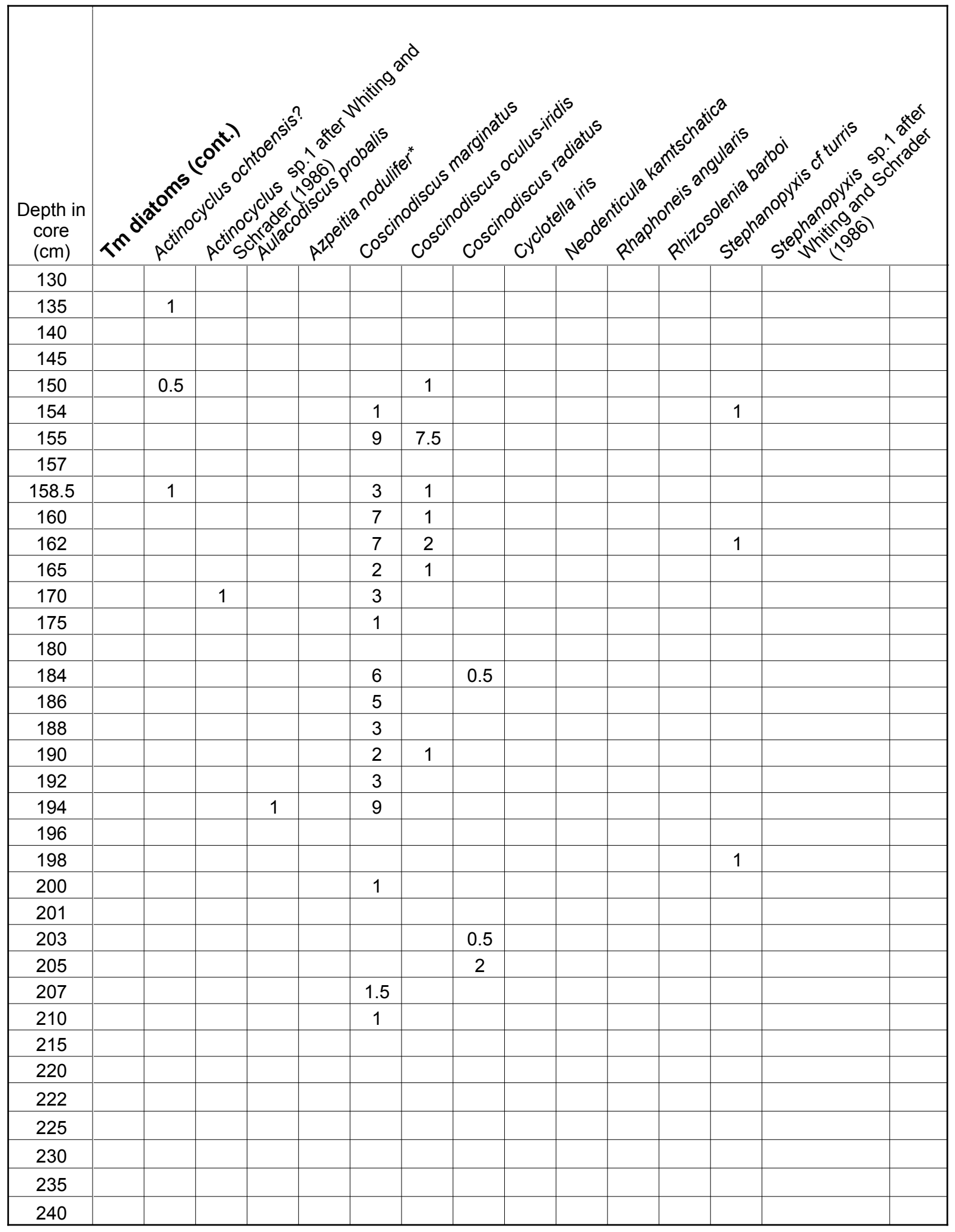


Appendix 4. Downcore diatom data from Bradley Lake (raw counts).

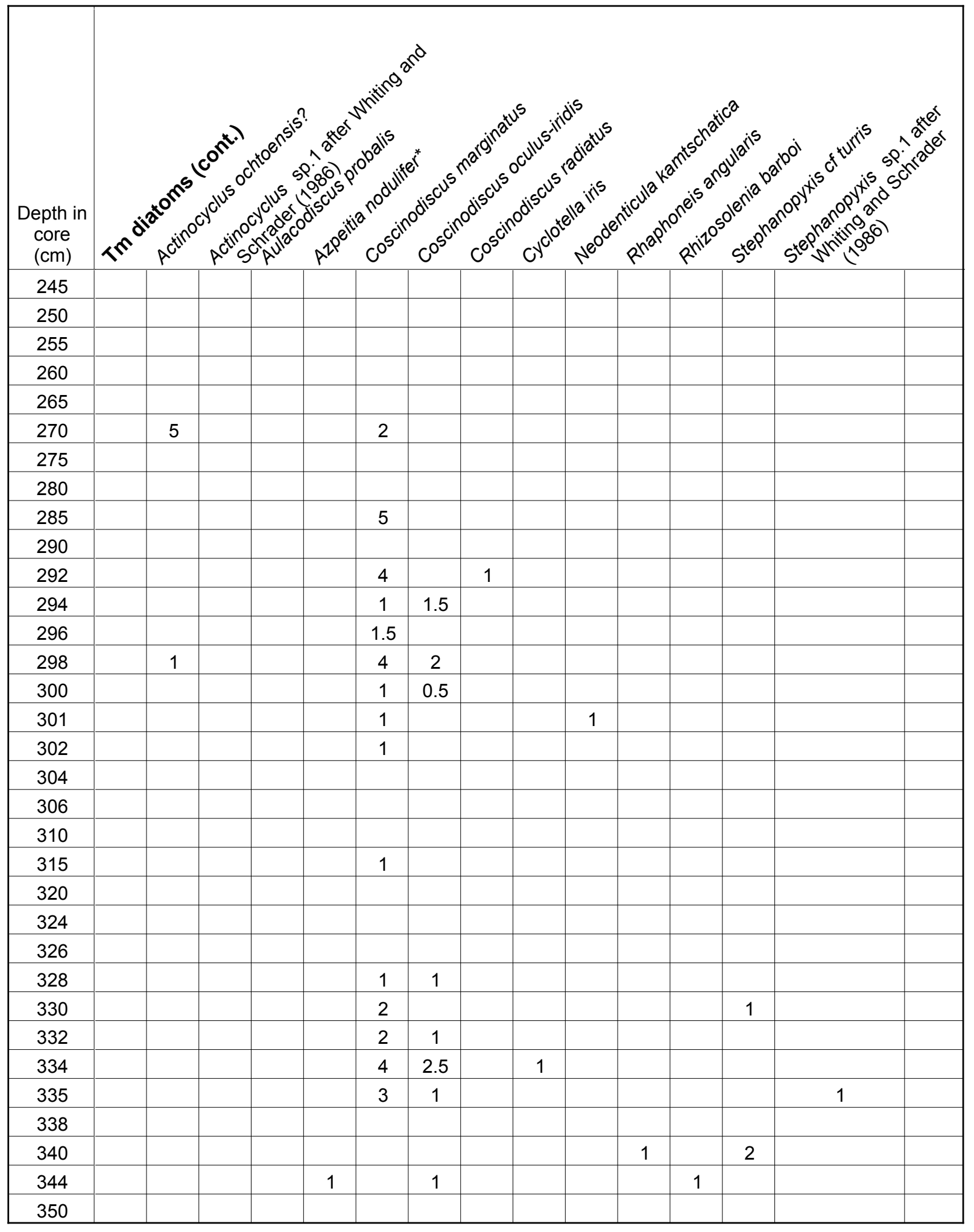


Appendix 4. Downcore diatom data from Bradley Lake (raw counts).

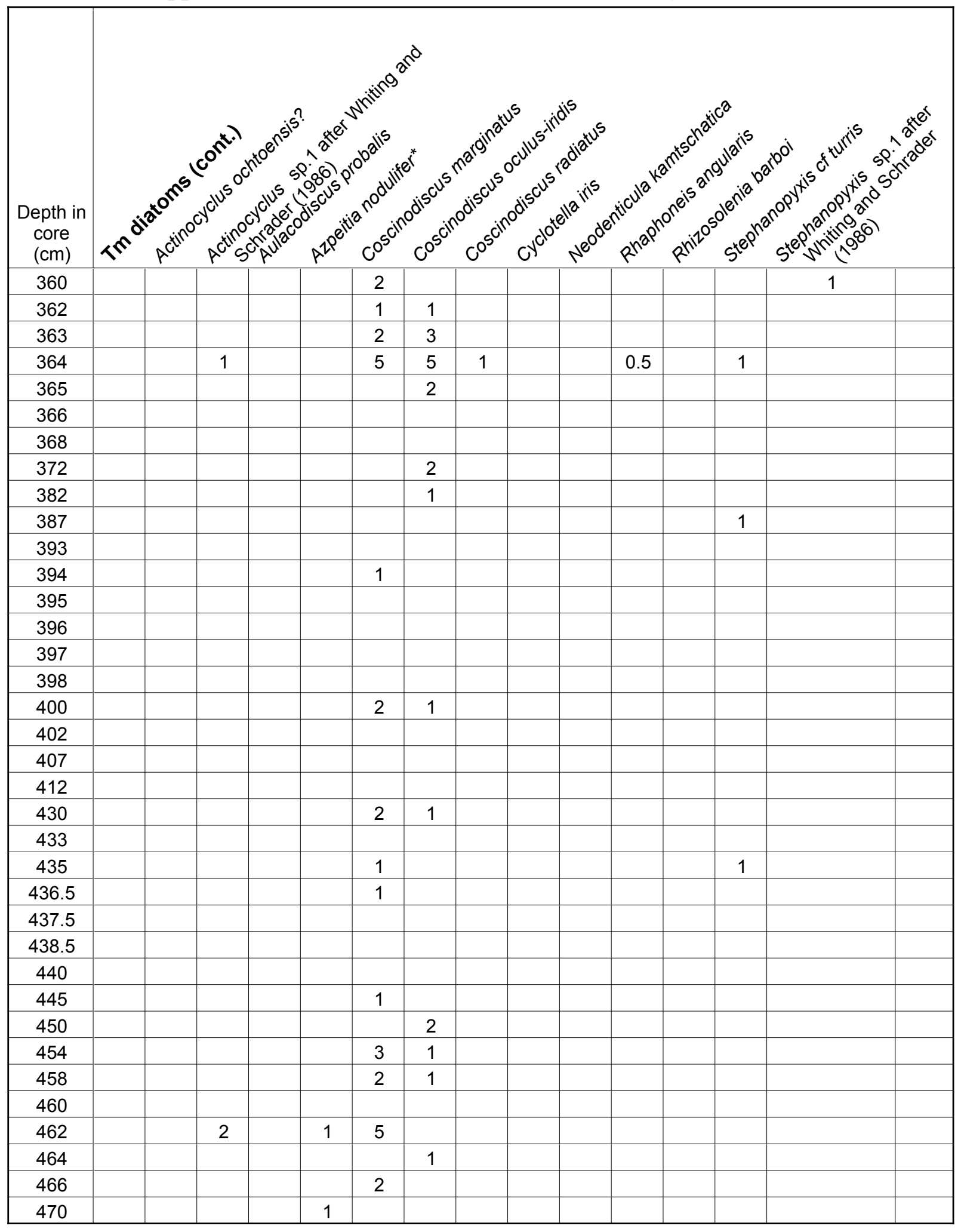


Appendix 4. Downcore diatom data from Bradley Lake (raw counts).

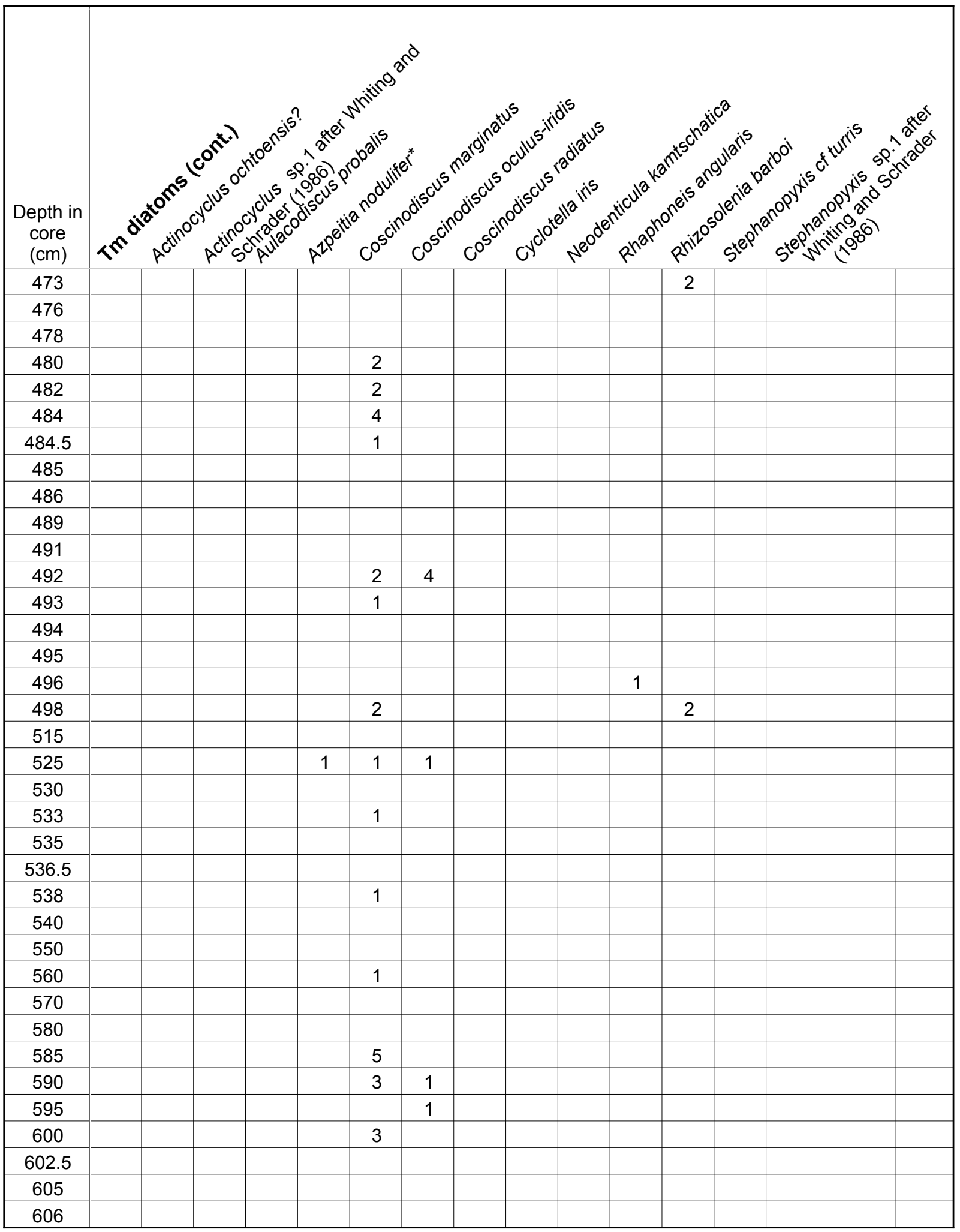


Appendix 4. Downcore diatom data from Bradley Lake (raw counts).

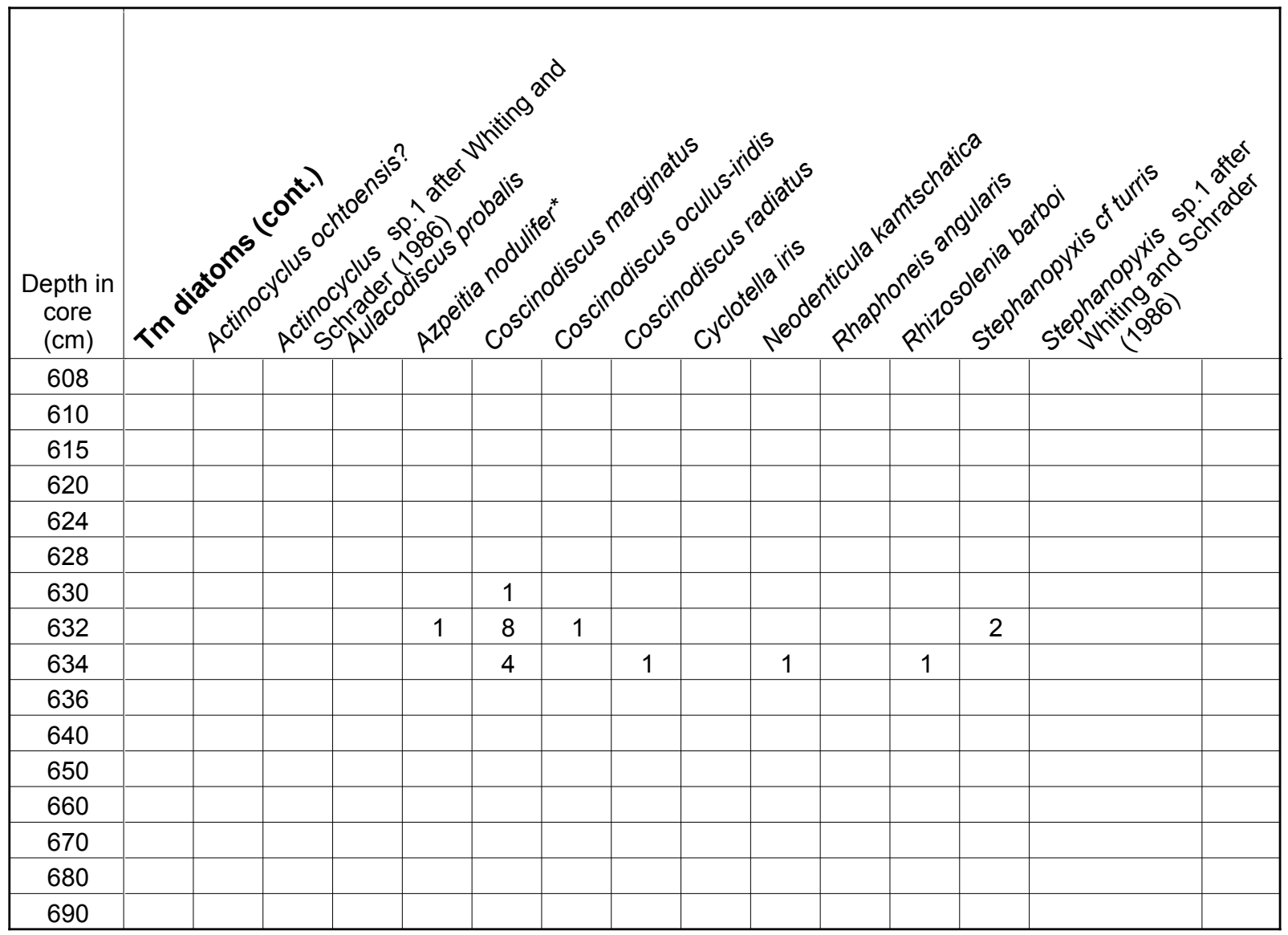


Appendix 4. Downcore diatom data from Bradley Lake (raw counts).

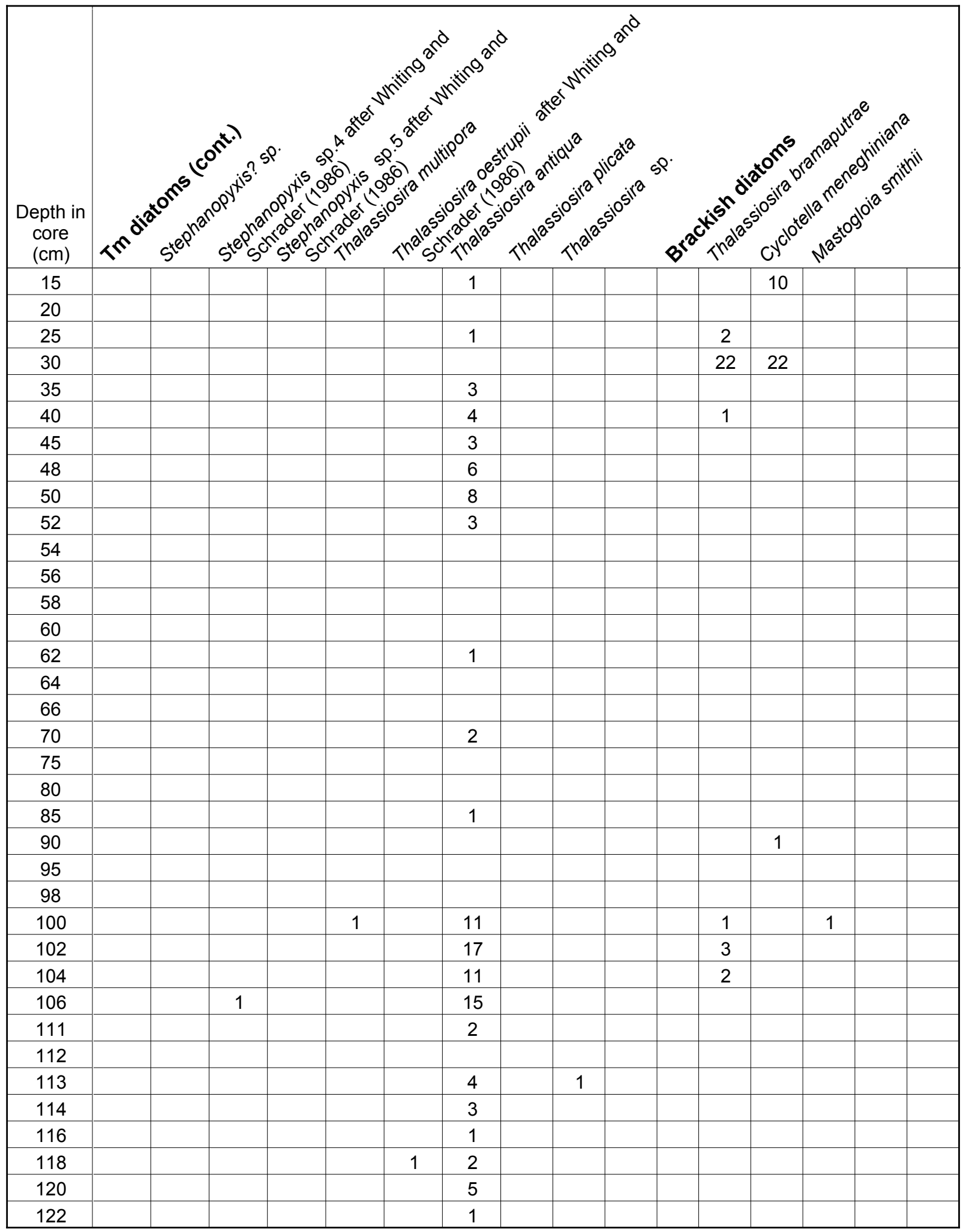


Appendix 4. Downcore diatom data from Bradley Lake (raw counts).

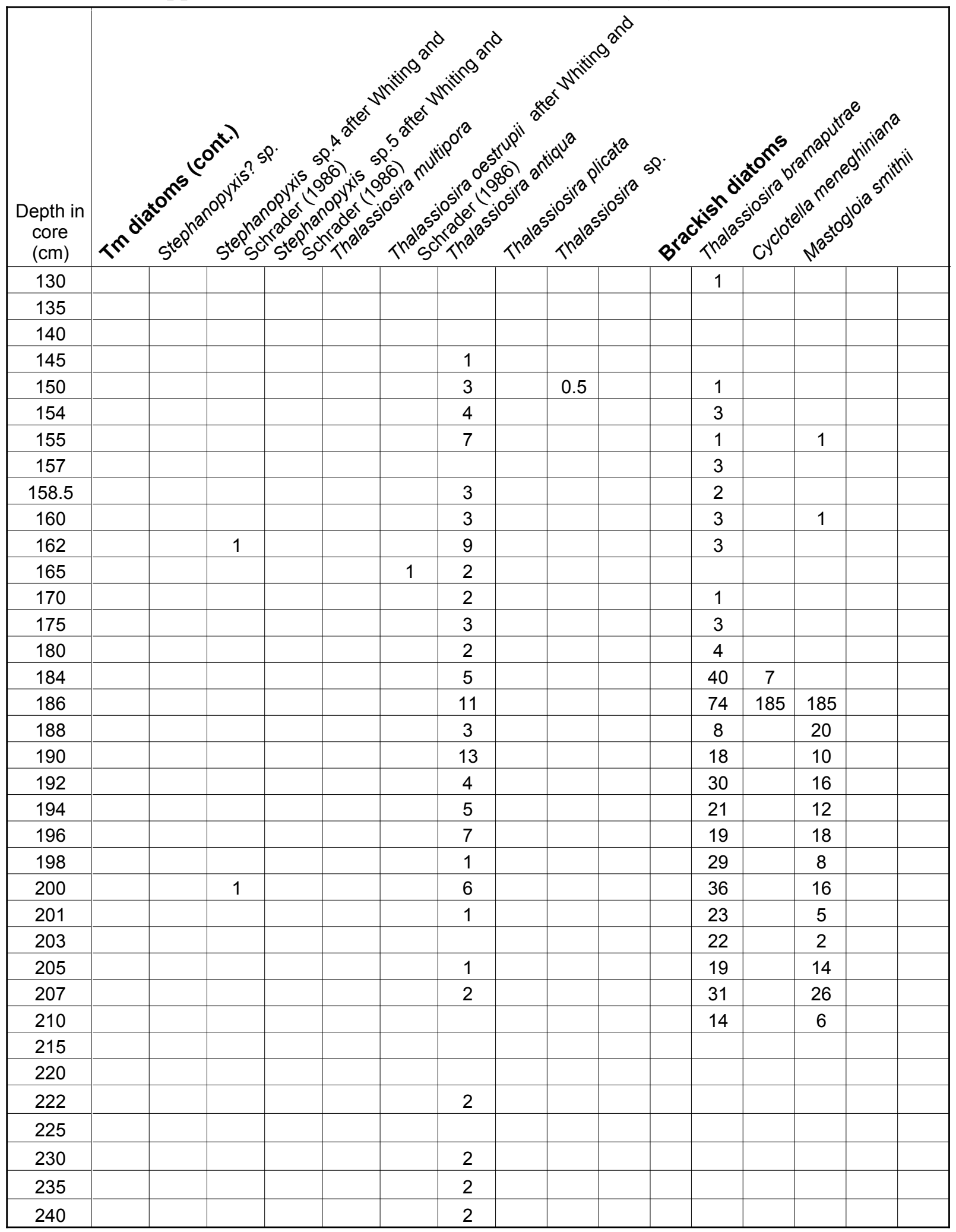


Appendix 4. Downcore diatom data from Bradley Lake (raw counts).

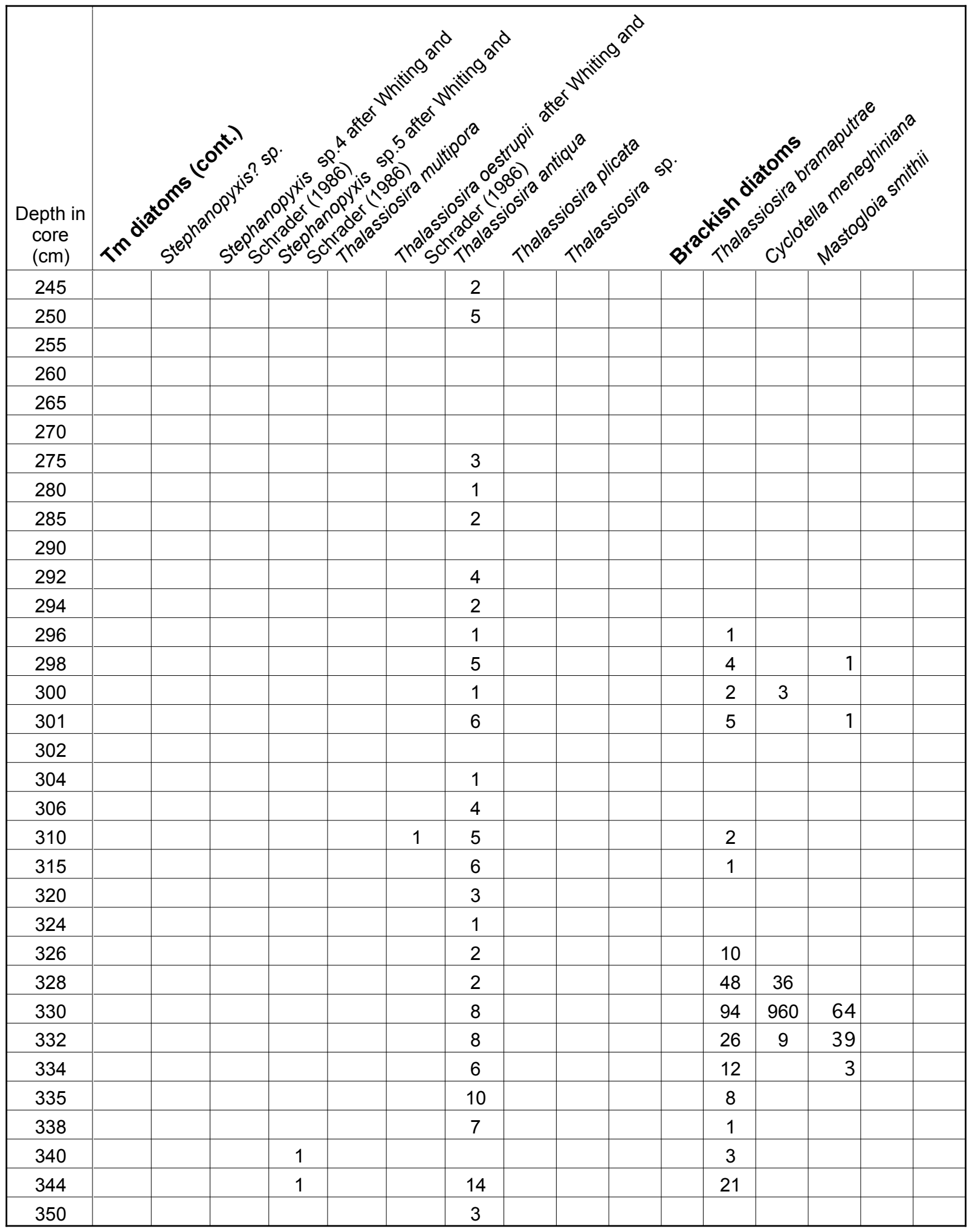


Appendix 4. Downcore diatom data from Bradley Lake (raw counts).

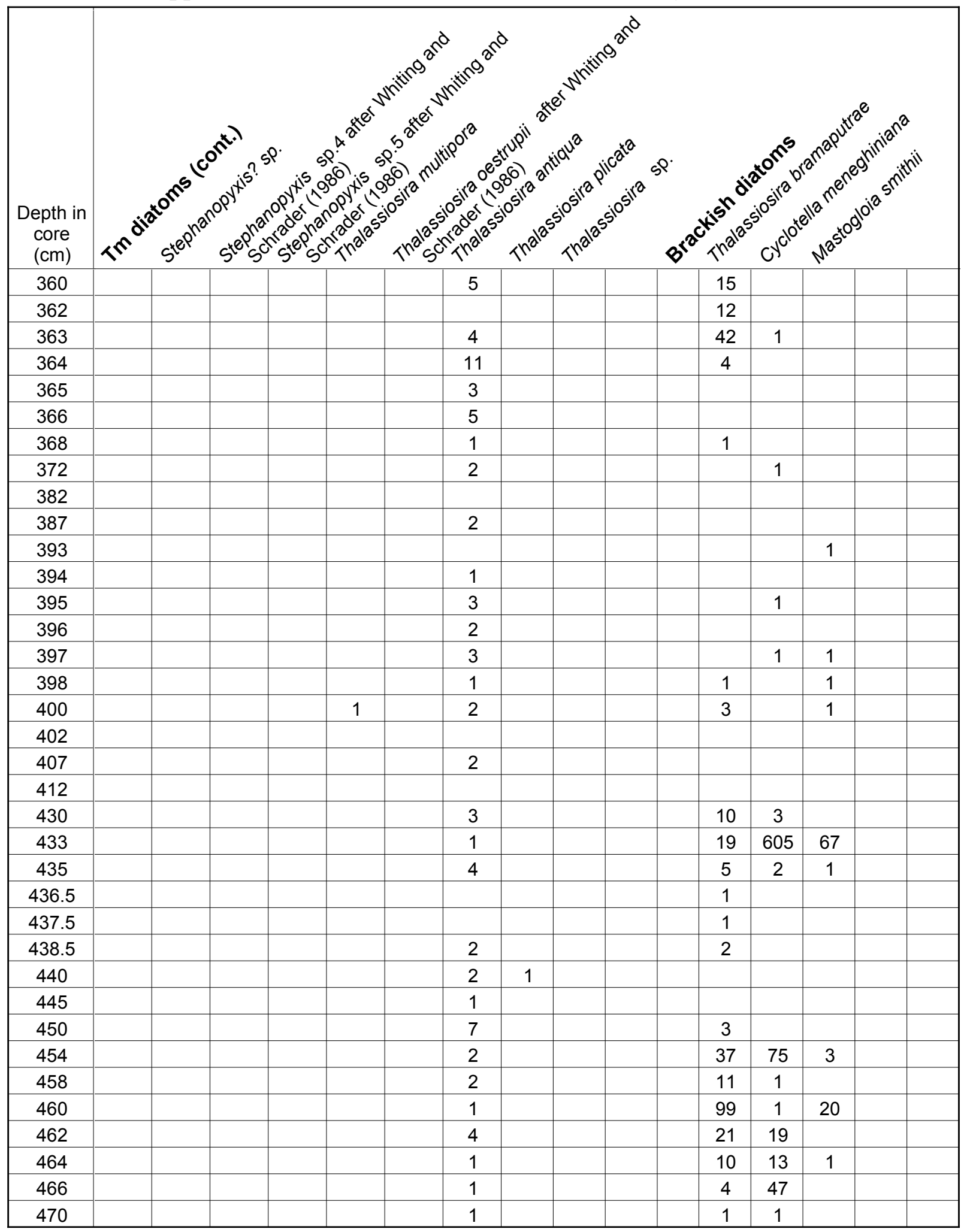


Appendix 4. Downcore diatom data from Bradley Lake (raw counts).

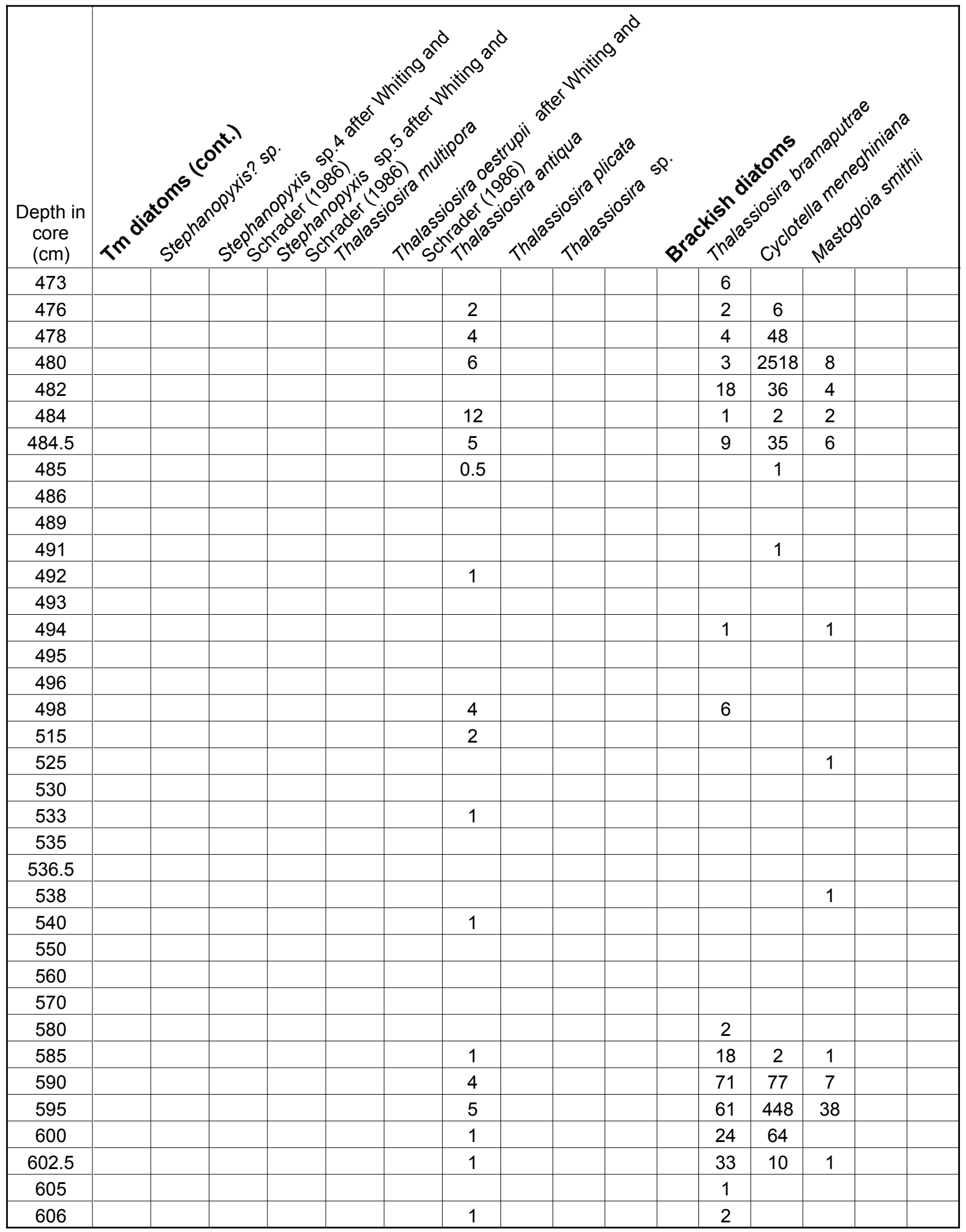


Appendix 4. Downcore diatom data from Bradley Lake (raw counts).

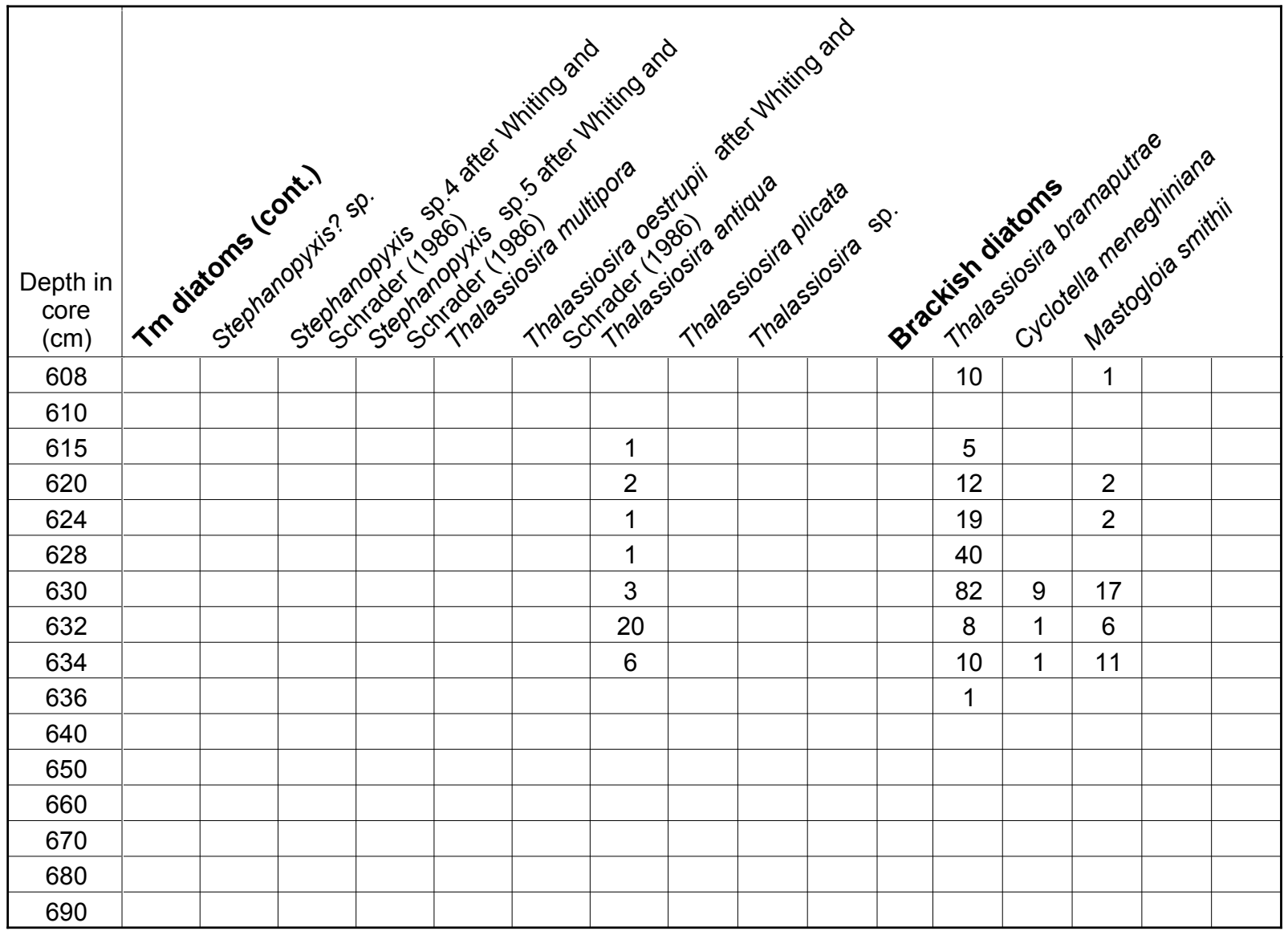


Appendix 4. Downcore diatom data from Bradley Lake (raw counts).

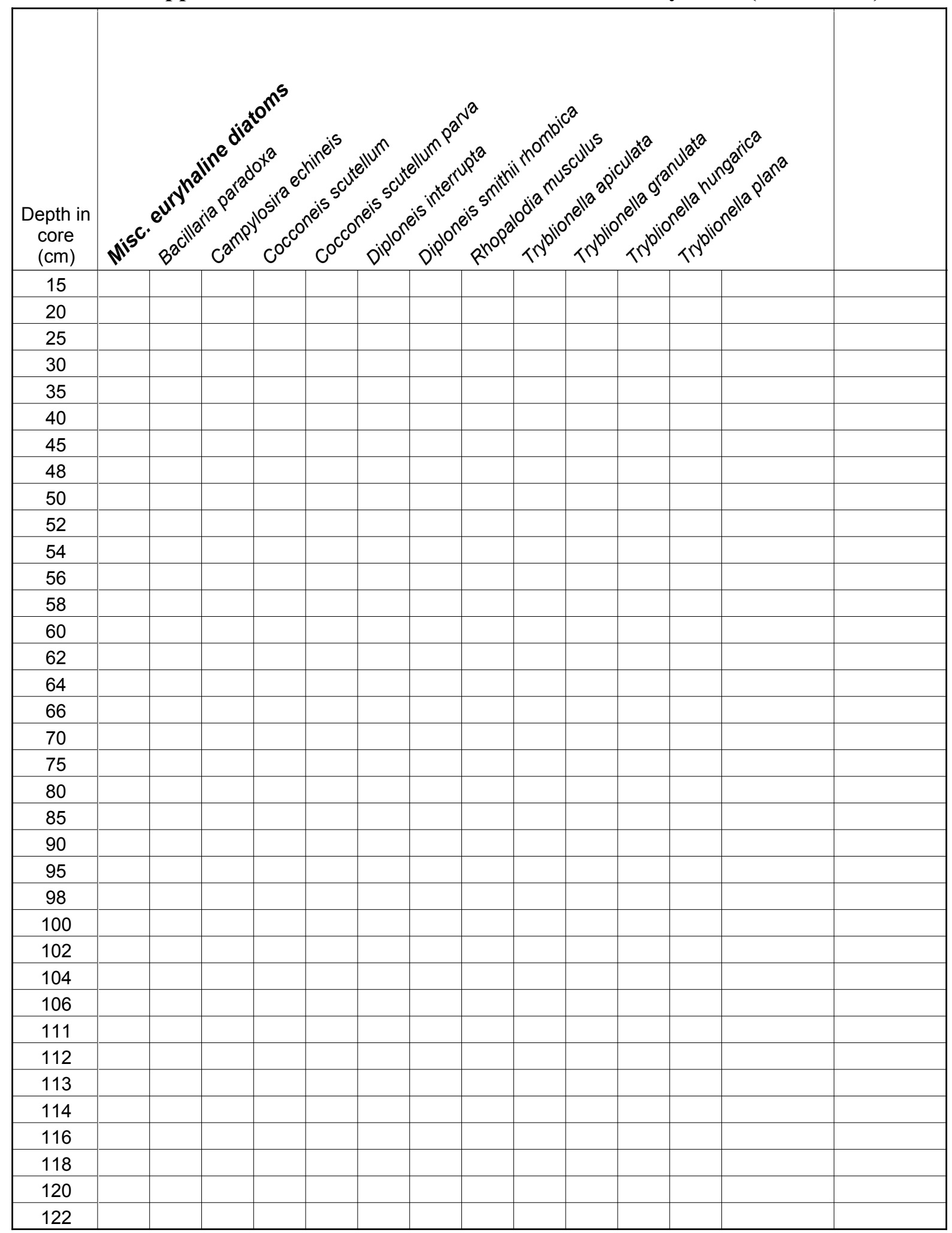


Appendix 4. Downcore diatom data from Bradley Lake (raw counts).

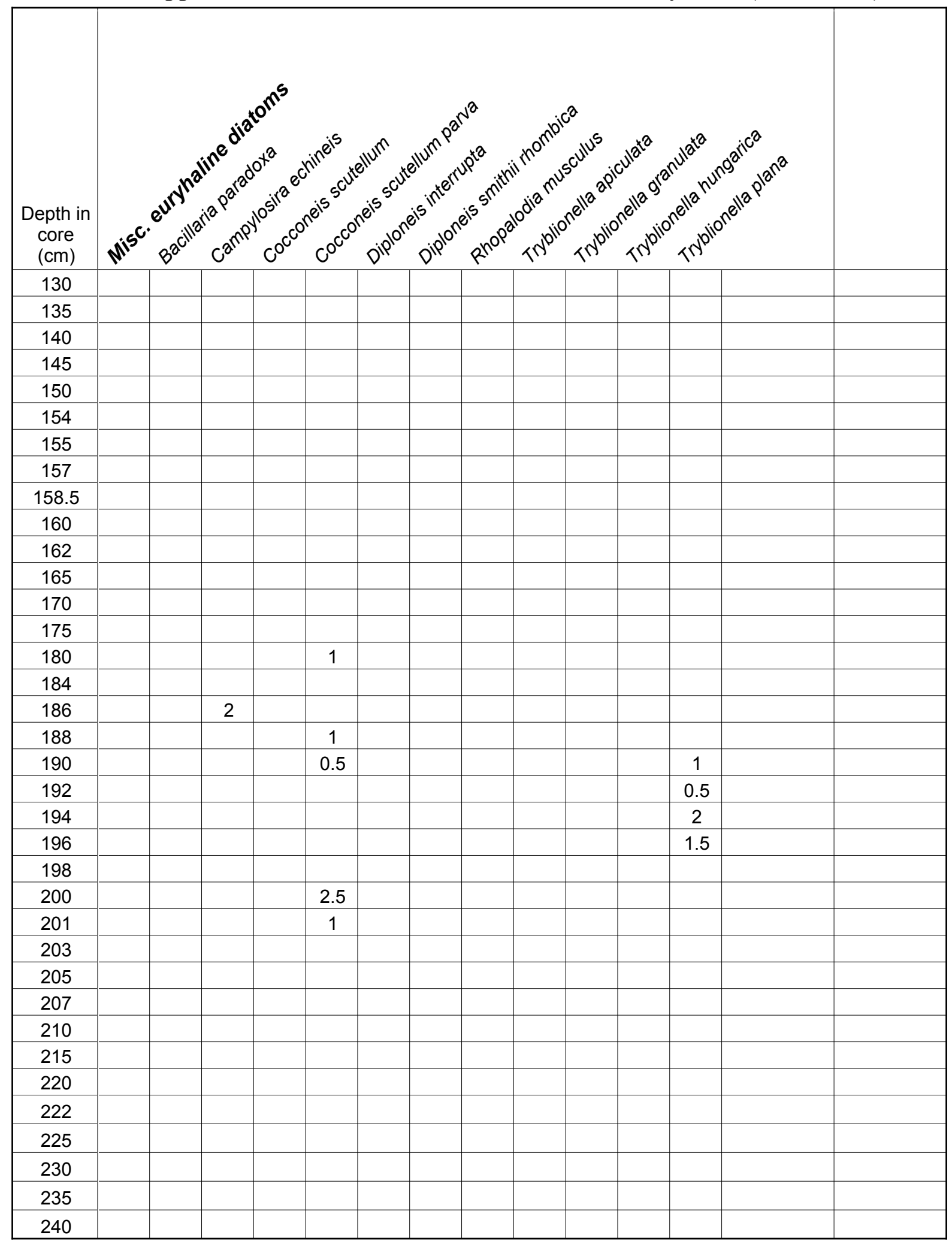


Appendix 4. Downcore diatom data from Bradley Lake (raw counts).

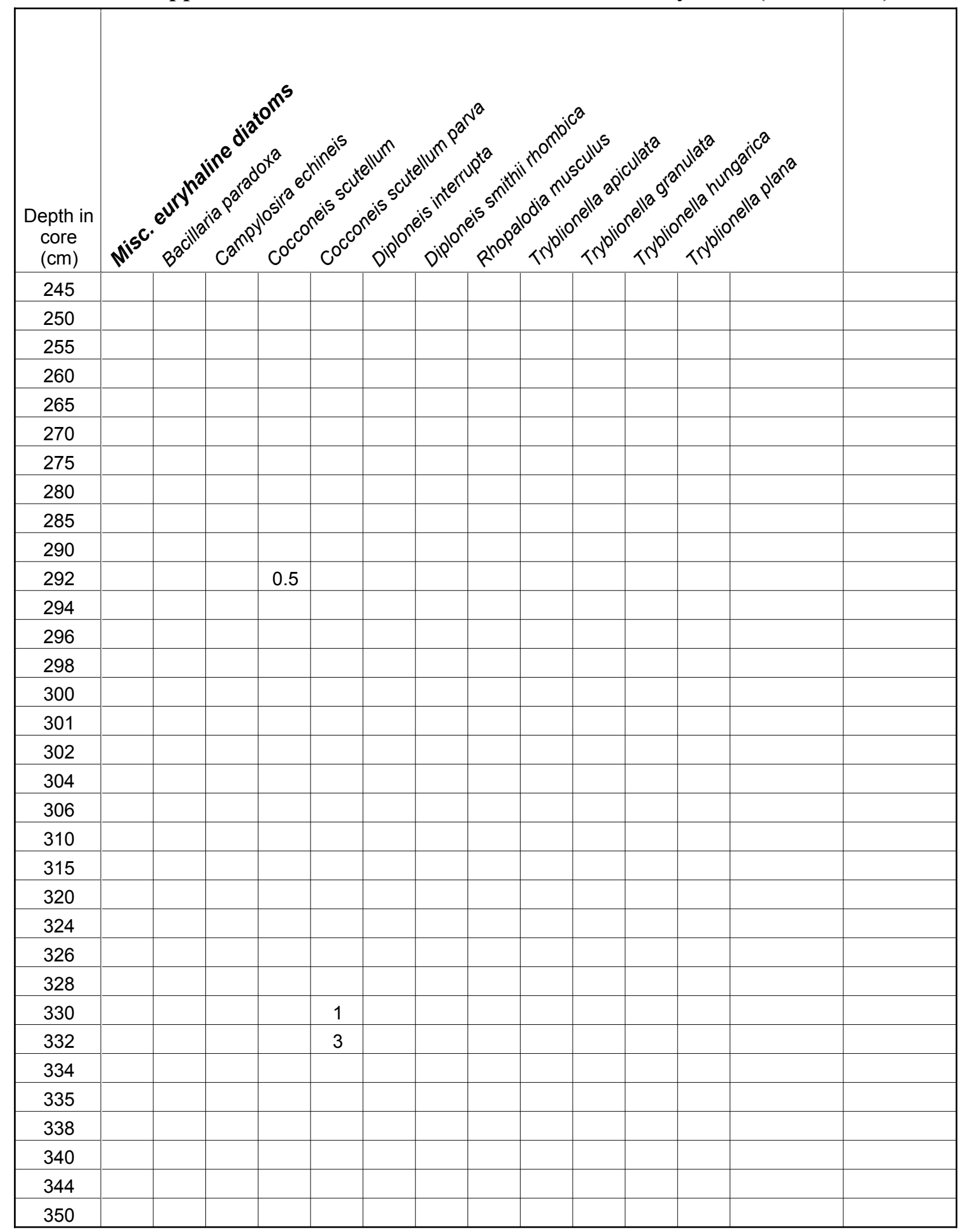


Appendix 4. Downcore diatom data from Bradley Lake (raw counts).

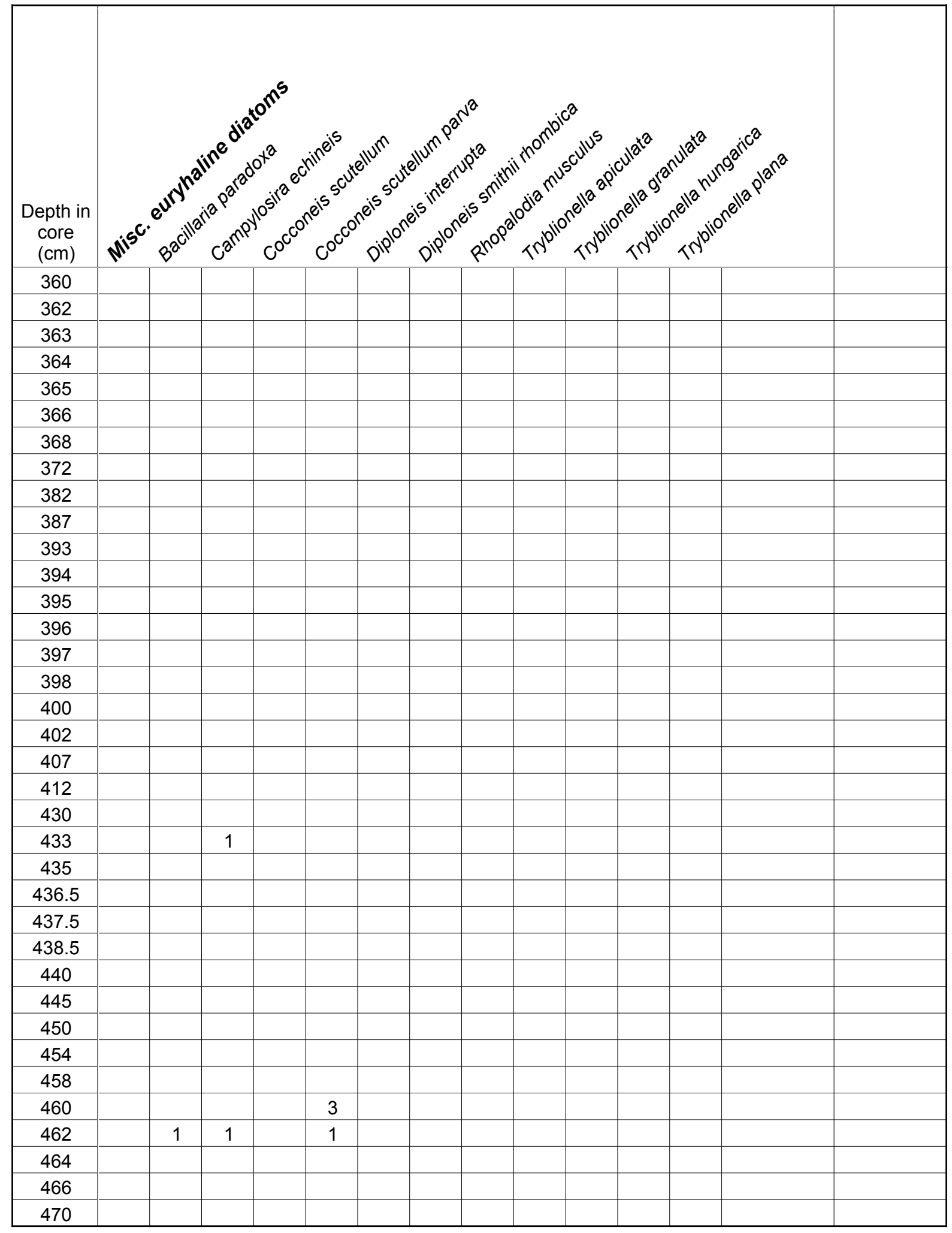


Appendix 4. Downcore diatom data from Bradley Lake (raw counts).

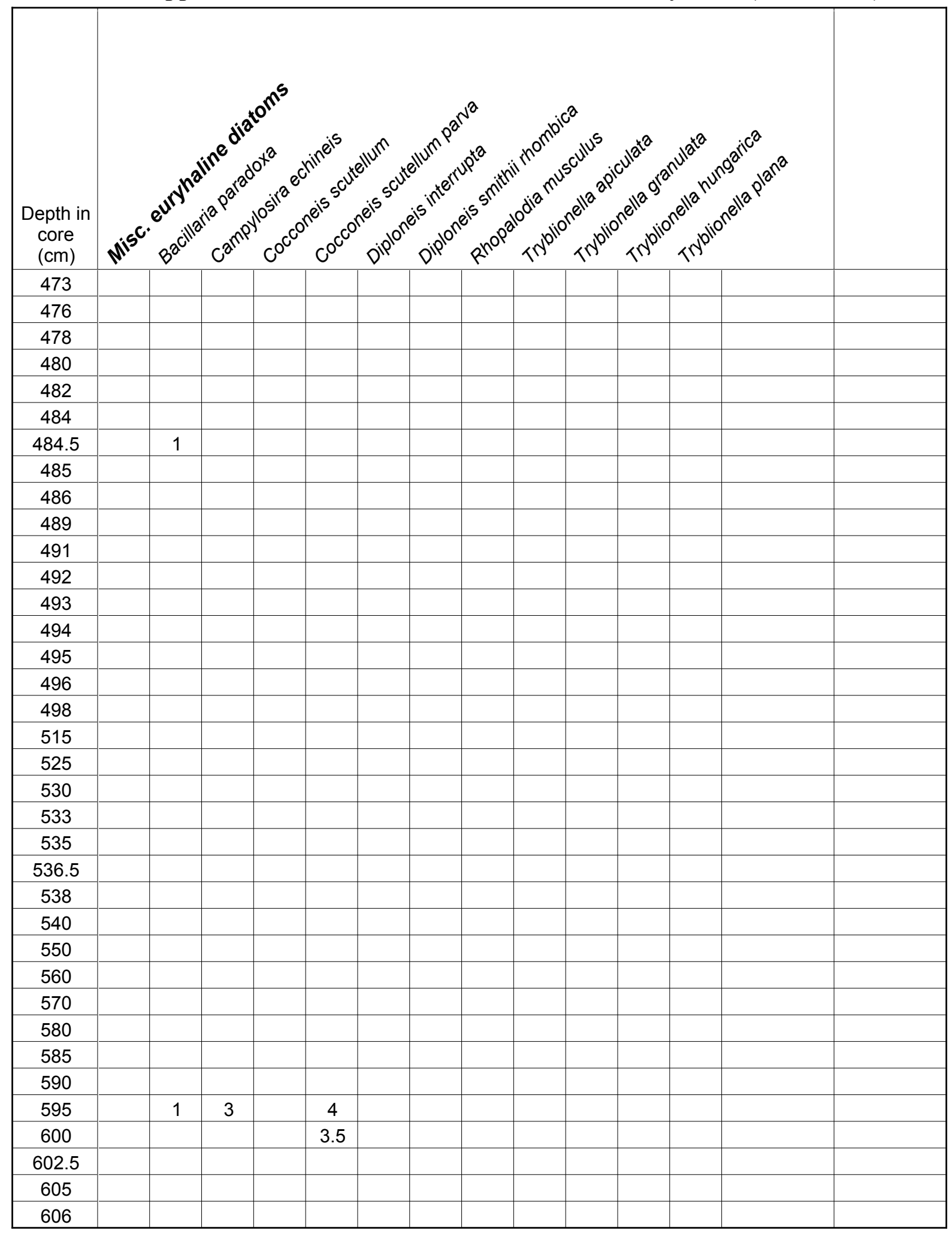


Appendix 4. Downcore diatom data from Bradley Lake (raw counts).

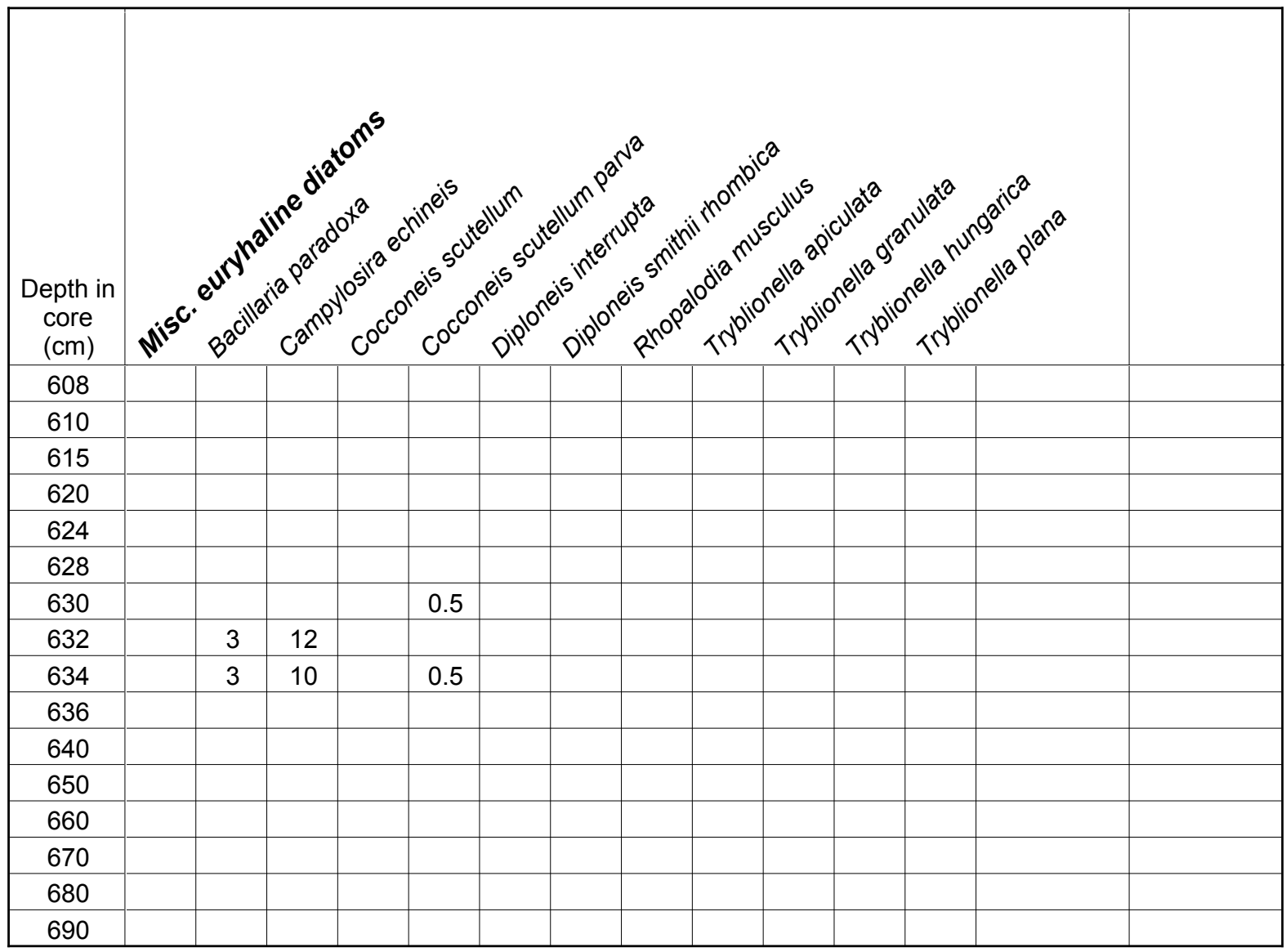


Appendix 4. Downcore diatom data from Bradley Lake (raw counts).

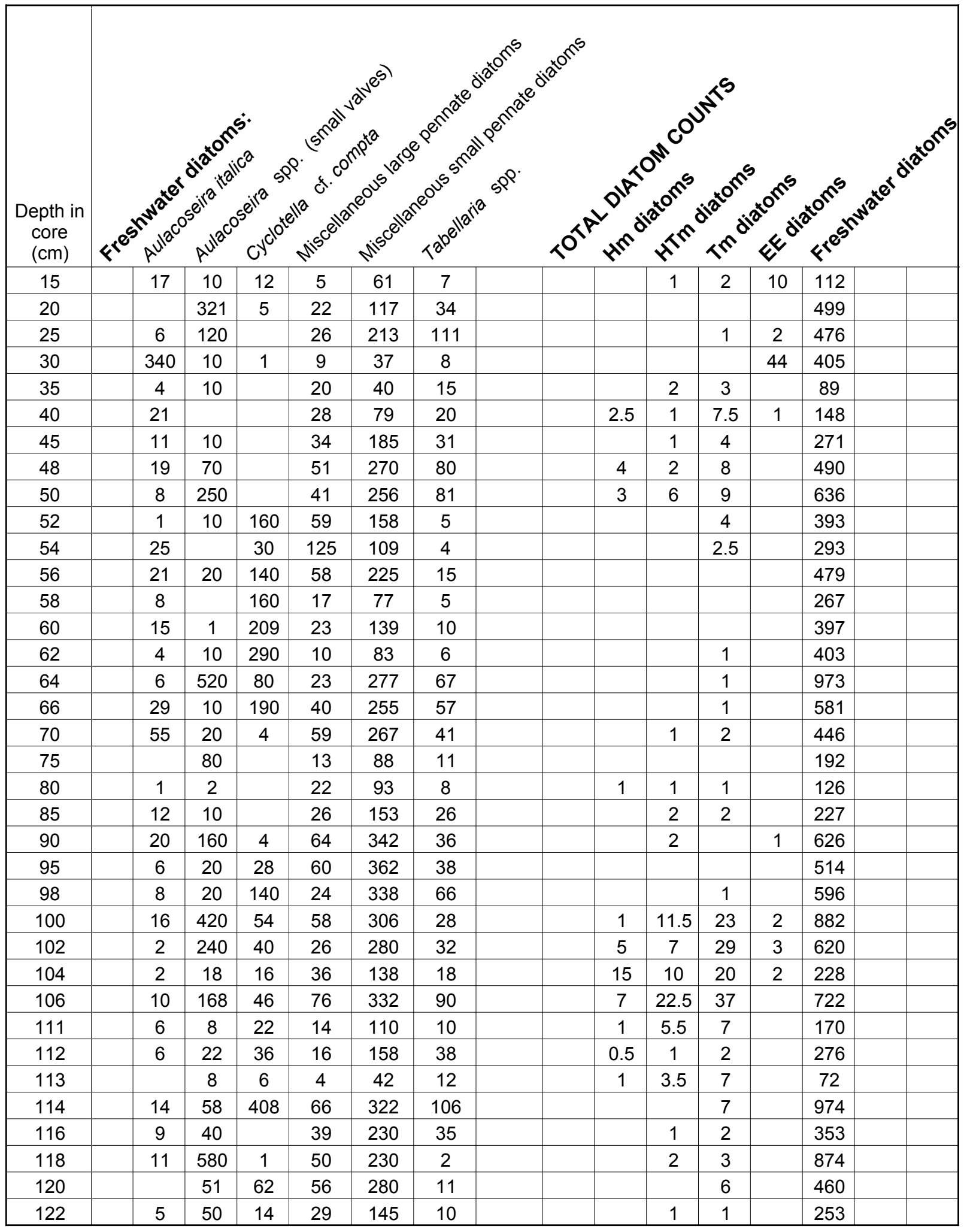


Appendix 4. Downcore diatom data from Bradley Lake (raw counts).

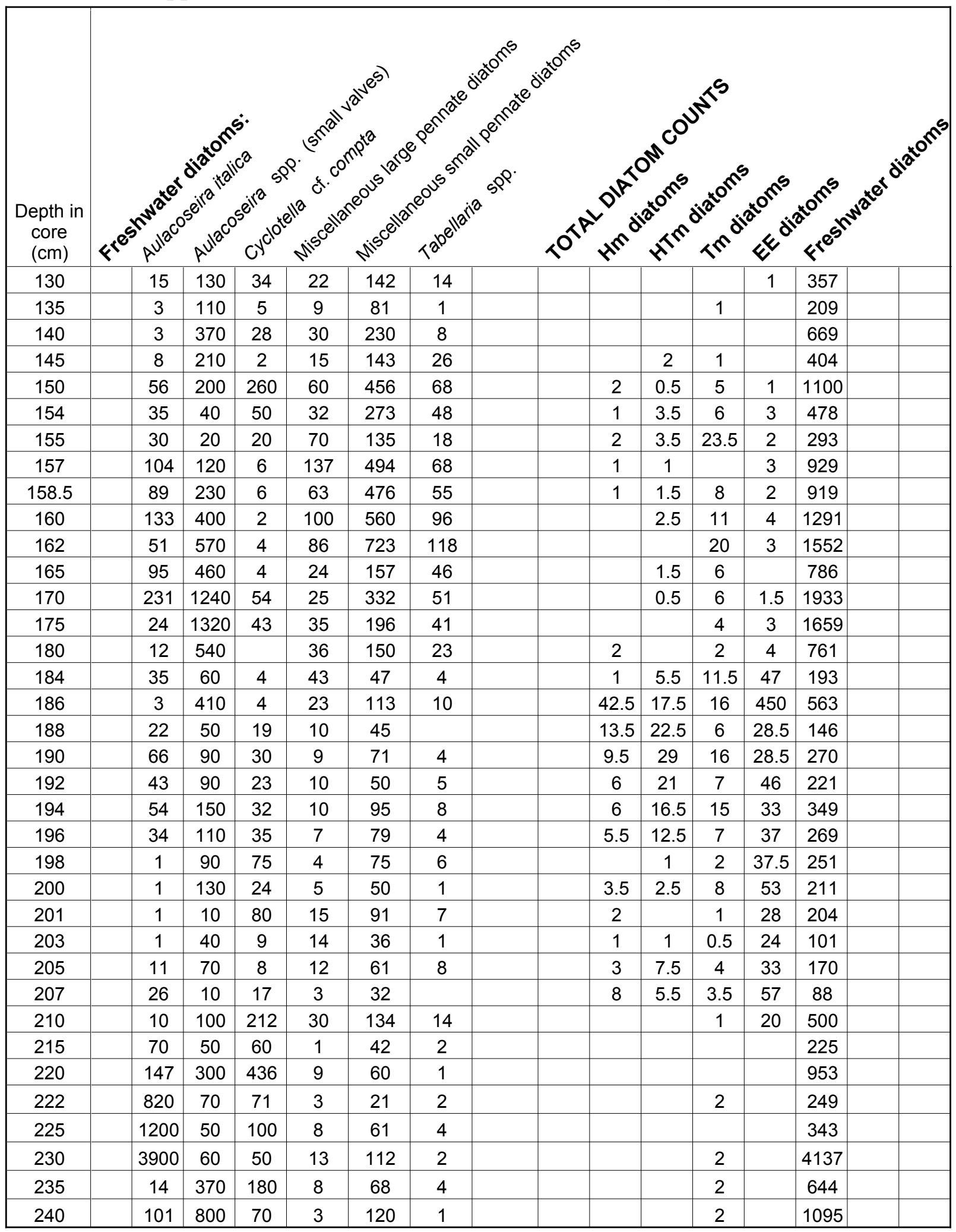


Appendix 4. Downcore diatom data from Bradley Lake (raw counts).

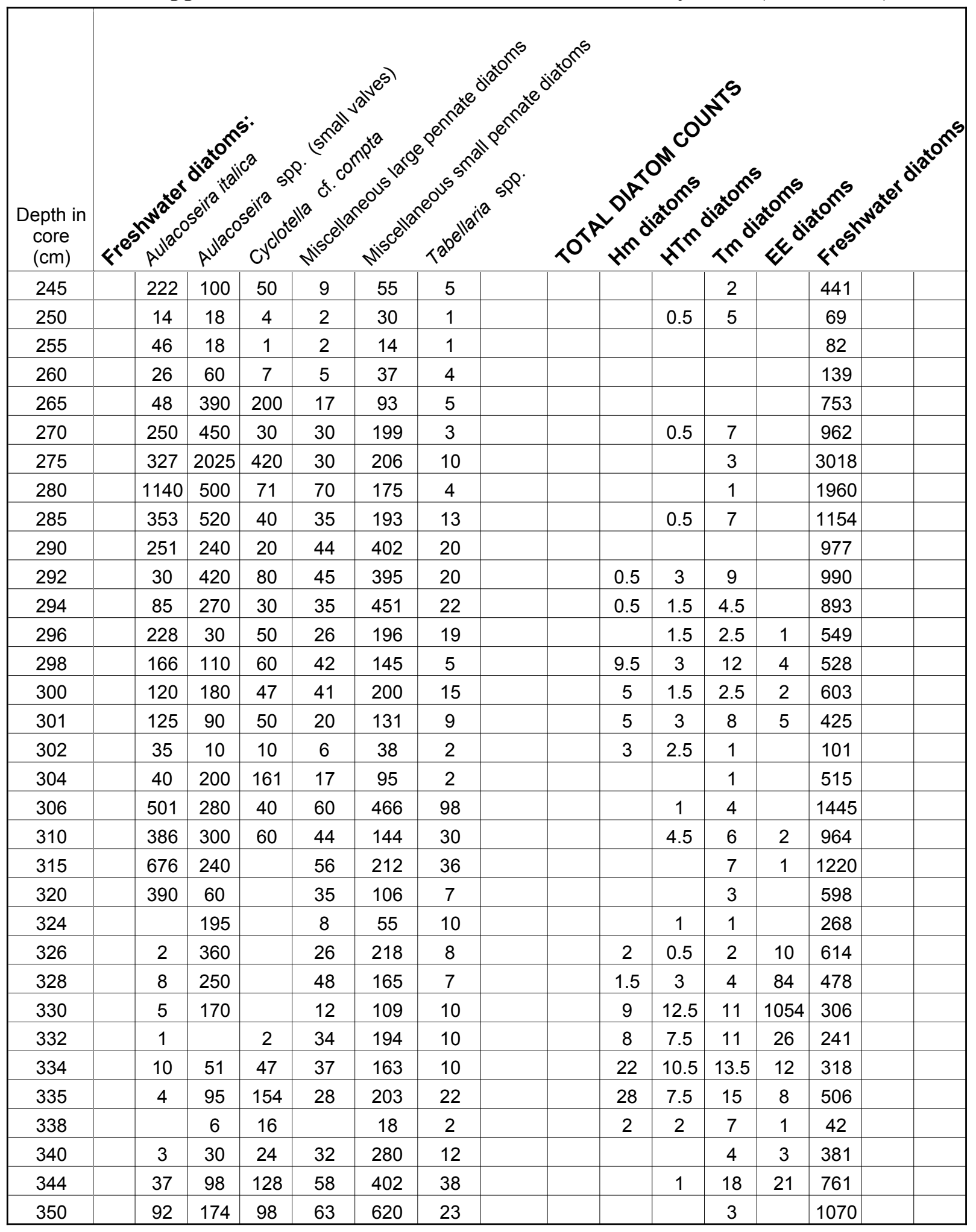


Appendix 4. Downcore diatom data from Bradley Lake (raw counts).

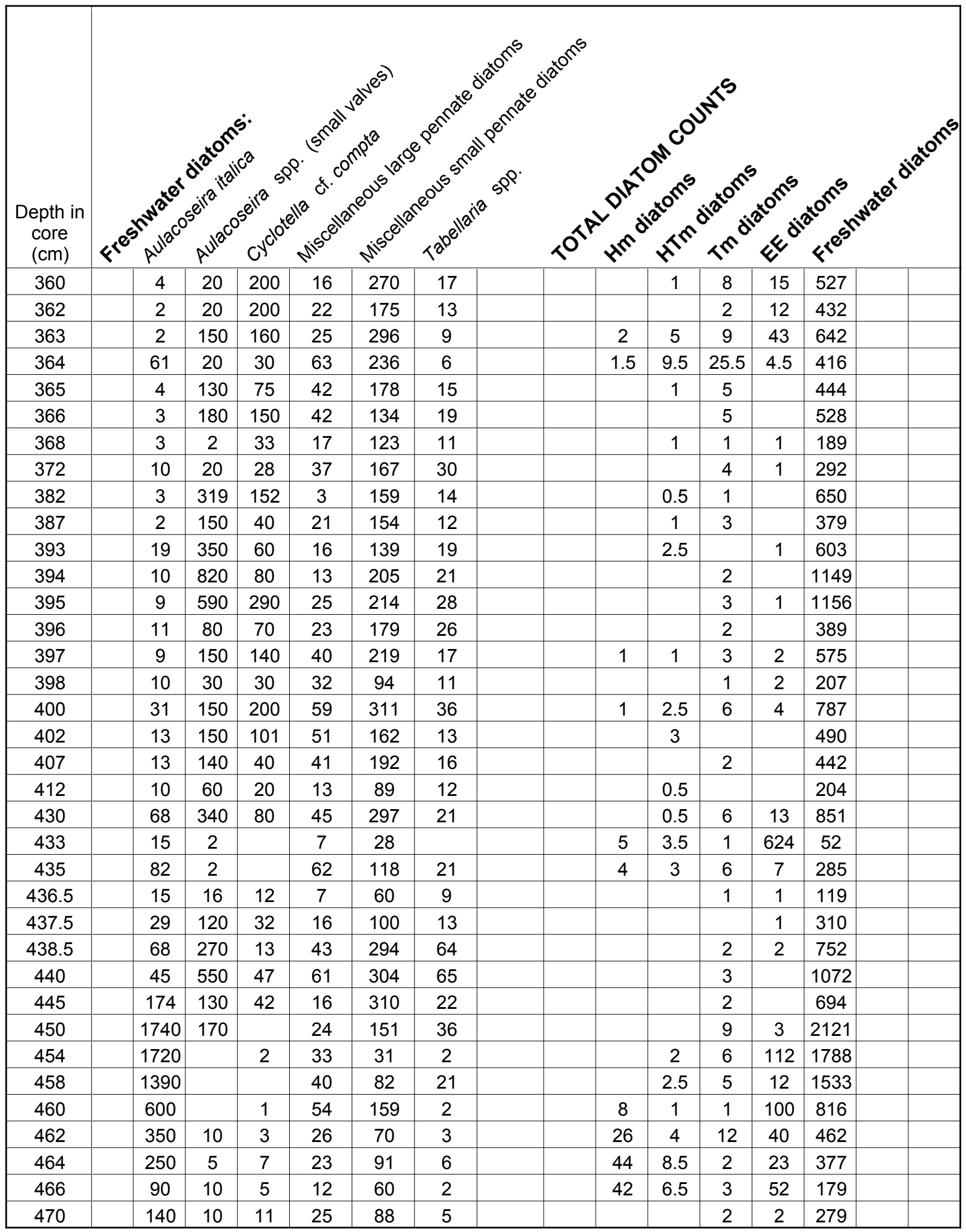


Appendix 4. Downcore diatom data from Bradley Lake (raw counts).

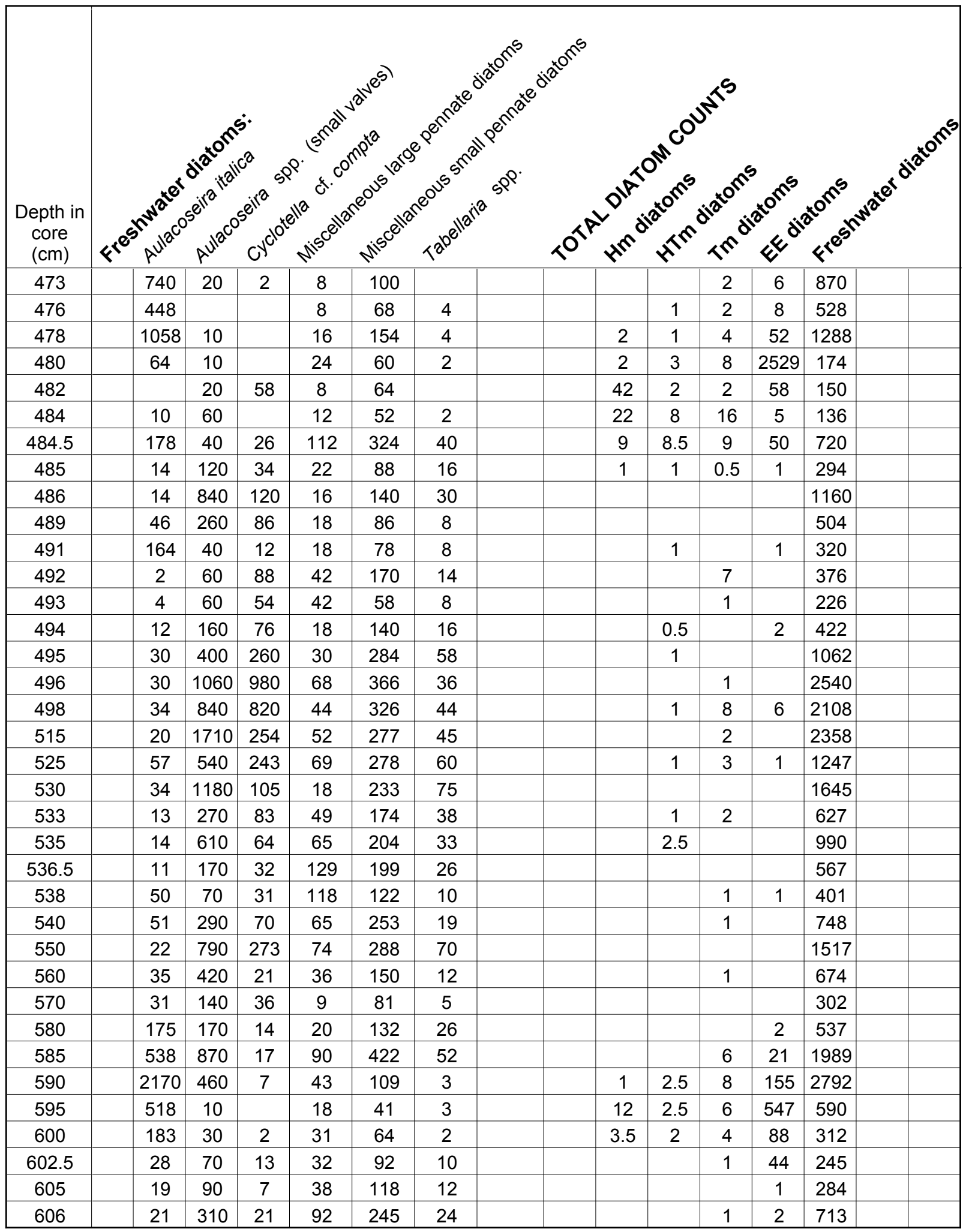


Appendix 4. Downcore diatom data from Bradley Lake (raw counts).

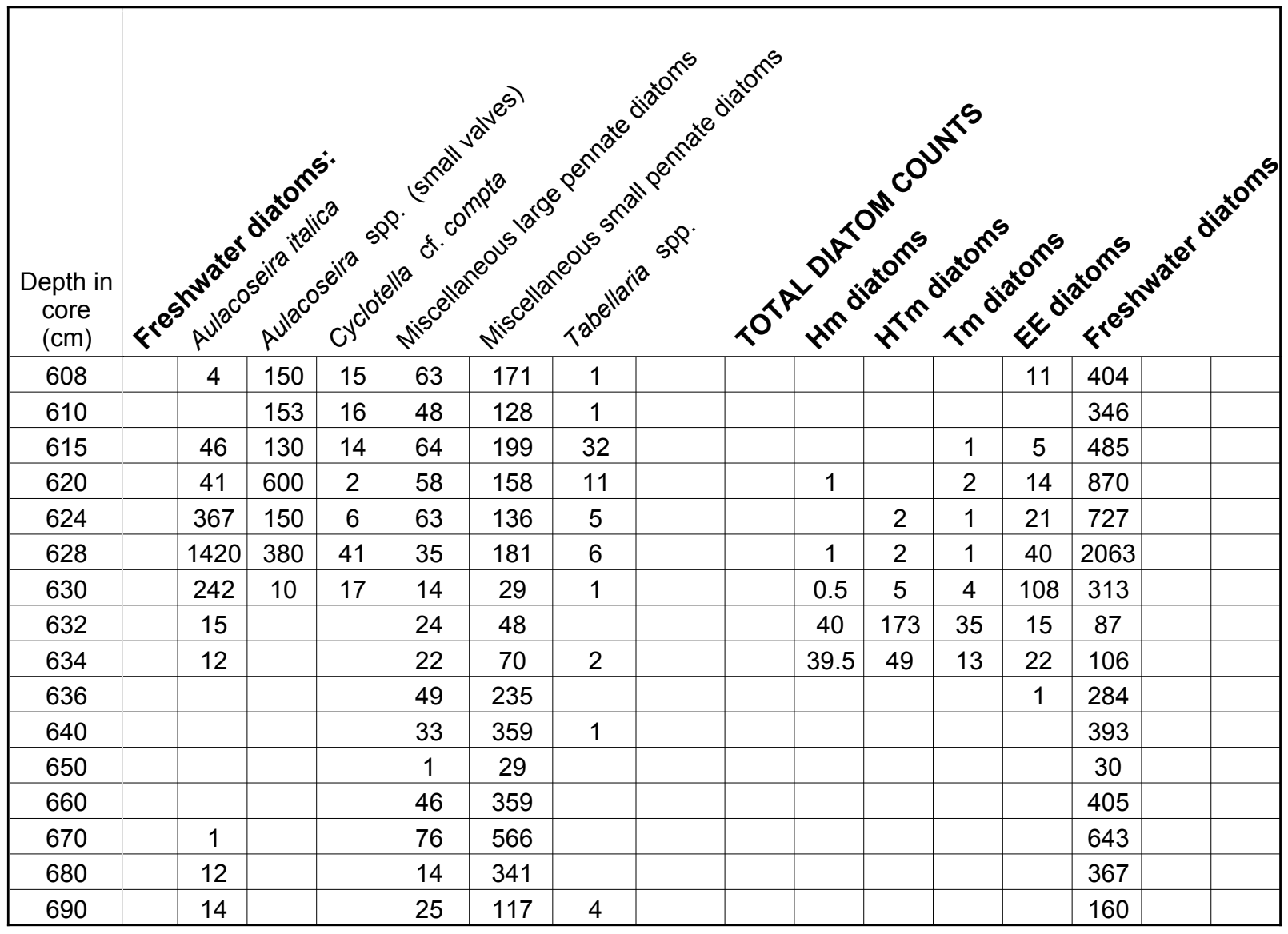


Appendix 4. Downcore diatom data from Bradley Lake (raw counts).

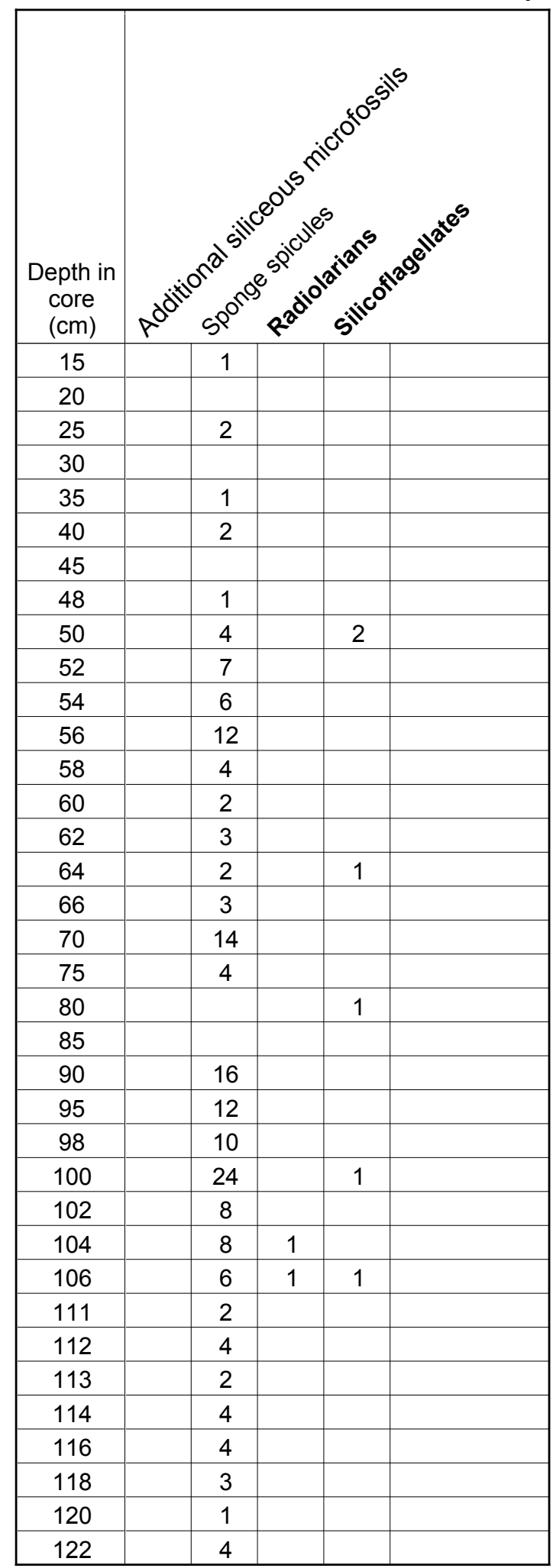


Appendix 4. Downcore diatom data from Bradley Lake (raw counts).

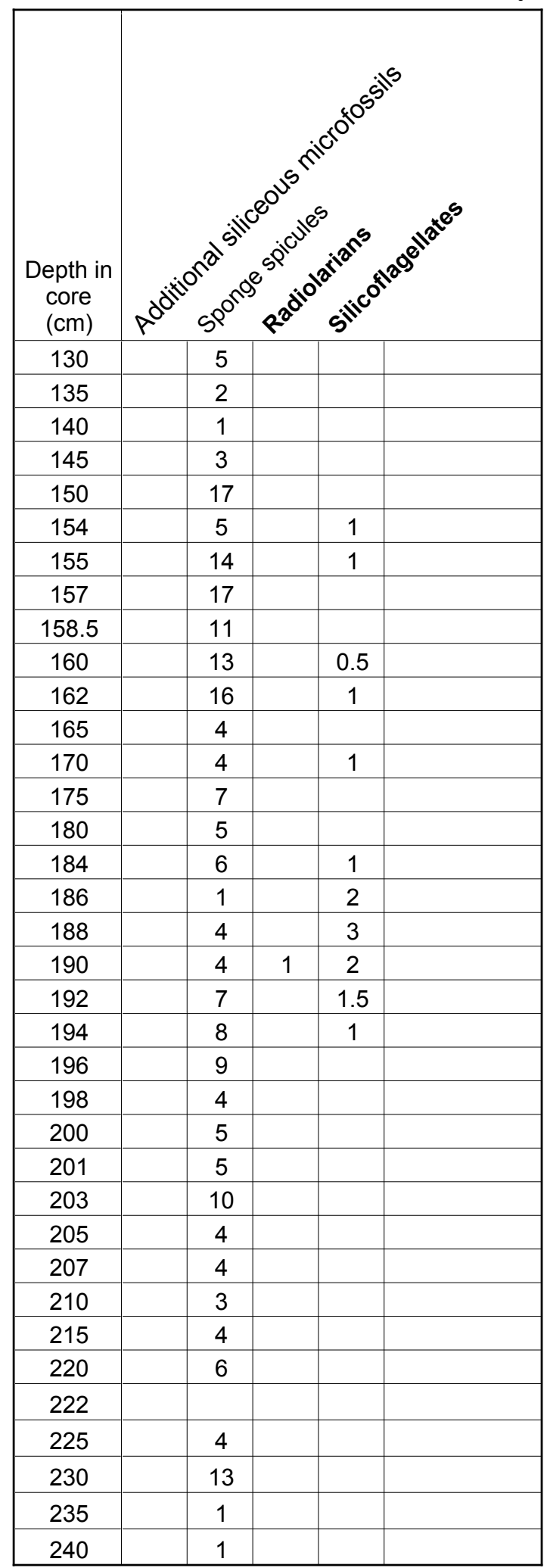


Appendix 4. Downcore diatom data from Bradley Lake (raw counts).

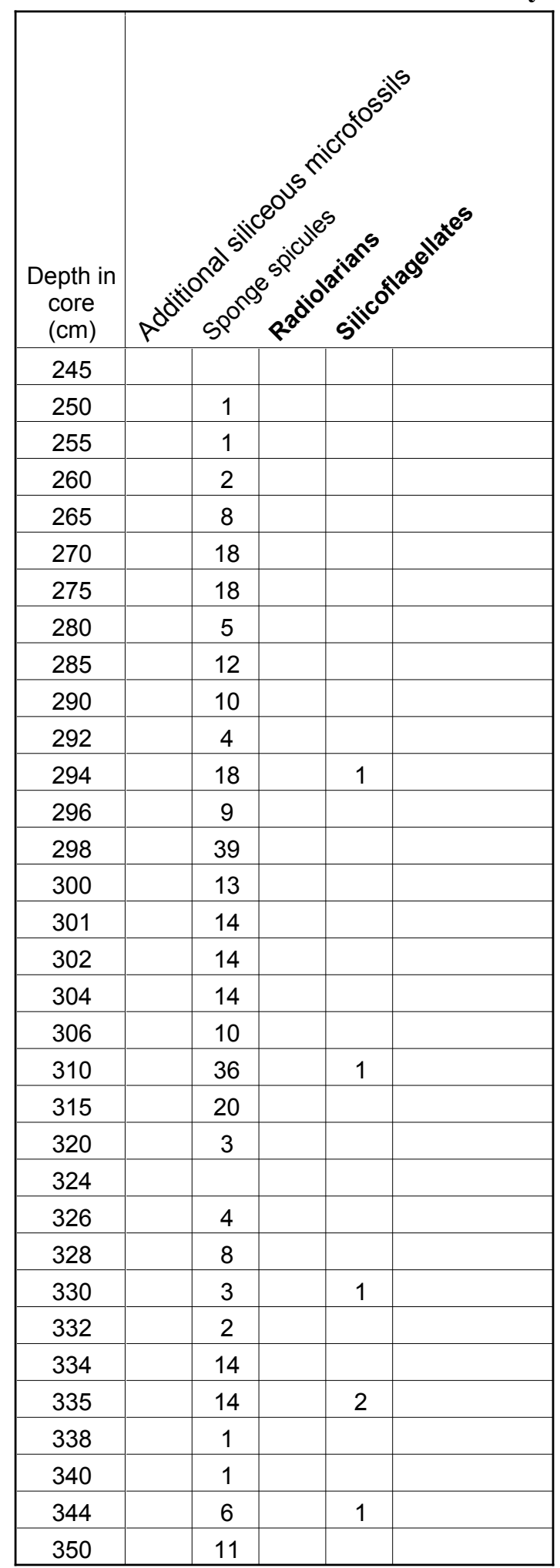


Appendix 4. Downcore diatom data from Bradley Lake (raw counts).

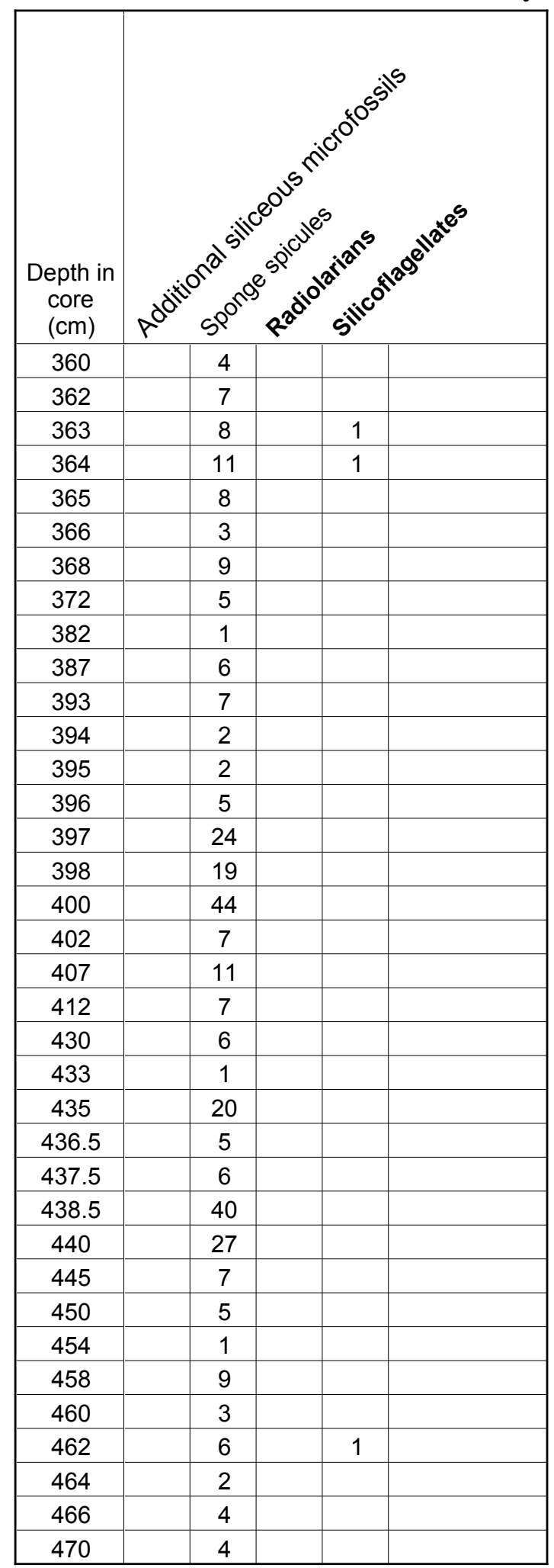


Appendix 4. Downcore diatom data from Bradley Lake (raw counts).

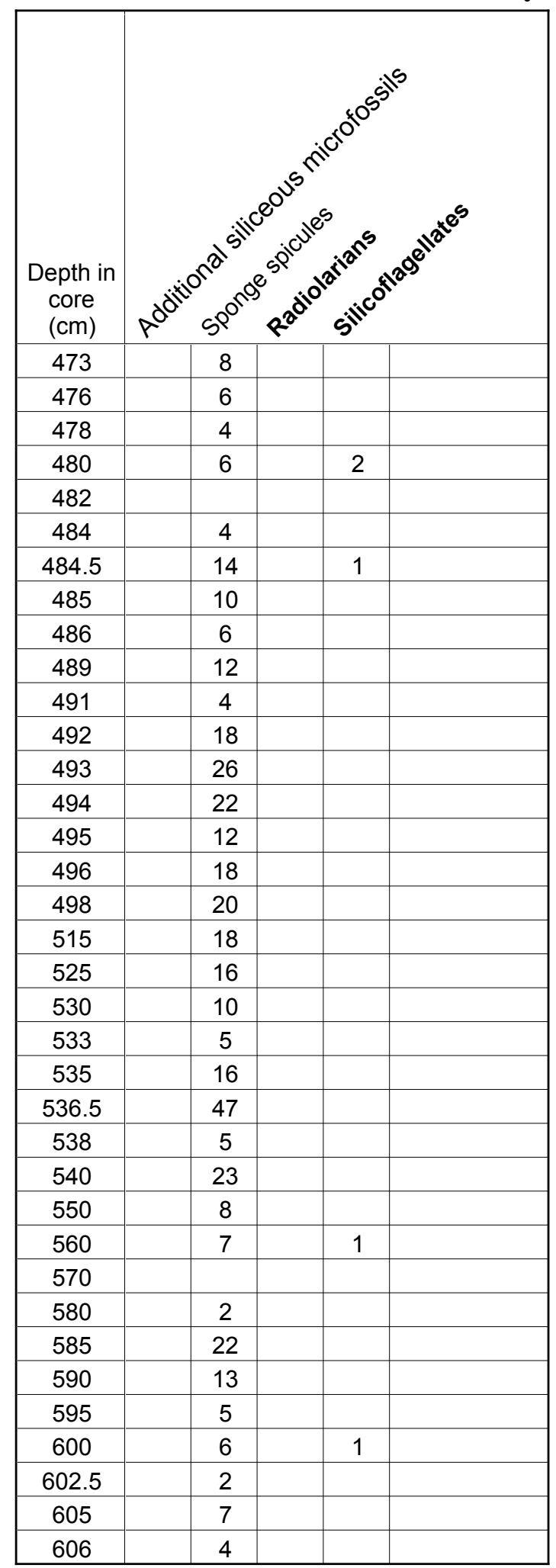


Appendix 4. Downcore diatom data from Bradley Lake (raw counts).

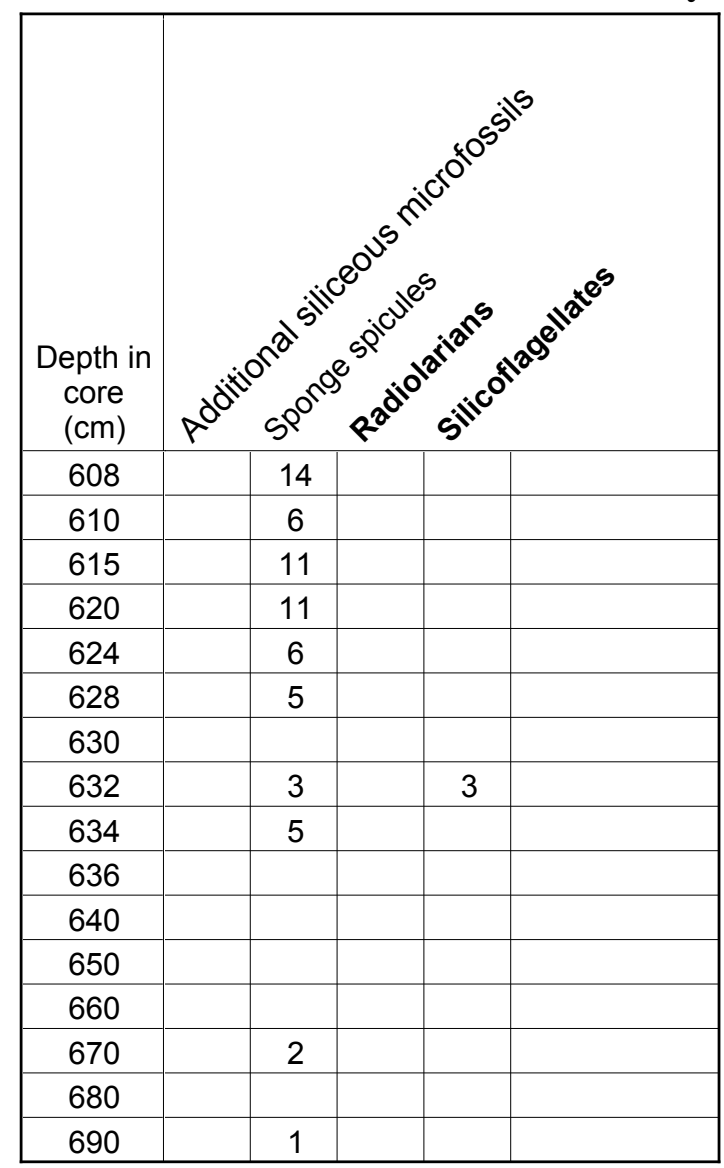

